\title{
Biological mechanisms of environmental stressors in psychiatry : the role of the immune system
}

Citation for published version (APA):

Guloksuz, I. S. (2015). Biological mechanisms of environmental stressors in psychiatry : the role of the immune system. [Doctoral Thesis, Maastricht University]. Maastricht University. https://doi.org/10.26481/dis.20151202ig

Document status and date:

Published: 01/01/2015

DOI:

10.26481/dis.20151202ig

Document Version:

Publisher's PDF, also known as Version of record

\section{Please check the document version of this publication:}

- A submitted manuscript is the version of the article upon submission and before peer-review. There can be important differences between the submitted version and the official published version of record.

People interested in the research are advised to contact the author for the final version of the publication, or visit the DOI to the publisher's website.

- The final author version and the galley proof are versions of the publication after peer review.

- The final published version features the final layout of the paper including the volume, issue and page numbers.

Link to publication

\footnotetext{
General rights rights.

- You may freely distribute the URL identifying the publication in the public portal. please follow below link for the End User Agreement:

www.umlib.nl/taverne-license

Take down policy

If you believe that this document breaches copyright please contact us at:

repository@maastrichtuniversity.nl

providing details and we will investigate your claim.
}

Copyright and moral rights for the publications made accessible in the public portal are retained by the authors and/or other copyright owners and it is a condition of accessing publications that users recognise and abide by the legal requirements associated with these

- Users may download and print one copy of any publication from the public portal for the purpose of private study or research.

- You may not further distribute the material or use it for any profit-making activity or commercial gain

If the publication is distributed under the terms of Article $25 \mathrm{fa}$ of the Dutch Copyright Act, indicated by the "Taverne" license above, 


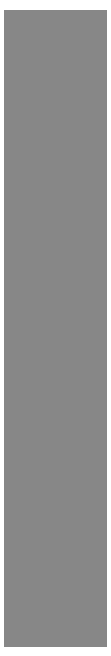

Biological Mechanisms of Environmental Stressors in Psychiatry

\section{The Role of the Immune System}

Ismail Sinan Guloksuz 
DESIGN | bayt • www.bayt.com.tr • +903124313062 • Ankara

COVER DESIGN | Timuçin Oral

PRINT | Filmsan

(C) Ismail Sinan Guloksuz, New Haven 2015

This thesis may be reprinted, reproduced, and shared for non-commercial purposes without formal permission of the author, provided full attribution is given. 


\title{
Biological Mechanisms of Environmental Stressors in Psychiatry \\ The Role of the Immune System
}

\author{
DISSERTATION \\ to obtain the degree of Doctor \\ at Maastricht University, \\ on the authority of the Rector Magnificus, \\ Prof Dr L.L.G. Soete \\ in accordance \\ with the decision of the Board of Deans, \\ to be defended in public \\ on Wednesday 2 December 2015, at 14.00 hours
}

by

Ismail Sinan Guloksuz

Born 27 February 1981 in Ankara, Turkey 


\section{Supervisor}

Prof. Dr. J. van Os

\section{Co-supervisors}

Dr. B.P.F. Rutten

Dr. M. Drukker

\section{Assessment committee}

Prof. Dr. F. Peeters (Chair)

Prof. Dr. T. van Amelsvoort

Prof. Dr. M. De Baets

Prof. Dr. H. Drexhage (Erasmus MC, the Netherlands)

Prof. Dr. W. Hoogendijk (Erasmus MC, the Netherlands)

The research presented in this thesis was conducted at the School for Mental Health and Neuroscience, Department of Psychiatry and Neuropsychology of Maastricht University, Maastricht University Medical Centre, Maastricht, the Netherlands and Bakirkoy Research and Training Hospital for Psychiatry, Neurology, and Neurosurgery, Istanbul, Turkey. 
In memory of my father... 


\section{Paranymphs}

Ehsan Pishva

Selin Aktan Guloksuz 
A Hair perhaps divides the False and True;

Yes; and a single Alif were the clue-

Could you but find it-to the Treasure-house,

And peradventure to The Master too;

Omar Khayyám (1048-1131) 


\section{Contents}

CHAPTER 1 Introduction

CHAPTER 2 Cytokine levels in euthymic bipolar patients 19

CHAPTER 3 Evidence for an association between tumor necrosis factor-alpha levels and lithium response 33

CHAPTER 4 Plasma concentrations of soluble cytokine receptors in euthymic bipolar patients with and without subsyndromal symptoms

CHAPTER 5 Depressive symptoms in Crohn's disease: relationship with immune activation and tryptophan availability

CHAPTER 6 The immune system and electroconvulsive therapy for depression

CHAPTER 7 The impact of electroconvulsive therapy on the tryptophan-kynurenine metabolic pathway

CHAPTER 8 Hypoxia-response genes moderate the impact of prospectively assessed obstetric complications on psychopathology in a general population female twin cohort

CHAPTER 9 Epilogue

Summary

Valorization

Acknowledgement

Curriculum Vitae

List of Publications 



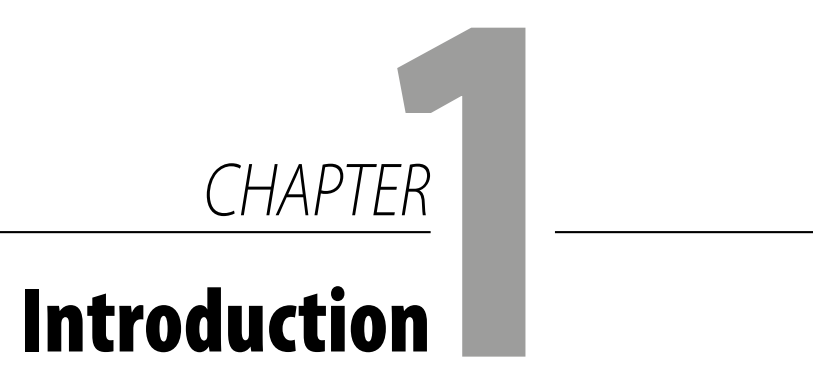





\section{Unmet needs in mood disorders}

As a broad diagnosis, mood disorders include both Major Depressive Disorder (MDD) and Bipolar Disorder (BD), which are distinguished by the presence of only depressive episodes in the former, and accompanying or isolated manic or hypomanic episodes in the latter. Common symptoms of MDD comprise depressed mood, anhedonia, sleep and appetite disturbance, loss of energy and sexual drive, feelings of worthlessness, concentration problems and recurrent thoughts of suicide, whereas mania, which can be considered the other end of the spectrum, is characterized by elevated or irritable mood, increased self-esteem, increased goal-directed and risky pleasurable activities, concentration problems, excessive talking, racing thoughts and sleep disturbance. MDD and BD were categorized as Mood Disorders in the Diagnostic and Statistical Manual of Disease (DSM) 4th Edition (APA, 2000); however, the most recent version of DSM includes two distinct chapters titled Depressive Disorders and Bipolar and Related Disorders, respectively (APA, 2013).

Mood disorders are among the most common psychiatric diagnoses leading to high rates of morbidity and mortality. According to a recent study, lifetime morbid risk (i.e., the proportion of people who will eventually develop the disorder at some time in their life whether or not they have a lifetime history at the time of assessment) /12-month prevalence estimates of broad category of mood disorders, MDD and BD in the United States are 29.9/8.6\% and 4.1/1.8\%, respectively (Kessler et al., 2012).

The most recent Global Burden of Disease report, which provides a list of diseases and injuries ranked according to disability-adjusted life years (DALYs) worldwide, has shown that MDD has increased from $15^{\text {th }}$ to $11^{\text {th }}$ place with a $37 \%$ increase from 1990 (Murray et al., 2012). MDD ranked even higher in developed regions, e.g. 5th in Central Europe and the United States(Murray et al., 2012). Suicide is the most worrisome outcome of mood disorders; with lifetime rates of suicide attempts around $30 \%$ in bipolar disorder and 15\% in unipolar depressive disorder (Chen and Dilsaver, 1996, Leverich et al., 2003).

Over the years, there has been progress in providing safe and effective treatments of mood disorders. However, current medications are still far from being the ideal option. The rates of subsyndromal symptoms causing decreases in quality of life and the prevalence of treatment-resistant cases are exceptionally high in both MDD and BD. Strikingly, the STAR-D trial demonstrated that only one-third of patients diagnosed with MDD reach remission with citalopram, a selective serotonin reuptake inhibitor (SSRI), which was chosen as the first level treatment in this study (Rush et al., 2006). Similarly, maintenance studies in BD show that even lithium, which is closest to the definition of an ideal mood stabilizer among current psychotropic agents and remains the cornerstone of treatment in $\mathrm{BD}$ for over 60 years, has limited 
success as a monotherapy in the majority of patients with BD (Balance investigators collaborators et al., 2010).

Overall, it appears that there are certainly several unmet needs in the treatment of mood disorders, and the pathogenesis should be elucidated in the first place to develop promising medications with novel mechanism of action.

\section{Neurobiology of mood disorders: monoamine theory and beyond}

The majority of our current established knowledge on the pathogenesis of mood disorders is based on the thorough investigation of the mechanisms of action of serendipitously discovered medications with therapeutic effects in mood disorders. For example, the discovery of mood elevating effects of iproniazid, which was primarily designed to treat tuberculosis, lead to the emergence of the monoamine theory of mood disorders. In the same manner, the mood balancing effects of valproate, originally used to treat epilepsy, precipitated the development of the kindling theory in BD (Baumeister et al., 2010). Initially, decreased availability of noradrenalin in the central nervous system was put forward as the underlying pathophysiological basis for MDD according to monoamine theory. Subsequently, depletion of serotonin has been emphasized; and recent evidence strongly counts the importance of dopamine (Hasler, 2010). Over the years, monoamine theory has proven itself to be the most widely accepted underlying pathophysiological mechanism for MDD and BD, and is supported by a great amount of evidence. All current antidepressants target monoamine systems. However, the monoamine theory is still far from explaining all features of mood disorders. Moreover, the response rates of current monoaminergic medications do not meet expectations, particularly in recurrent MDD and bipolar depression (Rush et al., 2006, Pacchiarotti et al., 2013). Another emerging theory in mood disorders emphasizes the importance of the imbalance between glutamate and gamma-aminobutyric acid (GABA) neurotransmission. A single dose of ketamine, a glutamate N-methyl-D-aspartate (NMDA) receptor antagonist, showed rapid and large antidepressant effects in patients with treatment-resistant MDD in several clinical trials, and neuroimaging, genetic and postmortem studies show evidence for glutamate and GABA neurotransmission (Aan Het Rot et al., 2012, Krystal et al., 2013).

In addition to these theories, current progress in methodological techniques as well as contemporary evidence based on genetic findings led to research into cellular signaling networks, e.g. protein kinase $\mathrm{C}(\mathrm{PKC})$, glycogen synthase kinase $3 \beta$ (GSK3 $\beta$ ), and neurotrophic factors, e.g. nerve growth factor (NGF) and brain-derived 
neurotrophic factor (BDNF) that might be involved in the pathogenesis of mood disorders (Martinowich et al., 2009, Hasler, 2010).

\section{Emergence of inflammatory theory of mood disorders: close relationship between immune-related diseases and mood disorders}

A growing body of evidence shows that immune-related mechanisms underpinning the pathogenesis of mood disorders may be promising; therefore, comprehension of these mechanisms may contribute to the development of novel treatment options providing better prognosis for these disabling psychiatric conditions. The link between the immune system and mood disorders has long been observed in clinical practice far before methodological studies were performed. These clinical observations confirm that: (i) sickness-like behaviors (i.e. somnolence, fatigue, loss of appetite, loss of interest) which resemble core features of mood disorders are commonly observed in the diseases originating from altered immune function, e.g. Crohn's disease (CD), rheumatoid arthritis (RA), multiple sclerosis (MS) (Dantzer, 2004, Gold and Irwin, 2009, Minderhoud et al., 2007, Helzer et al., 1984); (ii) anti-inflammatory treatments used in these conditions, i.e. infliximab, adalimumab, etanercept have mood regulating effects (Soczynska et al., 2009); (iii) mood symptoms are common side-effects of pro-inflammatory treatments such as interferon (IFN) used in hepatitis $\mathrm{C}$ treatment (Asnis and De La Garza, 2005); (iv) the rates of medical illness comorbidity involving immune dysregulation, e.g. diabetes mellitus, cardiovascular illness, are remarkably high in mood disorders (Beyer et al., 2005, Musselman et al., 1998).

Later controlled studies confirmed those early observations. The risk of MDD was more than two-fold increased in $\mathrm{CD}, \mathrm{MS}$ and RA when compared to the general population (Siegert and Abernethy, 2005, Dickens et al., 2002, Kurina et al., 2001, Loftus et al., 2011). Obviously, one may argue that the increased prevalence of MDD comorbidity is due to general burden of chronic debilitating diseases. However, a large study investigating the effects of etanercept in patients with psoriasis showed that these antidepressant effects appeared to be independent of the disease activity, as shown through objective measures of skin clearance or joint pain (Tyring et al., 2006). In the light of these findings, several studies aimed to investigate the safety and efficacy of medication with tumor necrosis factor alpha (TNF- $\alpha$ ) antagonist properties, such as minocyline and infliximab, in treatment-resistant unipolar and bipolar depression (Raison et al., 2012, Savitz et al., 2012, Miyaoka et al., 2012). Recently, Raison et al. demonstrated that infliximab displayed antidepressant effects in depressed patients

with increased inflammation (as demonstrated by high circulating C-reactive protein 
(CRP) and TNF- $\alpha$ concentrations) at baseline (Raison et al., 2012). However, whole sample analysis showed no difference between infliximab and placebo, which in turn leads to think about the possibility of a distinct subtype of depression precipitated by an aberrant immune functioning.

These findings suggest that one possible approach to help clarify the relationship between mood disorders and immune system function may be to focus on medical illnesses with certain immune pathogenesis and the effects of immune-modulatory agents. Chapter 5 presents a study investigating the impact of infliximab, a TNF- $\alpha$ antagonist, in CD patients on depressive symptoms, and the possibility that improvement of depressive symptoms occurs in parallel with changes in TRP availability imposed by a reduction in inflammation as reflected by levels of acute phase proteins (APP).

In addition to the clinical evidence highlighted above, findings from translational research point to neuroendocrine and neuroimmune alterations in mood disorders. These include abnormal functioning of the Hypothalamic-Pituitary-Adrenal (HPA) axis, imbalance of pro-inflammatory/anti-inflammatory cytokine activity, and inflammation-induced tryptophan degradation pathway.

\section{The role of a disturbed cytokine network}

Cytokines are small glycoproteins that primarily serve as chemical messengers in the regulation of immune response by interacting with numerous cells and other biochemical mediators (Kronfol and Remick, 2000). Several proposed theories for communication between cytokines and brain cells demonstrate that cytokines display both peripheral and central effects and play a role in neural plasticity in both normal development such as synaptic pruning as well as in disease-related apoptosis (Watkins et al., 1995, Gibney and Drexhage, 2013, Kronfol and Remick, 2000). A considerable amount of evidence suggests that cytokines play an important role in the pathogenesis of mood disorders by interacting with several biological pathways, i.e. corticotropinreleasing hormone $(\mathrm{CRH})$, and IFN- $\gamma$ induced indoleamine 2,3-dioxygenase (IDO) activity leading to increased neurotoxic molecules, TNF- $\alpha$ modulated nuclear factor kappa-light-chain-enhancer of activated B cells (NF- $\kappa \mathrm{B}$ ) induced apoptosis (Brietzke and Kapczinski, 2008, Soczynska et al., 2009, Dantzer et al., 2008).

Abnormal functioning of the HPA-axis in mood disorders has been implicated in research showing increased cortisol levels, impaired dexamethasone suppression, and blunted adrenocorticotrophic hormone (ACTH) release (Carpenter and Bunney, 1971, Rubin, 1967, Gibbons and Mc, 1962, Nuller and Ostroumova, 1980, Holsboer et al., 1986). In earlier studies, depression had been associated with accompanying mild 
suppression of the immune system, as evidenced by lower proliferative responses of lymphocytes and reduced activity of Natural Killer (NK) cells (Zorrilla et al., 2001). As knowledge about the immune system has been extended, it has become clear that depression is indeed a pro-inflammatory state accompanied by increased levels of inflammatory mediators and activated immune cells.

In the early 1990s, the macrophage theory of depression was first coined based on an extensive synthesis of the available literature at the time (Smith, 1991). According to this theory, depression is a pro-inflammatory state evidenced by activated lymphocytes, hyperactive HPA-axis, increased concentration of acute phase response reactants and pro-inflammatory cytokines such as interleukin (IL)-1, IL-6 and TNF- $\alpha$. Although the theory brings a new insight about the role of immune-related mechanisms in the pathogenesis of depression, more clinical studies were required to directly test this theory (Dantzer et al., 2008). Over the last two decades, a substantial amount of research has provided critical evidence further supporting this theory, which has evolved to a more comprehensive "inflammatory and (neuro)degenerative (I\&ND) hypothesis of depression" (Maes, 2011). MDD is associated with increased immune activation as demonstrated by pro-inflammatory/anti-inflammatory cytokine imbalance (Schiepers et al., 2005). Large-scale studies and meta-analyses report increased circulating CRP (Howren et al., 2009, Wium-Andersen et al., 2013), IL-1 (Howren et al., 2009), IL-6 (Howren et al., 2009, Dowlati et al., 2010), and TNF- $\alpha$ (Dowlati et al., 2010) in patients with MDD. Moreover, it appears that immune activation is associated with treatment resistance in MDD given that increased TNF- $\alpha$ concentration at baseline predicts poor antidepressant response over the course of illness (Myint et al., 2005, Eller et al., 2008).

Consequently, the immune theory has been extended to include BD because of its proximity to depression. This has been tested in numerous samples. Increased concentrations of pro-inflammatory cytokines, e.g. TNF- $\alpha$, IL- 6 and increased oxidative stress have been observed during manic episodes, indicating an escalated immune response (Kim et al., 2004, Ortiz-Dominguez et al., 2007, Tsai et al., 1999, Brietzke et al., 2009, O'Brien et al., 2006, Breunis et al., 2003, Drexhage et al., 2011). Similar to unipolar depression, bipolar depression might also be considered a proinflammatory state; however, more studies are required to reach a certain conclusion (O’Brien et al., 2006, Brietzke et al., 2009, Ortiz-Dominguez et al., 2007).

Recently, the TNF- $\alpha$ signaling pathway was proposed as one of the critical molecular targets involved in pathogenesis of BD based on the evidence showing increased TNF- $\alpha$ concentration in manic episodes which are maintained throughout euthymia, and the beneficial effects of TNF- $\alpha$ antagonists on depressive symptoms (Brietzke and Kapczinski, 2008, Soczynska et al., 2009). Pathological TNF- $\alpha$ 
concentrations disturb the NF-KB-modulated dual signaling cascade, which regulates apoptosis cell survival in neurons and microglia by binding to its receptor, TNF-R1 (Tracey et al., 2008). Neurotrophic factors such as BDNF and NGF were proposed as protective factors that may limit the above-mentioned immune-activated neuronal loss (Brietzke and Kapczinski, 2008). Taking into account the accumulating evidence, it is reasonable to argue that $\mathrm{BD}$ is associated with immune system disturbances. The most intriguing question, however, is whether these immune changes are solely unique to the acute episodes as state markers or whether they persist throughout euthymia as trait markers.

Unfortunately, the cyclic nature of $\mathrm{BD}$ as well as the confounding effects of psychiatric medications on immune markers constitute a challenge in addressing this topic. Chapter 2 presents a study investigating whether there were any differences in pro- and anti-inflammatory cytokine balance (IFN- $\gamma$, TNF- $\alpha$, IL-2, IL-4, IL-5, and IL-10) between euthymic BD patients (medication-free and lithium-monotherapy groups) and healthy controls, and if so whether these differences were trait markers or due to the confounding effect of the medication.

According to the model proposed for staging BD with the use of biomarkers, progression through later stages with social and cognitive dysfunction and persistent subsyndromal symptoms in euthymia is associated with increased oxidative stress and inflammation, demonstrated peripherally by high 3-nitrotyrosine and TNF- $\alpha$ concentrations and low IL-10 and BDNF concentrations (Kapczinski et al., 2009). The Latent Stage is defined by a positive family history of mood disorders, and subthreshold mood or anxiety symptoms. Stage 1 is defined by euthymic periods without overt psychiatric symptoms. Stage 2 is defined by subthreshold symptoms in euthymia and comorbid psychiatric disorders. Stage 3 is defined by marked impairment in cognition and functioning. Stage 4 is defined by the need of a caregiver in daily life due to severe impairment in cognition and functioning. Based on these findings and our previous work primarily focusing on the cytokine network in euthymic patients with $\mathrm{BD}$, chapter 4 presents a study investigating whether there is an ongoing chronic pro-inflammatory process in euthymic bipolar patients with subsyndromal symptoms, characterized by higher concentrations of soluble tumor necrosis factor receptor- 1 (sTNF-R1), soluble interleukin-6 receptor (sIL-6R) and soluble interleukin-2 receptor (sIL-2R).

\section{Tryptophan catabolite pathway}

Tryptophan (TRP) is an essential amino acid, which serves as a precursor of serotonin. Studies show that TRP depletion leads to the emergence of depressive symptoms 
in remitted MDD patients as well as in individuals with an increased risk of MDD (Delgado et al., 1990, Bell et al., 2005). In addition, low peripheral TRP concentrations and low TRP availability (TRP/competing amino acids) have been demonstrated in patients with MDD (Maes et al., 1996, Maes et al., 1986, Dantzer et al., 2008, Cowen et al., 1989). Therefore, the role of the serotonin-kynurenine metabolic pathway in the pathogenesis of MDD was originally formulated with more emphasis on immuneactivated TRP metabolism leading to serotonin deficiency (Oxenkrug, 2013). In the light of evidence showing various effects of TRP metabolites on the Central Nervous System, the emphasis shifted toward the neurotoxic role of TRP metabolites (Oxenkrug, 2013). In normal conditions, the majority of TRP is catabolized in the liver by tryptophan dioxygenase (TDO); and the amount catabolized by the extrahepatic enyzme IDO is negligible (Wichers and Maes, 2004, Myint et al., 2012). However, IFN- $\gamma$ and TNF- $\alpha$-induced IDO activity increases during inflammatory conditions. Consequently, TRP availability for the synthesis of serotonin decreases, and increased activity of IDO leads to formation of kynurenine (KYN). KYN is either catabolized to 3-hydroxykynurenine (3-HK) by kynurenine-3-monoxygenase (K3MO) or kynurenic acid (KA) by kynurenine aminotransferase. $3 \mathrm{HK}$ is considered a neurotoxic metabolite, which increases reactive oxygen species and lipid peroxidation; whereas KA is speculated to be a neuroprotective molecule serving as an NMDA antagonist (Myint et al., 2012, Myint and Kim, 2013). However, it should also be noted that excessive KA may also impair cognitive functioning under non-physiological conditions due to glutamatergic hypo-functioning. 3HK is further catabolized to another neurotoxic metabolite, quinolinic acid (QA), which is an NMDA agonist inducing excitotoxicity (Myint and Kim, 2013). In the brain, astrocytes degrade KYN to KA, whereas microglias produce QA from KYN.

Studies showed increased levels of neurotoxic TRP catabolites in patients with MDD (Myint et al., 2007, Myint et al., 2013). Higher concentrations of KYN KA (KYN turnover ratio) and QA during treatment with IFN- $\alpha$ therapy were associated with depressive symptoms and subsequent depressive episodes (Kenis et al., 2011). In vitro studies demonstrate antidepressants re-establish the balance between neuroprotective and neurotoxic metabolites in astrocyte cultures (Krause et al., 2012, Kocki et al., 2012). However, there is limited knowledge about the in vivo effects of available treatments for MD on the TRP-KYN catabolite pathway. In chapter 6, a study focusing on the long-term effects of electroconvulsive therapy (ECT) on immune-modulated catabolic pathway of TRP-KYN is presented. Moreover, chapter 5 presents a study investigating the possible influence of TNF- $\alpha$ antagonist, infliximab on TRP availability in patients with $\mathrm{CD}$. 


\section{Immunomodulatory effects of psychiatric treatments}

Current evidence indicates that nearly all psychiatric medications have an effect on the immune system (Pollmacher et al., 2000, Hannestad et al., 2011). Certainly, lithium first comes to mind when the immune-modulating effects of psychiatric medications are considered. In fact, the efficacy of adjuvant lithium treatment was investigated in many other medical illnesses based on its immune-modulating effects, such as in antiviral therapy for the herpes simplex virus (Amsterdam et al., 1990) and human immunodeficiency infections (Ances et al., 2008), clozapine induced leukopenia (Mattai et al., 2009), and hematopoietic and thyroid cancers (Yung, 1984). Unfortunately, these immune-modulating effects are also partly responsible for several different side-effects of lithium such as psoriasis (Knijff et al., 2005) and dysregulation of thyroid functioning (Lazarus, 2009). In this regard, the immunomodulatory effects of lithium have been investigated extensively in both in vivo and in vitro studies. IL-2, sIL-2R and sIL-6R concentrations were increased in healthy volunteers after 30 days of lithium treatment; whereas lithium treatment normalized increased levels of sIL-2R and sIL-6R in rapid cycling bipolar patients (Rapaport et al., 1999). Increased IL-4 and IL-10, and decreased IL-2 and IFN- $\gamma$ production in monocytes exposed to lithium in healthy volunteers has been observed (Rapaport and Manji, 2001). Overall, these findings indicate that lithium treatment might be beneficial in normalizing mild immune activation through suppressing pro-inflammatory cytokines, while up-regulating cytokines with anti-inflammatory properties in patients with BD. However, data are inconclusive to clarify the effect of lithium on healthy volunteers. Lower numbers of IL-2, IL-6, IL-10 and IFN- $\gamma$ secreting cells in comparison to healthy volunteers were found in patients with BD on chronic lithium treatment over 3 months, and in originally medication-naive patients after 3 months of lithium treatment (Boufidou et al., 2004). Additionally, the addition of lithium in vitro restores the imbalanced production of IL- $1 \beta$ and IL- 6 by monocytes (abnormal IL- $1 \beta /$ IL- 6 production ratio) (Knijff et al., 2007). In the light of these findings, lithium can be contemplated as a complex immune-regulatory molecule influencing both pro- inflammatory and antiinflammatory cascades. However, more evidence is required to conclude whether this immune-modulating effect has a role in lithium's mood stabilizing properties. In chapter 3, the study investigating the possible association between longitudinal lithium response and TNF- $\alpha$ level, a major pro-inflammatory cytokine is presented.

Although the immune-modulating effects of psychiatric medications have been extensively studied, the impact of electroconvulsive therapy (ECT) on immune functioning and the possible role of immune alterations as one of the mechanisms of action of ECT rarely have been discussed. Therefore, a literature review examining the 
effects of ECT on immune functioning, and the degree to which these represent possible mechanisms mediating the therapeutic action of ECT is presented in chapter 7.

\section{Hypoxia-ischaemia as a mechanism underlying psychiatric syndromes}

In recent years, there has been a growth in the amount of studies investigating the impact of prenatal and perinatal complications on the maternal immune activation and microglial activity. These studies have reported (i) increased concentrations of neurotoxic inflammatory markers in cerebrospinal fluid of newborn infants with perinatal hypoxic-ischaemic brain injury(Sävman et al., 2013), (ii) an interplay between hypoxia-ischaemia and maternal infection on stroke-like events and neonatal white matter deterioration in spastic cerebral palsy(Leviton and Dammann, 2004, Nelson and Lynch, 2004, Grether and Nelson, 1997, Fleiss and Gressens, 2012), (iii) potentiating effect of prenatal exposure to immune activating factors on cerebral hypoxia-ischaemia(Larouche et al., 2004, Stridh et al., 2013).

Registry studies have thus far demonstrated that there exists an association between obstetric complications and the risk for psychiatric syndromes, particularly schizophrenia(Nosarti et al., 2012, Cannon et al., 2002, Freedman et al., 2013, Gale and Martyn, 2004); and synopsis of biological studies suggest that hypoxia-response is likely the underlying mechanism(Mittal et al., 2008, Schmidt-Kastner et al., 2006). Previous studies have reported that the impact of severe obstetric complications on schizophrenia risk is moderated by certain variants in the schizophrenia candidate genes AKT1, BDNF, DTNBP1, GRM3(Nicodemus et al., 2008), and a recent systematic annotation of genes involved in hypoxia-response and genes associated with schizophrenia has provided in silico evidence linking obstetric complications, hypoxia-response, and schizophrenia(Schmidt-Kastner et al., 2012).

Based on the findings showing that extended phenotypes of subthreshold psychopathology can be identified throughout the population(van Os, 2013), and that the impact of obstetric complications on psychopathology is general rather than specific for schizophrenia, the study in chapter 8 aimed to investigate the geneenvironment interaction model in the general population. Data from a cohort of young adult female twin pairs with increased risk for obstetric complications were analyzed to determine whether prospectively collected measures of obstetric complications are associated with expression of mental ill health, and whether these associations are moderated by a set of genes a priori selected on the basis of previous reports linking these genes with both hypoxia-response and schizophrenia(Schmidt-Kastner et al., 
2012) in a well characterized cohort of young adult female twin pairs with increased risk for obstetric complications.

\section{Aims of this thesis}

The overall aim of this thesis was to investigate the role of immune-related pathways in the pathogenesis of mood disorders and related medical disorders through examining circulating immune markers. In order to understand this complex interacting network, this broad topic was grasped by using several different strategies.

Chapter 2 aimed to determine whether there were any differences in pro- and anti-inflammatory cytokine balance (IFN- $\gamma$, TNF- $\alpha$, IL-2, IL-4, IL-5, and IL-10) between euthymic BD patients (medication-free and lithium-monotherapy) and healthy controls, and if these differences were trait markers or due to the effect of medication. The findings of this study led us to further investigate whether the therapeutic effects of lithium, a cornerstone in BD treatment, are mediated by its complex balancing effect on immune parameters through influencing both pro- and anti-inflammatory cascades. Therefore, chapter 3 aimed to investigate the possible association between lithium response and TNF- $\alpha$ concentration, which is one of the major pro-inflammatory cytokines. Chapter $\mathbf{4}$ aimed to investigate the possible immune origin of subsyndromal symptoms observed in BD that are associated with severe impairment during inter-episodic periods and reduced treatment response.

Chapter 5 aimed to investigate the impact of infliximab, a TNF- $\alpha$ antagonist on depressive symptoms in CD patients, and the possibility that improvement of depressive symptoms occurs in parallel with changes in TRP availability imposed by a reduction in inflammation as reflected by levels of APPs.

Chapter 6 presents a review of in vitro studies that examined the impact of ECT on immune functioning in patients with depression. Consequently, chapter 7 aimed to investigate the impact of ECT on the TRP-KYN metabolic pathway, in association with the therapeutic action of ECT in a long-term follow-up study.

Chapter 8 aimed to investigate whether hypoxia-response genes moderate the impact of prospectively assessed obstetric complications on psychopathology in a general population female twin cohort. 


\section{References}

AAN HET ROT, M., ZARATE, C. A., JR., CHARNEY, D. S. \& MATHEW, S. J. 2012.

Ketamine for depression: where do we go from here? Biol Psychiatry, 72, 537-47.

AMSTERDAM, J. D., MAISLIN, G. \& RYBAKOWSKI, J. 1990. A possible antiviral action of lithium carbonate in herpes simplex virus infections. Biol Psychiatry, 27, 447-53.

ANCES, B. M., LETENDRE, S. L., ALEXANDER, T. \& ELLIS, R. J. 2008. Role of psychiatric medications as adjunct therapy in the treatment of HIV associated neurocognitive disorders. Int Rev Psychiatry, 20, 89-93.

APA 2000. Diagnostic and statistical manual of mental disorders (4th ed., text rev.), Washington, DC: American Psychiatric Publishing.

APA 2013. Diagnostic and statistical manual of mental disorders (5th ed.), Arlington, VA: American Psychiatric Publishing.

ASNIS, G. M. \& DE LA GARZA, R., 2ND 2005. Interferon-induced depression: strategies in treatment. Prog Neuropsychopharmacol Biol Psychiatry, 29, 808-18.

BALANCE INVESTIGATORS COLLABORATORS, GEDDES, J. R., GOODWIN, G. M., RENDELL, J., AZORIN, J. M., CIPRIANI, A., OSTACHER, M. J., MORRISS, R., ALDER, N. \& JUSZCZAK, E. 2010. Lithium plus valproate combination therapy versus monotherapy for relapse prevention in bipolar I disorder (BALANCE): a randomised open-label trial. Lancet, 375, 385-95.

BAUMEISTER, A. A., HAWKINS, M. F. \& LOPEZ-MUNOZ, F. 2010. Toward standardized usage of the word serendipity in the historiography of psychopharmacology. $J$ Hist Neurosci, 19, 253-70.

BELL, C. J., HOOD, S. D. \& NUTT, D. J. 2005. Acute tryptophan depletion. Part II: clinical effects and implications. Aust N Z J Psychiatry, 39, 565-74.

BEYER, J., KUCHIBHATLA, M., GERSING, K. \& KRISHNAN, K. R. 2005. Medical comorbidity in a bipolar outpatient clinical population. Neuropsychopharmacology, 30, 401-4.

BOUFIDOU, F., NIKOLAOU, C., ALEVIZOS, B., LIAPPAS, I. A. \& CHRISTODOULOU, G. N. 2004. Cytokine production in bipolar affective disorder patients under lithium treatment. $J$ Affect Disord, 82, 309-13.

BREUNIS, M. N., KUPKA, R. W., NOLEN, W. A., SUPPES, T., DENICOFF, K. D., LEVERICH, G. S., POST, R. M. \& DREXHAGE, H. A. 2003. High numbers of circulating activated $T$ cells and raised levels of serum IL-2 receptor in bipolar disorder. Biol Psychiatry, 53, 157-65.

BRIETZKE, E. \& KAPCZINSKI, F. 2008. TNFalpha as a molecular target in bipolar disorder. Progress in neuro-psychopharmacology \& biological psychiatry, 32, 1355-61.

BRIETZKE, E., STERTZ, L., FERNANDES, B. S., KAUER-SANT'ANNA, M., MASCARENHAS, M., ESCOSTEGUY VARGAS, A., CHIES, J. A. \& KAPCZINSKI, F. 2009. Comparison of cytokine levels in depressed, manic and euthymic patients with bipolar disorder. J Affect Disord, 116, 214-7.

CANNON, M., JONES, P. B. \& MURRAY, R. M. 2002. Obstetric complications and schizophrenia: historical and meta-analytic review. The American journal of psychiatry, 159, 1080-92.

CARPENTER, W. T., JR. \& BUNNEY, W. E., JR. 1971. Adrenal cortical activity in depressive illness. Am J Psychiatry, 128, 31-40.

CHEN, Y. W. \& DILSAVER, S. C. 1996. Lifetime rates of suicide attempts among subjects with bipolar and unipolar disorders relative to subjects with other Axis I disorders. Biol Psychiatry, 39, 896-9.

COWEN, P. J., PARRY-BILLINGS, M. \& NEWSHOLME, E. A. 1989. Decreased plasma tryptophan levels in major depression. Journal of affective disorders, 16, 27-31.

DANTZER, R. 2004. Cytokine-induced sickness behaviour: a neuroimmune response to activation of innate immunity. Eur $J$ Pharmacol, 500, 399-411. 
DANTZER, R., O'CONNOR, J. C., FREUND, G. G., JOHNSON, R. W. \& KELLEY, K. W. 2008. From inflammation to sickness and depression: when the immune system subjugates the brain. Nature reviews. Neuroscience, 9, 46-56.

DELGADO, P. L., CHARNEY, D. S., PRICE, L. H., AGHAJANIAN, G. K., LANDIS, H. \& HENINGER, G. R. 1990. Serotonin function and the mechanism of antidepressant action. Reversal of antidepressant-induced remission by rapid depletion of plasma tryptophan. Arch Gen Psychiatry, 47, 411-8.

DICKENS, C., MCGOWAN, L., CLARKCARTER, D. \& CREED, F. 2002. Depression in rheumatoid arthritis: a systematic review of the literature with meta-analysis. Psychosom Med, 64, 52-60.

DOWLATI, Y., HERRMANN, N., SWARDFAGER, W., LIU, H., SHAM, L., REIM, E. K. \& LANCTOT, K. L. 2010. A meta-analysis of cytokines in major depression. Biol Psychiatry, 67, 446-57.

DREXHAGE, R. C., HOOGENBOEZEM, T. H., VERSNEL, M. A., BERGHOUT, A., NOLEN, W. A. \& DREXHAGE, H. A. 2011. The activation of monocyte and $\mathrm{T}$ cell networks in patients with bipolar disorder. Brain Behav Immun, 25, 1206-13.

ELLER, T., VASAR, V., SHLIK, J. \& MARON, E. 2008. Pro-inflammatory cytokines and treatment response to escitalopram in major depressive disorder. Prog Neuropsychopharmacol Biol Psychiatry, 32, 445-50.

FLEISS, B. \& GRESSENS, P. 2012. Tertiary mechanisms of brain damage: a new hope for treatment of cerebral palsy? The Lancet Neurology, 11, 556-566.

FREEDMAN, D., BAO, Y., KREMEN, W. S., VINOGRADOV, S., MCKEAGUE, I. W. \& BROWN, A. S. 2013. Birth weight and neurocognition in schizophrenia spectrum disorders. Schizophr Bull, 39, 592-600.

GALE, C. R. \& MARTYN, C. N. 2004. Birth weight and later risk of depression in a national birth cohort. Br J Psychiatry, 184, 28-33.

GIBBONS, J. L. \& MC, H. P. 1962. Plasma cortisol in depressive illness. J Psychiatr Res, 1, 16271.
GIBNEY, S. M. \& DREXHAGE, H. A. 2013. Evidence for a dysregulated immune system in the etiology of psychiatric disorders. $J$ Neuroimmune Pharmacol, 8, 900-20.

GOLD, S. M. \& IRWIN, M. R. 2009. Depression and immunity: inflammation and depressive symptoms in multiple sclerosis. Immunol Allergy Clin North Am, 29, 309-20.

GRETHER, J. K. \& NELSON, K. B. 1997. Maternal infection and cerebral palsy in infants of normal birth weight. Jama, 278, 207-211.

HANNESTAD, J., DELLAGIOIA, N. \& BLOCH, M. 2011. The effect of antidepressant medication treatment on serum levels of inflammatory cytokines: a meta-analysis. Neuropsychopharmacology, 36, 2452-9.

HASLER, G. 2010. Pathophysiology of depression: do we have any solid evidence of interest to clinicians? World Psychiatry, 9, 155-61.

HELZER, J. E., CHAMMAS, S., NORLAND, C. C., STILlingS, W. A. \& ALPERS, D. H. 1984. A study of the association between Crohn's disease and psychiatric illness. Gastroenterology, 86, 324-30.

HOLSBOER, F., GERKEN, A., VON BARDELEBEN, U., GRIMM, W., BEYER, H., MULLER, O. A. \& STALLA, G. K. 1986. Human corticotropin-releasing hormone in depression--correlation with thyrotropin secretion following thyrotropin-releasing hormone. Biol Psychiatry, 21, 601-11.

HOWREN, M. B., LAMKIN, D. M. \& SULS, J. 2009. Associations of depression with C-reactive protein, IL-1, and IL-6: a metaanalysis. Psychosom Med, 71, 171-86.

KAPCZINSKI, F., DIAS, V. V., KAUERSANT'ANNA, M., BRIETZKE, E., VAZQUEZ, G. H., VIETA, E. \& BERK, M. 2009. The potential use of biomarkers as an adjunctive tool for staging bipolar disorder. Prog Neuropsychopharmacol Biol Psychiatry, 33, 1366-71.

KENIS, G., PRICKAERTS, J., VAN OS, J., KOEK, G. H., ROBAEYS, G., STEINBUSCH, H. W. \& WICHERS, M. 2011. Depressive symptoms following interferon-alpha therapy: mediated by immune-induced reductions in brain-derived neurotrophic factor? Int $J$ Neuropsychopharmacol, 14, 247-53. 
KESSLER, R. C., PETUKHOVA, M., SAMPSON, N. A., ZASLAVSKY, A. M. \& WITTCHEN, H. U. 2012. Twelve-month and lifetime prevalence and lifetime morbid risk of anxiety and mood disorders in the United States. Int J Methods Psychiatr Res, 21, 169-84.

KIM, Y. K., MYINT, A. M., LEE, B. H., HAN, C. S., LEE, S. W., LEONARD, B. E. \& STEINBUSCH, H. W. 2004. T-helper types 1, 2 , and 3 cytokine interactions in symptomatic manic patients. Psychiatry Res, 129, 267-72.

KNIJFF, E. M., BREUNIS, M. N., KUPKA, R. W., DE WIT, H. J., RUWHOF, C., AKKERHUIS, G. W., NOLEN, W. A. \& DREXHAGE, H. A. 2007. An imbalance in the production of IL-1beta and IL-6 by monocytes of bipolar patients: restoration by lithium treatment. Bipolar Disord, 9, 743-53.

KNIJFF, E. M., KUPKA, R. W., RUWHOF, C., BREUNIS, M. N., PRENS, E. P., NOLEN, W. A. \& DREXHAGE, H. A. 2005. Evidence that the immunopathogenic mechanism of lithiuminduced psoriasis differs from that of regular psoriasis. Bipolar Disord, 7, 388-9.

KOCKI, T., WNUK, S., KLOC, R., KOCKI, J., OWE-LARSSON, B. \& URBANSKA, E. M. 2012. New insight into the antidepressants action: modulation of kynurenine pathway by increasing the kynurenic acid/3hydroxykynurenine ratio. J Neural Transm, 119, 235-43.

KRAUSE, D. L., RIEDEL, M., MULLER, N., WEIDINGER, E., SCHWARZ, M. J. \& MYINT, A. M. 2012. Effects of antidepressants and cyclooxygenase-2 inhibitor on cytokines and kynurenines in stimulated in vitro blood culture from depressed patients. Inflammopharmacology, 20, 169-76.

KRONFOL, Z. \& REMICK, D. G. 2000. Cytokines and the brain: implications for clinical psychiatry. The American journal of psychiatry, 157, 683-94.

KRYSTAL, J. H., SANACORA, G. \& DUMAN, R. S. 2013. Rapid-acting glutamatergic antidepressants: the path to ketamine and beyond. Biol Psychiatry, 73, 1133-41.

KURINA, L. M., GOLDACRE, M. J., YEATES, D. \& GILL, L. E. 2001. Depression and anxiety in people with inflammatory bowel disease. $J$ Epidemiol Community Health, 55, 716-20.
LAROUCHE, A., ROY, M., KADHIM, H., TSANACLIS, A., FORTIN, D. \& SEBIRE, G. 2004. Neuronal injuries induced by perinatal hypoxic-ischemic insults are potentiated by prenatal exposure to lipopolysaccharide: animal model for perinatally acquired encephalopathy. Developmental neuroscience, 27, 134-142.

LAZARUS, J. H. 2009. Lithium and thyroid. Best Pract Res Clin Endocrinol Metab, 23, 723-33.

LEVERICH, G. S., ALTSHULER, L. L., FRYE, M. A., SUPPES, T., KECK, P. E., JR., MCELROY, S. L., DENICOFF, K. D., OBROCEA, G., NOLEN, W. A., KUPKA, R., WALDEN, J., GRUNZE, H., PEREZ, S., LUCKENBAUGH, D. A. \& POST, R. M. 2003. Factors associated with suicide attempts in 648 patients with bipolar disorder in the Stanley Foundation Bipolar Network. J Clin Psychiatry, 64, 50615.

LEVITON, A. \& DAMMANN, O. 2004. Coagulation, inflammation, and the risk of neonatal white matter damage. Pediatric research, 55, 541-545.

LOFTUS, E. V., JR., GUERIN, A., YU, A. P., WU, E. Q., YANG, M., CHAO, J. \& MULANI, P. M. 2011. Increased risks of developing anxiety and depression in young patients with Crohn's disease. Am J Gastroenterol, 106, 1670-7.

MAES, M. 2011. Depression is an inflammatory disease, but cell-mediated immune activation is the key component of depression. Prog Neuropsychopharmacol Biol Psychiatry, 35, 664-75.

MAES, M., DE RUYTER, M., HOBIN, P. \& SUY, E. 1986. The diagnostic performance of the L-tryptophan/competing amino acids ratio in major depression. Acta psychiatrica Belgica, $86,257-65$.

MAES, M., WAUTERS, A., VERKERK, R., DEMEDTS, P., NEELS, H., VAN GASTEL, A., COSYNS, P., SCHARPE, S. \& DESNYDER, R. 1996. Lower serum L-tryptophan availability in depression as a marker of a more generalized disorder in protein metabolism. Neuropsychopharmacology, 15, 243-51.

MARTINOWICH, K., SCHLOESSER, R. J. \& MANJ, H. K. 2009. Bipolar disorder: from genes to behavior pathways. J Clin Invest, 119, 726-36. 
MATTAI, A., FUNG, L., BAKALAR, J., OVERMAN, G., TOSSELL, J., MILLER, R., RAPOPORT, J. \& GOGTAY, N. 2009. Adjunctive use of lithium carbonate for the management of neutropenia in clozapinetreated children. Hum Psychopharmacol, 24, 584-9.

MINDERHOUD, I. M., SAMSOM, M. \& OLDENBURG, B. 2007. Crohn's disease, fatigue, and infliximab: is there a role for cytokines in the pathogenesis of fatigue? World journal of gastroenterology : WJG, 13, 2089-93.

MITTAL, V. A., ELLMAN, L. M. \& CANNON, T. D. 2008. Gene-environment interaction and covariation in schizophrenia: the role of obstetric complications. Schizophrenia bulletin, 34, 1083-94.

MIYAOKA, T., WAKE, R., FURUYA, M., LIAURY, K., IEDA, M., KAWAKAMI, K., TSUCHIE, K., TAKI, M., ISHIHARA, K., ARAKI, T. \& HORIGUCHI, J. 2012. Minocycline as adjunctive therapy for patients with unipolar psychotic depression: an openlabel study. Prog Neuropsychopharmacol Biol Psychiatry, 37, 222-6.

MURRAY, C. J., VOS, T., LOZANO, R., NAGHAVI, M., FLAXMAN, A. D., MICHAUD, C., EZZATI, M., SHIBUYA, K., SALOMON, J. A., ABDALLA, S., ABOYANS, V., ABRAHAM, J., ACKERMAN, I., AGGARWAL, R., AHN, S. Y., ALI, M. K., ALVARADO, M., ANDERSON, H. R., ANDERSON, L. M., ANDREWS, K. G., ATKINSON, C., BADDOUR, L. M., BAHALIM, A. N., BARKER-COLLO, S., BARRERO, L. H., BARTELS, D. H., BASANEZ, M. G., BAXTER, A., BELL, M. L., BENJAMIN, E. J., BENNETT, D., BERNABE, E., BHALLA, K., BHANDARI, B., BIKBOV, B., BIN ABDULHAK, A., BIRBECK, G., BLACK, J. A., BLENCOWE, H., BLORE, J. D., BLYTH, F., BOLLIGER, I., BONAVENTURE, A., BOUFOUS, S., BOURNE, R., BOUSSINESQ, M., BRAITHWAITE, T., BRAYNE, C., BRIDGETT, L., BROOKER, S., BROOKS, P., BRUGHA, T. S., BRYAN-HANCOCK, C., BUCELLO, C., BUCHBINDER, R., BUCKLE, G., BUDKE, C. M., BURCH, M., BURNEY, P., BURSTEIN, R., CALABRIA, B., CAMPBELL, B., CANTER, C. E.,
CARABIN, H., CARAPETIS, J., CARMONA, L., CELLA, C., CHARLSON, F., CHEN, H., CHENG, A. T., CHOU, D., CHUGH, S. S., COFFENG, L. E., COLAN, S. D., COLQUHOUN, S., COLSON, K. E., CONDON, J., CONNOR, M. D., COOPER, L. T., CORRIERE, M., CORTINOVIS, M., DE VACCARO, K. C., COUSER, W., COWIE, B. C., CRIQUI, M. H., CROSS, M., DABHADKAR, K. C., DAHIYA, M., DAHODWALA, N., DAMSERE-DERRY, J., DANAEI, G., DAVIS, A., DE LEO, D., DEGENHARDT, L., DELLAVALLE, R., DELOSSANTOS, A., DENENBERG, J., DERRETT, S., DES JARLAIS, D. C., DHARMARATNE, S. D., et al. 2012.

Disability-adjusted life years (DALYs) for 291 diseases and injuries in 21 regions, 1990-2010: a systematic analysis for the Global Burden of Disease Study 2010. Lancet, 380, 2197-223.

MUSSELMAN, D. L., EVANS, D. L. \& NEMEROFF, C. B. 1998. The relationship of depression to cardiovascular disease: epidemiology, biology, and treatment. Arch Gen Psychiatry, 55, 580-92.

MYINT, A. M., BONDY, B., BAGHAI, T. C., ESER, D., NOTHDURFTER, C., SCHULE, C., ZILL, P., MULLER, N., RUPPRECHT, R. \& SCHWARZ, M. J. 2013. Tryptophan metabolism and immunogenetics in major depression: a role for interferon-gamma gene. Brain Behav Immun, 31, 128-33.

MYINT, A. M. \& KIM, Y. K. 2013. Network beyond IDO in Psychiatric Disorders: Revisiting Neurodegeneration Hypothesis. Prog Neuropsychopharmacol Biol Psychiatry.

MYINT, A. M., KIM, Y. K., VERKERK, R., SCHARPE, S., STEINBUSCH, H. \& LEONARD, B. 2007. Kynurenine pathway in major depression: evidence of impaired neuroprotection. J Affect Disord, 98, 143-51.

MYINT, A. M., LEONARD, B. E., STEINBUSCH, H. W. \& KIM, Y. K. 2005. Th1, Th2, and Th3 cytokine alterations in major depression. $J$ Affect Disord, 88, 167-73.

MYINT, A. M., SCHWARZ, M. J. \& MULLER, N. 2012. The role of the kynurenine metabolism in major depression. J Neural Transm, 119, 245-51. 
NELSON, K. B. \& LYNCH, J. K. 2004. Stroke in newborn infants. The Lancet Neurology, 3, 150-158.

NICODEMUS, K. K., MARENCO, S., BATTEN, A. J., VAKKALANKA, R., EGAN, M. F., STRAUB, R. E. \& WEINBERGER, D. R. 2008. Serious obstetric complications interact with hypoxia-regulated/vascular-expression genes to influence schizophrenia risk. Molecular psychiatry, 13, 873-7.

NOSARTI, C., REICHENBERG, A., MURRAY, R. M., CNATTINGIUS, S., LAMBE, M. P., YIN, L., MACCABE, J., RIFKIN, L. \& HULTMAN, C. M. 2012. Preterm birth and psychiatric disorders in young adult life. Arch Gen Psychiatry, 69, E1-8.

NULLER, J. L. \& OSTROUMOVA, M. N. 1980. Resistance to inhibiting effect of dexamethasone in patients with endogenous depression. Acta Psychiatr Scand, 61, 169-77.

O'BRIEN, S. M., SCULLY, P., SCOTT, L. V. \& DINAN, T. G. 2006. Cytokine profiles in bipolar affective disorder: focus on acutely ill patients. J Affect Disord, 90, 263-7.

ORTIZ-DOMINGUEZ, A., HERNANDEZ, M. E., BERLANGA, C., GUTIERREZ-MORA, D., MORENO, J., HEINZE, G. \& PAVON, L. 2007. Immune variations in bipolar disorder: phasic differences. Bipolar Disord, 9, 596-602.

OXENKRUG, G. 2013. Serotonin-kynurenine hypothesis of depression: historical overview and recent developments. Curr Drug Targets, 14, 514-21.

PACCHIAROTTI, I., BOND, D. J., BALDESSARINI, R. J., NOLEN, W. A., GRUNZE, H., LICHT, R. W., POST, R. M., BERK, M., GOODWIN, G. M., SACHS, G. S., TONDO, L., FINDLING, R. L., YOUNGSTROM, E. A., TOHEN, M., UNDURRAGA, J., GONZALEZPINTO, A., GOLDBERG, J. F., YILDIZ, A., ALTSHULER, L. L., CALABRESE, J. R., MITCHELL, P. B., THASE, M. E., KOUKOPOULOS, A., COLOM, F., FRYE, M. A., MALHI, G. S., FOUNTOULAKIS, K. N., VAZQUEZ, G., PERLIS, R. H., KETTER, T. A., CASSIDY, F., AKISKAL, H., AZORIN, J. M., VALENTI, M., MAZZEI, D. H., LAFER, B., KATO, T., MAZZARINI, L., MARTINEZARAN, A., PARKER, G., SOUERY, D.,
OZERDEM, A., MCELROY, S. L., GIRARDI, P., BAUER, M., YATHAM, L. N., ZARATE, C. A., NIERENBERG, A. A., BIRMAHER, B., KANBA, S., EL-MALLAKH, R. S., SERRETTI, A., RIHMER, Z., YOUNG, A. H., KOTZALIDIS, G. D., MACQUEEN, G. M., BOWDEN, C. L., GHAEMI, S. N., LOPEZJARAMILLO, C., RYBAKOWSKI, J., HA, K., PERUGI, G., KASPER, S., AMSTERDAM, J. D., HIRSCHFELD, R. M., KAPCZINSKI, F. \& VIETA, E. 2013. The International Society for Bipolar Disorders (ISBD) Task Force Report on Antidepressant Use in Bipolar Disorders. Am J Psychiatry.

POLLMACHER, T., HAACK, M., SCHULD, A., KRAUS, T. \& HINZE-SELCH, D. 2000. Effects of antipsychotic drugs on cytokine networks. J Psychiatr Res, 34, 369-82.

RAISON, C. L., RUTHERFORD, R. E., WOOLWINE, B. J., SHUO, C., SCHETTLER, P., DRAKE, D. F., HAROON, E. \& MILLER, A. H. 2012. A Randomized Controlled Trial of the Tumor Necrosis Factor Antagonist Infliximab for Treatment-Resistant Depression: The Role of Baseline Inflammatory Biomarkers. Archives of general psychiatry, $1-11$.

RAPAPORT, M. H., GUYLAI, L. \& WHYBROW, P. 1999. Immune parameters in rapid cycling bipolar patients before and after lithium treatment. J Psychiatr Res, 33, 335-40.

RAPAPORT, M. H. \& MANJI, H. K. 2001. The effects of lithium on ex vivo cytokine production. Biol Psychiatry, 50, 217-24.

RUBIN, R. T. 1967. Adrenal cortical activity changes in manic-depressive illness. Influence on intermediary metabolism of tryptophan. Arch Gen Psychiatry, 17, 671-9.

RUSH, A. J., TRIVEDI, M. H., WISNIEWSKI, S. R., NIERENBERG, A. A., STEWART, J. W., WARDEN, D., NIEDEREHE, G., THASE, M. E., LAVORI, P. W., LEBOWITZ, B. D., MCGRATH, P. J., ROSENBAUM, J. F., SACKEIM, H. A., KUPFER, D. J., LUTHER, J. \& FAVA, M. 2006. Acute and longer-term outcomes in depressed outpatients requiring one or several treatment steps: a STAR*D report. Am J Psychiatry, 163, 1905-17.

SAVITZ, J., PRESKORN, S., TEAGUE, T. K., DREVETS, D., YATES, W. \& DREVETS, W. 
2012. Minocycline and aspirin in the treatment of bipolar depression: a protocol for a proof-ofconcept, randomised, double-blind, placebocontrolled, 2x2 clinical trial. BMJ open, 2, $\mathrm{e} 000643$.

SÄVMAN, K., HEYES, M. P., SVEDIN, P. \& KARLSSON, A. 2013. Microglia/macrophagederived inflammatory mediators galectin-3 and quinolinic acid are elevated in cerebrospinal fluid from newborn infants after birth asphyxia. Translational stroke research, 4, 228-235.

SCHIEPERS, O. J., WICHERS, M. C. \& MAES, M. 2005. Cytokines and major depression. Prog Neuropsychopharmacol Biol Psychiatry, 29, 201-17.

SCHMIDT-KASTNER, R., VAN OS, J., ESQUIVEL, G., STEINBUSCH, H. W. \& RUTTEN, B. P. 2012. An environmental analysis of genes associated with schizophrenia: hypoxia and vascular factors as interacting elements in the neurodevelopmental model. Molecular psychiatry.

SCHMIDT-KASTNER, R., VAN OS, J., H, W. M. S. \& SCHMITZ, C. 2006. Gene regulation by hypoxia and the neurodevelopmental origin of schizophrenia. Schizophrenia research, 84, 253-71.

SIEGERT, R. J. \& ABERNETHY, D. A. 2005. Depression in multiple sclerosis: a review. $J$ Neurol Neurosurg Psychiatry, 76, 469-75.

SMITH, R. S. 1991. The macrophage theory of depression. Med Hypotheses, 35, 298-306.

SOCZYNSKA, J. K., KENNEDY, S. H., GOLDSTEIN, B. I., LACHOWSKI, A., WOLDEYOHANNES, H. O. \& MCINTYRE, R. S. 2009. The effect of tumor necrosis factor antagonists on mood and mental healthassociated quality of life: novel hypothesisdriven treatments for bipolar depression? Neurotoxicology, 30, 497-521.

STRIDH, L., MOTTAHEDIN, A., JOHANSSON, M. E., VALDEZ, R. C., NORTHINGTON, F., WANG, X. \& MALLARD, C. 2013. Toll-like receptor-3 activation increases the vulnerability of the neonatal brain to hypoxia-ischemia. The Journal of Neuroscience, 33, 12041-12051.
TRACEY, D., KLARESKOG, L., SASSO, E. H., SALFELD, J. G. \& TAK, P. P. 2008. Tumor necrosis factor antagonist mechanisms of action: a comprehensive review. Pharmacol Ther, 117, 244-79.

TSAI, S. Y., CHEN, K. P., YANG, Y. Y., CHEN, C. C., LEE, J. C., SINGH, V. K. \& LEU, S. J. 1999. Activation of indices of cell-mediated immunity in bipolar mania. Biol Psychiatry, 45, 989-94.

TYRING, S., GOTTLIEB, A., PAPP, K., GORDON, K., LEONARDI, C., WANG, A., LALLA, D., WOOLLEY, M., JAHREIS, A., ZITNIK, R., CELLA, D. \& KRISHNAN, R. 2006. Etanercept and clinical outcomes, fatigue, and depression in psoriasis: doubleblind placebo-controlled randomised phase III trial. Lancet, 367, 29-35.

VAN OS, J. 2013. The dynamics of subthreshold psychopathology: implications for diagnosis and treatment. Am J Psychiatry, 170, 695-8.

WATKINS, L. R., MAIER, S. F. \& GOEHLER, L. E. 1995. Cytokine-to-brain communication: a review $\&$ analysis of alternative mechanisms. Life Sci, 57, 1011-26.

WICHERS, M. C. \& MAES, M. 2004. The role of indoleamine 2,3-dioxygenase (IDO) in the pathophysiology of interferon-alpha-induced depression. J Psychiatry Neurosci, 29, 11-7.

WIUM-ANDERSEN, M. K., ORSTED, D. D., NIELSEN, S. F. \& NORDESTGAARD, B. G. 2013. Elevated C-reactive protein levels, psychological distress, and depression in 73, 131 individuals. JAMA Psychiatry, 70, 176-84.

YUNG, C. Y. 1984. A review of clinical trials of lithium in medicine. Pharmacol Biochem Behav, 21 Suppl 1, 51-5.

ZORRILLA, E. P., LUBORSKY, L., MCKAY, J. R., ROSENTHAL, R., HOULDIN, A., TAX, A., MCCORKLE, R., SELIGMAN, D. A. \& SCHMIDT, K. 2001. The relationship of depression and stressors to immunological assays: a meta-analytic review. Brain Behav Immun, 15, 199-226. 


\section{Cytokine levels in euthymic bipolar patients}

Sinan Guloksuz, Esin Aktas Cetin, Turan Cetin, Gunnur Deniz, Esat Timucin Oral, David J. Nutt.

Journal of Affective Disorders (2010): 126(3):458-62. 

Abstract

\section{Background}

The pathophysiology of bipolar disorder is not thoroughly understood. Several studies have investigated the possible role of cytokines in psychiatric disorders, based on their role in neuro-immune modulation; however, findings in studies on bipolar disorder remain limited and contradictory, and most studies have focused on either manic or depressive episodes. These studies suggest that both manic and depressive episodes could be proinflammatory states. The present study aimed to determine whether there are enduring differences in cytokine levels -unrelated to the effects of medication- between euthymic bipolar patients and healthy controls.

\section{Methods}

The study included 31 euthymic bipolar patients-16 medication-free (MF) and 15 on lithium monotherapy (LM) and 16 healthy volunteers in whom serum cytokine levels were measured. The 3 groups were homogenous in terms of age, gender, and ethnicity. IFN- $\gamma$, TNF-a, IL- 2, IL-4, IL-5, and IL-10 levels were measured in all groups using flow cytometer.

\section{Results}

There were no differences in cytokine levels between MF euthymic bipolar patients and healthy controls. TNF- $\alpha$ and IL-4 levels in LM euthymic bipolar patients were higher than in both the MF euthymic bipolar patients and controls.

\section{Limitations}

The small and strictly selected study sample could limit the generalizability of the findings.

\section{Conclusions}

Cytokine production in MF euthymic bipolar patients was similar to that in healthy controls. The present study shows that the pro-inflammatory state resolves in euthymia and that lithium had an influence on the cytokine profile, which could create a confounding factor while investigating disease- related immunopathology of bipolar disorder.

Keywords: Bipolar disorder, Cytokines, Interleukin, Euthymic, Inflammation, Tumor necrosis factor 


\section{Introduction}

Although there are many promising studies on the psychosocial, biological, and genetic factors contributing the pathophysiology of bipolar disorder (BD), the mechanism of this highly prevalent and severe illness remains unknown. The phasic nature of BD - manic, depressive, and euthymic states - adds to the difficulty of studying $\mathrm{BD}$, as compared to other relatively more stable conditions, such as schizophrenia and depression. In the last decade several studies have investigated the possible role of cytokines in psychiatric disorders, based on their close association with central neurotransmitters and evidence of a role for autoimmunity in schizophrenia, and hypothalamo-pituitary-adrenocortical axis abnormalities in depression (Kronfol and Remick, 2000). Despite a growing body of evidence for the involvement of cytokines in psychiatric and neurodegenerative disorders, findings related to BD remain limited.

Research into the role of cytokines in BD followed reports of increased proinflammatory cytokine levels, such as interleukin- 1 (IL-1), IL-6, and tumor necrosis factor-alpha (TNF- $\alpha$ ), in depression and schizophrenia (Strous and Shoenfeld, 2006, Miller et al., 2009, Maes et al., 2009). To the best of our knowledge no study has compared cytokine levels in all phases of BD; therefore, findings are limited and contradictory, and most of the studies on BD focused on either manic or depressive episodes. Increased levels of pro-inflammatory cytokines, such as IL-6, TNF- $\alpha$ (O'Brien et al., 2006, Kim et al., 2007, Ortiz-Dominguez et al., 2007, Brietzke et al., 2009), IL-8 (O'Brien et al., 2006), and serum soluble IL-6 receptor (sIL-6R) (Rapaport et al., 1999), as compared to healthy controls were reported during manic episodes, suggesting that mania could be a pro-inflammatory state. Moreover, some researchers think that TNF- $\alpha$ could be a trait marker because of its steady high levels following the treatment of acute episode (Brietzke and Kapczinski, 2008, Soczynska et al., 2009). Findings regarding IL-2, sIL-2R, and a Thelper 2-cell (Th2) anti-inflammatory cytokine IL-4 (Rapaport et al., 1999, Tsai et al., 1999, Tsai et al., 2001, Su et al., 2002, Liu et al., 2004, Ortiz-Dominguez et al., 2007, Brietzke et al., 2009) in mania are inconsistent. Similar to mania, increased levels of IL-6 (Ortiz-Dominguez et al., 2007, Brietzke et al., 2009) and TNF- $\alpha$ (O'Brien et al., 2006; Ortíz-Domingues et al., 2007) were also observed during depressive episodes. No differences were observed between the levels of IL-10 in depressive, manic, and euthymic states of BD ( $\mathrm{Su}$ et al., 2002, Liu et al., 2004, O’Brien et al., 2006, Brietzke et al., 2009). A few studies that focused on the euthymic state have reported increased levels of IL-4 (Brietzke et al., 2009) and no difference in sIL-2R levels in bipolar patients compared to controls (Rapaport, 1994). Boufidou et al. (Boufidou et al., 2004) reported euthymic BD patients receiving chronic lithium treatment have lower numbers of IL-2, IL-6, IL-10, and interferon-gamma (IFN- $\gamma$ )-secreting cells in comparison to controls. 
The inconsistency of the findings might be due to small samples, different methods of cytokine measurement, and samples differing with respect to illness characteristics. Moreover, it has been shown that cytokine levels are affected by age, body mass index (BMI), gender, smoking habits, and prior medication use (Haack et al., 1999, Rapaport et al., 1999, Himmerich et al., 2005). To date, most findings have come from studies that compared cytokine levels in medicated BD patients; therefore, the results should be carefully interpreted, taking all confounding factors into account.

The present study aimed to determine if there were any differences in cytokine levels between euthymic BD patients and healthy controls, and to determine if the differences were due to the effect of medication. We compared the IFN- $\gamma$, TNF- $\alpha$, IL-2, IL-4, IL-5, and IL-10 levels in medication-free (MF) euthymic BD patients, euthymic BD patients receiving lithium monotherapy (LM), and healthy controls.

\section{Methods}

\subsection{Study population}

The study included $16 \mathrm{MF}$ euthymic BD patients and $15 \mathrm{LM}$ euthymic BD patients (matched for age, gender, and ethnicity) that were selected from among 746 patients registered at Rasit Tahsin Mood Disorders Outpatient Unit (RTMDOU) of Bakirkoy Research and Training Hospital for Psychiatry, Neurology, and Neurosurgery. MF $\mathrm{BD}$ patients were selected from among outpatients that presented to RTMDOU during the study period and were medication-free for at least 4 weeks. All the MF BD patients had decided themselves to stop taking their medication prior to being evaluated. RTMDOU patient records were evaluated and patients that were receiving only lithium monotherapy for at least 8 weeks were invited to participate in the study and comprise the LM group. Although the clinical efficacy of lithium can be observed within 4 weeks, the effect of lithium on the immune-modulatory system can be evaluated later (Boufidou et al., 2004); thus, we chose to set the minimum time period of lithium monotherapy at 8 weeks in order to understand the effect of lithium on the immune-modulatory system. The control group consisted of 16 healthy volunteers recruited from the hospital staff that matched the patient groups in terms of age, gender, and ethnicity. The study was approved by the local ethics committee and all the participants provided informed consent for the study.

Patients were diagnosed based on a clinical interview and medical chart review, and then the diagnosis was confirmed using the Structured Clinical Interview for DSM-IV-Axis I (SCID-I). The Young Mania Rating Scale (YMRS) and 17 items Hamilton Depression Rating Scale (HAM-D) were used to assess manic and depressive symptoms. 
Healthy volunteers were evaluated by a clinician (SG) during a clinical interview to screen for psychiatric disorders. Healthy volunteers were excluded if they had a current Axis I psychiatric disorder or a first-degree relative with a history of major psychiatric disorder. The controls were free of any prescribed medications for at least 4 weeks.

All the participants underwent a complete medical history, physical examination, and complete laboratory evaluation, including complete blood count, blood chemistry, urine analysis, and thyroid function test. Serum lithium levels were also measured in the LM BD patients. Height and weight were measured and BMI was calculated for each participant. Exclusion criteria for all participants were having had an allergic or infectious disease within the last 4 weeks, use of any potential immunosuppressive, such as corticosteroids and non-steroid steroid anti-inflammatory drugs within the last 4 weeks, pregnancy or breastfeeding, current use of alcohol exceeding 5 standard units a week, current intake of caffeine exceeding 3 cups a day, and smoking more than 10 cigarettes a day. Exclusion criteria for all patients were fulfilling the DSM-IV criteria for a mood episode, and a HAM- D or YMRS total score N7. Patients that had other co-morbid Axis I psychiatric disorder were also excluded.

\subsection{Procedure}

Blood samples were obtained between 09.00 and $10.00 \mathrm{am}$, and were collected into anticoagulant-free tubes; serum samples were stored at $-80{ }^{\circ} \mathrm{C}$ until analyzed. Th1 and Th2 cytokines, including IL-2, IL-4, IL-5, IL-10, IFN- $\gamma$, and TNF- $\alpha$, were quantified simultaneously using a human Th1/Th2 cytokine cytometric bead array (CBA) kit (Pharmingen, San Diego, CA). The CBA technique is based on microparticles matched with antibodies, in which the particles are dyed to 6 different fluorescence (FL) intensities. The dye has a maximal emission wavelength of approximately $650 \mathrm{~nm}$ (FL-3). Six standard curves (standard ranging from 0 to $5000 \mathrm{pg} / \mathrm{ml}$ ) were obtained from 1 set of calibrators and 6 results were obtained from 1 test sample. Serum samples were incubated with each Ab-bead reagent and $\mathrm{Ab}-\mathrm{PE}$ detector, and then were incubated in the dark at room temperature for $160 \mathrm{~min}$, followed by washing prior to data acquisition with flow cytometry. Twocolor cytometric analysis was carried out using FACSCalibur ${ }^{\circledR}$ flow cytometry (BD Bioscience, San Jose, CA). Data were obtained and analyzed by CBA software. Units for assessment were protein expression in supernatants of stimulated whole blood cultures $(\mathrm{pg} / \mathrm{ml})$. The limits of detections for individual cytokines were as follows: IL-2, $2.6 \mathrm{pg} / \mathrm{ml}$; TNF- $\alpha, 2.8 \mathrm{pg} / \mathrm{ml}$; IL-10, $2.8 \mathrm{pg} / \mathrm{ml}$; IFN- $\gamma, 7.1 \mathrm{pg} / \mathrm{ml}$; IL4, $2.6 \mathrm{pg} / \mathrm{ml} ; \mathrm{IL}-5,2.4 \mathrm{pg} / \mathrm{ml}$. 


\subsection{Statistical analysis}

Data were analyzed for normal distribution using the Kolmogorov-Smirnov test. Since the data showed normal distribution, we decided to use parametric tests. Oneway analysis of variance was performed to determine group differences with Tukey tests used for comparisons between 3 groups. T test was used for evaluating the 2 groups. Pearson's product-moment correlations were used to examine the relationship between clinical characteristics and cytokine levels. Statistical significance was set at $\mathrm{p}<0.05$. NCSS 2007 and PASS 2008 statistical software (Utah, USA) were used for statistical analysis.

\section{Results}

Demographic and clinical characteristics are presented in Table 1. The groups did not differ significantly with respect to age or BMI. There were no significant differences in clinical characteristics between the MF BD and LM BD groups. Mean duration of non-medication in the MF BD group was 16.5 \pm 14.0 weeks (range: 4-44 weeks). Mean duration of lithium monotherapy was $155.1 \pm 183.1$ weeks (range: 8-712 weeks) in the MF BD group. Mean lithium concentration in the LM BD group was $0.83 \pm 0.10 \mathrm{mEg} / 1$ (range: $0.68-1.09 \mathrm{mEg} / \mathrm{l}$ ).

As shown in Table 2, there were no significant differences in cytokine levels between the MF BD and control group. TNF- $\alpha$ and IL-4 levels in the LM BD were higher than in both the MF BD and control groups. There was not a correlation between cytokine levels, and age, duration of illness, or duration of euthymia in either patient group. Correlations between cytokine levels, and lithium concentration and duration of lithium monotherapy in the LM BD group, and medication-free period in the MF BD group were not significant.

\section{Discussion}

To the best of our knowledge this is the first study to examine cytokine levels in non-medicated euthymic BD patients. The major outcomes of the present study are as follows: 1. Cytokine levels in MF BD patients did not differ from those in healthy controls; and 2. Lithium treatment had an influence on the cytokine profile in the LM BD patients.

Earlier studies report that both manic and depressive episodes might be associated with a pro-inflammatory state, based on the observation of high TNF- $\alpha$ and IL-6 levels (O'Brien et al., 2006, Kim et al., 2007, Ortiz-Dominguez et al., 2007, Brietzke 
Table 1. Demographic and clinical characteristics of the study population.

\begin{tabular}{|c|c|c|c|c|c|}
\hline & $\begin{array}{l}\text { Control } \\
(n=16)\end{array}$ & $\begin{array}{l}\text { MF BD } \\
(n=16)\end{array}$ & $\begin{array}{l}\text { LM BD } \\
(n=15)\end{array}$ & $\begin{array}{c}\text { Test } \\
\text { Statistic }\end{array}$ & $P$ \\
\hline Sex (male/female) & $12 / 4$ & $12 / 4$ & $11 / 4$ & & \\
\hline Age $(\text { years })^{a}$ & $31.8 \pm 4.8$ & $32.3 \pm 6.5$ & $31.8 \pm 7.1$ & 0.01 & 0.986 \\
\hline Body Mass Index $\left(\mathrm{kg} / \mathrm{m}^{2}\right)^{\mathrm{a}}$ & $23.8 \pm 3.1$ & $26.6 \pm 5.5$ & $23.6 \pm 3.1$ & 2.66 & 0.081 \\
\hline Diagnosis (BD-I/BD-II) & & $12 / 4$ & $14 / 1$ & & \\
\hline Age at onset (years) ${ }^{b}$ & & $22,2 \pm 5,9$ & $20.3 \pm 4.4$ & 1.022 & 0.315 \\
\hline Duration of illness (years) $^{b}$ & & $9.9 \pm 5.3$ & $11.5 \pm 6.6$ & 0.745 & 0.462 \\
\hline Onset Episode (mania/depression) & & $8 / 8$ & $8 / 7$ & & \\
\hline $\begin{array}{l}\text { Last Episode (mania/hypomania/ } \\
\text { mixed/depression) }\end{array}$ & & $6 / 2 / 1 / 7$ & $7 / 2 / 0 / 6$ & & \\
\hline Total number of past episodes ${ }^{b}$ & & $5.9 \pm 3.9$ & $5.1 \pm 2.7$ & 0.657 & 0.517 \\
\hline Mania & & $1.9 \pm 1.5$ & $2.3 \pm 1.7$ & & \\
\hline Hypomania & & $1.4 \pm 2.0$ & $1.2 \pm 1.6$ & & \\
\hline Mixed & & $0.6 \pm 1.1$ & $0.2 \pm 0.8$ & & \\
\hline Depression & & $2.0 \pm 1.5$ & $1.5 \pm 1.2$ & & \\
\hline Duration of euthymia (weeks) ${ }^{b}$ & & $133.7 \pm 137.5$ & $190.4 \pm 181.4$ & 0.984 & 0.333 \\
\hline
\end{tabular}

MF BD: medication-free euthymic BD patients.

LM BD: lithium monotherapy euthymic BD patients.

${ }^{\mathrm{a} O n e-w a y ~ A N O V A,}{ }^{\mathrm{b}} \mathrm{T}$ test.

et al., 2009). It was also hypothesized that the persistence of high TNF- $\alpha$ levels in euthymia following treatment of episode might indicate the importance of the role of TNF- $\alpha$ in understanding the pathophysiology of BD (Brietzke and Kapczinski, 2008, Soczynska et al., 2009). Although we observed higher levels of TNF- $\alpha$ in the LM BD patients, there were no differences between the MF BD patients and healthy controls. Considering the normal levels of TNF- $\alpha$ in the MF BD patients, higher levels of TNF- $\alpha$ and IL-4 in the LM BD patients might have been due to the effect of lithium on TNF- $\alpha$, rather than the influence of BD on the immune system (Haack et al., 1999, Himmerich et al., 2005, Rapaport and Manji, 2001). The present findings agree with those showing that both euthymic patients treated with lithium and healthy controls had similar levels of IFN- $\gamma$, IL-2, IL-6, and IL-10, which were measured without antigenic stimulation (Boufidou et al., 2004). In a recent study Brietzke et al. (Brietzke et al., 2009) observed increased levels of IL-4 in euthymia and suggested that increased cytokine levels could have been due to the short duration of euthymia 
Table 2. Cytokine levels in the study population.

\begin{tabular}{|l|c|c|c|c|c|c|}
\hline & $\begin{array}{c}\text { Control } \\
(\mathbf{n}=\mathbf{1 6})\end{array}$ & $\begin{array}{c}\text { MF BD } \\
(\mathbf{n}=\mathbf{1 6})\end{array}$ & $\begin{array}{c}\text { LM BD } \\
(\mathbf{n}=\mathbf{1 5})\end{array}$ & $\boldsymbol{F}$ & $\mathbf{d f}$ & $\boldsymbol{P}$ \\
\hline $\mathbf{I F N -} \boldsymbol{\gamma}(\mathrm{pg} / \mathrm{ml})$ & $28.80 \pm 11.34$ & $28.54 \pm 12.30$ & $36.30 \pm 14.88$ & 1.75 & 2,44 & 0.178 \\
\hline $\mathbf{T N F - \alpha}(\mathrm{pg} / \mathrm{ml})$ & $4.01 \pm 1.31$ & $3.36 \pm 0.96$ & $5.35 \pm 1.84$ & 8.02 & 2,44 & $0.001^{\mathrm{a}, \mathrm{b}}$ \\
\hline $\mathbf{I L - 1 0}(\mathrm{pg} / \mathrm{ml})$ & $7.39 \pm 2.50$ & $7.95 \pm 4.38$ & $9.21 \pm 2.93$ & 1.17 & 2,44 & 0.319 \\
\hline $\mathbf{I L - 5}(\mathrm{pg} / \mathrm{ml})$ & $3.74 \pm 0.94$ & $3.81 \pm 1.83$ & $4.41 \pm 0.98$ & 1.15 & 2,44 & 0.325 \\
\hline $\mathbf{I L - 4}(\mathrm{pg} / \mathrm{ml})$ & $5.75 \pm 1.68$ & $5.32 \pm 1.03$ & $7.99 \pm 2.73$ & 8.45 & 2,44 & $0.001^{\mathrm{a}, \mathrm{b}}$ \\
\hline $\mathbf{I L - 2}(\mathrm{pg} / \mathrm{ml})$ & $22.49 \pm 6.60$ & $20.80 \pm 4.53$ & $24.82 \pm 5.67$ & 1.96 & 2,44 & 0.153 \\
\hline
\end{tabular}

MF BD: Medication-free euthymic BD patients.

LM BD: Lithium monotherapy euthymic BD patients.

${ }^{a} \mathrm{LM}$ BD $>$ MF BD; ${ }^{b} \mathrm{LM}$ BD $>$ control.

prior to sample collection. They did not observe any differences in IL-2, IL-6, IL-10, IFN- $\gamma$, or TNF- $\alpha$ levels between healthy controls and euthymic patients. These results are in agreement with the present study's findings that there were no differences in IL-2, IL-4, IL-10, IFN- $\gamma$, or TNF- $\alpha$ levels between the MF BD patients and healthy controls.

Current evidence indicates that immune system abnormalities in BD patients are state-dependent and are not a potential trait biomarker. It is also very difficult to determine if change in cytokine levels in the acute phase of BD is a consequence of their role in the pathophysiology of BD. Given the effects of sleep disturbance and physical activity on cytokine production (Patel et al., 2009, Moldoveanu et al., 2001), it can be speculated that changes in cytokine levels in the acute phases of BD may be secondary to the physiological symptoms of mania and depression. Nonetheless, it should be noted that a rise in pro-inflammatory cytokine levels also exacerbates the symptoms of BD. As such, use of immune modulators in the treatment of the acute phase of BD may provide an opportunity to break this never-ending cycle.

We conducted the present study with a homogenous group, in terms of age, gender, BMI, medication, and clinical characteristics. The study population was selected from a tertiary referral mood disorders outpatient unit with good medical record keeping procedures. Although the study design eliminated possible confounding factors, it also made generalizing the findings difficult, as the selected sample was small.

In conclusion, we report that cytokine production in MF BD patients did not differ from that in healthy controls. The present findings show that the pro-inflammatory state of mania and depression in BD patients resolved during euthymia in patients without medication. Moreover, it should also be noted that the influence of medications 
like lithium on cytokine levels is an important confounding factor while investigating disease- related immunopathology of bipolar disorder. In order to clarify the potential role of immune variables in $\mathrm{BD}$, large-scale prospective studies that focus on the state-dependent changes in immune variables (i.e. manic, euthymic and depressive episodes of the same patients) are needed. 


\section{Role of funding source}

The funders have no role in the study design; in the collection, analysis and interpretation of data; in the writing of the report; and in the decision to submit the paper for publication.

\section{Conflict of interest}

All authors declare that they have no potential conflict of interest.

\section{Acknowledgement}

Authors would like to thank Aysegul Ozerdem for her comments on the manuscript.

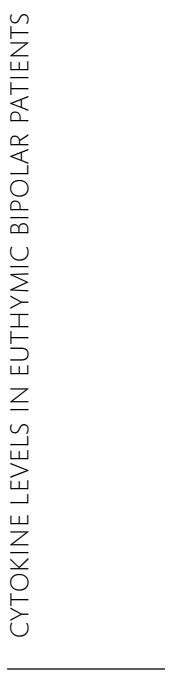




\section{References}

BOUFIDOU, F., NIKOLAOU, C., ALEVIZOS, B., LIAPPAS, I. A. \& CHRISTODOULOU, G. N. 2004. Cytokine production in bipolar affective disorder patients under lithium treatment. $J$ Affect Disord, 82, 309-13.

BRIETZKE, E. \& KAPCZINSKI, F. 2008. TNFalpha as a molecular target in bipolar disorder. Progress in neuro-psychopharmacology \& biological psychiatry, 32, 1355-61.

BRIETZKE, E., STERTZ, L., FERNANDES, B. S., KAUER-SANT'ANNA, M., MASCARENHAS, M., ESCOSTEGUY VARGAS, A., CHIES, J. A. \& KAPCZINSKI, F. 2009. Comparison of cytokine levels in depressed, manic and euthymic patients with bipolar disorder. J Affect Disord, 116, 214-7.

HAACK, M., HINZE-SELCH, D., FENZEL, T., KRAUS, T., KUHN, M., SCHULD, A. \& POLLMACHER, T. 1999. Plasma levels of cytokines and soluble cytokine receptors in psychiatric patients upon hospital admission: effects of confounding factors and diagnosis. Journal of psychiatric research, 33, 407-18.

HIMMERICH, H., KOETHE, D., SCHULD, A., YASSOURIDIS, A. \& POLLMACHER, T. 2005. Plasma levels of leptin and endogenous immune modulators during treatment with carbamazepine or lithium. Psychopharmacology (Berl), 179, 447-51.

KIM, Y. K., JUNG, H. G., MYINT, A. M., KIM, H. \& PARK, S. H. 2007. Imbalance between proinflammatory and anti-inflammatory cytokines in bipolar disorder. J Affect Disord, 104, 91-5.

KRONFOL, Z. \& REMICK, D. G. 2000. Cytokines and the brain: implications for clinical psychiatry. The American journal of psychiatry, 157, 683-94.

LIU, H. C., YANG, Y. Y., CHOU, Y. M., CHEN, K. P., SHEN, W. W. \& LEU, S. J. 2004. Immunologic variables in acute mania of bipolar disorder. J Neuroimmunol, 150, 116-22.

MAES, M., YIRMYIA, R., NORABERG, J., BRENE, S., HIBBELN, J., PERINI, G., KUBERA, M., BOB, P., LERER, B. \& MAJ, M. 2009. The inflammatory \& neurodegenerative (I\&ND) hypothesis of depression: leads for future research and new drug developments in depression. Metab Brain Dis, 24, 27-53.

MILLER, A. H., MALETIC, V. \& RAISON, C. L. 2009. Inflammation and its discontents: the role of cytokines in the pathophysiology of major depression. Biological psychiatry, 65, 732-41.

MOLDOVEANU, A. I., SHEPHARD, R. J. \& SHEK, P. N. 2001. The cytokine response to physical activity and training. Sports Med, 31, 115-44.

O’BRIEN, S. M., SCULLY, P., SCOTT, L. V. \& DINAN, T. G. 2006. Cytokine profiles in bipolar affective disorder: focus on acutely ill patients. J Affect Disord, 90, 263-7.

ORTIZ-DOMINGUEZ, A., HERNANDEZ, M. E., BERLANGA, C., GUTIERREZ-MORA, D., MORENO, J., HEINZE, G. \& PAVON, L. 2007. Immune variations in bipolar disorder: phasic differences. Bipolar Disord, 9, 596-602.

PATEL, S. R., ZHU, X., STORFER-ISSER, A., MEHRA, R., JENNY, N. S., TRACY, R. \& REDLINE, S. 2009. Sleep duration and biomarkers of inflammation. Sleep, 32, 200-4.

RAPAPORT, M. H. 1994. Immune parameters in euthymic bipolar patients and normal volunteers. J Affect Disord, 32, 149-56.

RAPAPORT, M. H., GUYLAI, L. \& WHYBROW, P. 1999. Immune parameters in rapid cycling bipolar patients before and after lithium treatment. J Psychiatr Res, 33, 335-40.

RAPAPORT, M. H. \& MANJI, H. K. 2001. The effects of lithium on ex vivo cytokine production. Biol Psychiatry, 50, 217-24.

SOCZYNSKA, J. K., KENNEDY, S. H., GOLDSTEIN, B. I., LACHOWSKI, A., WOLDEYOHANNES, H. O. \& MCINTYRE, R. S. 2009. The effect of tumor necrosis factor antagonists on mood and mental healthassociated quality of life: novel hypothesisdriven treatments for bipolar depression? Neurotoxicology, 30, 497-521.

STROUS, R. D. \& SHOENFELD, Y. 2006. Schizophrenia, autoimmunity and immune system dysregulation: a comprehensive model updated and revisited. J Autoimmun, 27, 71-80. 
SU, K. P., LEU, S. J., YANG, Y. Y., SHEN, W. W., CHOU, Y. M. \& TSAI, S. Y. 2002. Reduced production of interferon-gamma but not interleukin-10 in bipolar mania and subsequent remission. J Affect Disord, 71, 205-9.

TSAI, S. Y., CHEN, K. P., YANG, Y. Y., CHEN, C. C., LEE, J. C., SINGH, V. K. \& LEU, S. J. 1999. Activation of indices of cell-mediated immunity in bipolar mania. Biol Psychiatry, 45, 989-94.

TSAI, S. Y., YANG, Y. Y., KUO, C. J., CHEN, C. C. \& LEU, S. J. 2001. Effects of symptomatic severity on elevation of plasma soluble interleukin-2 receptor in bipolar mania. J Affect Disord, 64, 185-93. 



\section{Evidence for an association between tumor necrosis factor-alpha levels and lithium response}

Sinan Guloksuz, Kursat Altinbas, Esin Aktas Cetin, Gunter Kenis, Sema Bilgic Gazioglu, Gunnur Deniz, Esat Timucin Oral, Jim van Os

Journal of Affective Disorders (2012): 143(1-3):148-52. 

Abstract

\section{Background}

The role of inflammation in bipolar disorder has recently emerged as a potential pathophysiological mechanism. Tumor necrosis factor-alpha (TNF-a) modulation may represent a pathogenic molecular target and a biomarker for staging bipolar disorder. In this context, the possible association between lithium response and TNF-a level was examined.

\section{Methods}

Sixty euthymic bipolar patients receiving lithium therapy were recruited for assessment of TNF-a level. The ALDA lithium response scale (LRS) was used to evaluate longitudinal lithium response in bipolar patients, using cut-offs of poor response, partial response and good response. TNF-a level was assessed using enzyme-linked immunosorbent assay.

\section{Results}

There was a significant increase in TNF-a level in patients with poor lithium response compared to those with good response, also after controlling for a range of potential confounders (adjusted effect size: $0.47, p=0.011$ ). Partial response showed a directionally similar, but attenuated and statistically inconclusive association (adjusted effect size: 0.16 , $\mathrm{p}=0.326)$.

\section{Limitations}

Assessment of response was retrospective and natural course cannot be separated easily from treatment response in an observational design. Selection of additional inflammatory markers could provide for a better understanding of underlying immune changes.

\section{Conclusions}

This study strengthens the hypothesis that TNF-a level may mark or mediate lithium response, and that continuous immune imbalance in poor lithium responders may occasion treatment resistance. Further investigation of immune alterations in treatment-resistant bipolar patients may be productive.

Keywords: Bipolar disorder, Tumor necrosis factor, Lithium, Cytokine, Inflammation, Treatment 


\section{Introduction}

The discovery of the neuromodulating action of cytokines has inspired researchers to focus on the role of cytokines in mood disorders. The role of inflammation in bipolar disorder (BD) has recently emerged as a promising mechanism, complementary to the well-known monoamine theory, and may contribute to a better understanding of BD.

Even though the findings pertaining to patients in the manic phase of BD are not conclusive, there is an indication that mania represents a pro-inflammatory state with higher circulating levels of pro-inflammatory cytokines, such as interleukin-1 (IL1), IL-6, and tumor necrosis factor-alpha (TNF- $\alpha$ ) (Brietzke et al., 2009, Kim et al., 2007, O'Brien et al., 2006, Ortiz-Dominguez et al., 2007). Fewer studies show that a depressive episode in the context of $\mathrm{BD}$ may also be regarded as a pro-inflammatory state(Ortiz-Dominguez et al., 2007, O'Brien et al., 2006, Brietzke et al., 2009), whereas the pro/anti-inflammatory balance may be restored in euthymia (Guloksuz et al., 2010, Kapczinski et al., 2011, Kunz et al., 2011).

TNF- $\alpha$ is a potent pro-inflammatory cytokine that exerts pleiotropic functions in immunity, inflammation, control of cell proliferation, differentiation, and regulation of the immune response (Wallach et al., 1999). Recently, TNF- $\alpha$ modulation has been proposed as a molecular target in the pathophysiology of BD. This is based on studies showing (i) high levels of TNF- $\alpha$ in acute episodes, (ii) elevated prevalence rates of medical comorbidity related to inflammation (e.g. metabolic syndrome and cardiovascular disease), and (iii) association of the TNF- $\alpha-308 \mathrm{G} / \mathrm{A}$ promoter polymorphism with BD (Brietzke and Kapczinski, 2008, Soczynska et al., 2009). Moreover, Kapczinski and colleagues (Kapczinski et al., 2009) have suggested that TNF- $\alpha$ represents a potential biomarker for different stages of BD, higher levels of TNF- $\alpha$ marking advanced stages of BD accompanied with severe impairment during inter-episodic periods and reduced treatment response.

Current evidence also indicates that many psychotropic drugs have immunemodulatory effects. Among these, lithium in particular is a focus of much research. The role of the effects of lithium on the cytokine network in its mechanism of action has not been clarified due to the complex bi-directional interaction between immune parameters, cellular signal transduction pathways and gene expression. The data may indicate that lithium has a complex balancing effect on immune parameters by influencing both pro-inflammatory and anti-inflammatory cascades (Boufidou et al., 2004, Knijff et al., 2007, Rapaport et al., 1999).

Despite the fact that lithium is still considered the cornerstone in the treatment of BD, studies show that a considerable number of patients do not respond (Balance investigators collaborators et al., 2010). Therefore, the neurobiological mechanism underlying variation in therapeutic response to lithium remains a topic requiring 
urgent further study. The aim of this study was to examine the possible association between lithium response and TNF- $\alpha$ level.

\section{Methods}

\subsection{Study population}

Among 910 registered patients at the Rasit Tahsin Mood Disorders Outpatient Unit of the Bakirkoy Research and Training Hospital for Psychiatry, Neurology, and Neurosurgery, 60 euthymic bipolar patients on current lithium therapy were recruited. Patients were diagnosed according to DSM-IV criteria and evaluation of standardized medical records as prescribed by the SKIP-TURK nationwide mood disorder followup program (Tirpan et al., 2004). In order to eliminate the confounding effect of mania and depression on TNF- $\alpha$ level, only euthymic patients were recruited. Patients were euthymic for at least 8 weeks with total scores $<7$ on both the Young Mania Rating Scale (YMRS) and the 17-item Hamilton Depression Rating Scale (HAM-D). The study was approved by the local ethics committee and all participants provided written informed consent.

Patients underwent examinations including full medical history, physical examination, laboratory evaluation including complete blood count, blood chemistry, urinalysis, and thyroid function test. Serum lithium level and body mass index were measured.

Exclusion criteria were (i) history of allergic, autoimmune or infectious disease within the last 4 weeks, (ii) use of any non-psychotropic drug with the potential to alter immune or endocrine function within the last 4 weeks, (iii) pregnancy or breastfeeding, (iv) current use of alcohol exceeding 5 standard units a week, (v) current intake of caffeine exceeding 3 cups a day, and (vi) smoking more than 10 cigarettes a day.

\subsection{Assessment of lithium response}

The ALDA lithium response scale (LRS) was used to evaluate longitudinal lithium response in bipolar patients retrospectively (Grof et al., 2002). The LRS consists of a Criterion A measuring the degree of improvement over the course of lithium treatment and a Criterion $B$ assessing the causality between improvement and lithium treatment. Criterion A is scored from 0 to 10 taking into account the change of frequency, duration and severity of episodes. Criterion B consists of 5 items assessing the number of episodes before lithium treatment, frequency of episodes before lithium treatment, duration of lithium treatment, compliance during lithium treatment and use of additional medication during lithium treatment, respectively. Each of these items in 
Criterion B is scored from 0 to 2 and a higher total score on Criterion B indicates that the link between improvement and lithium treatment is less certain. The total score of the LRS is calculated by subtracting the total score of Criterion B from Criterion A. The cut-off points are: $0-1=$ poor response, $2-6$ partial response, $7-10=$ good response (hereafter referred to as: LRS groups), based on a recent study investigating the genetic basis of the clinical response to lithium treatment (Schulze et al., 2010).

\subsection{Enzyme-linked immunosorbent assay (ELISA) for TNF-a}

The blood samples were obtained between 08.00 AM and 10.00 AM and were collected in heparin vacuum tubes. The blood samples were immediately centrifuged for $10 \mathrm{~min}$ at $3000 \mathrm{rpm}$ and the plasma samples were stored at $-80^{\circ} \mathrm{C}$ until analysis. TNF- $\alpha$ level in the plasma was assessed using an ELISA kit (Invitrogen, Inc, Camarillo, USA) according to the manufacturer's instructions. Supplied standards were used to generate the standard curves. Briefly, the samples and standards were applied to the wells coated with anti-TNF- $\alpha$ antibodies. Unbound protein was removed by washing, and biotinylated anti-TNF- $\alpha$ antibodies and horseradish peroxidase-conjugated streptavidin were added in a step-wise manner. After the color reaction with substrate, the optical density was recorded at 450-nm wavelength with an automated ELISAplate reader. The absorbance at $450 \mathrm{~nm}$ was converted to picograms per millilitre (pg/ $\mathrm{ml}$ ) for TNF- $\alpha$. The minimal detection limit for TNF- $\alpha$ is $<1.7 \mathrm{pg} / \mathrm{ml}$.

\subsection{Statistical Analysis}

Associations between the three LRS groups and approximately normally distributed TNF- $\alpha$ level were expressed as regression coefficients (B) from multiple regression procedures with TNF- $\alpha$ as dependent variable and dummy variables of LRS groups as independent variable, the good response group serving as reference. Standardized regression coefficients $(\beta)$ served as standardized effect size. Associations between TNF- $\alpha$ and a priori selected confounders (gender, age, body mass index, age at onset, duration of illness, total number of past manic, depressive, mixed episodes, total number of episodes per year, total number of hospitalizations, serum lithium level and medication groups (lithium monotherapy, lithium+mood stabilizer, lithium+antipsychotic, lithium+antidepressant, lithium + mood stabilizer+antipsychotic, lithium+antipsychotic + antidepressant, lithium + mood stabi lizer+antipsychotic+antidepressant) were assessed using Pearson's product-moment correlation for continuous and one-way ANOVA for categorical variables. Two-sided statistical significance was set at $\mathrm{p}<0.05$. STATA version 12.0 (STATA Corporation, College Station, TX, USA) was used to carry out the statistical analyses. 


\section{Results}

Demographic, clinical and treatment characteristics of the LRS groups are presented in Table 1. The only potential confounder associated with TNF- $\alpha$ level was serum lithium level $(r=0.26, \mathrm{p}=0.046)$. Medication groups were not associated with TNF- $\alpha$ level $(F(6,53)=0.78, \mathrm{p}=0.593)$, but were strongly associated with total LRS scores $(F(6,53)=4.42, \mathrm{p}=0.001)$. As the association between medication groups and LRS scores caused collinearity in the regression model with TNF- $\alpha$ level as the dependent variable (artificially inflating both effect size and statistical significance of LRS in

Table 1. Sample demographic, clinical and treatment characteristics, and association of potential confounders with TNF-a level

\begin{tabular}{|c|c|c|c|c|c|}
\hline & $\begin{array}{c}\text { Good lithium } \\
\text { response } \\
(\mathrm{n}=17) \\
\text { Mean (SD) } \\
\text { or } \mathbf{n}(\%)\end{array}$ & $\begin{array}{c}\text { Partial lithium } \\
\text { response } \\
(\mathrm{n}=\mathbf{2 3}) \\
\text { Mean (SD) } \\
\text { or } \mathbf{n}(\%)\end{array}$ & $\begin{array}{c}\text { Poor lithium } \\
\text { response } \\
(\mathrm{n}=\mathbf{2 0}) \\
\text { Mean }(\mathrm{SD}) \\
\text { or } \mathbf{n}(\%)\end{array}$ & $\begin{array}{l}\text { Association with } \\
\text { TNF- } \alpha \text { level }\left(r^{\mathrm{a}}\right)\end{array}$ & $P$-value \\
\hline Female gender ${ }^{\mathrm{b}}$ & $11(64.7)$ & $14(60.9)$ & $10(50.0)$ & $F(1,58)=0.00^{b}$ & 0.956 \\
\hline Age (years) & $30.18(6.87)$ & $34.13(8.94)$ & $31.60(8.13)$ & 0.18 & 0.153 \\
\hline Body mass index $\left(\mathrm{kg} / \mathrm{m}^{2}\right)$ & $26.64(3.64)$ & $28.72(3.36)$ & $29.91(4.92)$ & 0.13 & 0.304 \\
\hline Age at onset (years) & $20.88(6.41)$ & $22.48(8.71)$ & $22.95(8.86)$ & 0.08 & 0.522 \\
\hline Duration of illness (years) & $9.29(6.41)$ & $11.65(8.85)$ & $8.65(6.70)$ & 0.11 & 0.394 \\
\hline Past manic episodes & $1.88(1.05)$ & $3.00(4.59)$ & $3.50(4.01)$ & 0.09 & 0.475 \\
\hline Past depressive episodes & $1.76(1.52)$ & $2.26(2.67)$ & $2.21(1.87)$ & -0.15 & 0.247 \\
\hline Past mixed episodes & $0.24(0.56)$ & $0.83(1.30)$ & $0.84(1.57)$ & 0.02 & 0.891 \\
\hline $\begin{array}{l}\text { Total number of episodes } \\
\text { per year }\end{array}$ & $0.73(0.84)$ & $0.67(0.43)$ & $1.26(1.02)$ & -0.06 & 0.640 \\
\hline $\begin{array}{l}\text { Total number of } \\
\text { hospitalizations }\end{array}$ & $1.18(0.88)$ & $2.43(4.59)$ & $2.15(1.78)$ & 0.02 & 0.850 \\
\hline $\begin{array}{l}\text { Serum lithium level } \\
(\mathrm{mEq} / \mathrm{L})\end{array}$ & $0.76(0.09)$ & $0.83(0.11)$ & $0.81(0.15)$ & 0.26 & 0.046 \\
\hline Li monotherapy & $10(58.8)$ & $4(17.4)$ & 0 & \multirow{7}{*}{$F(6,53)=0.78^{b}$} & \multirow{7}{*}{0.593} \\
\hline $\mathbf{L i}+\mathbf{M S}$ & $1(35.3)$ & $3(13.0)$ & $2(10.0)$ & & \\
\hline $\mathbf{L i}+\mathbf{A P}$ & $6(5.9)$ & $6(26.1)$ & $10(50.0)$ & & \\
\hline $\mathbf{L i}+\mathbf{A D}$ & 0 & $1(4.3)$ & 0 & & \\
\hline $\mathbf{L i}+\mathbf{M S}+\mathbf{A P}$ & 0 & $9(39.1)$ & $6(30.0)$ & & \\
\hline $\mathbf{L i}+\mathbf{A P}+\mathbf{A D}$ & 0 & 0 & $1(5.0)$ & & \\
\hline $\mathbf{L i}+\mathbf{M S}+\mathbf{A P}+\mathbf{A D}$ & 0 & 0 & $1(5.0)$ & & \\
\hline
\end{tabular}

Li: Lithium, MS: Mood stabilizer, AP: Antipsychotic, AD: Antidepressant

${ }^{a}$ Correlation coefficient between TNF- $\alpha$ level and each potential confounder

${ }^{\mathrm{b} O n e w a y ~ A N O V A}$ 


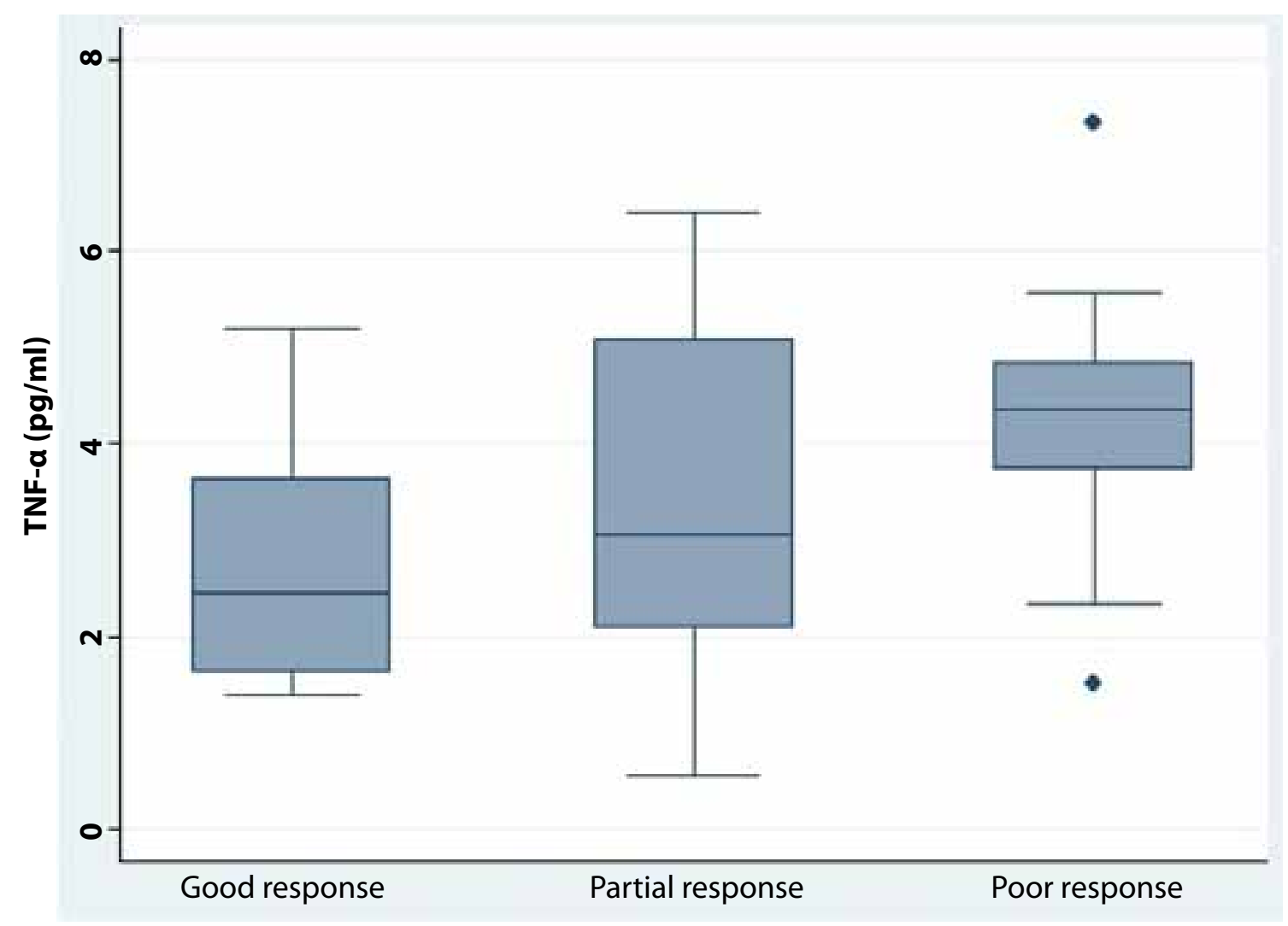

Figure 1. TNF- $\alpha$ level and lithium response.

Box-plot of plasma TNF-a level grouped according to lithium response. Median levels are indicated by horizontal lines and outliers are indicated by ".".

the model of TNF- $\alpha$ level), medication groups conservatively were not included in the final adjusted model. The mean TNF- $\alpha$ level was $2.75(\mathrm{SD}=1.17), 3.50(\mathrm{SD}=$ $1.73)$ and $4.29(\mathrm{SD}=1.20)$ in good, partial and poor lithium responders, respectively (Figure 1). There was a significant increase in TNF- $\alpha$ level in poor responders compared with good responders ( $\mathrm{B}=1.54, \mathrm{p}=0.002$; standardized effect size: 0.48 ), also after controlling for serum lithium level $(B=1.41, p=0.004$; standardized effect size: 0.44$)$ and after controlling for all a priori confounders $(\mathrm{B}=1.54, \mathrm{p}=0.011$; standardized effect size: 0.47 ). There was an attenuated and directionally similar association between partial response to lithium and TNF- $\alpha$ level, that remained statistically inconclusive (fully adjusted model: $\mathrm{B}=0.52, \mathrm{p}=0.326$; standardized effect size: 0.16). Both LRS Criterion A scores (fully adjusted standardized effect size: $-0.32, p=0.007$ ) and total LRS scores (fully adjusted standardized effect size: $-0.30, \mathrm{p}=0.015$ ) were negatively associated with TNF- $\alpha$ level. 


\section{Discussion}

To the best of our knowledge, this is the first study evaluating TNF- $\alpha$ level in patients with $\mathrm{BD}$ as a function of lithium response. The main findings were: (i) TNF- $\alpha$ level in patients with a poor response to lithium were higher than in patients with a good response, (ii) both Criterion A and total LRS scores were negatively associated with TNF- $\alpha$ level and (iii) associations were not reducible to confounding including confounding by current medication.

Several clinical and pre-clinical studies have investigated the effects of lithium on immune variables in healthy volunteers as well as in patients with BD. Rapaport and Manji (Rapaport and Manji, 2001) demonstrated that lithium causes an increase in levels of anti-inflammatory cytokines, IL-4 and IL-10, and a decrease in levels of proinflammatory cytokines, IL-2 and IFN- $\gamma$ in healthy volunteers. It has been argued that lithium restores the immune balance in BD by decreasing the ratio of pro- and antiinflammatory cytokines after lithium treatment (Boufidou et al., 2004, Knijff et al., 2007, Rapaport et al., 1999). Moreover, TNF- $\alpha$ levels in euthymic patients with BD are not different from healthy controls (Barbosa et al., 2012, Drexhage et al., 2011, Guloksuz et al., 2010, Kapczinski et al., 2011, Kunz et al., 2011). When we combine this background with our present findings showing an inverse correlation between TNF- $\alpha$ level and lithium response, it is plausible to speculate that lithium exerts its long-term mood stabilizing effects by down-regulating a pro-inflammatory immune phenotype in addition to several other postulated mechanisms. A high TNF- $\alpha$ level in poor lithium responders also indicates that there is a prolonged pro-inflammatory state in this group and that lithium treatment augmented with other psychotropics is still not effective in restoring the altered immune balance and stabilizing the course of BD.

Kapczinski and colleagues (Kapczinski et al., 2009) proposed a model for staging BD by making use of several biomarkers including TNF- $\alpha$. In this model, increased TNF- $\alpha$ is regarded as the sign of progression to late stages of BD with severe impairment, ongoing subsyndromal symptoms, shortened duration of euthymia between episodes and treatment resistance. Taking this into account, poor lithium responders in our study can be seen as patients in the later stages of BD. It should be considered that these patients may benefit from augmentation strategies combining mood stabilizers and antipsychotics with anti-inflammatory agents. The preliminary findings from a double-blind, randomized, placebo-controlled study in bipolar depression showed that celecoxib could be used for augmentation therapy, as evidenced by a rapid response in patients who took celecoxib as adjunctive treatment (Nery et al., 2008). The use of anti-inflammatory agents in BD, particularly TNF- $\alpha$ antagonists, has been proposed. The rational for this is that numerous effects exist of TNF- $\alpha$ on the central nervous system such as TNF- $\alpha$ mediated apoptosis via modulation of nuclear factor- 
kappa B (NF-kB), activation of indoleamine 2,3- dioxygenase (IDO) and glutamate excitotoxicity (Brietzke and Kapczinski, 2008, Soczynska et al., 2009). However, we cannot clearly specify which mechanism may play a role due to the many complex interactions between numerous immune-mediators. It is more reasonable to suggest that there may be ongoing alterations in the immune system in the late stages of BD. Hopefully, two ongoing studies evaluating the efficacy of minocycline, with TNF- $\alpha$ antagonist properties, in the treatment of bipolar depression along with assessment of the association between efficacy and circulating levels of inflammatory markers will give us more insight in the association between the TNF- $\alpha$ system and treatment response in BD (trial identifier NCT01403662; NCT01429272, http://clinicaltrials. gov).

The present study was conducted at a tertiary referral mood disorders outpatient unit with standardized high-quality medical record keeping procedures that gave us the advantage to evaluate lithium response more precisely. Nevertheless, there are several limitations that should be taken into account while interpreting the results. A healthy control group could have given us the chance to investigate the relevance of TNF- $\alpha$ as a biomarker of BD in a case-control comparison. Similarly, availability of a placebo group would have provided us with the opportunity to assess specificity in relation to treatment. However, the principal aim of this study was to evaluate the association between lithium response and TNF- $\alpha$ level in patients with BD, rather than investigating TNF- $\alpha$ as a potential trait marker of BD or its treatment. Thus, we only recruited patients who were currently on lithium without additional control or placebo groups. Nearly three-quarters of the patients were on concomitant medication (e.g. valproic acid, atypical antipsychotics). Although medication groups were not associated with TNF- $\alpha$ level, it is possible that earlier, currently discontinued, treatment was associated with both TNF- $\alpha$ level and longitudinal assessment of treatment response, thus possibly confounding the results. However, it should be appreciated that it is nearly impossible to totally eliminate this confounder in a study evaluating lithium response since progressive augmentation strategies are standard practice in patients with poor or partial lithium response. Currently, TNF- $\alpha$ is perceived as a prominent pro-inflammatory cytokine that is strongly related to mood disorders with several articles advocating its role in BD. However, selection of additional inflammatory markers could provide us with a better understanding of underlying immune changes in BD. Finally, the only way to formally assess response to lithium is to conduct a placebo-controlled randomized controlled trial. In an observational design, lithium is only one of many factors impacting on course and outcome, any of which may be marked by TNF- $\alpha$ level. Although the LRS attempts to make a judgment on the specific impact of lithium treatment on illness course, it is difficult to assess this retrospectively in an observational design. 
In conclusion, the present findings suggest that TNF- $\alpha$ level may impact on the clinical response to lithium and suggest that a continuous immune imbalance in poor lithium responders may be related to treatment resistance. The inverse association between TNF- $\alpha$ level and response to lithium also fortifies this notion. Although these findings require further replication and cannot be taken to indicate that TNF- $\alpha$ represents a biomarker for response in clinical practice, further studies are warranted that focus on immune alterations in treatment resistant bipolar patients in order to clarify the association between treatment response and inflammation. 


\section{Role of funding source}

The funders have no role in the study design; in the collection, analysis and interpretation of data; in the writing of the report; and in the decision to submit the paper for publication.

\section{Conflict of interest}

All authors declare that they have no potential conflict of interest.

\section{Acknowledgement}

Sinan Guloksuz, Gunter Kenis and Jim van Os are supported by the European Community's Seventh Framework Program under Grant agreement no. HEALTHF2-2009-241909 (Project EU-GEI). 


\section{References}

\section{BALANCE INVESTIGATORS}

COLLABORATORS, GEDDES, J. R., GOODWIN, G. M., RENDELL, J., AZORIN, J. M., CIPRIANI, A., OSTACHER, M. J., MORRISS, R., ALDER, N. \& JUSZCZAK, E. 2010. Lithium plus valproate combination therapy versus monotherapy for relapse prevention in bipolar I disorder (BALANCE): a randomised open-label trial. Lancet, 375, 385-95.

BARBOSA, I. G., ROCHA, N. P., HUGUET, R. B., FERREIRA, R. A., SALGADO, J. V., CARVALHO, L. A., PARIANTE, C. M. \& TEIXEIRA, A. L. 2012. Executive dysfunction in euthymic bipolar disorder patients and its association with plasma biomarkers. $J$ Affect Disord, 137, 151-5.

BOUFIDOU, F., NIKOLAOU, C., ALEVIZOS, B., LIAPPAS, I. A. \& CHRISTODOULOU, G. N. 2004. Cytokine production in bipolar affective disorder patients under lithium treatment. $J$ Affect Disord, 82, 309-13.

BRIETZKE, E. \& KAPCZINSKI, F. 2008. TNFalpha as a molecular target in bipolar disorder. Progress in neuro-psychopharmacology \& biological psychiatry, 32, 1355-61.

BRIETZKE, E., STERTZ, L., FERNANDES, B. S., KAUER-SANT'ANNA, M., MASCARENHAS, M., ESCOSTEGUY VARGAS, A., CHIES, J. A. \& KAPCZINSKI, F. 2009. Comparison of cytokine levels in depressed, manic and euthymic patients with bipolar disorder. J Affect Disord, 116, 214-7.

DREXHAGE, R. C., HOOGENBOEZEM, T. H., VERSNEL, M. A., BERGHOUT, A., NOLEN, W. A. \& DREXHAGE, H. A. 2011. The activation of monocyte and $\mathrm{T}$ cell networks in patients with bipolar disorder. Brain Behav Immun, 25, 1206-13.

GROF, P., DUFFY, A., CAVAZZONI, P., GROF, E., GARNHAM, J., MACDOUGALL, M., O'DONOVAN, C. \& ALDA, M. 2002. Is response to prophylactic lithium a familial trait? J Clin Psychiatry, 63, 942-7.

GULOKSUZ, S., CETIN, E. A., CETIN, T., DENIZ, G., ORAL, E. T. \& NUTT, D. J. 2010. Cytokine levels in euthymic bipolar patients. $J$ Affect Disord, 126, 458-62.
KAPCZINSKI, F., DAL-PIZZOL, F., TEIXEIRA, A. L., MAGALHAES, P. V., KAUERSANT'ANNA, M., KLAMT, F., MOREIRA, J. C., DE BITTENCOURT PASQUALI, M. A., FRIES, G. R., QUEVEDO, J., GAMA, C. S. \& POST, R. 2011. Peripheral biomarkers and illness activity in bipolar disorder. Journal of psychiatric research, 45, 156-61.

KAPCZINSKI, F., DIAS, V. V., KAUERSANT'ANNA, M., BRIETZKE, E., VAZQUEZ, G. H., VIETA, E. \& BERK, M. 2009. The potential use of biomarkers as an adjunctive tool for staging bipolar disorder. Progress in neuro-psychopharmacology \& biological psychiatry, 33, 1366-71.

KIM, Y. K., JUNG, H. G., MYINT, A. M., KIM, H. \& PARK, S. H. 2007. Imbalance between proinflammatory and anti-inflammatory cytokines in bipolar disorder. $J$ Affect Disord, 104, 91-5.

KNIJFF, E. M., BREUNIS, M. N., KUPKA, R. W., DE WIT, H. J., RUWHOF, C., AKKERHUIS, G. W., NOLEN, W. A. \& DREXHAGE, H. A. 2007. An imbalance in the production of IL-1beta and IL- 6 by monocytes of bipolar patients: restoration by lithium treatment. Bipolar Disord, 9, 743-53.

KUNZ, M., CERESER, K. M., GOI, P. D., FRIES, G. R., TEIXEIRA, A. L., FERNANDES, B. S., BELMONTE-DE-ABREU, P. S., KAUERSANT'ANNA, M., KAPCZINSKI, F. \& GAMA, C. S. 2011. Serum levels of IL-6, IL-10 and TNF-alpha in patients with bipolar disorder and schizophrenia: differences in pro- and anti-inflammatory balance. Revista brasileira de psiquiatria, 33, 268-74.

NERY, F. G., MONKUL, E. S., HATCH, J. P., FONSECA, M., ZUNTA-SOARES, G. B., FREY, B. N., BOWDEN, C. L. \& SOARES, J. C. 2008. Celecoxib as an adjunct in the treatment of depressive or mixed episodes of bipolar disorder: a double-blind, randomized, placebo-controlled study. Hum Psychopharmacol, 23, 87-94.

O'BRIEN, S. M., SCULLY, P., SCOTT, L. V. \& DINAN, T. G. 2006. Cytokine profiles in bipolar affective disorder: focus on acutely ill patients. J Affect Disord, 90, 263-7. 
ORTIZ-DOMINGUEZ, A., HERNANDEZ, M. E., BERLANGA, C., GUTIERREZ-MORA, D., MORENO, J., HEINZE, G. \& PAVON, L. 2007. Immune variations in bipolar disorder: phasic differences. Bipolar Disord, 9, 596-602.

RAPAPORT, M. H., GUYLAI, L. \& WHYBROW, P. 1999. Immune parameters in rapid cycling bipolar patients before and after lithium treatment. J Psychiatr Res, 33, 335-40.

RAPAPORT, M. H. \& MANJI, H. K. 2001. The effects of lithium on ex vivo cytokine production. Biol Psychiatry, 50, 217-24.

SCHULZE, T. G., ALDA, M., ADLI, M., AKULA, N., ARDAU, R., BUI, E. T., CHILLOTTI, C., CICHON, S., CZERSKI, P., DEL ZOMPO, M., DETERA-WADLEIGH, S. D., GROF, P., GRUBER, O., HASHIMOTO, R., HAUSER, J., HOBAN, R., IWATA, N., KASSEM, L., KATO, T., KITTEL-SCHNEIDER, S., KLIWICKI, S., KELSOE, J. R., KUSUMI, I., LAJE, G., LECKBAND, S. G., MANCHIA, M., MACQUEEN, G., MASUI, T., OZAKI, N., PERLIS, R. H., PFENNIG, A., PICCARDI, P., RICHARDSON, S., ROULEAU, G., REIF, A., RYBAKOWSKI, J. K., SASSE, J., SCHUMACHER, J., SEVERINO, G., SMOLLER, J. W., SQUASSINA, A., TURECKI, G., YOUNG, L. T., YOSHIKAWA, T., BAUER, M. \& MCMAHON, F. J. 2010. The International Consortium on Lithium Genetics (ConLiGen): an initiative by the NIMH and IGSLI to study the genetic basis of response to lithium treatment. Neuropsychobiology, 62, 72-8.
SOCZYNSKA, J. K., KENNEDY, S. H., GOLDSTEIN, B. I., LACHOWSKI, A., WOLDEYOHANNES, H. O. \& MCINTYRE, R. S. 2009. The effect of tumor necrosis factor antagonists on mood and mental healthassociated quality of life: novel hypothesisdriven treatments for bipolar depression? Neurotoxicology, 30, 497-521.

TIRPAN, K., OZERDEM, A., TUNCA, Z., YAZICI, O., ORAL, E. T., KURT, E. \& VAHIP, S. 2004. A computerized registry program for bipolar illness in Turkey. Journal of affective disorders, 78(suppl), 126-127.

WALLACH, D., VARFOLOMEEV, E. E., MALININ, N. L., GOLTSEV, Y. V., KOVALENKO, A. V. \& BOLDIN, M. P. 1999. Tumor necrosis factor receptor and Fas signaling mechanisms. Annu Rev Immunol, 17, 331-67. 


\section{Plasma concentrations of soluble cytokine receptors in euthymic bipolar patients with and without subsyndromal symptoms}

Turan Cetin*, Sinan Guloksuz*, Esin Aktas Cetin, Sema Bilgic Gazioglu, Gunnur Deniz, Esat Timucin Oral, Jim van Os 

Abstract

\section{Background}

Current evidence suggests that high concentrations of pro-inflammatory markers are associated with bipolar disorder characterized by severe impairment during inter-episodic periods, reduced treatment response and persistent subsyndromal symptoms. We tested whether persistent subsyndromal symptoms in euthymic bipolar patients were associated with markers of an ongoing chronic pro-inflammatory process.

\section{Methods}

Forty-five euthymic bipolar patients (22 with subsyndromal symptoms (BD+) and 23 without subsyndromal symptoms (BD-)) and 23 well controls (WC) were recruited for assessment of soluble tumor necrosis factor receptor-1 (sTNF-R1), soluble interleukin-6 receptor (sIL-6R) and soluble interleukin-2 receptor (sIL-2R) concentrations. Soluble cytokine receptor concentrations were assessed using enzyme-linked immunosorbent assay.

\section{Results}

In comparison to WC, sTNF-R1 concentration was higher in both BD- and BD+ (age and sex adjusted standardized $\beta$, respectively: $\beta=0.34, p=0.012$ and $\beta=0.41, p=0.003$ ). Similarly, compared to WC, sIL-6R concentration was higher in both BD- and BD+ (age and sex adjusted standardized $\beta$, respectively: $\beta=0.44, p=0.001$ and $\beta=0.37, p=0.008$ ). There was no difference between BD- and BD+ in the concentration of either sTNF-R1 or sIL-6R; plasma concentration of sIL-2R was not analyzed as $75 \%$ percent of the samples were non-detectable.

\section{Conclusions}

Although bipolar patients present with a pro-inflammatory shift compared to well controls, subsyndromal symptoms are not associated with additive increasing effects. Longitudinal studies with larger samples are required to clarify the relationship between illness course and inflammatory markers in bipolar disorder.

Keywords: Bipolar disorder, Cytokine, Interleukin, Inflammation, Tumor necrosis factor, Euthymic, Subsyndromal, Staging, Biomarker 


\section{Background}

Bipolar disorder (BD) has long been considered an episodic illness characterized by complete symptomatic recovery during inter-episodic periods. However, a growing body of evidence shows that the rate of inter-episodic morbidity in the form of subsyndromal symptoms is much higher than previously thought (Judd et al., 2003, Marangell, 2004). Therefore, early recognition and treatment of subsyndromal symptoms represents an important target for clinicians, given associations with increased risk of relapse, decrement in functioning and cognitive dysfunction(Marangell, 2004, Marangell et al., 2009, Montoya et al., 2010). However, treatment alternatives are limited for the patients with subsyndromal symptoms, many of whom do not respond adequately to conventional therapies (Montoya et al., 2010).

Recent data indicate that immune modulation may play an important role in the pathophysiology of $\mathrm{BD}$, with the possibility of novel mechanistic options for treatment (Goldstein et al., 2009, Soczynska et al., 2009). Alterations in cytokine functioning may represent a fitting theoretical perspective underlying possible immuno-modulatory treatment approaches. Current knowledge about cytokines points to regulatory effects in the central nervous system, similar to their role in the immune system (Kronfol and Remick, 2000). Studies comparing cytokine concentrations in bipolar patients and healthy controls have demonstrated that mania and depression show characteristics of pro-inflammatory states with higher concentrations of pro-inflammatory cytokines and lower concentrations of anti-inflammatory cytokines (Soczynska et al., 2009). Additionally, up-regulation of the immune system appears to resolve during euthymia (Brietzke et al., 2009, Guloksuz et al., 2010, Kunz et al., 2011, Kapczinski et al., 2011). In the light of this evidence, inflammation in BD may be regarded as a state arising during acute episodes rather than a trait influencing longitudinal course of illness. However, findings of studies far from consistent; selection of heterogeneous study populations may represent an important factor underlying between-study discrepancies. For example, previous work by our group suggests that concentrations of tumor necrosis factor-alpha (TNF- $\alpha$ ), a major pro-inflammatory cytokine, may represent heterogeneity between euthymic BD patients in association with longitudinal measures of lithium response (Guloksuz et al., 2012). Indeed, the use of inflammatory markers for staging BD has been proposed (Kapczinski et al., 2009, Post et al., 2012). According to this model, high concentrations of TNF- $\alpha$ are associated with advanced stages of BD with severe impairment during inter-episodic periods, reduced treatment response and ongoing subsyndromal symptoms.

Therefore, the current study aimed to determine if there is an ongoing chronic pro-inflammatory process in euthymic bipolar patients with subsyndromal symptoms, characterised by higher concentrations of soluble tumor necrosis factor receptor-1 
(sTNF-R1), soluble interleukin-6 receptor (sIL-6R) and soluble interleukin-2 receptor (sIL-2R), all of which are thought to represent reliable markers of inflammatory activity and all of which have been widely investigated in BD. Moreover, a recent meta-analysis, examining a wide range of cytokines and soluble cytokine receptors, shows evidence of higher concentrations of sTNF-R1 and sIL-2R in bipolar patients (Munkholm et al., 2012). To this end, the study sampling frame provided comparisons between three groups: (i) euthymic bipolar patients with subsyndromal symptoms (BD+); (ii) euthymic bipolar patients without subsyndromal symptoms (BD-); (iii) well controls (WC).

\section{Methods}

\section{Study population}

A total of 45 patients, who met the DSM-IV criteria for BD-I, were recruited among long-term follow-up outpatients of the Rasit Tahsin Mood Disorders Outpatient Unit (RTMDOU) of the Bakirkoy Research and Training Hospital for Psychiatry, Neurology, and Neurosurgery. All of the 910 registered BD patients at RTMDOU continue to be evaluated with standardized medical forms based on a nation-wide mood disorders follow-up program named SKIP-TURK (Tirpan et al., 2004). The SKIP-TURK form, which is similar to the "Clinical Monitoring Form" (CMF) used in the Systematic Treatment Enhancement Program for Bipolar Disorder (STEPBD) (Sachs et al., 2003), was put into use to (i) assess the clinical characteristics of BD patients (e.g. polarity of the first episode, duration of illness) and (ii) to evaluate illness course of BD patients over clinical follow-up. The diagnosis of the patients was confirmed both by clinical interview and by the SKIP-TURK procedure. Of the patients, 23 were euthymic without subsyndromal symptoms (BD-). BD+ status was defined a priori on the basis of consensus decisions in SKIP-TURK; thus, 22 patients were in a euthymic state with at least 2 moderate affective symptoms coded in the SKIP-TURK form at 2 consecutive clinical evaluations during a follow-up period of minimally two months, however without meeting criteria for a full affective episode as defined in DSM-IV. All the patients were medicated either with mono-therapy of either of mood stabilizer, an antipsychotic or an antidepressant, or with combination therapy combining any of these.

Twenty-three well controls were also recruited from the hospital staff, reflecting the general population socioeconomic strata. A clinical psychiatrist (TC) evaluated well controls with a standard clinical psychiatric interview to screen for psychiatric disorders. The exclusion criterion for well controls was presence of any current Axis I psychiatric disorder. The study was approved by the standing Medical Ethics Committee of Bakirkoy Research and Training Hospital for Psychiatry, Neurology, 
and Neurosurgery, and carried out in accordance with the Declaration of Helsinki. All the participants gave informed consent before enrolment in the study.

Information including medical history, physical examination, laboratory evaluation including complete blood count, blood chemistry, urinalysis, thyroid function test and electrocardiogram were obtained from all participants in order to evaluate potential exclusion criteria. The exclusion criteria for all participants were any allergic disease, an infectious disease within the last four weeks, use of any potentially immunosuppressive drug such as corticosteroids, non-steroid anti-inflammatory drugs within the last four weeks, pregnancy or breastfeeding, current use of alcohol at more than 5 standard units per week, current intake of caffeine at more than three cups of coffee per day, and current use of tobacco at more than 10 cigarettes a day.

\section{Enzyme-linked immunosorbent assays (ELISAs) for sTNF-R1 and sIL-6R}

The blood samples were obtained between 08.00 AM and 10.00 AM and were collected in heparin vacuum tubes. The blood samples were immediately centrifuged for $10 \mathrm{~min}$ at $3000 \mathrm{rpm}$ and the plasma samples were stored at $-80^{\circ} \mathrm{C}$ until analysis. sIL2R, sIL-6R and sTNF-R1 concentrations in the plasma were assessed using an ELISA kit (BioSource International, Inc, Camarillo, USA) according to the manufacturer's directions. Plasma samples were diluted 1:100 for sIL-6R and 1:4 for sIL-2R detection in the sample using diluent buffer provided with the ELISA kit. Supplied standards were used to generate the standard curves. The samples and standards were applied to wells. Unbound protein was removed by washing, and biotin-conjugate, followed by horseradish peroxidase-conjugated streptavidin, were added in a stepwise manner. After the color reaction with substrate, the optical density was recorded at $450-\mathrm{nm}$ wavelength with an automated ELISA reader. The absorbance at $450 \mathrm{~nm}$ was converted to picograms per millilitre $(\mathrm{pg} / \mathrm{ml})$ for sIL-6R, sIL-2R and nanograms per millilitre $(\mathrm{ng} / \mathrm{ml})$ for sTNF-R1. The minimal detection limits were: for sIL-2R : $16 \mathrm{pg} / \mathrm{ml}$, for sIL-6R : $8 \mathrm{pg} / \mathrm{ml}$ and for sTNF-R1 : $0.03 \mathrm{ng} / \mathrm{ml}$.

\section{Statistical Analysis}

Plasma concentrations of sIL-6R and sTNF-R1 were detectable in all participants. Plasma concentration of sIL-2R was not analyzed as $75 \%$ percent of the samples were non-detectable. Demographic, clinical and treatment characteristics were analyzed by one-way ANOVA, two tailed t-test and chi-square test as indicated. Associations between sTNF-R1 and sIL-6R concentrations and a priori selected confounders (sex, age) were assessed using Pearson's product-moment correlation for age and one-way ANOVA for sex. Pearson's product-moment correlation was also used to analyze the association between duration of illness and soluble cytokine receptor concentrations. Associations between the three groups (WC, $\mathrm{BD}-, \mathrm{BD}+$ ) and approximately normally 
distributed sTNF-R1 and sIL-6R concentrations were expressed as standardized regression coefficients $(\beta)$ from multiple regression procedures with sTNF-R1 and sIL-6R as dependent variable and dummy variables of the three groups as independent variable, the WC group serving as reference. Two-sided statistical significance was set at $\mathrm{p}<0.05$. STATA version 12.0 (STATA Corporation, College Station, TX, USA) was used to carry out the statistical analyses.

\section{Results}

Table 1 lists the demographic, clinical and treatment characteristics. Compared to BD-, $\mathrm{BD}+$ had a greater number of episodes in general $(\mathrm{t}(43)=2.93, \mathrm{p}=0.005)$, depressive episodes $(\mathrm{t}(43)=3.41, \mathrm{p}=0.001)$ and episodes per year $(\mathrm{t}(43)=3.44, \mathrm{p}=0.001)$. There were no other differences between $\mathrm{BD}+$ and $\mathrm{BD}$ - in terms of clinical characteristics.

Table 1. Demographic, clinical and treatment characteristics

\begin{tabular}{|c|c|c|c|c|}
\hline & $\begin{array}{c}\text { WC } \\
(n=23) \\
\text { Mean (SD) } \\
\text { or n (\%) }\end{array}$ & $\begin{array}{c}\text { BD- } \\
(n=23) \\
\text { Mean (SD) } \\
\text { or } n(\%)\end{array}$ & $\begin{array}{c}\text { BD+ } \\
(n=22) \\
\text { Mean (SD) } \\
\text { or } n(\%)\end{array}$ & P-value \\
\hline Female sex & $12(52.2)$ & $13(56.5)$ & $12(54.5)$ & $0.957^{\mathrm{a}}$ \\
\hline Age (years) & $31.65(5.21)$ & $34.61(7.28)$ & $36.86(7.03)$ & $0.034^{\mathrm{b}}$ \\
\hline Age at onset (years) & & $22.13(6.37)$ & $21.64(6.21)$ & $0.793^{c}$ \\
\hline Onset episode (mania/depression) & & $15(65.2) / 8(34.8)$ & $11(50) / 11(50)$ & $0.302^{\mathrm{a}}$ \\
\hline Duration of illness (years) & & $12.48(7.23)$ & $15.23(7.65)$ & $0.222^{\mathrm{c}}$ \\
\hline Total number of episodes & & $4.69(3.08)$ & $8.95(6.21)$ & $0.005^{\mathrm{c}}$ \\
\hline Mania & & $2.96(2.14)$ & $4.09(4.62)$ & $0.292^{\mathrm{c}}$ \\
\hline Depression & & $1.13(1.79)$ & $3.45(2.70)$ & $0.014^{c}$ \\
\hline Mixed & & $0.09(0.29)$ & $0.45(1.22)$ & $0.168^{c}$ \\
\hline Total number of episodes per year & & $0.35(0.17)$ & $0.55(0.23)$ & $0.001^{\mathrm{c}}$ \\
\hline Family history of mood disorder & & $10(43.5)$ & $10(45.5)$ & $0.894 \mathrm{a}$ \\
\hline MS & & $9(39.13)$ & $1(4.55)$ & $0.006 \mathrm{a}$ \\
\hline MS+AP & & $12(52.17)$ & $13(59.09)$ & \\
\hline MS+AD & & $2(8.70)$ & $2(9.09)$ & \\
\hline $\mathbf{M S}+\mathbf{A P}+\mathbf{A D}$ & & 0 & $6(27.27)$ & \\
\hline $\begin{array}{l}\text { Duration of ongoing subsyndromal } \\
\text { symptoms (months) }\end{array}$ & & & $4.95(3.43)$ & \\
\hline $\begin{array}{l}\text { Subtype of ongoing subsyndromal } \\
\text { symptoms (depressive/manic/mixed) }\end{array}$ & & & $14 / 6 / 2$ & \\
\hline
\end{tabular}

WC: well controls, BD-: euthymic bipolar patients without subsyndromal symptoms, BD+: euthymic bipolar patients with subsyndromal symptoms. MS: Mood stabilizer, AP: Antipsychotic, AD: Antidepressant

${ }^{\text {a Chi square }}$

${ }^{\mathrm{b} O n e-w a y ~ A N O V A}$

ct test 


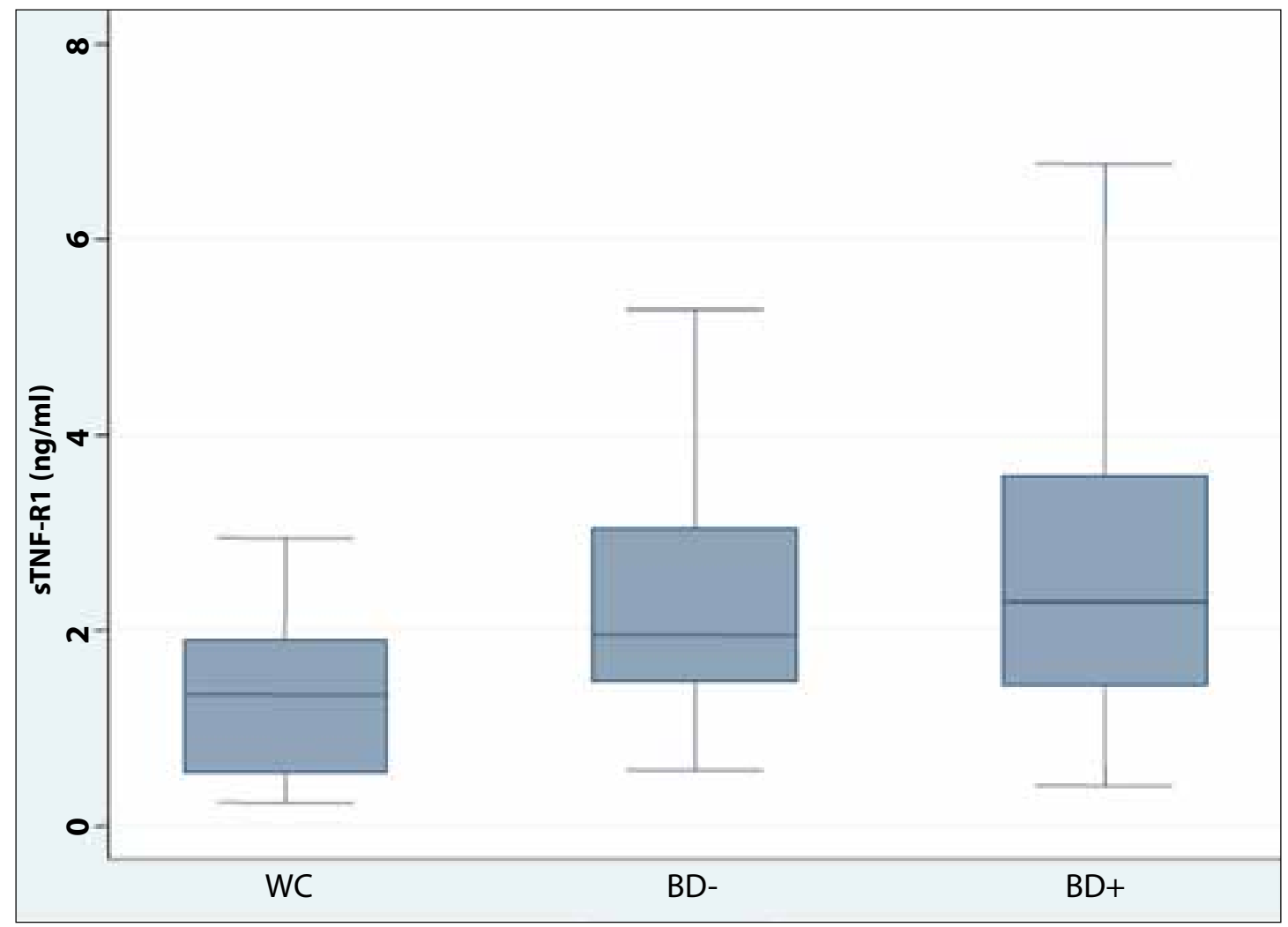

Figure 1. Box-plot of plasma sTNF-R1 concentration in WC, BD- and BD+.

Median levels are indicated by horizontal lines. WC: well controls, BD-: euthymic bipolar patients without subsyndromal symptoms, BD+: euthymic bipolar patients with subsyndromal symptoms.

Age was associated with both sTNF-R1 concentration $(r=0.30, \mathrm{p}=0.013)$ and sIL-6R concentration $(r=0.25, \mathrm{p}=0.038)$. There was no strong or significant association between sex and either sTNF-R1 concentration $(F(1,66)=0.04$, $\mathrm{p}=0.835)$ or sIL-6R concentration $(F(1,66)=0.02, \mathrm{p}=0.877)$. The mean sTNF-R1 concentration was $1.26(\mathrm{SD}=0.74), 2.31(\mathrm{SD}=1.13)$ and $2.62(\mathrm{SD}=1.64) \mathrm{ng} / \mathrm{ml}$ in $\mathrm{WC}, \mathrm{BD}-$ and $\mathrm{BD}+$, respectively (Figure 1). The mean sIL-6R concentration was $116.12(\mathrm{SD}=48.46), 192.04(\mathrm{SD}=72.69)$ and $184.78(\mathrm{SD}=82.62) \mathrm{pg} / \mathrm{ml}$ in $\mathrm{WC}$, $\mathrm{BD}$ - and $\mathrm{BD}+$, respectively (Figure 2 ). In comparison to $\mathrm{WC}$, sTNF-R1concentration was higher in $\mathrm{BD}-$ and $\mathrm{BD}+$ (uncontrolled standardized $\beta$, respectively: $\beta=0.37$, $\mathrm{p}=0.005$ and $\beta=0.48, \mathrm{p}<0.001$; age and sex adjusted standardized $\beta$, respectively: $\beta=0.34, p=0.012$ and $\beta=0.41, p=0.003$ ). There was no difference between BD- and $\mathrm{BD}+$ in sTNF-R1 concentration (uncontrolled standardized $\beta: \beta=0.10, \mathrm{p}=0.403$; age and sex adjusted standardized $\beta: \beta=0.07, p=0.559$ ). In comparison to WC, sIL-6R concentration was higher in $\mathrm{BD}$ - and $\mathrm{BD}+$ (uncontrolled standardized $\beta$, respectively: $\beta=0.47, \mathrm{p}<0.001$ and $\beta=0.42, \mathrm{p}=0.001$; age and sex adjusted standardized $\beta$, 


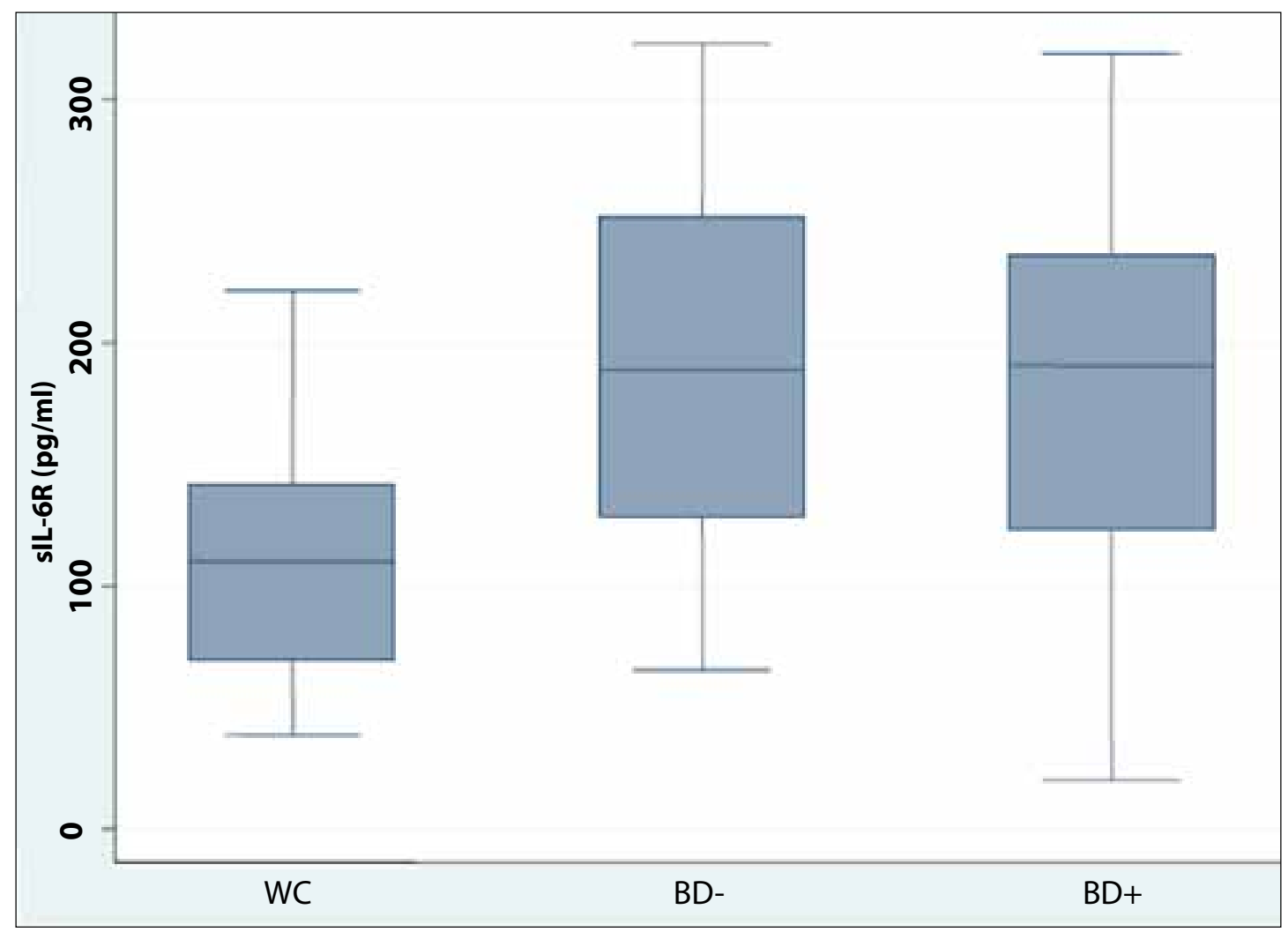

Figure 2. Box-plot of plasma slL-6R concentration in WC, BD- and BD+

Median levels are indicated by horizontal lines. WC: well controls, BD-: euthymic bipolar patients without subsyndromal symptoms, BD+: euthymic bipolar patients with subsyndromal symptoms.

respectively: $\beta=0.44, p=0.001$ and $\beta=0.37, p=0.008)$. There was no difference between BD- and BD+ in sIL-6R concentration (uncontrolled standardized $\beta$ : $\beta=-0.05$, $\mathrm{p}=0.726$; age and sex adjusted standardized $\beta$ : $\beta=-0.08, \mathrm{p}=0.587$ ). There was no strong or significant association between duration of illness and either sTNF-R1 concentration $(r=0.20, \mathrm{p}=0.183)$ or sIL-6R concentration $(r=0.08, \mathrm{p}=0.585)$.

\section{Discussion}

This study demonstrates that there were no differences between $\mathrm{BD}$ - and $\mathrm{BD}+$ in terms of sTNF-R1 and sIL-6R concentrations. However, sTNF-R1 and sIL-6R concentrations were higher in both $\mathrm{BD}-$ and $\mathrm{BD}+$ in comparison to $\mathrm{WC}$.

Our findings are in line with a previous study reporting higher concentrations of sTNF-R1 in euthymic BD patients compared to controls (Barbosa et al., 2011, Barbosa et al., 2012a). It has been suggested that soluble cytokine receptors may 
better reflect the activity of the cytokines in question, given that they are detectable in plasma even when cytokine concentrations are undetectable (Barbosa et al., 2011). Thus, it is plausible to think of soluble cytokine receptors as more reliable markers of activity. In the light of this evidence, both sTNF-R1 and sIL-6R can be considered as markers reflecting pro-inflammatory activity. Both TNF- $\alpha$ and IL- 6 are primary regulators of pro-inflammatory process due to their initiating roles in the inflammatory cascade of the acute phase response (Kronfol and Remick, 2000). They have the ability of affecting various cells and therefore are regarded as possessing pleiotropic properties. It has been demonstrated that the degradation of tryptophan (TRP) by the indoleamine 2,3 dioxygenase (IDO) enzyme is mainly induced by interferon gamma (IFN-y), but also, to a degree, by TNF- $\alpha$ and IL-6 (Leonard and Maes, 2012). Induced IDO activity causes degradation of TRP, which serves as a precursor for serotonin. Moreover, induced IDO activity leads to the formation of neurotoxic metabolites, 3-hydroxykynurenine and quinolinic acid (Dantzer et al., 2008). Several studies have shown an association between IDO activation and mood disorder, particularly unipolar depression (Leonard and Maes, 2012). Recently, the TNF- $\alpha$ system has been postulated as a target for understanding the pathophysiology of BD (Brietzke and Kapczinski, 2008, Soczynska et al., 2009). TNF- $\alpha$ exerts its effects via the cell surface receptors called TNFR1 and TNFR2. The effect of TNFR2 is negligible to TNFR1, since TNFR1is expressed in most cells, whereas TNFR2 is expressed only in hematopoietic cells. TNFR1mediates apoptosis, cytokine production and activation of nuclear factor kappa $\mathrm{B}(\mathrm{NF}-\mathrm{\kappa} \mathrm{B})$, which induces transcription of cell survival genes (i.e. cellular inhibitors of apoptosis (cIAP), B-cell lymphoma 2 (Bcl-2) family) (Soczynska et al., 2009). It has been postulated that there is a shift towards apoptosis during mood episodes and that this shift arises from increased TNF- $\alpha$ concentration and cessation of NF- $\mathrm{kB}$ neuronal translocation due to decreased brain-derived neurotrophic factor (BDNF) and nerve growth factor (NGF) (Brietzke and Kapczinski, 2008). On balance, the TNF- $\alpha$ system may be considered an important factor playing a role in the regulation of neuroplasticity. Moreover, the notion of TNF- $\alpha$ as a trait marker of $\mathrm{BD}$ has some validity given evidence of higher TNF- $\alpha$ concentration in patients with BD than in healthy controls, evidence of effects of TNF- $\alpha$ antagonists on mood symptoms and effects of psychotropics on TNF- $\alpha$ (Goldstein et al., 2009, Soczynska et al., 2009). However, it is still premature to count TNF- $\alpha$ as a trait marker of BD due to the influence of several confounding factors, particularly the use of medication, on the immune system. Likewise, the results of our study should be interpreted carefully considering medication use as a potential confounder (Haack et al., 1999). Controlling for this was not possible, as only patients used medication, resulting in collinearity. Recent studies showing no difference between medicated euthymic BD patients 
and well controls in terms of TNF- $\alpha$ and IL- 6 concentrations contradict the current findings (Brietzke et al., 2009, Kunz et al., 2011, Kapczinski et al., 2011, Barbosa et al., 2012b). The conclusion is that additional studies evaluating inflammatory markers in the euthymic state, ideally comparing medication-free BD patients and matched controls in large samples, are still needed in order to clarify if ongoing inflammation is a trait in BD.

According to the model for staging BD with the use of biomarkers, progression through later stages with social and cognitive dysfunction and persistent subsyndromal symptoms in the inter-episode period is associated with increased oxidative stress and inflammation, which can be demonstrated by high 3-nitrotyrosine and TNF- $\alpha$ concentrations (Kapczinski et al., 2009, Post et al., 2012). This model stages BD in five categories according to clinical features: Latent Stage is defined by positive family history of mood disorders, subthreshold mood or anxiety symptoms; Stage 1 is defined by euthymic periods without overt psychiatric symptoms; Stage 2 is defined by symptoms during inter-episodic periods and comorbid psychiatric disorders; Stage 3 is defined by marked impairment in cognition and functioning; Stage 4 is defined by need of a caregiver in daily life due to severe impairment in cognition and functioning (Kapczinski et al., 2009). The patients with subsyndromal symptoms in our study had persistent symptoms during euthymia, and experienced a greater number of episodes. Thus, they can be considered as patients presenting at a later stage of illness than the group of patients without subsyndromal symptoms. However, we did not find any differences between these two groups in terms of sTNF-R1 and sIL-6R concentrations. In their evaluation of brain-derived neurotrophic factor and cytokines in early and late stage BD patients, Kauer-Sant'Anna and colleagues demonstrated that TNF- $\alpha$ concentration remained higher in late stage patients even after controlling for subsyndromal symptoms (Kauer-Sant'Anna et al., 2009). Consequently, they propose that higher TNF- $\alpha$ concentration in the later stages of illness may be due to the cumulative effect of past mood episodes or the cumulative effect of pro-inflammatory shifts throughout the course of illness, rather than the effect of subsyndromal symptoms. In accordance with this finding, the current analysis confirms that subsyndromal symptoms have minimal effect on cytokine concentrations. Nevertheless, we do not underestimate the cumulative effect of ongoing subsyndromal symptoms in patients with advanced duration of illness. BD+ patients had a greater number of episodes per year, which can be counted as an identifier for poor prognosis in the future. Thus, it is also plausible to think that pro-inflammatory shifts may become more evident later in the course of illness in BD+ compared to BD-. Alternatively, BD- and BD+ could belong to same stage, in contrast to what was hypothesized. An in-depth evaluation 
of social and cognitive functioning could have provided more variables for empirical staging.

To the best of our knowledge, this is the first study investigating immune changes in subsyndromal BD patients. Although our analyses focused on potential inflammatory markers of subsyndromal symptoms in BD-I, no actual associations were presented between inflammatory markers and specific symptoms. Instead, we relied on grouplevel comparisons of patients with and without subsyndromal symptoms. To the degree that these groups differ in other aspects other than symptomatology, results could have been confounded. Therefore, follow-up research focusing on comparisons at the symptom level in larger samples is required. Although the study had the benefit of recruiting patients with subsyndromal symptoms with the help of standardized assessments in a specialized mood disorders outpatient unit, the definition for subsyndromal state recommended by the International Society of Bipolar Disorder (ISBD) could have been measured more precisely (Tohen et al., 2009). However, there was no consensus on the definition of subsyndromal states when the study recruitment was initiated. Moreover, the cross-sectional design of the study limits our further prediction about the effect of subsyndromal symptoms on cytokines in the long term. It is also important to emphasize that we were unable to assess body mass index as a potential confounder. Only soluble receptors of TNF- $\alpha$ and IL-6 were assessed, which are the most studied cytokines in BD and considered as molecular targets (Brietzke and Kapczinski, 2008, Soczynska et al., 2009, Munkholm et al., 2012). Nevertheless, evaluation of additional inflammatory markers could provide the opportunity of interpreting the findings in more detail. All patients were on medication. As psychotropics (i.e. lithium) may impact on cytokine concentrations (Guloksuz et al., 2010, Guloksuz et al., 2012, Haack et al., 1999), this could have confounded the results. Given the fact that almost all patients in this small study had unique, nonoverlapping, treatment modalities (i.e. different combinations of medications and/or different doses), it was impossible to group according to treatment modality in detail and describe medication-related effects in the patient sample. Moreover, previous work suggests that medications have different, sometimes interacting effects on immune mediators (Haack et al., 1999). Although it could be argued that medication equivalents might have been used in analyses within the patient group, this method can only be applied to antipsychotics. Furthermore, caution must be taken when using this methodology, since medication equivalents reflect efficacy rather than biological mechanisms. Thus, it was decided not to analyze the effect of each separate medication on immune mediators in this relatively small sample. This is a limitation. On the other hand, eliminating this possibly confounding effect is nearly impossible given the fact that augmentation strategies, resulting in patient-unique medication mixes, 
are routine practice in the treatment of bipolar disorder (Munkholm et al., 2012). The cross-sectional design of the study also prevented us to evaluate the effects of earlier, currently discontinued treatment. Given the possibility of residual confounding by medication, and the difficulties in disentangling confounding by medication within patient-specific polypharmacy approaches, follow-up semi-experimental studies are required to settle this issue. Finally, the sample size of the study was relatively small, which had the inherent risk of type-II error.

\section{Conclusions}

Despite its preliminary character, findings of our study appear to indicate that subsyndromal symptoms do not influence sTNF-R1 and sIL-6R concentrations. Nevertheless, longitudinal studies with larger samples are required in order to clarify the relationship between illness course and inflammatory markers in BD. 


\section{Competing Interests}

All authors declare that they have no potential conflict of interest.

\section{Authors' contributions}

TC and ETO designed the study and wrote the protocol. EAC, SBG and GD commented on the protocol. TC undertook clinical evaluations. EAC and SBG carried out the immunoassays. SG and JVO undertook the statistical analysis. SG wrote the first draft of the manuscript. ETO and JVO commented on the manuscript. All authors contributed to and have approved the final manuscript.

\section{Acknowledgements}

Dr. Sinan Guloksuz and Prof. Jim van Os are supported by the European Community's Seventh Framework Programme under Grant agreement no. HEALTH-F2-2009-241909 (Project EU-GEI). 


\section{References}

BARBOSA, I. G., HUGUET, R. B., MENDONCA, V. A., SOUSA, L. P., NEVES, F. S., BAUER, M. E. \& TEIXEIRA, A. L. 2011. Increased plasma levels of soluble TNF receptor I in patients with bipolar disorder. European archives of psychiatry and clinical neuroscience, 261, 139-43.

BARBOSA, I. G., ROCHA, N. P., DE MIRANDA, A. S., MAGALHAES, P. V., HUGUET, R. B., DE SOUZA, L. P., KAPCZINSKI, F. \& TEIXEIRA, A. L. 2012a. Increased levels of adipokines in bipolar disorder. Journal of psychiatric research, 46, 389-93.

BARBOSA, I. G., ROCHA, N. P., HUGUET, R. B., FERREIRA, R. A., SALGADO, J. V., CARVALHO, L. A., PARIANTE, C. M. \& TEIXEIRA, A. L. 2012b. Executive dysfunction in euthymic bipolar disorder patients and its association with plasma biomarkers. Journal of affective disorders, 137, 151-5.

BRIETZKE, E. \& KAPCZINSKI, F. 2008. TNFalpha as a molecular target in bipolar disorder. Progress in neuro-psychopharmacology \& biological psychiatry, 32, 1355-61.

BRIETZKE, E., STERTZ, L., FERNANDES, B. S., KAUER-SANT'ANNA, M., MASCARENHAS, M., ESCOSTEGUY VARGAS, A., CHIES, J. A. \& KAPCZINSKI, F. 2009. Comparison of cytokine levels in depressed, manic and euthymic patients with bipolar disorder. Journal of affective disorders, 116, 214-7.

DANTZER, R., O'CONNOR, J. C., FREUND, G. G., JOHNSON, R. W. \& KELLEY, K. W. 2008. From inflammation to sickness and depression: when the immune system subjugates the brain. Nature reviews. Neuroscience, 9, 46-56.

GOLDSTEIN, B. I., KEMP, D. E., SOCZYNSKA, J. K. \& MCINTYRE, R. S. 2009. Inflammation and the phenomenology, pathophysiology, comorbidity, and treatment of bipolar disorder: a systematic review of the literature. The Journal of clinical psychiatry, 70, 1078-90.

GULOKSUZ, S., ALTINBAS, K., AKTAS CETIN, E., KENIS, G., BILGIC GAZIOGLU, S., DENIZ, G., ORAL, E. T. \& VAN OS, J.
2012. Evidence for an association between tumor necrosis factor-alpha levels and lithium response. Journal of affective disorders.

GULOKSUZ, S., CETIN, E. A., CETIN, T., DENIZ, G., ORAL, E. T. \& NUTT, D. J. 2010. Cytokine levels in euthymic bipolar patients. Journal of affective disorders, 126, 458-62.

HAACK, M., HINZE-SELCH, D., FENZEL, T., KRAUS, T., KUHN, M., SCHULD, A. \& POLLMACHER, T. 1999. Plasma levels of cytokines and soluble cytokine receptors in psychiatric patients upon hospital admission: effects of confounding factors and diagnosis. Journal of psychiatric research, 33, 407-18.

JUDD, L. L., AKISKAL, H. S., SCHETTLER, P. J., CORYELL, W., ENDICOTT, J., MASER, J. D., SOLOMON, D. A., LEON, A. C. \& KELLER, M. B. 2003. A prospective investigation of the natural history of the longterm weekly symptomatic status of bipolar II disorder. Arch Gen Psychiatry, 60, 261-9.

KAPCZINSKI, F., DAL-PIZZOL, F., TEIXEIRA, A. L., MAGALHAES, P. V., KAUERSANT'ANNA, M., KLAMT, F., MOREIRA, J. C., DE BITTENCOURT PASQUALI, M. A., FRIES, G. R., QUEVEDO, J., GAMA, C. S. \& POST, R. 2011. Peripheral biomarkers and illness activity in bipolar disorder. Journal of psychiatric research, 45, 156-61.

KAPCZINSKI, F., DIAS, V. V., KAUERSANT'ANNA, M., BRIETZKE, E., VAZQUEZ, G. H., VIETA, E. \& BERK, M. 2009. The potential use of biomarkers as an adjunctive tool for staging bipolar disorder. Progress in neuro-psychopharmacology \& biological psychiatry, 33, 1366-71.

KAUER-SANT'ANNA, M., KAPCZINSKI, F., ANDREAZZA, A. C., BOND, D. J., LAM, R. W., YOUNG, L. T. \& YATHAM, L. N. 2009. Brain-derived neurotrophic factor and inflammatory markers in patients with early- vs. late-stage bipolar disorder. The international journal of neuropsychopharmacology / official scientific journal of the Collegium Internationale Neuropsychopharmacologicum, 12, 447-58.

KRONFOL, Z. \& REMICK, D. G. 2000. Cytokines 
and the brain: implications for clinical psychiatry. The American journal of psychiatry, 157, 683-94.

KUNZ, M., CERESER, K. M., GOI, P. D., FRIES, G. R., TEIXEIRA, A. L., FERNANDES, B. S., BELMONTE-DE-ABREU, P. S., KAUERSANT'ANNA, M., KAPCZINSKI, F. \& GAMA, C. S. 2011. Serum levels of IL-6, IL-10 and TNF-alpha in patients with bipolar disorder and schizophrenia: differences in pro- and anti-inflammatory balance. Revista brasileira de psiquiatria, 33, 268-74.

LEONARD, B. \& MAES, M. 2012. Mechanistic explanations how cell-mediated immune activation, inflammation and oxidative and nitrosative stress pathways and their sequels and concomitants play a role in the pathophysiology of unipolar depression. Neuroscience and biobehavioral reviews, 36, 764-85.

MARANGELL, L. B. 2004. The importance of subsyndromal symptoms in bipolar disorder. The Journal of clinical psychiatry, 65 Suppl 10, 24-7.

MARANGELL, L. B., DENNEHY, E. B., MIYAHARA, S., WISNIEWSKI, S. R., BAUER, M. S., RAPAPORT, M. H. \& ALLEN, M. H. 2009. The functional impact of subsyndromal depressive symptoms in bipolar disorder: data from STEP-BD. Journal of affective disorders, 114, 58-67.

MONTOYA, A., TOHEN, M., VIETA, E., CASILLAS, M., CHACON, F., POLAVIEJA, P. \& GILABERTE, I. 2010. Functioning and symptomatic outcomes in patients with bipolar I disorder in syndromal remission: a 1-year, prospective, observational cohort study. Journal of affective disorders, 127, 50-7.

MUNKHOLM, K., VINBERG, M. \& VEDEL KESSING, L. 2012. Cytokines in bipolar disorder: A systematic review and metaanalysis. Journal of affective disorders.

POST, R. M., FLEMING, J. \& KAPCZINSKI, F. 2012. Neurobiological correlates of illness progression in the recurrent affective disorders. Journal of psychiatric research, 46, 561-73.

SACHS, G. S., THASE, M. E., OTTO, M. W., BAUER, M., MIKLOWITZ, D., WISNIEWSKI, S. R., LAVORI, P.,
LEBOWITZ, B., RUDORFER, M., FRANK, E., NIERENBERG, A. A., FAVA, M., BOWDEN, C., KETTER, T., MARANGELL, L., CALABRESE, J., KUPFER, D. \& ROSENBAUM, J. F. 2003. Rationale, design, and methods of the systematic treatment enhancement program for bipolar disorder (STEP-BD). Biological psychiatry, 53, 102842.

SOCZYNSKA, J. K., KENNEDY, S. H., GOLDSTEIN, B. I., LACHOWSKI, A., WOLDEYOHANNES, H. O. \& MCINTYRE, R. S. 2009. The effect of tumor necrosis factor antagonists on mood and mental healthassociated quality of life: novel hypothesisdriven treatments for bipolar depression? Neurotoxicology, 30, 497-521.

TIRPAN, K., OZERDEM, A., TUNCA, Z., YAZICI, O., ORAL, E. T., KURT, E. \& VAHIP, S. 2004. A computerized registry program for bipolar illness in Turkey. Journal of affective disorders, 78(suppl), 126-127.

TOHEN, M., FRANK, E., BOWDEN, C. L., COLOM, F., GHAEMI, S. N., YATHAM, L. N., MALHI, G. S., CALABRESE, J. R., NOLEN, W. A., VIETA, E., KAPCZINSKI, F., GOODWIN, G. M., SUPPES, T., SACHS, G. S., CHENGAPPA, K. R., GRUNZE, H., MITCHELL, P. B., KANBA, S. \& BERK, M. 2009. The International Society for Bipolar Disorders (ISBD) Task Force report on the nomenclature of course and outcome in bipolar disorders. Bipolar disorders, 11, 453-73. 


\section{Depressive symptoms in Crohn's disease: relationship with immune activation and tryptophan availability}

Sinan Guloksuz, Marieke Wichers, Gunter Kenis, Maurice G. V. M. Russel, Annick Wauters, Robert Verkerk, Baer Arts, Jim van Os

Plos One (2013): 8(3):e60435. 

Abstract

Crohn's disease $(C D)$ is associated with immune activation and depressive symptoms. This study determines the impact of anti-tumor necrosis factor (TNF)-a treatment in CD patients on depressive symptoms and the degree to which tryptophan (TRP) availability and immune markers mediate this effect. Fifteen patients with $C D$, eligible for anti-TNF- $a$ treatment were recruited. Disease activity (Harvey-Bradshaw Index (HBI), Crohn's Disease Activity Index (CDAI)), fatigue (Multidimensional Fatigue Inventory (MFI)), quality of life (Inflammatory Bowel Disease Questionnaire (IBDQ)), symptoms of depression and anxiety (Symptom Checklist (SCL-90), Beck Depression Inventory (BDI), Hamilton Depression Rating Scale (HDRS)), immune activation (acute phase proteins (APP)), zinc and TRP availability were assessed before treatment and after 2, 4 and 8 weeks. Anti-TNF-a increased IBDQ scores and reduced all depression scores; however only SCL-90 depression scores remained decreased after correction for HBI. Positive APPs decreased, while negative APPs increased after treatment. After correction for $\mathrm{HBI}$, both level and percentage of $\gamma$ fraction were associated with SCL-90 depression scores over time. After correction for $\mathrm{HBI}$, patients with current/past depressive disorder displayed higher levels of positive APPs and lower levels of negative APPs and zinc. TRP availability remained invariant over time and there was no association between SCL-90 depression scores and TRP availability. Inflammatory reactions in $C D$ are more evident in patients with comorbid depression, regardless of disease activity. Anti-TNF-a treatment in CD reduces depressive symptoms, in part independently of disease activity; there was no evidence that this effect was mediated by immune-induced changes in TRP availability.

Keywords: Crohn's disease, Depression, Fatigue, Quality of life, Inflammation, Tumor necrosis factor alpha, Acute phase proteins, Tryptophan, Serotonin, Infliximab 


\section{Introduction}

Crohn's disease (CD) has been associated with an increased prevalence of psychopathology. In addition, it is proposed that $\mathrm{CD}$ is more likely to occur in subjects with predisposing personality traits, such as high level of neuroticism and introversion (Robertson et al., 1989). Previous studies show mixed results concerning the temporal relationship between the onset of gastrointestinal complaints and symptoms of mental disorder (Helzer et al., 1984, North et al., 1991, Kurina et al., 2001, Camara et al., 2011, Mardini et al., 2004, Mittermaier et al., 2004, Banovic et al., 2009). However, once present, bouts of disease activity and symptoms of anxiety and depression tend to co-occur. Elevated levels of inflammatory mediators have been implicated in the pathophysiology of CD. The immune response in CD patients typically has been considered majorly as Th1-type, assessed by elevated expression of interleukin (IL)-12, tumor necrosis factor (TNF)- $\alpha$ and interferon (IFN)- $\gamma$, which are proinflammatory cytokines that increase macrophage and natural killer cell activation, antigen presenting cell function, and lead to the production of other pro-inflammatory mediators (Papadakis and Targan, 2000, Plevy et al., 1997, Strober et al., 2010). In addition, the role of Th-17-mediated response in pathophysiology of $\mathrm{CD}$ has recently been implicated (Strober et al., 2010).

Considering that the presence of depression predicts lower remission rates and decreases the time to retreatment of CD (Persoons et al., 2005), it is plausible to hypothesize that there is an interaction between depression and CD. A growing body of evidence also supports the notion that immune-modulation plays a role in pathogenesis of depression (Dantzer et al., 2008, Miller et al., 2009, Leonard and Maes, 2012). Administration of the pro-inflammatory cytokine IFN- $\alpha$ in humans triggers the development of depressive symptoms in up to $45 \%$ of participants (Van Gool et al., 2003). Furthermore, increased production of IL-6, IL-1 $\beta$, IFN- $\gamma$ and TNF- $\alpha$, as well as signs of an acute phase response, i.e. increased production of positive acute phase proteins (APPs) and decreased production of negative APPs, are associated with depression (Maes et al., 1995, Sluzewska et al., 1996, Leonard, 2001, Licinio and Wong, 1999, Dantzer et al., 2008, Miller et al., 2009, Maes et al., 1997). The observation of higher levels of positive APPs accompanied by low levels of negative APPs supports the notion that depression is inflammatory-related. Likewise, zinc, which plays a role in inflammatory mechanisms as a key antioxidant, has been reported at reduced levels in patients with depression (Maes et al., 1999, Maes et al., 1997). In addition, increased levels of complement factors C3c and C4, as well as immunoglobulin $\mathrm{M}(\mathrm{IgM})$ and $\operatorname{IgG}$ are also observed in this disorder (Song et al., 1994). Immune activation may impact on mood, by decreasing the availability of peripheral tryptophan (TRP) that may cross the blood-brain-barrier (Leonard 
and Maes, 2012, Dantzer et al., 2008, Miller et al., 2009) . TRP is the precursor of serotonin (5-HT), a neurotransmitter synthesized in the brain and important in the regulation of mood. Earlier studies show that indicators of the availability of TRP to brain, serum/plasma TRP, as well as the ratio of TRP to the sum of competing amino acids (CAA) - known to compete for the cerebral uptake mechanism of TRP-, are lower in depression (Maes et al., 1993, Maes et al., 1994, Maes et al., 1996, Maes et al., 1997, Cowen et al., 1989, Maes et al., 1986).

The causal mechanism underlying the relationship between $\mathrm{CD}$ and mental disorder is unclear. Symptoms of depression and anxiety may represent the psychological response to disease activity. On the other hand, it may be hypothesized that activation of the inflammatory immune response causes both $\mathrm{CD}$ and symptoms of mental disorder, which could explain (i) the uncertain temporal relationship between onset of CD and symptoms of mental disorder, (ii) the close relationship between disease state and psychopathology, and (iii) personality differences between CD patients and controls. There is some evidence that depressive symptoms may be reduced in $\mathrm{CD}$ patients after infusion of anti-TNF- $\alpha$, an efficient treatment for gastrointestinal symptoms in CD (Persoons et al., 2005, Minderhoud et al., 2007).

Therefore, the aim of the current study was to determine the impact of antiTNF- $\alpha$ treatment in CD patients on depressive symptoms, and to examine the possibility that improvement of depressive symptoms occurs in parallel with changes in TRP availability imposed by a reduction in inflammation as reflected by levels of APPs.

\section{Methods}

\section{Subjects}

15 patients (4 men and 11 women) with $\mathrm{CD}$, eligible for anti-TNF- $\alpha$, infliximab (Remicade ${ }^{\circledR}$ ) infusion were recruited. Inclusion criteria were: having a HarveyBradshaw Index (HBI) score $>10$ or active perianal fistula, being allergic or not responding to the following treatments: azathioprine, methotrexate and/or corticosteroids. Exclusion criteria were: age $<18$ and $>65$ years, pregnancy or intention to get pregnant within the period of treatment and up to 6 months after discontinuation of therapy, women not practicing or not willing to practice safe methods of contraception during the treatment period up to 6 months after discontinuation of therapy, lactation, human immunodeficiency virus positivity, chemotherapy or systemic antiviral treatment during the 6 months prior to study entry, presence of other serious disease (e.g. malignancy, uncontrolled myocardial disease or severe arrhythmias), tuberculosis positivity (current or past), creatinine levels over 150 
$\mathrm{mmol} / \mathrm{L}$ or $1.70 \mathrm{mg} / \mathrm{dl}$, any condition which in the opinion of the (co-) investigator might interfere with the evaluation of the study objectives, patients meeting axis I criteria for mental disorders as defined by DSM-IV, except for patients meeting the criteria for a depressive or anxiety disorder.

The study was approved by the standing Medical Ethics Committee of Maastricht University, and carried out in accordance with the Declaration of Helsinki (Hong Kong Modification, 1989). Written informed consent was obtained from each subject prior to participation.

\section{Study design}

A within-subject design was used to determine (i) the effect of anti-TNF- $\alpha$ infusion on disease activity and markers of immune activation, (ii) effect of antiTNF- $\alpha$ infusion on mood, fatigue and quality of life, (iii) effect of altered immune activation on TRP levels, and (iv) effect of TRP levels on depressive symptoms.

Patients received an infusion of anti-TNF- $\alpha$, infliximab (Remicade $\left.{ }^{\circledR}\right)(5 \mathrm{mg} / \mathrm{kg}$ bodyweight). Psychological assessments and measurements of immune activation were performed before infusion (baseline) and 2, 4 and 8 weeks after infusion. Fasting blood samples were collected between 8.00 and $10.00 \mathrm{AM}$. Blood samples were centrifuged at $1300 \mathrm{xg}$ for 10 minutes. Serum was then stored at $-80^{\circ} \mathrm{C}$ until assayed.

\section{Disease activity and psychological assessments}

Disease activity was assessed using the HBI (Harvey and Bradshaw, 1980) and the Crohn's Disease Activity Index (CDAI) (Yoshida, 1999). The latter was assessed only at baseline, 4 and 8 weeks after infusion. Fatigue was assessed by the Multidimensional Fatigue Inventory (MFI), which is a self-report instrument consisting of five scales measuring general fatigue, physical fatigue, reduced activity, reduced motivation and mental fatigue (Smets et al., 1995). In order to limit the number of tests applied, only core fatigue dimensions of physical and mental fatigue were included in the analyses in order to avoid overlap with depression dimensions of reduced activity and motivation. Quality of Life was measured using the Inflammatory Bowel Disease Questionnaire (IBDQ) (Russel et al., 1997)

The presence of depressive symptoms was assessed by the 17-item Hamilton Depression Rating Scale (HDRS) (Hamilton, 1967). In addition, symptoms of depression and anxiety were assessed by self-report using the Beck Depression Inventory (BDI) (Beck and Steer, 1984, Bosscher et al., 1986) and the Symptom Checklist (SCL-90) (Derogatis et al., 1976). To determine the presence of axis I mental disorder, the Structured Clinical Interview for DSM-IV axis I Disorders Version 5.0 was administered. 


\section{Determination of markers of immune activation and TRP/CAA}

Immune activation was determined by using positive APPs $\left(\alpha_{1}-\right.$ antitrypsin, $\alpha_{1}-$ acid glycoprotein and $\alpha_{1}$ - antichymotrypsin, haptoglobin, ceruloplasmin, fibrinogen, complement factor C3), negative APPs (albumin, transferrin) and zinc as markers of inflammation described in more detail below. Five major fractions of serum proteins were determined using the capillary zone electrophoresis technique; albumin (negative APP), $\alpha_{1}, \alpha_{2}, \beta$ and $\gamma$ globulin fractions. $\alpha_{1}-$ antitrypsin, $\alpha_{1}-$ acid glycoprotein and $\alpha_{1}$ - antichymotrypsin, all positive APPs, migrate in the $\alpha_{1}$ zone, while haptoglobin and ceruloplasmin, also positive APPs, migrate in the $\alpha_{2}$ zone. Fibrinogen, complement factor $\mathrm{C} 3$ and transferrin migrate in the $\beta$ zone and immunoglobulins in the $\gamma$ zone. Total serum protein determination and electrophoresis for measurement of albumin and the $\alpha, \beta$ and $\gamma$ fractions were performed as described previously (Van Hunsel et al., 1996). Transferrin concentration was analysed using immunoturbidimetry. Serum zinc levels were determined using atomic absorption spectroscopy (Maes et al., 1999). Total TRP and CAA were assayed using high-performance liquid chromatography as explained previously (Wichers et al., 2005).

\section{Statistical analyses}

Normality of distribution was ascertained by Kolmogorov-Smirnov test. Levene statistics were used to check the assumption of homogeneity of variances. Distributions of transferrin and percentages of the $\alpha 1$ and $\alpha 2$ fractions were log-transformed to improve normality. The data were analyzed with the Stata computer program, version 12 (Stata Corporation, College Station, TX, USA). Multilevel random regression models were fitted testing main effects and interactions, using the XTREG routine in Stata. The XTREG procedure takes into account the fact that level-one units (repeated observation level) were hierarchically clustered into level-two units (subject level). Effect sizes of explanatory variables were expressed as regression coefficients (B) from the multilevel models. Regression analyses were performed to examine the effects of time (linear and factored) on the CDAI, mental and physical fatigue, dimensions of the IBDQ, HDRS and on the anxiety and depression scales of the SCL90 questionnaire. Effects of time on immune parameters were similarly estimated. In addition, regression analyses were used to determine associations, over time, between immune parameters and TRP/CAA ratio and between TRP/CAA ratio and measures of depression. Analyses were corrected a priori for age, smoking, sex, use of oral contraceptives, medication use during the study (mesalamine, corticosteroids, azathioprine and/or methotrexate), presence of past/current depression or anxiety disorder $(0=$ not present, $1=$ present $)$. In addition, the effect over time of past or current depression or anxiety disorder on immune parameters and TRP/CAA ratio was also 
investigated. Two-sided statistical significance was set at $\mathrm{p}<0.05$. Each hypothesis was corrected using the Simes' modification of the Bonferroni procedure for multiple testing (Simes, 1986). Hereafter, the notation for corrected $p$-values is: $\mathrm{p}_{\text {Simes. }}$

\section{Results}

\section{Subject characteristics and missing data}

The sample consisted of 15 patients, 4 men and 11 women. The mean age was $32.7(\mathrm{SD}=11.4)$ years. Six were cigarette smokers. Seven of 11 women used oral contraceptives. All patients, except one, received concomitant medication. Ten patients were on mesalamine medication, nine used corticosteroids, seven received azathioprine and two received methotrexate medication. Six of 15 patients received the anti-TNF- $\alpha$ infusion for the first time. Two patients fulfilled criteria for lifetime depressive disorder and two for current depressive disorder with melancholic features. Table 1 shows disease activity and assessment of behavioral and psychopathological parameters at each time point. Immune parameters and TRP/CAA at each time point are presented in Table 2. All patients completed the study. With respect to the administered questionnaires, one observation was missing. Six observations were

Table 1. Total scores of disease activity and psychopathological and behavioral assessments at each time point

\begin{tabular}{|l|c|c|c|c|}
\hline & Baseline & Week 2 & Week 4 & Week 8 \\
\hline HBI & $8.78(2.91)$ & $3.33(2.26)$ & $3.73(2.81)$ & $6.03(5.68)$ \\
\hline CDAI & $230.83(94.75)$ & NA & $102.02(66.24)$ & $144.84(105.71)$ \\
\hline MFI Physical Fatigue & $13.87(3.64)$ & $11.53(4.81)$ & $12.20(5.35)$ & $11.86(5.36)$ \\
\hline MFI Mental Fatigue & $9.40(5.62)$ & $7.20(3.10)$ & $8.27(3.94)$ & $9.04(5.29)$ \\
\hline IBDQ Bowel Symptoms & $41.87(6.00)$ & $58.13(6.28)$ & $58.80(6.10)$ & $53.18(12.05)$ \\
\hline IBDQ Systemic Symptoms & $19.13(5.36)$ & $26.67(5.11)$ & $26.73(3.97)$ & $25.44(6.63)$ \\
\hline IBDQ Emotional Status & $61.53(13.26)$ & $71.27(6.84)$ & $73.27(6.94)$ & $70.09(14.97)$ \\
\hline IBDQ Social Functioning & $24.33(6.50)$ & $29.93(3.65)$ & $30.80(3.51)$ & $28.78(7.06)$ \\
\hline HDRS & $9.47(5.58)$ & $5.87(5.85)$ & $5.27(4.15)$ & $6.94(7.55)$ \\
\hline BDI & $8.07(6.86)$ & $5.00(5.79)$ & $5.53(6.31)$ & $3.99(3.18)$ \\
\hline SCL-90 Depression & $1.91(0.71)$ & $1.68(0.64)$ & $1.55(0.32)$ & $1.41(0.32)$ \\
\hline SCL-90 Anxiety & $0.95(0.30)$ & $0.89(0.20)$ & $0.80(0.09)$ & $0.83(0.10)$ \\
\hline
\end{tabular}

The results were presented as mean $(s d)$

HBI: Harvey-Bradshaw Index, CDAI: Crohn's Disease Activity Index, MFI: Multidimensional Fatigue Inventory, IBDQ: Inflammatory Bowel Disease Questionnaire, HDRS: Hamilton Depression Rating Scale, BDI: Beck Depression Inventory, SCL-90: Symptom Checklist. 
Table 2. Immune parameters and TRP/CAA at each time point

\begin{tabular}{|c|c|c|c|c|}
\hline & Baseline & Week 2 & Week 4 & Week 8 \\
\hline Albumin (mg/dl) & $36.06(6.66)$ & $38.95(5.54)$ & $39.82(8.07)$ & $37.53(7.55)$ \\
\hline Albumin \% & $52.52(6.91)$ & $55.90(5.02)$ & $55.61(5.71)$ & $55.16(4.93)$ \\
\hline$\alpha_{1}(\mathrm{mg} / \mathrm{dl})$ & $5.72(0.94)$ & $5.37(0.99)$ & $5.45(1.20)$ & $5.16(1.21)$ \\
\hline$\alpha_{1} \%$ & $8.53(1.86)$ & $7.86(1.82)$ & $7.85(2.07)$ & $7.71(1.68)$ \\
\hline$\alpha_{2}(\mathrm{mg} / \mathrm{dl})$ & $8.86(1.07)$ & $7.71(1.08)$ & $8.15(1.40)$ & $8.04(1.39)$ \\
\hline$\alpha_{2} \%$ & $12.82(1.55)$ & $11.14(1.38)$ & $11.48(1.55)$ & $12.01(1.58)$ \\
\hline$\beta(\mathrm{mg} / \mathrm{dl})$ & $7.23(0.97)$ & $7.23(1.16)$ & $7.33(1.29)$ & $6.90(1.37)$ \\
\hline$\beta \%$ & $10.73(1.80)$ & $10.50(1.90)$ & $10.16(1.87)$ & $10.29(1.74)$ \\
\hline$\gamma(\mathrm{mg} / \mathrm{dl})$ & $10.28(3.15)$ & $10.30(2.96)$ & $10.67(2.99)$ & $10.13(2.93)$ \\
\hline$\gamma \%$ & $14.97(3.88)$ & $14.63(3.45)$ & $14.81(3.16)$ & $14.82(3.40)$ \\
\hline Total protein (mg/dl) & $68.25(6.93)$ & $69.68(7.30)$ & $71.03(11.91)$ & $67.90(11.17)$ \\
\hline Transferrin (mg/dl) & $256.79(56.63)$ & $271.28(42.34)$ & $281.29(49.33)$ & $257.75(55.58)$ \\
\hline TRP/CAA & $0.11(0.02)$ & $0.11(0.02)$ & $0.12(0.01)$ & $0.11(0.02)$ \\
\hline $\operatorname{Zinc}(\mu \mathrm{g} / \mathrm{dl})$ & $95.30(16.24)$ & $91.96(16.31)$ & $96.36(14.14)$ & $89.06(23.61)$ \\
\hline
\end{tabular}

The results were presented as mean $(s d)$

TRP/CAA: tryptophan/competing aminoacids

missing in the measurements of immune parameters $(10 \%)$. Because data were missing randomly, we used the Expectation Maximization (EM) method to impute missing data.

CDAI and HBI scores significantly decreased compared to baseline after antiTNF- $\alpha$ infusion at all time points (Table 3), and the association between these two measures over time was highly significant $(B=18.45, \mathrm{p}<0.001)$. Because of this high correlation, HBI scores were used in further analyses (Figure 1), as this was available at all four time points (CDAI being available only at three time points).

\section{Effects of anti-TNF-a on fatigue, quality of life and mood}

Administration of anti-TNF- $\alpha$ significantly increased scores on all dimensions of quality of life and reduced depression scores measured by the HDRS, BDI and SCL90 (Table 3). Anxiety, measured by the SCL-90, was significantly decreased only at one time point, namely 4 weeks after infusion. Physical and mental fatigue was decreased only at 2 weeks after infusion. Because of the impact that disease activity may have on mood, analyses were performed again corrected for HBI score (Table 4). IBDQ scores with respect to bowel symptoms, systemic symptoms and social functioning remained significantly increased with respect to baseline. In addition, 
Table 3. Effects of anti-TNF-a infusion on disease activity, fatigue, quality of life and mood compared to baseline reference value.

\begin{tabular}{|l|c|c|c|c|c|c|c|c|}
\hline & \multicolumn{2}{|c}{ Week 2 } & \multicolumn{2}{c|}{ Week 4 } & \multicolumn{2}{c|}{ Week 8 } & \multicolumn{2}{c|}{ Time (linear trend) } \\
\hline & B & $\mathbf{P}_{\text {Simes }}$ & B & P $_{\text {Simes }}$ & B & P $_{\text {Simes }}$ & B & P \\
\hline HBI & -5.57 & $<0.001$ & -5.17 & $<0.001$ & -2.87 & 0.006 & -0.77 & NS \\
\hline CDAI & NA & NA & -128.8 & $<0.001$ & -85.99 & $<0.001$ & -33.77 & $<0.001$ \\
\hline MFI physical & -2.33 & 0.027 & -1.67 & NS & -2.01 & NS & -0.53 & NS \\
\hline MFI mental & -2.20 & 0.012 & -1.13 & NS & -0.36 & NS & -0.00 & NS \\
\hline IBDQ bowel & 16.26 & $<0.001$ & 16.93 & $<0.001$ & 11.31 & $<0.001$ & 3.46 & $<0.001$ \\
\hline IBDQ systemic & 7.53 & $<0.001$ & 7.60 & $<0.001$ & 6.31 & $<0.001$ & 1.90 & $<0.001$ \\
\hline IBDQ emotional & 9.73 & 0.001 & 11.73 & $<0.001$ & 8.55 & 0.003 & 2.77 & 0.008 \\
\hline IBDQ social & 5.60 & $<0.001$ & 6.47 & $<0.001$ & 4.45 & 0.002 & 1.42 & 0.008 \\
\hline HDRS & -3.60 & 0.005 & -4.20 & 0.001 & -2.53 & NS & -0.82 & NS \\
\hline BDI & -3.07 & 0.002 & -2.53 & 0.009 & -2.81 & 0.005 & -0.81 & 0.016 \\
\hline SCL-90 Depression & -3.00 & 0.019 & -4.67 & $<0.001$ & -5.08 & $<0.001$ & -1.71 & $<0.001$ \\
\hline SCL-90 Anxiety & -0.80 & NS & -1.40 & 0.004 & -0.93 & NS & -0.34 & 0.032 \\
\hline
\end{tabular}

HBI: Harvey-Bradshaw Index, CDAI: Crohn's Disease Activity Index, MFI: Multidimensional Fatigue Inventory, IBDQ: Inflammatory Bowel Disease Questionnaire, HDRS: Hamilton Depression Rating Scale, BDI: Beck Depression Inventory, SCL-90: Symptom Checklist.

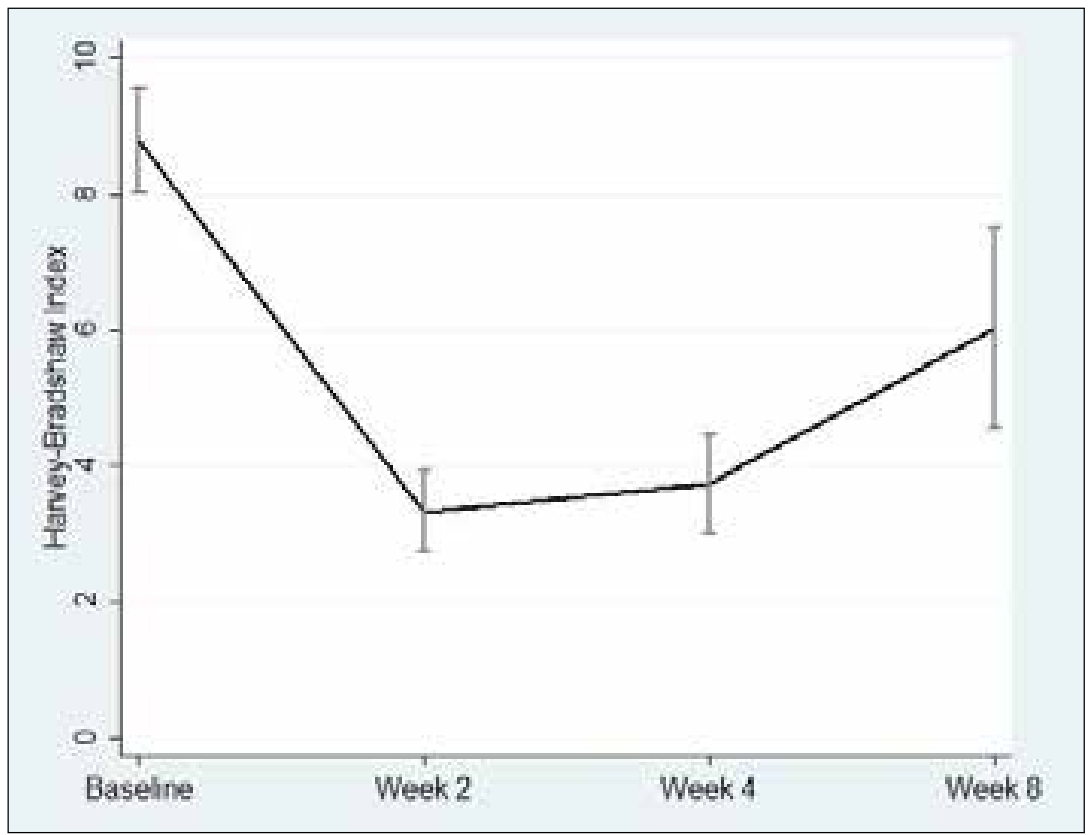

Figure 1. Overtime course of Harvey Bradshaw Index The line represents the mean score and the error bars represent the standard error at each time point. 
Table 4. Effects of anti-TNF-a on fatigue, quality of life and mood compared to baseline scores, corrected for disease activity

\begin{tabular}{|c|c|c|c|c|c|c|c|c|}
\hline & \multicolumn{2}{|c|}{ Week 2 } & \multicolumn{2}{c|}{ Week 4 } & \multicolumn{2}{c|}{ Week 8 } & \multicolumn{2}{c|}{ Time (linear trend) } \\
\hline & B & $\mathbf{P}_{\text {Simes }}$ & B & $\mathbf{P}_{\text {Simes }}$ & B & $\mathbf{P}_{\text {Simes }}$ & B & P \\
\hline MFI physical & 0.72 & NS & 1.17 & NS & -0.41 & NS & -0.17 & NS \\
\hline MFI mental & 0.81 & NS & 1.68 & NS & 1.35 & NS & 0.45 & NS \\
\hline IBDQ bowel & 9.12 & $<0.001$ & 10.28 & $<0.001$ & 7.44 & $<0.001$ & 1.85 & 0.006 \\
\hline IBDQ systemic & 3.49 & 0.012 & 3.84 & 0.004 & 4.17 & $<0.001$ & 1.14 & 0.003 \\
\hline IBDQ emotional & 3.25 & NS & 5.71 & NS & 5.19 & NS & 1.66 & NS \\
\hline IBDQ social & 3.07 & NS & 4.16 & 0.007 & 3.40 & 0.014 & 0.98 & 0.024 \\
\hline HDRS & 0.25 & NS & -0.61 & NS & -0.42 & NS & -0.22 & NS \\
\hline BDI & -1.58 & NS & -1.16 & NS & -2.07 & NS & -0.53 & NS \\
\hline SCL-90 Depression & -1.97 & NS & -3.72 & 0.016 & -4.58 & 0.001 & -1.51 & $<0.001$ \\
\hline SCL-90 Anxiety & -0.10 & NS & -0.73 & NS & -0.51 & NS & -0.21 & NS \\
\hline
\end{tabular}

MFI: Multidimensional Fatigue Inventory, IBDQ: Inflammatory Bowel Disease Questionnaire, HDRS: Hamilton Depression Rating Scale, BDI: Beck Depression Inventory, SCL-90: Symptom Checklist.

depressive symptom score measured by SCL-90 remained significantly decreased at 4 and 8 weeks after infusion, and also showed a significant reduction linear trend over time. Reductions in fatigue scores, BDI scores, HDRS scores and SCL-90 anxiety scores no longer were significant after correction for disease activity.

\section{Effects of anti-TNF- $\alpha$ on immune parameters and TRP/CAA}

Table 5 shows the changes in immune parameter and TRP/CAA ratio compared to baseline after anti-TNF- $\alpha$ infusion. Serum transferrin, albumin and the percentage of the albumin fraction were significantly increased after infusion, whereas $\alpha_{1}$ and $\alpha_{2}$ fractions and the percentages of $\alpha_{1}, \alpha_{2}$ and $\beta$ fractions were significantly decreased. There was no variation in TRP/CAA ratio compared to baseline after anti-TNF- $\alpha$ infusion. A higher HBI score was associated significantly with a lower TRP/CAA ratio $(B=-0.0009, p=0.031)$ over time. There were no significant associations between changes in immune parameters over time and the TRP/CAA ratio (results not shown).

\section{Effects of changes in TRP/CAA ratio and immune parameters over time on depressive symptoms}

As the SCL-90 depression score was most sensitive to mood changes after infusion of anti-TNF- $\alpha$ (Figure 2), the association between mood changes and immune 
Table 5. Effects of anti-TNF- $a$ infusion on immune parameters and TRP/CAA compared to baseline reference value

\begin{tabular}{|c|c|c|c|c|c|c|c|c|}
\hline & \multicolumn{2}{|c|}{ Week 2} & \multicolumn{2}{|c|}{ Week 4} & \multicolumn{2}{|c|}{ Week 8} & \multicolumn{2}{|c|}{ Time (linear trend) } \\
\hline & B & $\mathbf{P}_{\text {Simes }}$ & B & $\mathbf{P}_{\text {Simes }}$ & B & $\mathbf{P}_{\text {Simes }}$ & B & $\mathbf{P}$ \\
\hline Albumin & 2.88 & NS & 3.76 & 0.005 & 1.47 & NS & 0.53 & NS \\
\hline Albumin \% & 3.38 & $<0.001$ & 3.10 & $<0.001$ & 2.65 & $<0.001$ & 0.77 & 0.001 \\
\hline$\alpha_{1}$ & -0.35 & NS & -0.27 & NS & -0.56 & 0.009 & -0.16 & 0.019 \\
\hline $\log \alpha_{1} \%$ & -0.09 & 0.005 & -0.09 & 0.003 & -0.10 & 0.001 & -0.03 & 0.002 \\
\hline$\alpha_{2}$ & -1.15 & $<0.001$ & -0.71 & 0.004 & -0.82 & 0.001 & -0.20 & 0.034 \\
\hline $\log \alpha_{2} \%$ & -0.17 & $<0.001$ & -0.15 & $<0.001$ & -0.10 & $<0.001$ & -0.03 & 0.016 \\
\hline$\beta$ & -0.00 & NS & 0.09 & NS & -0.33 & NS & -0.09 & NS \\
\hline$\beta \%$ & -0.23 & NS & -0.57 & 0.003 & -0.44 & 0.020 & -0.17 & 0.007 \\
\hline$\gamma$ & 0.01 & NS & 0.39 & NS & -0.15 & NS & -0.01 & NS \\
\hline$\gamma \%$ & -0.34 & NS & -0.17 & NS & -0.15 & NS & -0.03 & NS \\
\hline Total protein & 1.42 & $\mathrm{NS}$ & 2.78 & NS & -0.35 & NS & 0.03 & NS \\
\hline Log transferrin & 0.07 & NS & 0.10 & 0.010 & 0.01 & NS & 0.01 & NS \\
\hline Zinc & -3.34 & NS & 2.97 & NS & -6.24 & NS & -1.28 & NS \\
\hline TRP/CAA & 0.00 & NS & 0.01 & NS & 0.00 & NS & 0.00 & NS \\
\hline
\end{tabular}

TRP/CAA: tryptophan/competing aminoacids

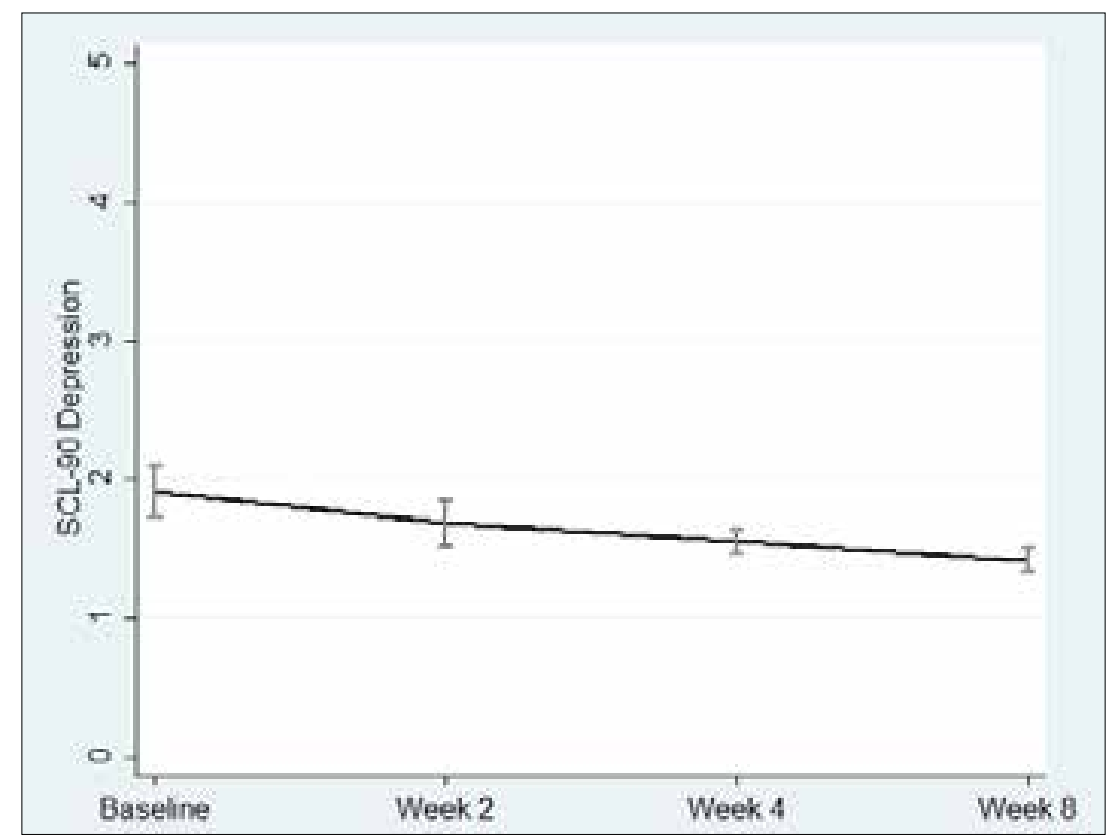

Figure 2. Overtime course of $\mathrm{SCl}-90$ Depression

The line represents the mean score and the error bars represent the standard error at each time point. 
Table 6. Association between SCL-90 depression scores and immune parameters and TRP/CAA over time.

\begin{tabular}{|c|c|c|c|c|}
\hline & \multicolumn{2}{|c|}{ SCL-90 Depression ${ }^{\mathrm{a}}$} & \multicolumn{2}{|c|}{ SCL-90 Depression ${ }^{\mathrm{b}}$} \\
\hline & B & $\mathbf{P}_{\text {Simes }}$ & B & $\mathbf{P}_{\text {Simes }}$ \\
\hline Albumin & -0.07 & NS & 0.09 & NS \\
\hline Albumin \% & -0.46 & $\mathrm{NS}$ & -0.19 & NS \\
\hline$\alpha_{1}$ & 0.11 & NS & 0.09 & NS \\
\hline $\log \alpha_{1} \%$ & -4.25 & NS & -5.82 & NS \\
\hline$\alpha_{2}$ & 1.26 & NS & 0.63 & NS \\
\hline $\log \alpha_{2} \%$ & 6.98 & NS & -2.75 & NS \\
\hline$\beta$ & 0.56 & NS & 0.98 & NS \\
\hline$\beta \%$ & -0.34 & NS & -0.45 & NS \\
\hline$\gamma$ & 0.69 & NS & 0.90 & 0.005 \\
\hline$\gamma \%$ & 1.15 & 0.001 & 1.18 & 0.001 \\
\hline Total protein & 0.07 & NS & 0.11 & NS \\
\hline Log transferrin & -9.67 & NS & -4.35 & NS \\
\hline Zinc & 0.03 & NS & 0.04 & NS \\
\hline TRP/CAA & 17.70 & NS & 48.21 & NS \\
\hline
\end{tabular}

${ }^{\mathrm{a}}$ without correction for disease activity ${ }^{\mathrm{b}}$ corrected for disease activity

SCL-90: Symptom Checklist, TRP/CAA: tryptophan/competing aminoacids

parameters was examined in more detail. Table 6 shows the association over time between SCL-90 depression scores on the one hand and immune parameters as well as TRP/CAA on the other, before and after correction for HBI scores. Overall percentage of $\gamma$ was associated with SCL-90 depression scores over time $\left(B=1.15, \mathrm{p}_{\text {Simes }}=0.001\right)$. After correction for disease activity, both level of $\gamma$ fraction and percentage of $\gamma$ were associated with SCL-90 depression scores over time $\left(B=0.90, \mathrm{p}_{\text {Simes }}=0.005\right.$ and $\left.\mathrm{B}=1.18, \mathrm{p}_{\text {Simes }}=0.001\right)$.

\section{Effects of current/ past depressive disorder on TRP/CAA ratio and immune parameters over time}

After correction for disease activity, overall levels of zinc $\left(B=-24.28, \mathrm{p}_{\text {Simes }}<\right.$ $0.001)$ albumin fraction $\left(B=-7.02, \mathrm{p}_{\text {Simes }}<0.001\right)$ and the percentage of the albumin fraction $\left(B=-7.56, p_{\text {Simes }}<0.001\right)$ were significantly lower and levels of $\alpha_{2}(B=1.15$, $\left.\mathrm{p}_{\text {Simes }}<0.001\right), \beta\left(B=0.64, \mathrm{p}_{\text {Simes }}=0.005\right)$ and $\gamma\left(B=2.02, \mathrm{p}_{\text {Simes }}=0.028\right)$ fractions and those of the percentages of $\alpha_{2}\left(B=0.18, \mathrm{p}_{\text {Simes }}<0.001\right), \beta\left(B=1.23, \mathrm{p}_{\text {Simes }}=0.002\right)$ and $\gamma\left(\mathrm{B}=3.39, \mathrm{p}_{\mathrm{Simes}}<0.001\right)$ fractions were significantly higher in subjects with a current/ past depressive disorder. Current/ past depressive disorder had no influence on overall TRP/CAA ratio. 


\section{Discussion}

To the best of our knowledge, this is the first prospective study investigating the impact of anti-TNF- $\alpha$ (infliximab) infusion on disease activity, quality of life, fatigue and depressive symptoms along with its possible relation to immune parameters and the TRP/CAA ratio in CD patients. The principal findings of this study were as follows: (i) scores of depression scales were decreased after anti-TNF- $\alpha$ infusion and this effect was to a degree, but not entirely, reducible to disease activity; (ii) there was no change in the TRP/CAA ratio after anti-TNF- $\alpha$ infusion and neither scores of depression scales, nor immune parameters were associated with TRP/CAA ratio; (iii) immune activation was higher in patients with current/past depressive disorder.

The association between the immune system and depression comes from several lines of evidence, including the induction of sickness behavior (which resembles core features of major depression in patients such as sleep disturbances, anergia and anhedonia) in animals treated with inflammatory agents, and the high comorbidity of inflammation related medical disorders - e.g. CD, rheumatoid arthritis, psoriasis and treatments with immune modulators - with psychopathology (Irwin and Miller, 2007, Dantzer et al., 2008, Miller et al., 2009) Moreover, it was shown that treatment of $\mathrm{CD}$ with anti-TNF- $\alpha$ reduces not only disease activity but also depressive symptoms (Minderhoud et al., 2007, Loftus et al., 2008, Banovic et al., 2009). The present findings, showing decrement in depressive symptom scores measured by SCL-90, BDI, and HDRS in patients with CD after anti-TNF- $\alpha$ treatment, are in agreement with these previous reports. Considering that depressive symptom scores measured by SCL-90 remained significantly decreased after correction for HBI scores compared to baseline, it is plausible that the decrease in depressive symptoms maybe mediated in part through changes in the immune system rather than only through reductions in psychological distress due to reduced disease activity. The differences between these three scales are likely related to differences in the constructs underlying the scales. (Cusin et al., 2010) The HDRS in fact taps into various symptom groups that may be associated with the nuclear depression syndrome, particularly somatic symptoms. Although the HDRS is widely used, the SCL-90 is a more unidimensional measure of the nuclear depression syndrome, whereas the BDI assesses attitudes and cognitions,

which are mostly stable overtime. Given these differences, the SCL-90 was chosen for further analysis.

In addition, it was found that decrements in depressive symptom scores after antiTNF- $\alpha$ infusion followed the reduction of inflammation as defined by an increase in negative APPs (albumin) and a decrease in positive APPs ( $\alpha_{1}$ and $\alpha_{2}$ fractions). Research suggests that an imbalance of the immune system plays a role in depression through several interacting mechanisms (Dantzer et al., 2008). There is some evidence 
that serotonin neurotransmission may play a role in the pathogenesis of depression and given the fact that TRP depletion decreases mood in vulnerable people, much attention has been focused on the degradation of TRP by the indoleamine 2,3 dioxygenase (IDO) enzyme, which is predominantly induced by IFN- $\gamma$ and TNF- $\alpha$ (Dantzer et al., 2008, Wichers and Maes, 2004). In contrast to earlier studies showing decreased TRP/ CAA ratios in patients with depression (Cowen et al., 1989, Maes et al., 1993, Maes et al., 1994, Maes et al., 1996, Maes et al., 1997) and correlations between depressive symptoms and TRP levels in IFN- $\gamma$ induced depression (Capuron et al., 2002, Capuron et al., 2003), we did not find any increase in TRP/CAA ratio over time and there was no association over time between SCL-90 depressive symptom scores and TRP/ CAA ratio after infusion of anti-TNF- $\alpha$. Considering the earlier findings showing decreased TRP/CAA ratio in IFN- $\gamma$ induced depression, the fall in TRP may explain the role of immune mediators in depression, albeit partially. It has been argued that IFN- $\gamma$ induced depression is associated with induction of IDO that increases levels of kynurenine $(\mathrm{KYN})$, which in turn leads to formation of neurotoxic metabolites, 3-hydroxykynurenine and quinolinic acid, rather than just TRP degradation by itself (Myint and Kim, 2003, Wichers and Maes, 2004, Wichers et al., 2005, Dantzer et al., 2008, Raison et al., 2010, Maes et al., 2011). Furthermore, it has been demonstrated there was no relationship between response to antidepressant treatment and TRP/CAA ratio in a large group of patients with major depression (Porter et al., 2005). In the light of these findings, it can be speculated that the reduction in depressive symptom scores in our sample is maybe associated with restoration of balance in KYN pathway rather than changes in TRP/CAA ratio.

Similar to the findings of the current study demonstrating invariant TRP/CAA ratio after treatment with anti-TNF- $\alpha$, it was shown adalimumab, which is also a TNF- $\alpha$ antagonist, exerts its immune-suppressant effect without influencing IDO activity and TRP levels in patients with rheumatoid arthritis (Kurz et al., 2011). Furthermore, the present study also failed to find an association between immune parameters and TRP/CAA ratio over time. Consequently, it may be reasoned that TNF- $\alpha$ antagonists exert effects on disease activity and depressive symptoms through several different pathways, for example nuclear factor kappa B modulation of cell survival and apoptosis, corticotrophin releasing factor, vasopressin, brain-derived neurotrophic factor (Dantzer et al., 2008, Miller et al., 2009, Soczynska et al., 2009, Kenis et al., 2011).

In the current study it was demonstrated that, even after correction for disease activity, levels and percentages of positive APPs $\left(\alpha_{2}, \beta, \gamma\right)$ were higher, while levels and percentages of albumin and levels of zinc were lower in patients with a current or past depressive episode. In other words, an inflammatory reaction was more 
evident in patients with depression, and not solely dependent on disease activity. The association between SCL-90 depression scores and $\gamma$ fraction after correction for disease activity also fortifies this notion. There are numerous studies showing that depression exacerbates CD and predicts lower remission rates in CD (Mardini et al., 2004, Mittermaier et al., 2004, Persoons et al., 2005, Camara et al., 2011). In order to clarify the additive effect of depression on immune activation and disease activity in $\mathrm{CD}$, studies comparing immune parameters between $\mathrm{CD}$ patients with and without depression are required.

In agreement with previous studies evaluating CD patients, improvement in quality of life after anti-TNF- $\alpha$ infusion was demonstrated by increases across all domains of IBDQ (van Balkom et al., 2002, Lichtenstein et al., 2002, Banovic et al., 2009). Likewise, in line with previous studies, anti-TNF- $\alpha$ infusion decreased physical and mental fatigue at week 2. Nevertheless, decreases in fatigue scores were no longer significant after correction for disease activity. Contrary to this latter finding, it has been suggested that fatigue in $\mathrm{CD}$ is secondary to depression rather than a primary manifestation of disease activity (Banovic et al., 2010).

The strength of this prospective study is that it has not only analysed the effect of anti-TNF- $\alpha$ treatment on depressive symptoms in CD patients, but also concentrated on the underlying immune mechanism by measuring TRP/CAA ratio and immune parameters with corrections for disease activity. Although the study design allowed us to use patients as their own controls over a time period of 8 weeks, the sample size was rather small which may have caused type-II errors. We carefully evaluated the presence of axis I mental disorder using the Structured Clinical Interview for DSM-IV axis I Disorders Version 5.0 in this sample. Two patients fulfilled criteria for lifetime depressive disorder and two for current depressive disorder with melancholic features. Since the presence of depressive disorder is a likely confounder, all analyses were corrected for this variable. We did not specifically collect information about patients' psychotropic treatment plan, however this likely overlaps with presence of mental disorder. Other limitations also apply. In the present study, TRP availability to the brain was estimated by the peripheral TRP/CAA ratio. Various previous studies measured brain tryptophan availability using the same TRP/CAA ratio. (Christmas et al., 2011, Wichers et al., 2005, Maes et al., 1996, Maes et al., 1993, Maes et al., 1994, Maes et al., 1997, Maes et al., 1986, Porter et al., 2005). Given that plasma TRP concentrations correlate poorly with those in cerebrospinal fluid (CSF), the TRP/CAA ratio gives us a more reliable measure of brain TRP availability taking into account the fact that CAA is competing for the cerebral uptake of TRP (Christmas et al., 2011). For a more direct approach, TRP and its metabolites would have to be measured in CSF, which might provide a better estimate (van Donkelaar et al., 2011). However, lumbar puncture in 
these patients ethically would be considered invasive, given lifetime chronic illness requiring major medical diagnostic testing and interventions over the course of the illness. As explained previously, measurement of IDO activity, along with its products and the ratio between neurotoxic and neuroprotective metabolites may allow for a more direct test of the question whether a decrease in depressive symptom scores after anti-TNF- $\alpha$ is due to changes in TRP and its metabolites, or whether several other mechanisms are involved. Another approach to understand the effect of TNF- $\alpha$ antagonists on depression may be to evaluate the effect of anti-TNF- $\alpha$ treatment on treatment response and immune markers in patients with depression. This approach may help to eliminate other potential confounders originating from the nature of autoimmune disorders like $\mathrm{CD}$ requiring use of concomitant medication influencing immune parameters. Ongoing studies evaluating the efficacy of drugs with antagonist properties at TNF- $\alpha$, namely infliximab and minocycline, for treatment of treatment resistant depression and bipolar depression along with the relationship between efficacy and inflammatory markers will hopefully shed more light on the association between TNF- $\alpha$ system and depression (Raison et al., 2012, Savitz et al., 2012).

Notwithstanding its limitations, this study does suggest that anti-TNF- $\alpha$ infusion in patients with $\mathrm{CD}$ reduces depressive symptoms, in part independently of disease activity, and that the effect on depressive symptoms is not associated with immuneinduced changes in TRP availability to the brain, as estimated indirectly by serum TRP/CAA ratio. 


\section{Author Contributions}

Conceived and designed the experiments: MW JvO MR. Performed the experiments: GK AW RV. Analyzed the data: SG MW JvO. Wrote the paper: SG JvO. Recruited the participants: MR.

\section{Funding}

Sinan Guloksuz and Jim van Os are supported by the European Community's Seventh Framework Programme under Grant agreement no. HEALTH-F2- 2009-241909 (Project EUGEI). The funders had no role in study design, data collection and analysis, decision to publish, or preparation of the manuscript.

\section{Competing Interests}

Co-author Jim van Os is a PLOS ONE Editorial Board member. The authors confirm that this does not alter their adherence to all the PLOS ONE policies on sharing data and materials. 


\section{References}

BANOVIC, I., GILIBERT, D. \& COSNES, J. 2009. Perception of improved state of health and subjective quality of life in Crohn's disease patients treated with Infliximab. Journal of Crohn's \& colitis, 3, 25-31.

BANOVIC, I., GILIBERT, D. \& COSNES, J. 2010. Crohn's disease and fatigue: constancy and covariations of activity of the disease, depression, anxiety and subjective quality of life.

Psychology, health \& medicine, 15, 394-405.

BECK, A. T. \& STEER, R. A. 1984. Internal consistencies of the original and revised Beck Depression Inventory. J Clin Psychol, 40, 1365-7.

BOSSCHER, R. J., KONING, H. \& VAN MEURS, R. 1986. Reliability and validity of the Beck Depression Inventory in a Dutch college population. Psychol Rep, 58, 696-8.

CAMARA, R. J., SCHOEPFER, A. M., PITTET, V., BEGRE, S. \& VON KANEL, R. 2011. Mood and nonmood components of perceived stress and exacerbation of Crohn's disease. Inflammatory bowel diseases, 17, 2358-65.

CAPURON, L., NEURAUTER, G., MUSSELMAN, D. L., LAWSON, D. H., NEMEROFF, C. B., FUCHS, D. \& MILLER, A. H. 2003. Interferon-alpha-induced changes in tryptophan metabolism. relationship to depression and paroxetine treatment. Biological psychiatry, 54, 906-14.

CAPURON, L., RAVAUD, A., NEVEU, P. J., MILLER, A. H., MAES, M. \& DANTZER, R. 2002. Association between decreased serum tryptophan concentrations and depressive symptoms in cancer patients undergoing cytokine therapy. Molecular psychiatry, 7, 468-73.

CHRISTMAS, D. M., POTOKAR, J. \& DAVIES, S. J. 2011. A biological pathway linking inflammation and depression: activation of indoleamine 2,3-dioxygenase. Neuropsychiatric disease and treatment, 7 , 431-9.

COWEN, P. J., PARRY-BILLINGS, M. \& NEWSHOLME, E. A. 1989. Decreased plasma tryptophan levels in major depression. Journal of affective disorders, 16, 27-31.
CUSIN, C., YANG, H., YEUNG, A. \& FAVA, M. 2010. Rating scales for depression. In: BAER, L. \& BLAIS, M. A. (eds.) Handbook of clinical rating scales and assessment in psychiatry and mental health (Current clinical psychiatry).

New York: Humana Press.

DANTZER, R., O'CONNOR, J. C., FREUND, G. G., JOHNSON, R. W. \& KELLEY, K. W. 2008. From inflammation to sickness and depression: when the immune system subjugates the brain. Nature reviews. Neuroscience, 9, 46-56.

DEROGATIS, L. R., RICKELS, K. \& ROCK, A. F. 1976. The SCL-90 and the MMPI: a step in the validation of a new self-report scale. $B r J$ Psychiatry, 128, 280-9.

HAMILTON, M. 1967. Development of a rating scale for primary depressive illness. Br J Soc Clin Psychol, 6, 278-96.

HARVEY, R. F. \& BRADSHAW, J. M. 1980. A simple index of Crohn's-disease activity. Lancet, 1, 514.

HELZER, J. E., CHAMMAS, S., NORLAND, C. C., STILLINGS, W. A. \& ALPERS, D. H. 1984. A study of the association between Crohn's disease and psychiatric illness. Gastroenterology, 86, 324-30.

IRWIN, M. R. \& MILLER, A. H. 2007. Depressive disorders and immunity: 20 years of progress and discovery. Brain Behav Immun, 21, 37483.

KENIS, G., PRICKAERTS, J., VAN OS, J., KOEK, G. H., ROBAEYS, G., STEINBUSCH, H. W. \& WICHERS, M. 2011. Depressive symptoms following interferon-alpha therapy: mediated by immune-induced reductions in brainderived neurotrophic factor? The international journal of neuropsychopharmacology / official scientific journal of the Collegium Internationale Neuropsychopharmacologicum, 14, 247-53.

KURINA, L. M., GOLDACRE, M. J., YEATES, D. \& GILL, L. E. 2001. Depression and anxiety in people with inflammatory bowel disease. $J$ Epidemiol Community Health, 55, 716-20.

KURZ, K., HEROLD, M., WINKLER, C., KLOTZ, W., RUSSE, E. \& FUCHS, D. 2011. Effects 
of adalimumab therapy on disease activity and interferon-gamma-mediated biochemical pathways in patients with rheumatoid arthritis. Autoimmunity, 44, 235-42.

LEONARD, B. \& MAES, M. 2012. Mechanistic explanations how cell-mediated immune activation, inflammation and oxidative and nitrosative stress pathways and their sequels and concomitants play a role in the pathophysiology of unipolar depression. Neuroscience and biobehavioral reviews, 36, 764-85.

LEONARD, B. E. 2001. The immune system, depression and the action of antidepressants. Prog Neuropsychopharmacol Biol Psychiatry, 25, 767-80.

LICHTENSTEIN, G. R., BALA, M., HAN, C., DEWOODY, K. \& SCHAIBLE, T. 2002. Infliximab improves quality of life in patients with Crohn's disease. Inflammatory bowel diseases, 8, 237-43.

LICINIO, J. \& WONG, M. L. 1999. The role of inflammatory mediators in the biology of major depression: central nervous system cytokines modulate the biological substrate of depressive symptoms, regulate stress-responsive systems, and contribute to neurotoxicity and neuroprotection. Mol Psychiatry, 4, 317-27.

LOFTUS, E. V., FEAGAN, B. G., COLOMBEL, J. F., RUBIN, D. T., WU, E. Q., YU, A. P., POLLACK, P. F., CHAO, J. \& MULANI, P. 2008. Effects of adalimumab maintenance therapy on health-related quality of life of patients with Crohn's disease: patient-reported outcomes of the CHARM trial. The American journal of gastroenterology, 103, 3132-41.

MAES, M., DE RUYTER, M., HOBIN, P. \& SUY, E. 1986. The diagnostic performance of the L-tryptophan/competing amino acids ratio in major depression. Acta psychiatrica Belgica, $86,257-65$.

MAES, M., DE VOS, N., DEMEDTS, P., WAUTERS, A. \& NEELS, H. 1999. Lower serum zinc in major depression in relation to changes in serum acute phase proteins. Journal of affective disorders, 56, 189-94.

MAES, M., LEONARD, B. E., MYINT, A. M., KUBERA, M. \& VERKERK, R. 2011. The new '5-HT' hypothesis of depression: cell-mediated immune activation induces indoleamine 2,3-dioxygenase, which leads to lower plasma tryptophan and an increased synthesis of detrimental tryptophan catabolites (TRYCATs), both of which contribute to the onset of depression. Progress in neuropsychopharmacology \& biological psychiatry, 35, 702-21.

MAES, M., MELTZER, H. Y., SCHARPE, S., BOSMANS, E., SUY, E., DE MEESTER, I., CALABRESE, J. \& COSYNS, P. 1993. Relationships between lower plasma L-tryptophan levels and immune-inflammatory variables in depression. Psychiatry research, 49, 151-65.

MAES, M., SCHARPE, S., MELTZER, H. Y., OKAYLI, G., BOSMANS, E., D'HONDT, P., VANDEN BOSSCHE, B. V. \& COSYNS, P. 1994. Increased neopterin and interferongamma secretion and lower availability of L-tryptophan in major depression: further evidence for an immune response. Psychiatry research, 54, 143-60.

MAES, M., VERKERK, R., VANDOOLAEGHE, E., VAN HUNSEL, F., NEELS, H., WAUTERS, A., DEMEDTS, P. \& SCHARPE, S. 1997. Serotonin-immune interactions in major depression: lower serum tryptophan as a marker of an immune-inflammatory response. European archives of psychiatry and clinical neuroscience, 247, 154-61.

MAES, M., WAUTERS, A., NEELS, H., SCHARPE, S., VAN GASTEL, A., D'HONDT, P., PEETERS, D., COSYNS, P. \& DESNYDER, R. 1995. Total serum protein and serum protein fractions in depression: relationships to depressive symptoms and glucocorticoid activity. J Affect Disord, 34, 61-9.

MAES, M., WAUTERS, A., VERKERK, R., DEMEDTS, P., NEELS, H., VAN GASTEL, A., COSYNS, P., SCHARPE, S. \& DESNYDER, R. 1996. Lower serum L-tryptophan availability in depression as a marker of a more generalized disorder in protein metabolism. Neuropsychopharmacology : official publication of the American College of Neuropsychopharmacology, 15, 243-51.

MARDINI, H. E., KIP, K. E. \& WILSON, J. W. 
2004. Crohn's disease: a two-year prospective study of the association between psychological distress and disease activity. Digestive diseases and sciences, 49, 492-7.

MILLER, A. H., MALETIC, V. \& RAISON, C. L. 2009. Inflammation and its discontents: the role of cytokines in the pathophysiology of major depression. Biological psychiatry, 65, 732-41.

MINDERHOUD, I. M., SAMSOM, M. \& OLDENBURG, B. 2007. Crohn's disease, fatigue, and infliximab: is there a role for cytokines in the pathogenesis of fatigue? World journal of gastroenterology : WJG, 13, 2089-93.

MITTERMAIER, C., DEJACO, C., WALDHOER, T., OEFFERLBAUER-ERNST, A., MIEHSLER, W., BEIER, M., TILLINGER, W., GANGL, A. \& MOSER, G. 2004. Impact of depressive mood on relapse in patients with inflammatory bowel disease: a prospective 18-month follow-up study. Psychosomatic medicine, 66, 79-84.

MYINT, A. M. \& KIM, Y. K. 2003. Cytokineserotonin interaction through IDO: a neurodegeneration hypothesis of depression. Medical hypotheses, 61, 519-25.

NORTH, C. S., ALPERS, D. H., HELZER, J. E., SPITZNAGEL, E. L. \& CLOUSE, R. E. 1991. Do life events or depression exacerbate inflammatory bowel disease? A prospective study. Ann Intern Med, 114, 381-6.

PAPADAKIS, K. A. \& TARGAN, S. R. 2000. Role of cytokines in the pathogenesis of inflammatory bowel disease. Annu Rev Med, 51, 289-98.

PERSOONS, P., VERMEIRE, S., DEMYTTENAERE, K., FISCHLER, B., VANDENBERGHE, J., VAN OUDENHOVE, L., PIERIK, M., HLAVATY, T., VAN ASSCHE, G., NOMAN, M. \& RUTGEERTS, P. 2005. The impact of major depressive disorder on the short- and long-term outcome of Crohn's disease treatment with infliximab. Alimentary pharmacology \& therapeutics, 22, 101-10.

PLEVY, S. E., LANDERS, C. J., PREHN, J., CARRAMANZANA, N. M., DEEM, R. L., SHEALY, D. \& TARGAN, S. R. 1997. A role for TNF-alpha and mucosal T helper-1 cytokines in the pathogenesis of Crohn's disease. J Immunol, 159, 6276-82.

PORTER, R. J., MULDER, R. T., JOYCE, P. R. \& LUTY, S. E. 2005. Tryptophan and tyrosine availability and response to antidepressant treatment in major depression. Journal of affective disorders, 86, 129-34.

RAISON, C. L., DANTZER, R., KELLEY, K. W., LAWSON, M. A., WOOLWINE, B. J., VOGT, G., SPIVEY, J. R., SAITO, K. \& MILLER, A. H. 2010. CSF concentrations of brain tryptophan and kynurenines during immune stimulation with IFN-alpha: relationship to CNS immune responses and depression. Molecular psychiatry, 15, 393-403.

RAISON, C. L., RUTHERFORD, R. E., WOOLWINE, B. J., SHUO, C., SCHETTLER, P., DRAKE, D. F., HAROON, E. \& MILLER, A. H. 2012. A Randomized Controlled Trial of the Tumor Necrosis Factor Antagonist Infliximab for Treatment-Resistant Depression: The Role of Baseline Inflammatory Biomarkers. Archives of general psychiatry, $1-11$.

ROBERTSON, D. A., RAY, J., DIAMOND, I. \& EDWARDS, J. G. 1989. Personality profile and affective state of patients with inflammatory bowel disease. Gut, 30, 623-6.

RUSSEL, M. G., PASTOOR, C. J., BRANDON, S., RIJKEN, J., ENGELS, L. G., VAN DER HEIJDE, D. M. \& STOCKBRUGGER, R. W. 1997. Validation of the Dutch translation of the Inflammatory Bowel Disease Questionnaire (IBDQ): a health-related quality of life questionnaire in inflammatory bowel disease. Digestion, 58, 282-8.

SAVITZ, J., PRESKORN, S., TEAGUE, T. K., DREVETS, D., YATES, W. \& DREVETS, W. 2012. Minocycline and aspirin in the treatment of bipolar depression: a protocol for a proof-ofconcept, randomised, double-blind, placebocontrolled, 2x2 clinical trial. BMJ open, 2, e000643.

SIMES, R. J. 1986. An improved Bonferroni procedure for multiple tests of significance. Biometrika, 73, 751-754.

SLUZEWSKA, A., RYBAKOWSKI, J., BOSMANS, E., SOBIESKA, M., BERGHMANS, R., MAES, M. \& WIKTOROWICZ, K. 1996. Indicators of 
immune activation in major depression.

Psychiatry Res, 64, 161-7.

SMETS, E. M., GARSSEN, B., BONKE, B. \& DE HAES, J. C. 1995. The Multidimensional Fatigue Inventory (MFI) psychometric qualities of an instrument to assess fatigue. J Psychosom Res, 39, 315-25.

SOCZYNSKA, J. K., KENNEDY, S. H., GOLDSTEIN, B. I., LACHOWSKI, A., WOLDEYOHANNES, H. O. \& MCINTYRE, R. S. 2009. The effect of tumor necrosis factor antagonists on mood and mental healthassociated quality of life: novel hypothesisdriven treatments for bipolar depression? Neurotoxicology, 30, 497-521.

SONG, C., DINAN, T. \& LEONARD, B. E. 1994. Changes in immunoglobulin, complement and acute phase protein levels in the depressed patients and normal controls. J Affect Disord, 30, 283-8.

STROBER, W., ZHANG, F., KITANI, A., FUSS, I. \& FICHTNER-FEIGL, S. 2010. Proinflammatory cytokines underlying the inflammation of Crohn's disease. Current opinion in gastroenterology, 26, 310-7.

VAN BALKOM, B. P., SCHOON, E. J., STOCKBRUGGER, R. W., WOLTERS, F. L., VAN HOGEZAND, R. A., VAN DEVENTER, S. J., OLDENBURG, B., VAN DULLEMEN, H. M. \& RUSSEL, M. G. 2002. Effects of antitumour necrosis factor-alpha therapy on the quality of life in Crohn's disease. Alimentary pharmacology \& therapeutics, 16, 1101-7.

VAN DONKELAAR, E. L., BLOKLAND, A., FERRINGTON, L., KELLY, P. A., STEINBUSCH, H. W. \& PRICKAERTS, J. 2011. Mechanism of acute tryptophan depletion: is it only serotonin? Molecular psychiatry, 16, 695-713.

VAN GOOL, A. R., KRUIT, W. H., ENGELS, F. K., STOTER, G., BANNINK, M. \& EGGERMONT, A. M. 2003. Neuropsychiatric side effects of interferon-alfa therapy. Pharm World Sci, 25, 11-20.

VAN HUNSEL, F., WAUTERS, A., VANDOOLAEGHE, E., NEELS, H., DEMEDTS, P. \& MAES, M. 1996. Lower total serum protein, albumin, and beta- and gamma-globulin in major and treatment- resistant depression: effects of antidepressant treatments. Psychiatry research, 65, 159-69.

WICHERS, M. C., KOEK, G. H., ROBAEYS, G., VERKERK, R., SCHARPE, S. \& MAES, M. 2005. IDO and interferon-alpha-induced depressive symptoms: a shift in hypothesis from tryptophan depletion to neurotoxicity. Molecular psychiatry, 10, 538-44.

WICHERS, M. C. \& MAES, M. 2004. The role of indoleamine 2,3-dioxygenase (IDO) in the pathophysiology of interferon-alphainduced depression. Journal of psychiatry \& neuroscience : JPN, 29, 11-7.

YOSHIDA, E. M. 1999. The Crohn's Disease Activity Index, its derivatives and the Inflammatory Bowel Disease Questionnaire: a review of instruments to assess Crohn's disease. Can J Gastroenterol, 13, 65-73. 


\section{The immune system and electroconvulsive therapy for depression}

Sinan Guloksuz, Bart P.F. Rutten, Baer Arts, Jim van Os, Gunter Kenis

Journal of ECT (2014): 30(2):132-7. 

Abstract

\section{Background}

Electroconvulsive therapy (ECT) remains the most effective and fast-acting treatment option for several psychiatric conditions, including treatment-resistant depression. Although ECT has been in use for 75 years, the mechanism of action is unknown, although there is emerging evidence that modulation of the hypothalamic-pituitary adrenal axis may mediate, in part, the therapeutic action of ECT. A growing body of evidence points to links between disturbances in the immune system and depression. However, the impact of ECT on immune functioning and the possible role of alterations in the immune system as a mechanism of action of ECT remain elusive.

\section{Objectives}

To provide a literature overview on the effects of ECT on the immune system.

\section{Methods}

Relevant articles and abstracts in English were retrieved from PubMed/Medline using search terms related to ECT, inflammation and immune system. The results of studies examining ECT-induced changes in immune functioning, and the degree to which these represent possible mechanisms mediating the therapeutic action of ECT were summarized.

\section{Results}

Our search identified only a limited number of studies. The findings suggest that a single session of ECT induces an acute, transient immune activation, whereas repetitive ECT treatment results in long-term down-regulation of immune activation. However, inconsistency in findings and methodological issues, including sample size and lack of consideration of confounding factors impacting cytokine concentrations, preclude definitive conclusion.

\section{Conclusions}

In order to elucidate the possible role of immunological changes mediating the effect of $\mathrm{ECT}$, more prospective controlled studies with larger sample sizes are required.

Keywords: ECT, Depression, Mechanism, Inflammation, Cytokine, Immunology 


\section{Introduction}

Electroconvulsive therapy (ECT) remains the most effective treatment option for several psychiatric conditions, and is mainly used in treatment-resistant depression (The UK ECT Review Group, 2003). The mechanism of action of ECT remains unknown. A complex network of effects on different neurotransmitter, neurohormone and neurotrophic systems may play a role (Sienaert and McCall, 2014, Lanzenberger, 2014, TBD, 2014, Boutros and Fink, 2014, Bolwig, 2014). Numerous studies show that the release of hormones that are associated with the hypothalamic-pituitary-adrenal (HPA) axis, e.g. prolactin, adrenocorticotropin, arginine vasopressin, growth hormone and neuropeptide $\mathrm{Y}$ are altered by ECT (Bolwig, 2011, TBD, 2014). The HPA-axis, thus, is one of the most extensively studied pathways underlying ECT. Although the findings of these studies are not always consistent, the majority reports normalization of HPA-axis deregulation, as measured by the dexamethasone suppression test, after successful ECT treatment, supporting the role of the HPA-axis in mediating the therapeutic effects of ECT (Bolwig, 2011, Fink, 2005).

An intriguing factor that has received relatively little attention in the search for the biological mechanism of ECT is the immune system. A growing body of evidence shows that disturbances in certain aspects of the immune system are involved in the pathogenesis of depression (Gibney and Drexhage, 2013, Raison et al., 2006). In addition, antidepressants have immunomodulating properties, and, vice versa, interventions that restore normal immune functioning can have antidepressant effects. It is therefore plausible to consider a role of immune pathways in the mechanism of action of ECT. In this review, we first provide a brief summary on the immune-related pathways that are proposed to underlie the pathogenesis of depression, and discuss the impact of ECT on the immune system in relation to its mechanism of action.

\section{Depression and the immune system}

About three decades ago, evidence accumulated that major depression was accompanied by signs of mild immunosuppression, mainly in the form of lower proliferative responses of lymphocytes and reduced activity of Natural Killer (NK) cells (Zorrilla et al., 2001). However, when knowledge on regulation of immune functioning increased, it became clear that depressed patients had increased levels of inflammatory mediators and activated immune cells. In the early 1990s, Robert Smith first coined the macrophage theory of depression, based on an extensive synthesis of the available literature at the time, stating that a heightened activity of the innate immune system was causally related to major depression (Smith, 1991). Today, the notion that the pro-inflammatory state in depressed patients contributes to etiology, pathogenesis and course of the disease is widely researched, on the 
basis of several lines of evidence: 1) large-scale epidemiological studies and metaanalyses have consistently found increased levels of pro-inflammatory mediators, in particular C-Reactive Protein (CRP) (Wium-Andersen et al., 2013, Howren et al., 2009), Interleukin-6 (IL-6) (Howren et al., 2009, Dowlati et al., 2010), IL-1 (Howren et al., 2009) and Tumor Necrosis Factor-a (TNF-a) (Dowlati et al., 2010) in depressed patients; 2) therapies using pro-inflammatory cytokines, i.e. Interferon-a (IFN-a) for Hepatitis-C infection, evoke depressive symptoms and clinical depression in a sizeable number of patients (Wichers et al., 2007, Kenis et al., 2011), 3) mood disorders have a high rate of co-morbidity with somatic diseases associated with chronic inflammation, e.g. diabetes mellitus, cardiovascular illness, and autoimmune diseases such as Crohn's disease and rheumatoid arthritis (Gibney and Drexhage, 2013). In addition, prolonged psychological stress, a well-established risk factor for depression, has been associated with a shift toward a pro-inflammatory state (Raison et al., 2006, Gibney and Drexhage, 2013). There is also some evidence that polymorphisms in immune genes are associated with major depression (Bufalino et al., 2013). To what degree these genetic factors, possibly in interaction with adverse environmental exposures such as chronic stress, represent true vulnerability for depression remains to be determined.

Several mechanistic pathways of how peripheral inflammation impacts on the neurobiological circuits of affect regulation have been described (Gibney and Drexhage, 2013, Miller et al., 2009, Haroon et al., 2012). For example, proinflammatory cytokines increase the catabolism of tryptophan through the kynurenine pathway, leading to decreased availability of tryptophan (the precursor for serotonin synthesis) and to accumulation of neurotoxic metabolites, i.e. 3-hydroxykynurenine and quinolinic acid, in the brain (Myint, 2012). In addition, pro-inflammatory cytokines stimulate the HPA-axis and impair glucocorticoid receptor function, resulting in HPAaxis deregulation and prolonged increases in circulating stress hormones (Zunszain et al., 2011), further contributing to a neurotoxic environment in the central nervous system. This neurotoxic challenge disturbs neurotransmitter homeostasis, neuronal growth factor synthesis and finally perturbs the normal functioning of the neuronal circuits of the limbic system (Miller et al., 2013).

If inflammatory processes indeed are causally related to major depression, it is tempting to speculate that antidepressants have anti-inflammatory properties or that successful alleviation of symptoms during therapy would be associated with decreases in immune activation. Immune-modulating effects of antidepressants have been described (Kenis and Maes, 2002, De Berardis et al., 2010). Recent meta-analyses indicated that treatment with antidepressants reduces the levels of pro-inflammatory cytokines (Hannestad et al., 2011, Hiles et al., 2012) and CRP (Hiles et al., 2012). It 
remains inconclusive however whether these reductions are associated with clinical improvement; it has been suggested that heterogeneity in findings may be due in part to differential effects of various types of antidepressants on circulating cytokine levels (Vogelzangs et al., 2012). Another factor impacting on heterogeneity may be that patients displaying chronic inflammation represent a depression subgroup with special clinical characteristics (Raison and Miller, 2013). For example, it has been suggested that patients with increased inflammation markers respond more poorly to antidepressants and have a more chronic course of the disease (Vogelzangs et al., 2014, Cattaneo et al., 2013), which is in agreement with recent findings that antiinflammatory interventions alleviate depressive symptoms in this subset of patients (Guloksuz et al., 2013, Raison et al., 2012).

Taken together, the findings indicate a possible role for chronic inflammation in depression, which may influence the success of antidepressant therapy, including ECT. We will therefore review studies that examined the effects of ECT on immune functioning.

\section{The impact of ECT on the immune system}

The characteristics of clinical studies investigating the impact of ECT on immune parameters are summarized in Table 1 . These studies concentrated on both the acute immunological effects after a single ECT session, and effects after repeated ECT sessions (reaching sufficient clinical improvement to discontinue ECT) on different immune parameters. The main immune parameters reported were measures of cellular immune function (lymphocyte subpopulations and NK cell activity) and levels of circulating cytokines.

\section{Acute effects of electroconvulsive seizure}

Several studies focusing on the acute effect of ECT on NK cell activity indicate an increment in NK cell activity within minutes after ECT administration (Fischler et al., 1992, Albrecht et al., 1985, Kronfol et al., 2002). IL-6 activity was increased after a single session of ECT (Kronfol et al., 1990). Fluitman et al., likewise demonstrated that a single session of ECT was associated with increased production of IL-6, IL-10 and TNF- $\alpha$ by monocytes after lipopolysaccharide (LPS) stimulation, and decreased production of IFN- $\gamma$ by T cells after CD2/CD28 stimulation (Fluitman et al., 2011). After the correction of the cytokine response by number of producing cells, changes in IL-6 and IFN- $\gamma$ still remained statistically significant (Fluitman et al., 2011). Additionally, acute increase in the total number of leukocytes, monocytes, granulocytes and NK cells, returning to baseline levels 30 minutes after the stimulus, were also demonstrated in this study (Fluitman et al., 2011). After a single session 


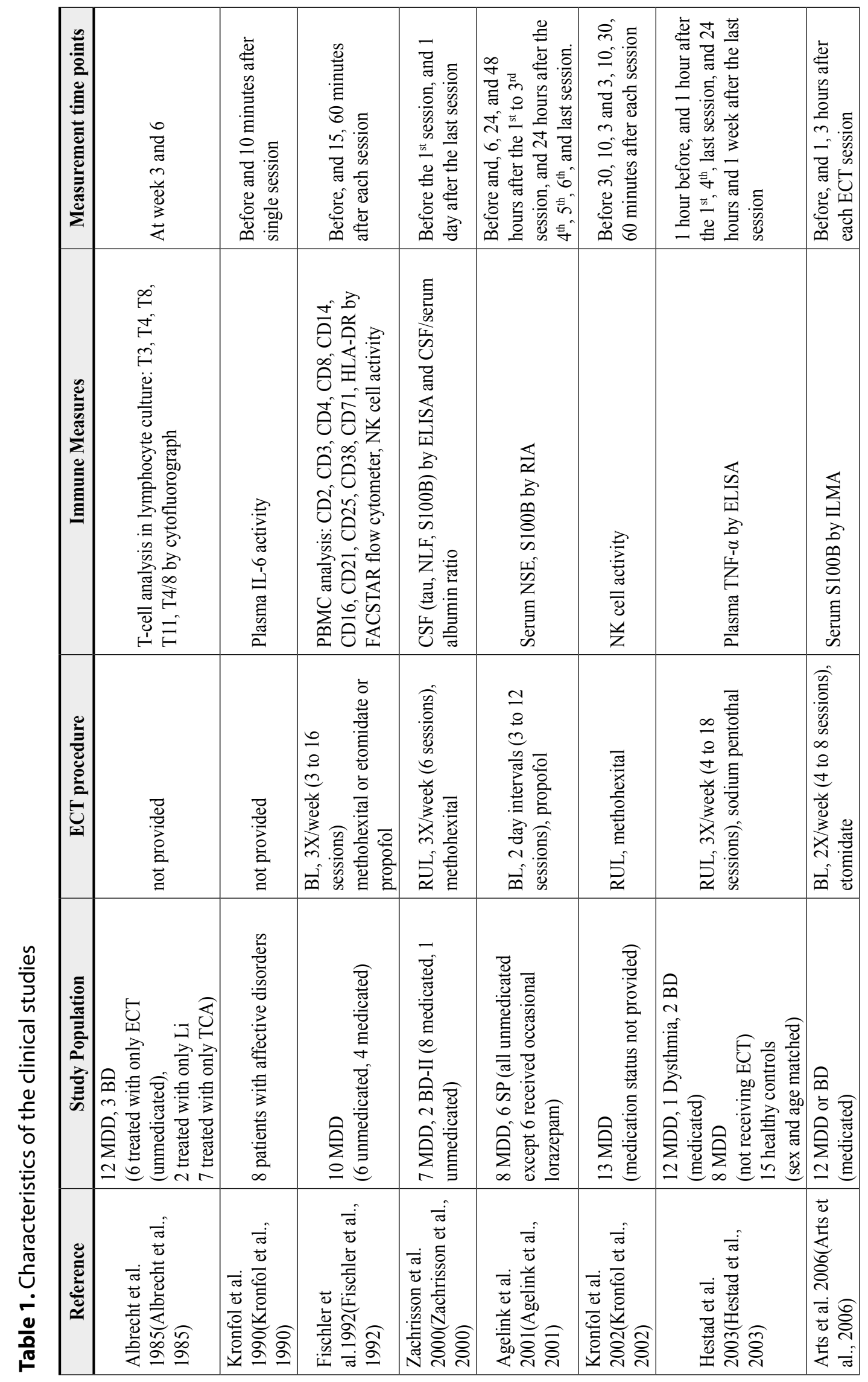




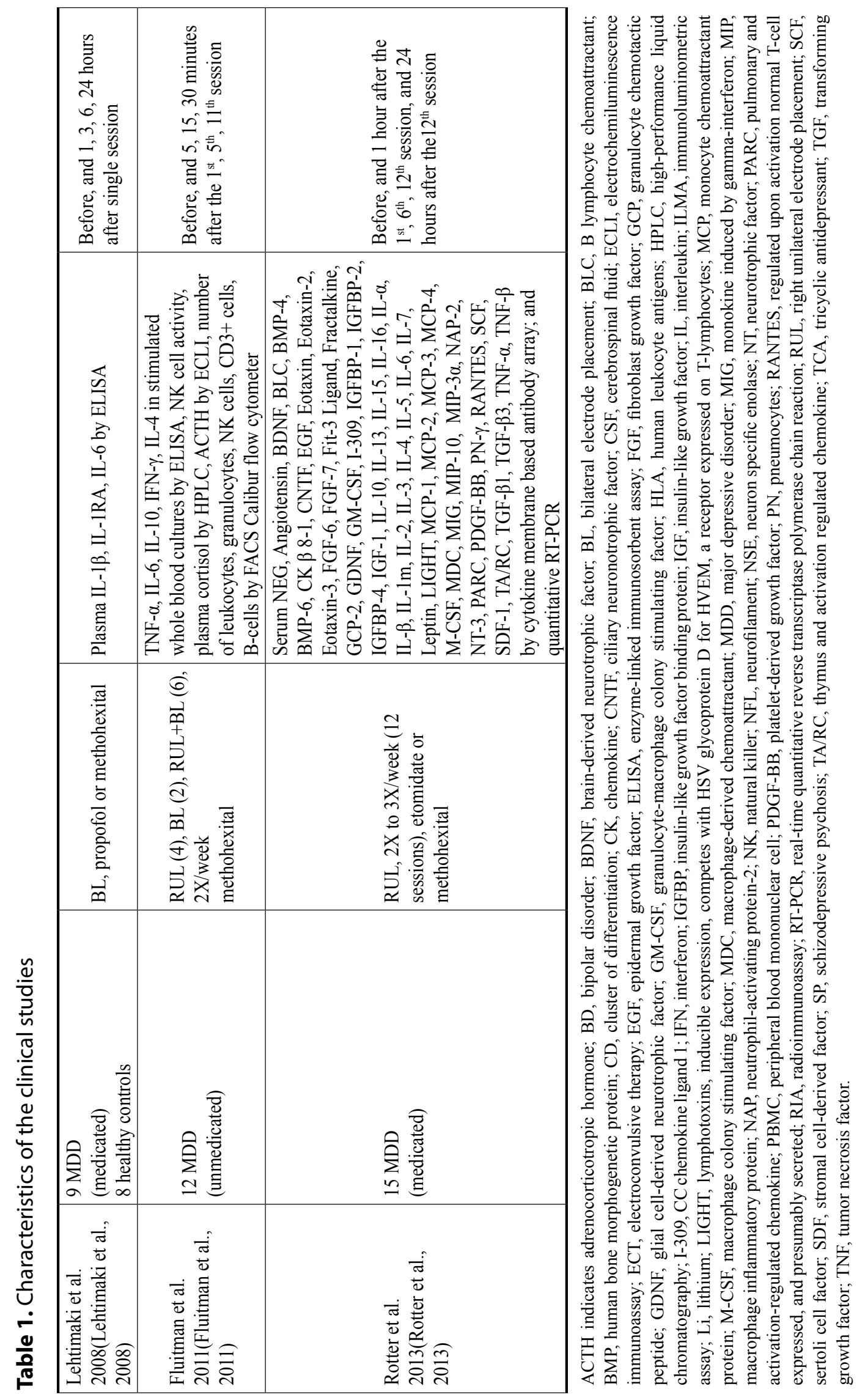


of ECT, plasma IL-1 $\beta$ and IL-6 concentrations increased over the following 3-hour time point, returning to baseline concentrations in 24 hours (Lehtimaki et al., 2008). Other studies have focused on markers of glial activity, i.e. S100B, in association with ECT induced cognitive impairment. S100B, a calcium-binding protein expressed by astrocytes and oligodendrocytes, has various functions in neuronal survival and apoptosis, and may be elevated in cerebrospinal fluid (CSF) and serum of patients with depression (Schroeter et al., 2013). ECT has been associated with an increase in serum S100B concentrations 1- and 3-hours after the ECT session (Arts et al., 2006), while another study found no change in S100B after ECT (Agelink et al., 2001).

\section{Long-term effects of ECT}

In addition to these studies investigating short-term effects of a single ECT session on the immune system, several studies focused on long-term effects after the end of the ECT treatment. In one of the earliest clinical trials, repetitive ECT sessions reduced both phytohemagglutinin, and concanavalin-A induced lymphocyte blastogenesis (Albrecht et al., 1985). Another study demonstrated that ECT resulted in immune system activation evidenced by enhancement in the number of lymphocytes expressing activation antigens (CD25 and CD38) after completion of treatment (Fischler et al., 1992). While ECT increases NK cell activity acutely, repeated ECT treatments did not show substantial changes in NK cell activity after completion of the ECT treatment (Fischler et al., 1992, Fluitman et al., 2011, Kronfol et al., 2002). Hestad et al. showed that depression-related increases in TNF- $\alpha$ concentrations before administration of ECT decreased during the ECT treatment period and reached a level comparable to that in healthy controls at the end of the study, whereas TNF- $\alpha$ concentrations during the study period remained stable in patients who received only drug treatment (Hestad et al., 2003). A recent study measuring an extensive array of cytokines by cytokine membrane techniques showed a decrease in the signal intensities of IL-5 and eotaxin-3, which are both pro-inflammatory cytokines involved in chronic inflammatory diseases such as asthma, 24 hours after the completion of a 12-session ECT treatment (Rotter et al., 2013). Although decreased eotaxin-2 and TNF- $\beta$ were also observed, these changes failed to reach statistical significance. Furthermore, in the same study, reverse transcription polymerase chain reaction method revealed an increase in TNF- $\beta$ (Rotter et al., 2013). Fluitman et al. demonstrated that ECT had an acute effect on immune parameters (TNF- $\alpha$, IL-6, IL-10, IFN- $\gamma$, IL-4, and total number of immune cells), whereas repeated ECT (11 sessions) did not have an additive effect on these changes (Fluitman et al., 2011). Several studies show that serum and CSF S100B concentrations are not influenced by ECT (Zachrisson et al., 2000, Agelink et al., 2001, Arts et al., 2006). Higher baseline S100B concentration 
was associated with poorer working memory performance after ECT, but also with less subjective cognitive impairment and less depression at follow-up (Arts et al., 2006). The authors argued that the negative association between baseline S100B concentrations and working memory performance further implicates possible frontal lobe involvement in the cognitive effects of ECT. There is no alteration in S100B expression after chronic electroconvulsive shock (ECS) administration in mice (Jinno and Kosaka, 2008). Other animal studies have provided further evidence that repeated ECS for 10 consecutive days in normal rats may down-regulate the immune system with attenuation of nitric oxide synthesis by the peritoneal macrophages assessed 24 hours after the last session (Roman et al., 2008, Roman and Nalepa, 2005).

\section{Conclusions and future work}

Taken together, only a limited number of studies have addressed functioning of the immune system in relation to ECT for depression. These studies mainly focused on peripheral markers of the immune system in humans, and their findings suggest that ECT induces a transient immune activation immediately after a single ECT session, whereas repeated ECT may down-regulate immune activation. However, it is difficult to reach firm conclusions owing to inconsistencies in the scarce data available on this topic. Moreover, the findings cannot be taken as evidence for a role of immune-moderation in the mechanism of action of ECT in the treatment of depression, since none of the studies provide evidence for criteria associated with causality, with the possible exception of temporal order. Additionally, several methodological issues should be considered when interpreting these findings. First, the most common limitation of these human studies is the small sample size, with risk of a type-II statistical error especially when measuring multiple immune markers. Second, small sample size also limits further post-hoc analyses, and, more importantly, hinders the consideration of potential confounding factors such as age, sex, concomitant medication and body mass index (BMI), all of which may influence immune markers (Haack et al., 1999). For example, with the exception of one study, all of the human studies consisted of patients who were on psychotropic medications. As explained before, nearly all psychotropic medications, especially antidepressants, have an effect on immune markers and it has been argued that down-regulation of an activated immune system in depression following treatment with psychotropics may play a therapeutic role (Kenis and Maes, 2002). Therefore, distinguishing the impact of ECT from that of psychotropics on immune markers is fundamental in order to elucidate possible ECT-regulated immune pathways. Although it is impossible to extract the net effect of ECT from the current studies, it is reasonable to speculate that changes in immune parameters are likely due to the ECT, as the majority of patients 
were on stable medication for extensive periods. In this regard, it should be noted that ECT is usually administered to patients that are refractory to antidepressants; the group of patients particularly displaying chronic inflammation (Vogelzangs et al., 2014, Cattaneo et al., 2013). Additionally, differentiating the immunological changes in responders and non-responders may also be informative. Finally, some factors inherent to the ECT procedure may also hamper a clear interpretation of the studies, i.e. electrode placement, stimulus intensity and frequency and seizure duration (which all may have different effects on the immune system), and the use of anesthetics, which is known to influence immune markers, although recent evidence is scarce (Wang et al., 2011, Mitchell et al., 1990).

While some of these limitations can and should be considered in the design of future studies, such as sample size and confounding factors (age, sex, BMI), some of them, e.g. concurrent medication use and anesthesia, are quite difficult or even impossible to eliminate. Here, animal studies investigating the effects of ECS on the immune system can be quite useful to understand the differential effects. To date, however, the effects of ECS on immune functioning have only been studied in healthy animals. Animal models of treatment resistant depression may provide a better basis to understand the working mechanism of ECT, especially when they also display an altered immune status.

The literature search revealed ECT-induced cognitive impairment in association with possible immunological pathways, which have not been investigated thoroughly, with the exception of S100B. Growing evidence suggests immune-mediated pathological pathways underlie the cognitive impairment related to numerous neuropsychiatric diseases such as Alzheimer's disease. Furthermore, cytokines such as IL-1 $\beta$, IL- 6 and TNF- $\alpha$ have been associated with cognitive decline and dementia in both cross-sectional and prospective population studies (McAfoose and Baune, 2009). Given the transient effects of ECT on cognition, particularly memory, it would be intriguing to investigate whether ECT-induced cognitive problems are related to immune changes (McClintock, 2014).

In conclusion, substantial evidence implicates a role for a disturbed immune system in depression. While the current data also indicate that ECT evokes differential immune responses, inconsistencies in published studies and lack of replication prevent us from making a solid statement on the role of the immune system in the mechanism of action of ECT. In order to further elucidate this topic, more prospective studies investigating a broad set of immune markers in large samples, achieving sufficient statistical power allowing to control for confounders and to perform post-hoc analyses, are required. Additionally, research should be carried out in order to elucidate the association between immune dysregulation and ECT-induced cognitive impairment, which may lead to a better understanding of the mechanism of action of ECT. 


\section{Acknowledgement}

Sinan Guloksuz, Bart P.F. Rutten, and Jim van Os are supported by the European Community's Seventh Framework Programme under Grant agreement no. HEALTH-F2-2009-241909 (Project EU-GEI). The remaining authors have no conflicts of interest or financial disclosures to report.

$\bullet$ 


\section{References}

AGELINK, M. W., ANDRICH, J., POSTERT, T., WURZINGER, U., ZEIT, T., KLOTZ, P. \& PRZUNTEK, H. 2001. Relation between electroconvulsive therapy, cognitive side effects, neuron specific enolase, and protein S-100. J Neurol Neurosurg Psychiatry, 71, 394-6.

ALBRECHT, J., HELDERMAN, J. H., SCHLESSER, M. A. \& RUSH, A. J. 1985. A controlled study of cellular immune function in affective disorders before and during somatic therapy. Psychiatry Res, 15, 185-93.

ARTS, B., PETERS, M., PONDS, R., HONIG, A., MENHEERE, P. \& VAN OS, J. 2006. S100 and impact of ECT on depression and cognition. $J$ $E C T, 22,206-12$.

BOLWIG, T. G. 2011. How does electroconvulsive therapy work? Theories on its mechanism. Can J Psychiatry, 56, 13-8.

BOLWIG, T. G. 2014. Imaging the brain during/ after ECT: a look inside the mechanism of action. $J E C T$.

BOUTROS, N. \& FINK, M. 2014. (Q)EEG changes during ECT: clues for its mechanism of action. $J E C T$.

BUFALINO, C., HEPGUL, N., AGUGLIA, E. \& PARIANTE, C. M. 2013. The role of immune genes in the association between depression and inflammation: a review of recent clinical studies. Brain Behav Immun, 31, 31-47.

CATTANEO, A., GENNARELLI, M., UHER, R., BREEN, G., FARMER, A., AITCHISON, K. J., CRAIG, I. W., ANACKER, C., ZUNSZTAIN, P. A., MCGUFFIN, P. \& PARIANTE, C. M. 2013. Candidate genes expression profile associated with antidepressants response in the GENDEP study: differentiating between baseline 'predictors' and longitudinal 'targets'. Neuropsychopharmacology, 38, 377-85.

DE BERARDIS, D., CONTI, C. M., SERRONI, N., MOSCHETTA, F. S., OLIVIERI, L., CARANO, A., SALERNO, R. M., CAVUTO, M., FARINA, B., ALESSANDRINI, M., JANIRI, L., POZZI, G. \& DI GIANNANTONIO, M. 2010. The effect of newer serotonin-noradrenalin antidepressants on cytokine production: a review of the current literature. Int J Immunopathol Pharmacol, 23, 417-22.

DOWLATI, Y., HERRMANN, N., SWARDFAGER, W., LIU, H., SHAM, L., REIM, E. K. \& LANCTOT, K. L. 2010. A meta-analysis of cytokines in major depression. Biol Psychiatry, 67, 446-57.

FINK, M. 2005. Should the dexamethasone suppression test be resurrected? Acta Psychiatr Scand, 112, 245-9.

FISCHLER, B., BOCKEN, R., SCHNEIDER, I., DE WAELE, M., THIELEMANS, K. \& DERDE, M. P. 1992. Immune changes induced by electroconvulsive therapy (ECT). Ann NY Acad Sci, 650, 326-30.

FLUITMAN, S. B., HEIJNEN, C. J., DENYS, D. A., NOLEN, W. A., BALK, F. J. \& WESTENBERG, H. G. 2011. Electroconvulsive therapy has acute immunological and neuroendocrine effects in patients with major depressive disorder. $J$ Affect Disord, 131, 388-92.

GIBNEY, S. M. \& DREXHAGE, H. A. 2013. Evidence for a dysregulated immune system in the etiology of psychiatric disorders. $J$ Neuroimmune Pharmacol, 8, 900-20.

GULOKSUZ, S., WICHERS, M., KENIS, G., RUSSEL, M. G., WAUTERS, A., VERKERK, R., ARTS, B. \& VAN OS, J. 2013. Depressive symptoms in Crohn's disease: relationship with immune activation and tryptophan availability. PLoS One, 8, e60435.

HAACK, M., HINZE-SELCH, D., FENZEL, T., KRAUS, T., KUHN, M., SCHULD, A. \& POLLMACHER, T. 1999. Plasma levels of cytokines and soluble cytokine receptors in psychiatric patients upon hospital admission: effects of confounding factors and diagnosis. Journal of psychiatric research, 33, 407-18.

HANNESTAD, J., DELLAGIOIA, N. \& BLOCH, M. 2011. The effect of antidepressant medication treatment on serum levels of inflammatory cytokines: a meta-analysis. Neuropsychopharmacology, 36, 2452-9.

HAROON, E., RAISON, C. L. \& MILLER, A. H. 2012. Psychoneuroimmunology meets 
neuropsychopharmacology: translational implications of the impact of inflammation on behavior. Neuropsychopharmacology, 37, 137-62.

HESTAD, K. A., TONSETH, S., STOEN, C. D., UELAND, T. \& AUKRUST, P. 2003. Raised plasma levels of tumor necrosis factor alpha in patients with depression: normalization during electroconvulsive therapy. $J E C T, 19,183-8$.

HILES, S. A., BAKER, A. L., DE MALMANCHE, T. \& ATTIA, J. 2012. Interleukin-6, C-reactive protein and interleukin-10 after antidepressant treatment in people with depression: a metaanalysis. Psychol Med, 42, 2015-26.

HOWREN, M. B., LAMKIN, D. M. \& SULS, J. 2009. Associations of depression with C-reactive protein, IL-1, and IL-6: a metaanalysis. Psychosom Med, 71, 171-86.

JINNO, S. \& KOSAKA, T. 2008. Reduction of Iba1-expressing microglial process density in the hippocampus following electroconvulsive shock. Exp Neurol, 212, 440-7.

KENIS, G. \& MAES, M. 2002. Effects of antidepressants on the production of cytokines. Int J Neuropsychopharmacol, 5, 401-12.

KENIS, G., PRICKAERTS, J., VAN OS, J., KOEK, G. H., ROBAEYS, G., STEINBUSCH, H. W. \& WICHERS, M. 2011. Depressive symptoms following interferon-alpha therapy: mediated by immune-induced reductions in brain-derived neurotrophic factor? Int $J$ Neuropsychopharmacol, 14, 247-53.

KRONFOL, Z., LEMAY, L., MADHAVAN, N. \& KLUGER, M. 1990. Electroconvulsive therapy increases plasma levels of interleukin-6. . Ann. NY Acad. Sci., 594, 463-465.

KRONFOL, Z., NAIR, M. P., WEINBERG, V., YOUNG, E. A. \& AZIZ, M. 2002. Acute effects of electroconvulsive therapy on lymphocyte natural killer cell activity in patients with major depression. J Affect Disord, 71, 211-5.

LANZENBERGER, R. 2014. Neurotransmitters and ECT. $J E C T$.

LEHTIMAKI, K., KERANEN, T., HUUHKA, M., PALMIO, J., HURME, M., LEINONEN, E. \& PELTOLA, J. 2008. Increase in plasma proinflammatory cytokines after electroconvulsive therapy in patients with depressive disorder. JECT, 24, 88-91.

MCAFOOSE, J. \& BAUNE, B. T. 2009. Evidence for a cytokine model of cognitive function. Neurosci Biobehav Rev, 33, 355-66.

MCCLINTOCK, S. M. 2014. Theories about (transient) cognitive effects of ECT. JECT.

MILLER, A. H., HAROON, E., RAISON, C. L. \& FELGER, J. C. 2013. Cytokine targets in the brain: impact on neurotransmitters and neurocircuits. Depress Anxiety, 30, 297-306.

MILLER, A. H., MALETIC, V. \& RAISON, C. L. 2009. Inflammation and its discontents: the role of cytokines in the pathophysiology of major depression. Biological psychiatry, 65, 732-41.

MITCHELL, P., SMYTHE, G. \& TORDA, T. 1990. Effect of the anesthetic agent propofol on hormonal responses to ECT. Biol Psychiatry, 28, 315-24.

MYINT, A. M. 2012. Kynurenines: from the perspective of major psychiatric disorders. FEBS J, 279, 1375-85.

RAISON, C. L., CAPURON, L. \& MILLER, A. H. 2006. Cytokines sing the blues: inflammation and the pathogenesis of depression. Trends Immunol, 27, 24-31.

RAISON, C. L. \& MILLER, A. H. 2013. Do cytokines really sing the blues? Cerebrum, 2013, 10.

RAISON, C. L., RUTHERFORD, R. E., WOOLWINE, B. J., SHUO, C., SCHETTLER, P., DRAKE, D. F., HAROON, E. \& MILLER, A. H. 2012. A Randomized Controlled Trial of the Tumor Necrosis Factor Antagonist Infliximab for Treatment-Resistant Depression: The Role of Baseline Inflammatory Biomarkers. Archives of general psychiatry, $1-11$.

ROMAN, A. \& NALEPA, I. 2005. Effect of repeated administration of paroxetine and electroconvulsive shock on the proliferative response of lymphocytes and the synthesis of nitric oxide by macrophages in rats. JECT, 21, 111-7.

ROMAN, A., NAWRAT, D. \& NALEPA, I. 2008. Chronic treatment with electroconvulsive shock may modulate the immune function of macrophages. JECT, 24, 260-7. 
ROTTER, A., BIERMANN, T., STARK, C., DECKER, A., DEMLING, J., ZIMMERMANN, R., SPERLING, W., KORNHUBER, J. \& HENKEL, A. 2013. Changes of cytokine profiles during electroconvulsive therapy in patients with major depression. J ECT, 29, 162-9.

SCHROETER, M. L., SACHER, J., STEINER, J., SCHOENKNECHT, P. \& MUELLER, K. 2013. Serum S100B represents a new biomarker for mood disorders. Curr Drug Targets, 14, 1237-48.

SIENAERT, P. \& MCCALL, M. 2014. Theories on ECT's mechanism of action: an overview. $J E C T$.

SMITH, R. S. 1991. The macrophage theory of depression. Med Hypotheses, 35, 298-306.

TBD 2014. Neuroendocrine hypotheses, including pituitary-adrenal axis. $J E C T$.

THE UK ECT REVIEW GROUP 2003. Efficacy and safety of electroconvulsive therapy in depressive disorders: a systematic review and meta-analysis. Lancet, 361, 799-808.

VOGELZANGS, N., BEEKMAN, A. T., VAN REEDT DORTLAND, A. K., SCHOEVERS, R. A., GILTAY, E. J., DE JONGE, P. \& PENNINX, B. W. 2014. Inflammatory and Metabolic Dysregulation and the 2-Year Course of Depressive Disorders in Antidepressant Users. Neuropsychopharmacology.

VOGELZANGS, N., DUIVIS, H. E., BEEKMAN, A. T., KLUFT, C., NEUTEBOOM, J., HOOGENDIJK, W., SMIT, J. H., DE JONGE, P. \& PENNINX, B. W. 2012. Association of depressive disorders, depression characteristics and antidepressant medication with inflammation. Transl Psychiatry, 2, e79.
WANG, N., WANG, X. H., LU, J. \& ZHANG, J. Y. 2011. The effect of repeated etomidate anesthesia on adrenocortical function during a course of electroconvulsive therapy. JECT, 27, 281-5.

WICHERS, M. C., KENIS, G., KOEK, G. H., ROBAEYS, G., NICOLSON, N. A. \& MAES, M. 2007. Interferon-alpha-induced depressive symptoms are related to changes in the cytokine network but not to cortisol. $J$ Psychosom Res, 62, 207-14.

WIUM-ANDERSEN, M. K., ORSTED, D. D., NIELSEN, S. F. \& NORDESTGAARD, B. G. 2013. Elevated C-reactive protein levels, psychological distress, and depression in 73, 131 individuals. JAMA Psychiatry, 70, 176-84.

ZACHRISSON, O. C., BALLDIN, J., EKMAN, R., NAESH, O., ROSENGREN, L., AGREN, H. \& BLENNOW, K. 2000. No evident neuronal damage after electroconvulsive therapy. Psychiatry Res, 96, 157-65.

ZORRILLA, E. P., LUBORSKY, L., MCKAY, J. R., ROSENTHAL, R., HOULDIN, A., TAX, A., MCCORKLE, R., SELIGMAN, D. A. \& SCHMIDT, K. 2001. The relationship of depression and stressors to immunological assays: a meta-analytic review. Brain Behav Immun, 15, 199-226.

ZUNSZAIN, P. A., ANACKER, C., CATTANEO, A., CARVALHO, L. A. \& PARIANTE, C. M. 2011. Glucocorticoids, cytokines and brain abnormalities in depression. Prog Neuropsychopharmacol Biol Psychiatry, 35, 722-9. 



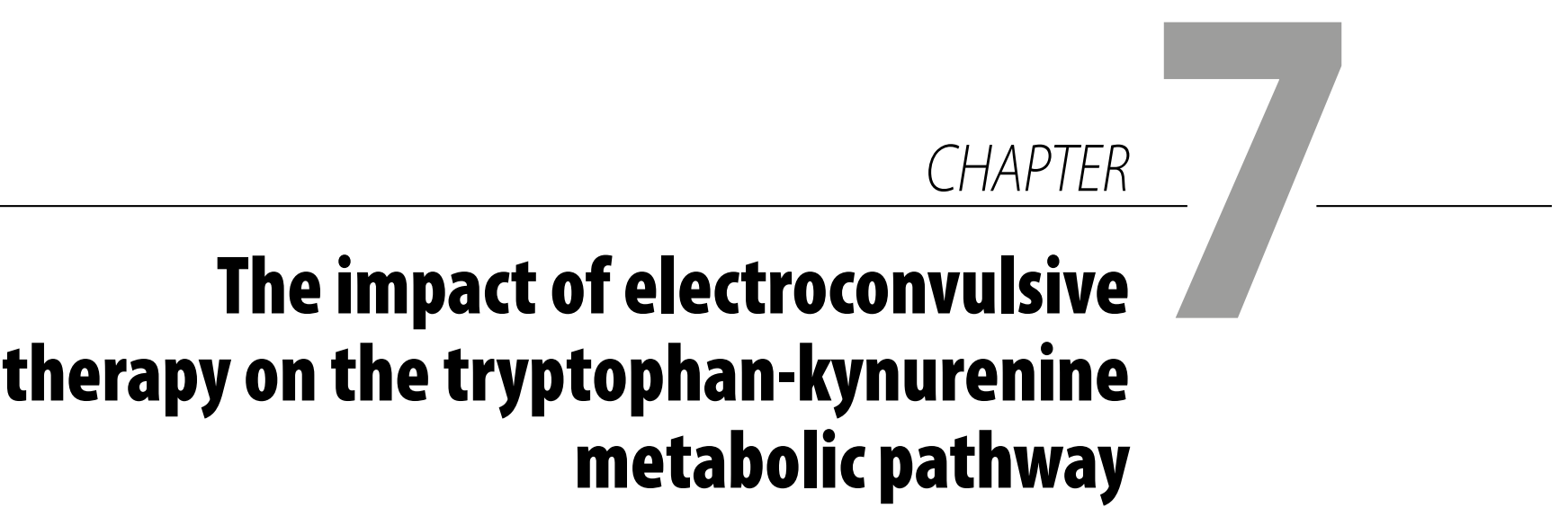

Sinan Guloksuz, Baer Arts, Sharon Walter, Marjan Drukker, Laura Rodriguez, Aye-Mu Myint, Markus J. Schwarz, Rudolf Ponds, Jim van Os, Gunter Kenis, Bart P.F. Rutten

Brain, Behavior, and Immunity (2015): doi: 10.1016/j.bbi.2015.02.029. 

Abstract

\section{Background}

There is still limited knowledge about the mechanism of action of electroconvulsive therapy (ECT) in the treatment of depression. Substantial evidence suggests a role for the immune-moderated tryptophan (TRP)-kynurenine (KYN) pathway in depression; i.e. a depression-associated disturbance in the balance between the TRP-KYN metabolites towards a neurotoxic process. We, therefore, aimed to investigate the impact of ECT treatment on the TRP-KYN pathway, in association with ECT-related alterations in depressive symptoms.

\section{Method}

Twenty-three patients with unipolar or bipolar depression, treated with bilateral ECT twice a week were recruited. Blood serum samples, and depression scores using the Hamilton Depression Rating Scale-17 items (HDRS) as well as the Beck Depression Inventory (BDI) were collected repeatedly during the period of ECT and until 6 weeks after the last ECT session. TRP and KYN metabolites were analyzed in serum using the High Performance Liquid Chromatography. Four patients could not complete the study; thereby yielding data of 19 patients. Analyses were performed using multilevel linear regression analysis.

\section{Results}

There was an increase in kynurenic acid (KYNA) $(B=0.04, p=0.001), K Y N / T R P$ ratio $(B=0.14$, $p=0.001), K Y N A / K Y N$ ratio $(B=0.07, p<0.0001)$, and $K Y N A / 3$-hydroxykynurenine ratio $(B=0.01$, $p=0.008)$ over time during the study period. $K Y N(B=-0.02, p=0.003)$ and $K Y N / T R P(B=-0.19$, $p=0.003$ ) were negatively associated with total HDRS over time. Baseline TRP metabolite concentrations did not predict time to ECT response.

\section{Conclusion}

Our findings show that ECT influences the TRP-KYN pathway, with a shift in TRP-KYN metabolites balance towards molecules with neuroprotective properties correlating with antidepressant effects of ECT; thereby providing a first line of evidence that the mechanism of action of ECT is (co)mediated by the TRP-KYN pathway.

Keywords: ECT, depression, tryptophan, kynurenine, kynurenic acid, immune, indoleamine 2,3-dioxygenase, kynurenine amino transferases, neuroprotection 


\section{Introduction}

Evidence is scarce about the mechanism of action of ECT (Sienaert, 2014), which appears to comprise a complex network of effects on neurotransmitters (Baldinger et al., 2014), neurohormones (Haskett, 2014), and epigenetic changes (de Jong et al., 2014). Current evidence suggests differential effects on molecular mediators of the immune system by single versus repetitive sessions of ECT (Guloksuz et al., 2014); single sessions of ECT have been associated with upregulation or activation of the immune system (Lehtimaki et al., 2008, Fluitman et al., 2011), whereas repeated ECT sessions appear to lead to downregulation or suppression of the immune system (Rotter et al., 2013, Hestad et al., 2003).

The disturbed functioning of tryptophan (TRP) metabolic pathway has been proposed as one of the crucial links between the aberrant immune functioning and the neurotransmitter deregulation involved in depression (Myint and Kim, 2003, Myint et al., 2012, Dantzer et al., 2011). In physiological conditions, nearly $90 \%$ of TRP is catabolized into kynurenine (KYN) by tryptophan dioxygenase, while the activity of indoleamine 2,3-dioxygenase (IDO) is negligible. However, in cases of interferon (IFN)- $\gamma$ and tumor necrosis factor (TNF)- $\alpha$ upregulation (such as is seen in inflammatory states, or with IFN- $\alpha$ treatment), the activity of IDO is induced, which in turn increases TRP turnover, and KYN accumulation (Krause et al., 2012) (Wichers et al., 2005, Raison et al., 2010). Moreover, and maybe more hazardously, it has been shown that immune activation, which induces both IDO and kynurenine-3monooxygenase (KMO), can increase the production of several neurotoxic metabolites such as 3-hydroxykynurenine (3-HK) and quinolinic acid (QA) in microglia (see Supp Fig. S1 for a schematic illustration). 3-HK increases reactive oxygen species (ROS), lipid peroxidation; and QA is a N-methyl-D-aspartate (NMDA) receptor agonist. Another metabolite of KYN, kynurenic acid (KYNA), is produced in astrocytes and is considered to display neuroprotective properties through its antagonistic effect on NMDA receptors (Dantzer et al., 2011, Krause et al., 2012). Depression has previously been related to increased TRP turnover (increased KYN/TRP) as well as an imbalance in the ratio between KYNA and KYN such that the ratio was shifted toward increased circulating neurotoxic metabolites in the KYN pathway (Myint et al., 2007, Myint et al., 2013). In vitro studies have furthermore indicated that deregulations in the KYN pathway in astroglial cultures can be partially normalized by antidepressants (Myint, 2012, Kocki et al., 2012).

Given this suggestive evidence for a role of the TRP-KYN metabolic pathway in depression, we aimed to investigate whether ECT influences the TRP-KYN metabolic pathway in this longitudinal study, whether changes in TRP-KYN metabolites may 


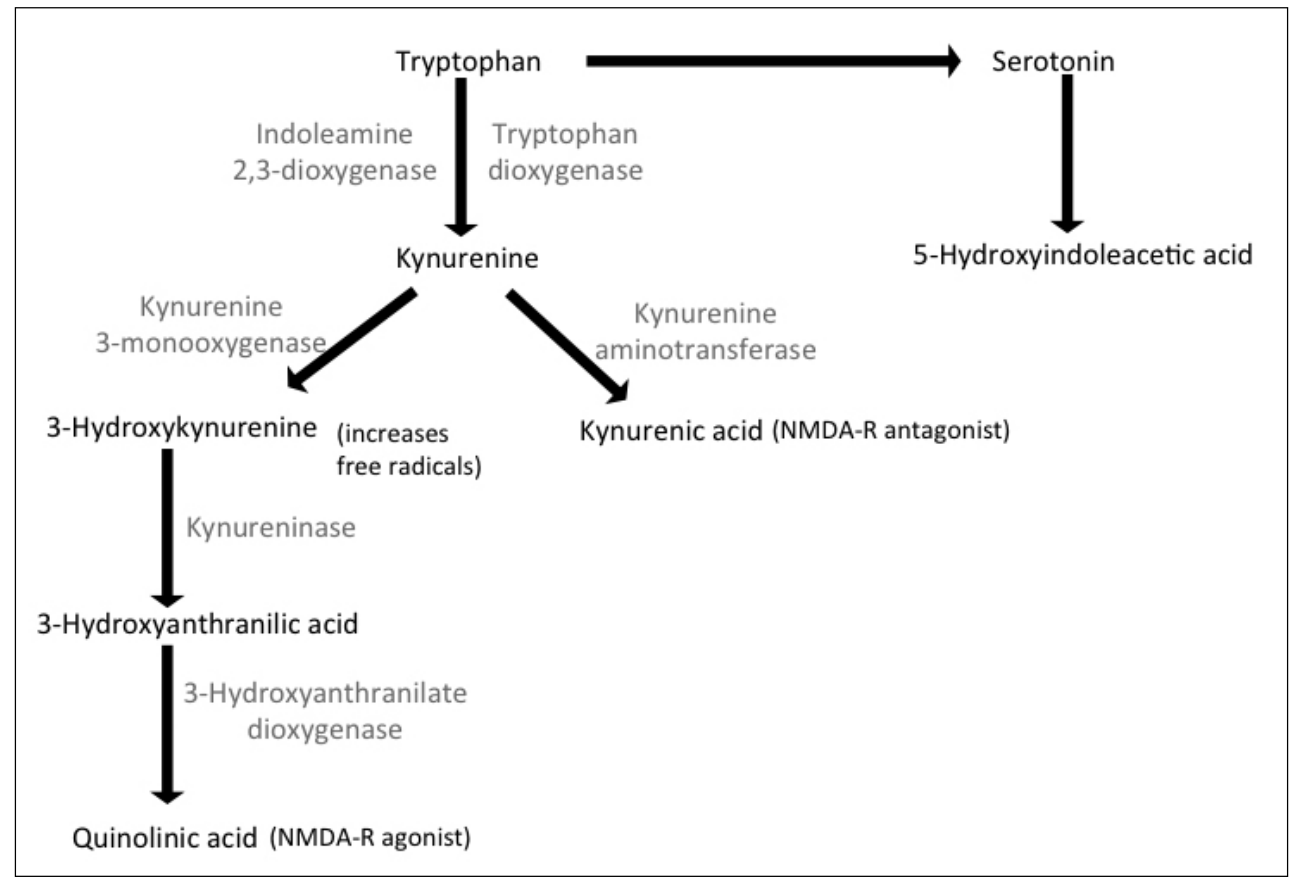

Fig. S1. Tryptophan-Kynurenine metabolic pathway NMDA-R $=\mathrm{N}$-methyl-D-aspartate receptor. The important effects of the metabolites relating to central nervous system functioning were given in brackets.

relate to depression scores, and whether levels of TRP-KYN metabolites may predict response to ECT.

\section{Methods}

Twenty-three patients diagnosed with unipolar or bipolar depression according to $D S M-I V$ were recruited from the Maastricht University Medical Centre. All patients were 'treatment- resistant'; in accordance with routine clinical guideline defined as the failure to produce significant clinical improvement (i.e. persistence of significant depressive symptoms) after at least two trials with antidepressants from different pharmacologic classes (adequate in dose, duration, and compliance). The study was approved by the Medical Ethics Committee, and carried out in accordance with the Declaration of Helsinki. Written informed consent was obtained from each patient prior to participation. Exclusion criteria were: age $<18$ and $>65$ years, illiteracy, major medical or psychiatric conditions that may interfere with the study procedures: cancer, cerebrovascular disorders, organic psychiatric syndromes, active drug abuse, mental retardation, dementia, neurodegenerative disorders, presence of an inflammatory condition, and regular use of immune-modulating medications (e.g. corticosteroid, non-steroid anti-inflammatory drugs). Two patients decided to leave the study on their 
Table S1. Medication used during the study

\begin{tabular}{|l|l|}
\hline & $\mathbf{n}$ \\
\hline AD monotherapy & $2^{*}$ \\
\hline AD combination therapy & 3 \\
\hline AP monotherapy & 1 \\
\hline AD and AP combination therapy & 7 \\
\hline AD and MS combination therapy & 3 \\
\hline AP and MS combination therapy & 1 \\
\hline AD, AP, and MS combination therapy & 2 \\
\hline
\end{tabular}

*Both patients were treated with a tricyclic antidepressant.

AD: Antidepressant, AP: Antipsychotic, MS: Mood stabilizer.

Note: the dose of the medications was not altered during the study period

own accord after the initial evaluation and 2 patients were excluded from the study due to (cardiovascular) side effects at first ECT session. Therefore, the final sample consisted 19 patients (12 major depression, and 7 bipolar depression). Only 3 patients had received ECT treatment previously.

Bilateral ECT with bifrontotemporal electrode placement was administered using Thymatron IV (brief pulse stimulation ( 0.5 milliseconds) and fixed dose at start of 350 $\mathrm{mC})$. ECT was administered twice a week, on Monday and Friday, with a mean of 6.1 sessions (range 3-11 sessions). Mean duration of EEG seizure time was 52 seconds (range, 10 - 200 seconds); the average charge applied was $462 \mathrm{mC}$ (range, 150 $900 \mathrm{mC})$. Etomidate $(0.1-0.2 \mathrm{mg} / \mathrm{kg}$ ) was used for anaesthesia, and succinylcholine $(0.5-1.0 \mathrm{mg} / \mathrm{kg})$ for muscle relaxation. Medications used by patients, including antidepressants, were continued during ECT, with the exception of benzodiazepines (which, according to routine medical care, was stopped before the start of ECT) (Supplementary Table S1).

The Hamilton Depression Rating Scale-17 items (HDRS) and the Beck Depression Inventory (BDI) were administered before the first ECT session (baseline), and each week during the ECT treatment period. Clinical assessments were administered on days without ECT sessions to avoid possible confounding of acute and transient impact of ECT (including the effects of anesthesia) on cognition. Blood samples were collected after overnight fasting before the first ECT session (i.e. baseline) and subsequently once a week before the ECT session (i.e. every other ECT session) during the treatment period. The treating psychiatrist made the decision to stop ECT treatment when no clinical improvement was observed, or when complete remission was obtained. Thus, this resulted in a different number of treatments in each subject. After the ECT period, the clinical assessments and blood samplings were repeated every other week up to 6 weeks. 


\section{Determination of tryptophan-kynurenine metabolic pathway metabolites}

Serum was separated immediately and stored at $-80 \mathrm{C}$. High performance liquid chromatography (HPLC) was used to measure serum levels of TRP, KYN, KYNA, 3-HK, 3-Hydroxyanthranilic acid (3-HAA) and 5-Hydroxyindoleacetic acid (5HIAA). The measurement was performed according to the method of Hervé et al. (Herve et al., 1996) with some modifications. The recently published method using HPLC (Oades et al., 2010a, Oades et al., 2010b) was used to measure 3-HK.

KYN was detected spectrophotometrically at $365 \mathrm{~nm}$. KYNA was detected fluorimetrically at an excitation wavelength of $334 \mathrm{~nm}$ and an emission wavelength of $388 \mathrm{~nm}$. KYNA was analyzed in serum that was deproteinized using perchloric acid. 3-HK was measured at a wavelength of $365 \mathrm{~nm}$ by UV detection. All analyses were conducted using HPLC with a reverse phase c-18 column. The 3-HK analysis method has been validated showing an absolute recovery of $85.8 \%$, intra-day precision of $3.9 \%$, and inter-day precision of $7.5 \%$; time series demonstrated perfect stability of the analyte 3-HK during our extraction and analysis steps. The intra and inter-assay coefficients of variation ranged from $5 \%$ to $7 \%$ for all of the metabolites.

The ratio between serum KYN and TRP concentrations was used to estimate TRP degradation (Myint et al., 2007). The ratio between serum KYNA and KYN concentrations was used to determine how much KYN was catabolised into KYNA (Myint et al., 2007). The ratio between serum KYNA and 3-HK concentrations was used to determine the balance between the two arms ("neuroprotective" versus "neurotoxic") of the KYN pathway (Oades et al., 2010b, Oades et al., 2010a). The ratio between 5HIAA and $\mathrm{KYN}$ ratio $(5 \mathrm{HIAA} / \mathrm{KYN})$ was also calculated to indicate the balance between TRP breakdown into KYN and synthesis of TRP into serotonin in the form of its stable metabolite, 5HIAA.

\section{Statistical analysis}

The data were analyzed using STATA version 12.0 (StataCorp, 2011). For the longitudinal analyses, multilevel linear regression analysis was applied using the XTREG command. This multilevel model takes into account that level-1 units (individual observations) are clustered into level-2 units (subjects). Effect sizes of explanatory variables were expressed as regression coefficients (B), which can be interpreted identically to the estimate in the unilevel linear regression analyses. To examine the effect of time in days on total HDRS, total BDI and TRP metabolite concentrations and ratios (TRP, KYN, KYNA, 3-HK, 3-HAA, 5-HIAA, KYN/TRP, KYNA/KYN, KYNA/3-HK, 5-HIAA/ KYN), cubic, quadratic and linear regression models were fitted based on a top-down model selection procedure: if the cubic time 
effect was not statistically significant at $\mathrm{p}<0.05$, it was removed, and we stepped down to the quadratic model and so on. TRP metabolite concentrations and ratios were also regressed on total clinical depression scores (HDRS and BDI). To assess baseline TRP metabolite concentrations and ratios as predictors for time to ECT response (50\% reduction in the HDRS total score), survival analyses with the Cox proportional hazards model were performed. All analyses were corrected for a-priori hypothesized confounders, age and sex. Two-sided statistical significance was set at $\mathrm{p}<0.05$. Given the number of statistical tests involved $(\mathrm{n}=10)$, each hypothesis was corrected using the Simes' modification of the Bonferroni procedure for multiple testing to determine statistical significance (Simes, 1986).

\section{Results}

Of 19 patients, 6 were male and 13 female, and the mean age was $52.6(\mathrm{SD}=14.4)$ years (range $=23-74$ ). The mean baseline clinical depression scores were 23.4 on the HDRS $(\mathrm{SD}=6.4)$ and $32.8(\mathrm{SD}=11.1)$ on the BDI, respectively.

\section{Longitudinal change in depression scores}

The change in depression scores over time was best modeled by cubic regression model (Fig. 1). Initially, there was a steep reduction in depression scores, followed by a slight increment (for BDI: $\mathrm{B}^{\text {linear }}=-1.13, \mathrm{p}<0.001 ; \mathrm{B}^{\text {square }}=0.02, \mathrm{p}<0.001 ; \mathrm{B}^{\text {cubic }}=$ $-0.0001, \mathrm{p}<0.001$; for HDRS: $\mathrm{B}^{\text {linear }}=-0.78, \mathrm{p}<0.001 ; \mathrm{B}^{\text {square }}=0.02, \mathrm{p}<0.001 ; \mathrm{B}^{\text {cubic }}$ $=-0.0001, \mathrm{p}<0.001)$.

\section{Longitudinal change in TRP metabolites}

The serum concentrations of KYNA $(B=0.04, p=0.001), \mathrm{KYN} / \mathrm{TRP}(\mathrm{B}=0.14, \mathrm{p}$ $=0.001), \mathrm{KYNA} / \mathrm{KYN}(\mathrm{B}=0.07, \mathrm{p}<0.001)$, and KYNA $/ 3-\mathrm{HK}(\mathrm{B}=0.01, \mathrm{p}=0.008)$ increased significantly over time, also after correction for multiple testing (Fig. 1). In these models, cubic as well as quadratic terms were removed from the models topdown $(\mathrm{p}>0.05)$ (Supplementary Table S2).

\section{Association between TRP metabolites and depression scores}

Total HDRS scores were negatively associated with KYN $(B=-0.02, p=0.003)$, and KYN/TRP $(B=-0.19, p=0.003)$, a pattern that was also observed with the selfreported BDI scores (data not shown). Table 1 provides the overview for the results on the association between TRP metabolites and the HDRS scores. 


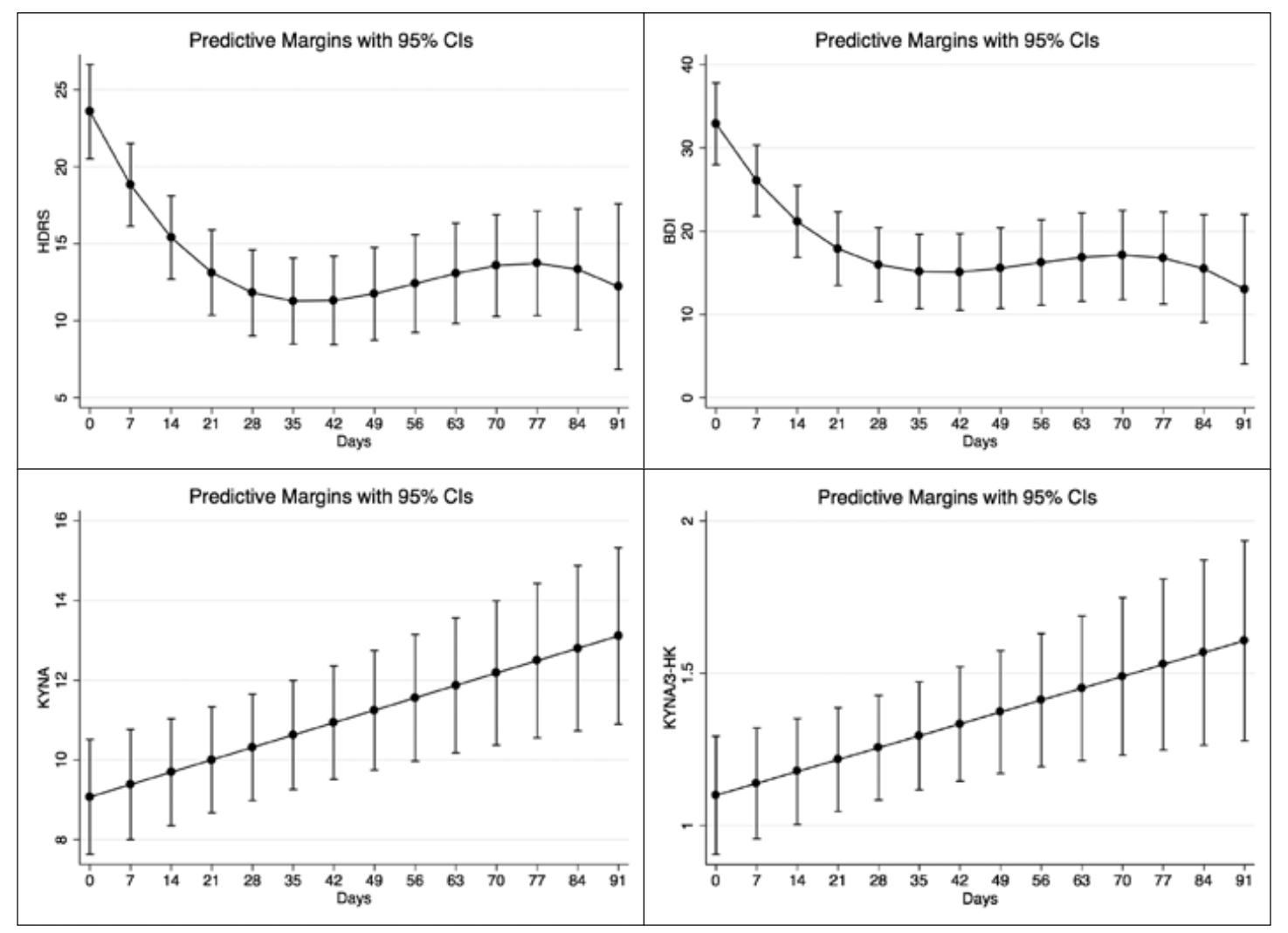

Fig. 1. Change in depression scores and kynurenic acid across the study period.

Graphs were truncated to save space.

Hamilton Depression Rating Scale-17 items; BDI, Beck Depression Inventory; KYNA, Kynurenic acid ( $\mathrm{ng} / \mathrm{ml})$; 3-HK, 3-Hydroxykynurenine $(\mathrm{ng} / \mathrm{ml})$

Table S2. Results on longitudinal changes of TRP metabolites

\begin{tabular}{|l|c|c|c|c|}
\hline & B & S.E & $\mathbf{9 5 \%} \mathbf{C I}$ & $\mathbf{p}$ \\
\hline TRP & -.003 & 0.005 & $-0.01 ; 0.005$ & 0.448 \\
\hline KYN & 0.92 & 0.49 & $-0.04 ; 1.88$ & 0.061 \\
\hline KYNA & 0.04 & 0.01 & $0.02 ; 0.07$ & $0.001^{\mathrm{a}}$ \\
\hline 3-HK & 0.02 & 0.01 & $-0.008 ; 0.04$ & 0.161 \\
\hline 3-HAA & -0.08 & 0.08 & $-0.24 ; 0.07$ & 0.294 \\
\hline 5-HIAA & 0.03 & 0.01 & $-0.0003 ; 0.06$ & 0.052 \\
\hline KYN/TRP & 0.14 & 0.04 & $0.06 ; 0.23$ & $0.001^{\mathrm{a}}$ \\
\hline KYNA/KYN & 0.07 & 0.02 & $0.03 ; 0.10$ & $<0.001^{\mathrm{a}}$ \\
\hline KYNA/3-HK & 0.01 & 0.002 & $0.001 ; 0.01$ & $0.008^{\mathrm{a}}$ \\
\hline 5-HIAA/ KYN & 0.00004 & 0.00003 & $-0.00002 ; 0.0001$ & 0.160 \\
\hline
\end{tabular}

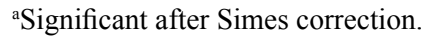

TRP, Tryptophan; KYN, Kynurenine; KYNA, Kynurenic acid; 3-HK, 3-Hydroxykynurenine; 3-HAA, 3-Hydroxyanthranilic acid; 5-HIAA, 5-Hydroxyindoleacetic acid 
Table 1. Association between HDRS scores and TRP metabolites

\begin{tabular}{|l|c|c|c|c|}
\hline & B & S.E & $\mathbf{9 5 \% C I}$ & p \\
\hline TRP & -0.35 & 0.76 & $-1.84 ; 1.15$ & 0.649 \\
\hline KYN & -0.02 & 0.01 & $-0.03 ;-0.01$ & $0.003^{\mathrm{a}}$ \\
\hline KYNA & -0.41 & 0.22 & $-0.85 ; 0.03$ & 0.066 \\
\hline 3-HK & -0.46 & 0.22 & $-0.89 ;-0.04$ & 0.034 \\
\hline 3-HAA & -0.02 & 0.04 & $-0.10 ; 0.05$ & 0.560 \\
\hline 5-HIAA & -0.16 & 0.20 & $-0.56 ; 0.23$ & 0.426 \\
\hline KYN/TRP & -0.19 & 0.07 & $-0.32 ;-0.07$ & $0.003^{\mathrm{a}}$ \\
\hline KYNA/KYN & -0.05 & 0.17 & $-0.39 ; 0.28$ & 0.768 \\
\hline KYNA/3-HK & -1.50 & 1.51 & $-4.46 ; 1.46$ & 0.322 \\
\hline 5-HIAA/ KYN & 73.33 & 104.47 & $-131.42 ; 278.09$ & 0.483 \\
\hline
\end{tabular}

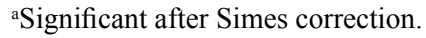

HDRS, Hamilton Depression Rating Scale-17 items; TRP, Tryptophan; KYN, Kynurenine; KYNA, Kynurenic acid;

3-HK, 3-Hydroxykynurenine; 3-HAA, 3-Hydroxyanthranilic acid; 5-HIAA, 5-Hydroxyindoleacetic acid

\section{Baseline TRP metabolites as predictors for time to treatment response}

We observed no statistically significant association between time to ECT response and any of the TRP metabolites levels at baseline (Supplementary Table S3).

Table S3. Baseline TRP metabolites as predictors for time to treatment response

\begin{tabular}{|l|c|c|c|c|}
\hline & \multicolumn{2}{|c|}{ Baseline Concentrations and Ratios } & \multicolumn{2}{c|}{ ECT Response* Time Predictor } \\
\hline & Mean & SD & HR & 0.090 \\
\hline TRP $(\boldsymbol{\mu g} / \mathbf{m l})$ & 8.34 & 1.23 & 1.57 & 0.674 \\
\hline KYN $(\mathbf{n g} / \mathbf{m l})$ & 535.44 & 150.74 & 1.00 & 0.785 \\
\hline KYNA $(\mathbf{n g} / \mathbf{m l})$ & 9.35 & 3.30 & 1.03 & 0.158 \\
\hline 3-HK $(\mathbf{n g} / \mathbf{m l})$ & 8.57 & 3.59 & 0.86 & 0.968 \\
\hline 3-HAA $(\mathbf{n g} / \mathbf{m l})$ & 54.57 & 19.90 & 1.00 & 0.392 \\
\hline 5-HIAA $(\mathbf{n g} / \mathbf{m l})$ & 12.09 & 3.04 & 1.11 & 0.605 \\
\hline KYN/TRP & 63.75 & 13.80 & 0.98 & 0.885 \\
\hline KYNA/KYN & 17.18 & 3.31 & 1.01 & 0.073 \\
\hline KYNA/3-HK & 1.23 & 0.58 & 2.43 & 0.853 \\
\hline 5-HIAA/ KYN & 0.02 & 0.01 & 65205.88 & \\
\hline
\end{tabular}

${ }^{*}$ Response was defined as 50\% reduction in the Hamilton Depression Rating Scale-17 items total score.

TRP, Tryptophan; KYN, Kynurenine; KYNA, Kynurenic acid; 3-HK, 3-Hydroxykynurenine; 3-HAA, 3-Hydroxyanthranilic acid; 5-HIAA, 5-Hydroxyindoleacetic acid 


\section{Discussion}

To the best of our knowledge, this is the first study investigating longitudinal changes in TRP metabolites in response to ECT. We found that KYNA, KYNA/3-HK, KYNA/ $\mathrm{KYN}$, and KYN/TRP levels increased after ECT, that levels of KYN and KYN/ TRP were negatively associated with total HDRS scores, and that TRP metabolite concentrations at baseline did not predict ECT response.

Previous research demonstrated no alteration in TRP concentrations after a single or a course of repetitive ECT (Kirkegaard et al., 1978, Whalley et al., 1980, Mokhtar et al., 1997), whereas Palmio et al. found an increase in TRP concentrations 2-24 hours after a single ECT session (Palmio et al., 2005). Another study demonstrated that lower TRP concentration and TRP availability increased after a course of repetitive ECT particularly in ECT responders (Hoekstra et al., 2001). While the authors suggested that their findings might be related to decreased catabolism of TRP in KYN pathway (Hoekstra et al., 2001), no direct marker of the KYN metabolic pathway was examined. We found that serum TRP concentrations remained stable over the course of the ECT treatment, and did not predict response to ECT.

It is important to note that $\mathrm{KYN}$ degradation into putative neurotoxic metabolites may play a more important role in cytokine-induced depression rather than decreased TRP availability to the brain per se (Dantzer et al., 2011). Several studies demonstrated circulating KYN/TRP concentrations were higher, whereas KYNA/KYN, KYNA, and TRP/ large neutral amino acids (LNAA) were lower in medication-free depression patients than in normal controls (Myint et al., 2013, Myint et al., 2007). The authors interpreted these findings as an indicator of a shift in KYN metabolism toward the QA pathway evidenced by increased TRP breakdown (lower TRP/LNAA and higher KYN/TRP ratios), lower KYNA and KYNA/KYN in depression (Myint et al., 2007). However, further solid conclusion could not be drawn, as QA and 3-HK concentrations were not measured in that study.

Our findings are thus in line with these studies reporting that almost all KYN metabolites remain stable after antidepressant treatment but KYN/TRP is increased (Myint et al., 2007, Myint et al., 2013). In accordance, we demonstrate now that KYN/TRP concentrations increase following ECT treatment. Given our findings showing a negative association between KYN/TRP (estimating TRP degradation) and total HDRS scores, KYN/TRP escalation might be interpreted as contradicting with an expected reduction in TRP turnover in response to successful treatment. However, accompanying invariant TRP concentrations over the course of the study suggests that increased KYN/TRP ratio likely occurred through a reduction in further downstream degradation of KYN -thereby leading to relatively increased KYN/TRP ratio- rather than increased TRP degradation per se. 
In the present study, we showed an increase in KYNA, an NMDA antagonist counterbalancing neurotoxic effects of QA. KYNA/3-HK, KYNA/KYN ratios increased over time, thereby suggesting a shift of the balance toward the neuroprotective side induced by ECT, also maintained in the post-ECT period. We can speculate that the gradual alterations of the TRP-KYN pathway in the post-ECT period may be related to molecular and cellular cascades induced by ECT and that, once initiated, continued to normalize after cessation of ECT through prolonged effects on gradually occurring normalization of the activation state or proliferation rate of immune-cells, which may potentially be mediated by epigenetic regulation of gene transcription(de Jong et al., 2014). Further, although the dose of antidepressants was not altered during the ECT, the effect of antidepressant use on TRP-KYN pathway during and after ECT treatment cannot be excluded. In accordance, Myint et al. found that KYNA/KYN ratio increased after successful antidepressant treatment in patients with first-episode depression (Myint et al., 2007). Moreover, a recent in vitro study using primary astroglial cultures of rats revealed the possible role of KYN pathway in therapeutic effectiveness of antidepressants evidenced by upregulated kynurenine aminotransferase (KAT)1 and KAT2 and downregulated KMO genes expressions, along with a rise in KYNA/3-HK in response to antidepressant exposure (Kocki et al., 2012).

Recent study showed that the detrimental effects of interleukin (IL)-1 $\beta$ on neurogenesis might be related to the upregulated IDO, KMO and kynureninase activity, and downregulated KAT(Zunszain et al., 2012). Furthermore, co-treatment with KMO inhibitor, Ro 61-8048 partially reversed the deleterious effects of IL-1 $\beta$ on neurogenesis (Zunszain et al., 2012). Given this growing body of evidence, it is therefore plausible to argue that cytokine-induced activation of KYN pathway plays an important role in immune-mediated mechanisms of depression through increased production of neurotoxic metabolites such as QA and 3-HK. Although, the definitive mechanism of action of ECT has still been unknown, animal studies and longitudinal neuroimaging studies have suggested that ECT exerts neurotrophic properties, which may (in addition to the neuronal cell types) be related to alterations in/of glial cells (Abbott et al., 2014, Ongur and Heckers, 2004). Thus, the increased neuroprotective/ neurotoxic ratio in KYN pathway metabolites, as observed in our sample, might be involved in mediating or moderating the neurotrophic effects of ECT. In this regard, given KYN metabolism is shifted toward the neurotoxic arm in the presence of immune activation, we can also speculate ECT might downregulate the immune activation implicated in pathogenesis of depression. The results of studies examining ECT-induced changes in immune functioning show repetitive ECT treatment may lead to long-term down-regulation of immune activation in patients with depression, albeit inconsistently (Guloksuz et al., 2014). 
This study provides a critical perspective about the long-term effects of ECT on the TRP-KYN metabolic pathway by using a repetitive data sampling that allowed analyses of longitudinal changes. However, it should be noted that the sample size was relatively small (particularly for prediction of treatment response), and our findings suggesting a temporal association therefore warrant replication in larger samples that include a control group of patients not receiving ECT. We furthermore cannot rule out a potential confounding effect of medication on the TRP-KYN metabolites, although such an effect is unlikely given that the dose of the antidepressant medication remained stable over the ECT period in our study. Finally, the use of anesthetics and muscle relaxants might also confound our findings; however, it was impossible to eliminate these factors, as they were inherent to the ECT procedure.

Notwithstanding its limitations, this study highlights the impact of ECT on the TRP-KYN pathway with a shift toward 'neuroprotective' side, which may play a role in its mechanism of action. 


\section{Acknowledgements}

Sinan Guloksuz, Bart P.F. Rutten, and Jim van Os are supported by the European Community's Seventh Framework Programme under Grant agreement no. HEALTH-F2-2009-241909 (Project EU-GEI). Bart P.F Rutten has received funds via a VENI Award from the Netherlands Organization for Scientific Research (NWO, grant number 916.11.086). Aye Mu Myint and Markus J Schwarz are supported by EU FP7 Collaborative Project Moodinflame (Grant No. 22963). 


\section{References}

ABBOTT, C. C., GALLEGOS, P., REDISKE, N., LEMKE, N. T. \& QUINN, D. K. 2014. A review of longitudinal electroconvulsive therapy: neuroimaging investigations. $J$ Geriatr Psychiatry Neurol, 27, 33-46.

BALDINGER, P., LOTAN, A., FREY, R., KASPER, S., LERER, B. \& LANZENBERGER, R. 2014. Neurotransmitters and electroconvulsive therapy. $J E C T, 30,116-21$.

DANTZER, R., O'CONNOR, J. C., LAWSON, M. A. \& KELLEY, K. W. 2011. Inflammationassociated depression: from serotonin to kynurenine. Psychoneuroendocrinology, 36, 426-36.

DE JONG, J. O., ARTS, B., BOKS, M. P., SIENAERT, P., VAN DEN HOVE, D. L., KENIS, G., VAN OS, J. \& RUTTEN, B. P. 2014. Epigenetic effects of electroconvulsive seizures. J ECT, 30, 152-9.

FLUITMAN, S. B., HEIJNEN, C. J., DENYS, D. A., NOLEN, W. A., BALK, F. J. \& WESTENBERG, H. G. 2011. Electroconvulsive therapy has acute immunological and neuroendocrine effects in patients with major depressive disorder. $J$ Affect Disord, 131, 388-92.

GULOKSUZ, S., RUTTEN, B. P., ARTS, B., VAN OS, J. \& KENIS, G. 2014. The immune system and electroconvulsive therapy for depression. $J$ ECT, 30, 132-7.

HASKETT, R. F. 2014. Electroconvulsive therapy's mechanism of action: neuroendocrine hypotheses. $J E C T, 30,107-10$.

HERVE, C., BEYNE, P., JAMAULT, H. \& DELACOUX, E. 1996. Determination of tryptophan and its kynurenine pathway metabolites in human serum by highperformance liquid chromatography with simultaneous ultraviolet and fluorimetric detection. J Chromatogr B Biomed Appl, 675, $157-61$.

HESTAD, K. A., TONSETH, S., STOEN, C. D., UELAND, T. \& AUKRUST, P. 2003. Raised plasma levels of tumor necrosis factor alpha in patients with depression: normalization during electroconvulsive therapy. $J E C T, 19,183-8$.
HOEKSTRA, R., VAN DEN BROEK, W. W., FEKKES, D., BRUIJN, J. A., MULDER, P. G. \& PEPPLINKHUIZEN, L. 2001. Effect of electroconvulsive therapy on biopterin and large neutral amino acids in severe, medication-resistant depression. Psychiatry Res, 103, 115-23.

KIRKEGAARD, C., MOLLER, S. E. \& BJORUM, N. 1978. Addition of L-tryptophan to electroconvulsive treatment in endogenous depression. A double-blind study. Acta Psychiatr Scand, 58, 457-62.

KOCKI, T., WNUK, S., KLOC, R., KOCKI, J., OWE-LARSSON, B. \& URBANSKA, E. M.

2012. New insight into the antidepressants action: modulation of kynurenine pathway by increasing the kynurenic acid/3hydroxykynurenine ratio. J Neural Transm, 119, 235-43.

KRAUSE, D. L., RIEDEL, M., MULLER, N., WEIDINGER, E., SCHWARZ, M. J. \& MYINT, A. M. 2012. Effects of antidepressants and cyclooxygenase-2 inhibitor on cytokines and kynurenines in stimulated in vitro blood culture from depressed patients. Inflammopharmacology, 20, 169-76.

LEHTIMAKI, K., KERANEN, T., HUUHKA, M., PALMIO, J., HURME, M., LEINONEN, E. \& PELTOLA, J. 2008. Increase in plasma proinflammatory cytokines after electroconvulsive therapy in patients with depressive disorder. $J E C T$, 24, 88-91.

MOKHTAR, A. S., MORGAN, C. J., BRADLEY, D. M. \& BADAWY, A. A. 1997. No early effects of electroconvulsive therapy on tryptophan metabolism and disposition in endogenous depression. Biol Psychiatry, 42, 201-5.

MYINT, A. M. 2012. AS15-02 - Antidepressants and antiinflammatory agents on immunekynurenine pathway: results from in-vitro studies. European psychiatry: the journal of the Association of European Psychiatrists, 27, 1.

MYINT, A. M., BONDY, B., BAGHAI, T. C., ESER, D., NOTHDURFTER, C., SCHULE, C., ZILL, P., MULLER, N., RUPPRECHT, 
R. \& SCHWARZ, M. J. 2013. Tryptophan metabolism and immunogenetics in major depression: a role for interferon-gamma gene. Brain Behav Immun, 31, 128-33.

MYINT, A. M. \& KIM, Y. K. 2003. Cytokineserotonin interaction through IDO: a neurodegeneration hypothesis of depression. Med Hypotheses, 61, 519-25.

MYINT, A. M., KIM, Y. K., VERKERK, R., SCHARPE, S., STEINBUSCH, H. \& LEONARD, B. 2007. Kynurenine pathway in major depression: evidence of impaired neuroprotection. J Affect Disord, 98, 143-51.

MYINT, A. M., SCHWARZ, M. J. \& MULLER, N. 2012. The role of the kynurenine metabolism in major depression. J Neural Transm, 119, 245-51.

OADES, R. D., DAUVERMANN, M. R., SCHIMMELMANN, B. G., SCHWARZ, M. J. \& MYINT, A. M. 2010a. Attention-deficit hyperactivity disorder (ADHD) and glial integrity: S100B, cytokines and kynurenine metabolism--effects of medication. Behav Brain Funct, 6, 29.

OADES, R. D., MYINT, A. M., DAUVERMANN, M. R., SCHIMMELMANN, B. G. \& SCHWARZ, M. J. 2010b. Attention-deficit hyperactivity disorder (ADHD) and glial integrity: an exploration of associations of cytokines and kynurenine metabolites with symptoms and attention. Behav Brain Funct, 6,32 .

ONGUR, D. \& HECKERS, S. 2004. A role for glia in the action of electroconvulsive therapy. Harv Rev Psychiatry, 12, 253-62.

PALMIO, J., HUUHKA, M., SARANSAARI, P., OJA, S. S., PELTOLA, J., LEINONEN, E., SUHONEN, J. \& KERANEN, T. 2005. Changes in plasma amino acids after electroconvulsive therapy of depressed patients. Psychiatry Res, 137, 183-90.
RAISON, C. L., DANTZER, R., KELLEY, K. W., LAWSON, M. A., WOOLWINE, B. J., VOGT, G., SPIVEY, J. R., SAITO, K. \& MILLER, A. H. 2010. CSF concentrations of brain tryptophan and kynurenines during immune stimulation with IFN-alpha: relationship to $\mathrm{CNS}$ immune responses and depression. $\mathrm{Mol}$ Psychiatry, 15, 393-403.

ROTTER, A., BIERMANN, T., STARK, C., DECKER, A., DEMLING, J., ZIMMERMANN, R., SPERLING, W., KORNHUBER, J. \& HENKEL, A. 2013. Changes of Cytokine Profiles During Electroconvulsive Therapy in Patients With Major Depression. JECT.

SIENAERT, P. 2014. Mechanisms of ECT: reviewing the science and dismissing the myths. JECT, 30, 85-6.

SIMES, R. J. 1986. An improved Bonferroni procedure for multiple tests of significance. Biometrika, 73, 751-754.

STATACORP 2011. Stata/SE Statistical Software, Release 12. College Station, TX: StataCorp LP.

WHALLEY, L. J., YATES, C. M. \& CHRISTIE, J. E. 1980. Effect of electroconvulsive therapy (ECT) on plasma tryptophan. Psychol Med, 10, 377-80.

WICHERS, M. C., KOEK, G. H., ROBAEYS, G., VERKERK, R., SCHARPE, S. \& MAES, M. 2005. IDO and interferon-alpha-induced depressive symptoms: a shift in hypothesis from tryptophan depletion to neurotoxicity. Mol Psychiatry, 10, 538-44.

ZUNSZAIN, P. A., ANACKER, C., CATTANEO, A., CHOUDHURY, S., MUSAELYAN, K., MYINT, A. M., THURET, S., PRICE, J. \& PARIANTE, C. M. 2012. Interleukin-1 beta: a new regulator of the kynurenine pathway affecting human hippocampal neurogenesis. Neuropsychopharmacology, 37, 939-49. 


\section{Hypoxia-response genes moderate the impact of prospectively assessed obstetric complications on psychopathology in a general population female twin cohort}

Sinan Guloksuz, Marjan Drukker, Rainald Schmidt-Kastner, Gunter Kenis, Wolfgang Viechtbauer, Ehsan Pishva, Marieke Wichers, Nele Jacobs, Evert Thiery, Catherine Derom, Inez Myin-Germeys, Ruud van Winkel, Jim van

Os, Bart P.F Rutten. 



\section{Abstract}

Obstetric complications (OC) increase the risk of mental disorders. Links between schizophrenia candidate genes and hypoxia-response, including vascular factors have been proposed. We investigated in a general population sample of 334 females in 180 twin pairs from the East-Flanders Prospective Twin Survey whether associations between OC and expression of psychopathology were moderated by selected single nucleotide polymorphisms (SNPs) in genes that were previously shown to be associated with hypoxiaresponse regulation and schizophrenia. 23 SNPs in AKT1, BDNF, CHRNA7, DTNBP1, GABRB2, GRM3, NRG1, PLXNA2, RELN, RGS4, SNAP25, YWHAE were determined. Phenotyping was performed using the Symptom Checklist-90-Revised (SCL-90), and neurocognitive tests for episodic memory (EM), and information processing speed (IPS). Severe OC was defined using the McNeil Sjöström Scale. Data were analyzed using multilevel linear regression analysis. SNPs in AKT1 (rs1130233), BDNF (rs11030101), CHRNA7 (rs3087454), GABRB2 (rs1816072), PLXNA2 (rs752016, rs841865, rs2478813), RELN (rs7341475), RGS4 (rs2661319), and YWHAE (rs28365859) moderated the associations between OC and SCL-90 total scores. We also found significant main genetic, and interactive effects on subscales of the SCL-90, but not on EM or IPS. When SNPs per gene were analyzed together in one model per gene, only the variants in AKT1 showed a statistically significant interaction with OC on SCL-90 total, depression, and psychoticism scores. Our findings suggest that the interaction between hypoxia-response genes and $\mathrm{OC}$ influences the expression of mental ill health in general, and not just the expression of schizophrenia-specific psychopathological dimensions. 


\section{Introduction}

Epidemiological data suggest that severe obstetric complications (OC) increase the risk of mental disorders, and that such effects may be mediated by hypoxiaresponse(Mittal et al., 2008, Schmidt-Kastner et al., 2006). Earlier work has suggested moderation of the impact of severe OC on schizophrenia risk by certain variants in the schizophrenia candidate genes $A K T 1, B D N F, D T N B P 1, G R M 3$ (Nicodemus et al., 2008), and a recent systematic annotation of genes involved in hypoxia-response and genes associated with schizophrenia has provided in silico evidence linking obstetric complications, hypoxia-response and schizophrenia (Schmidt-Kastner et al., 2012). Given evidence of extended phenotypes of subthreshold psychopathology that can be detected throughout the population(van Os, 2013), it may be hypothesized that obstetric complications impact on psychopathology in general (rather than specifically schizophrenia) and that such associations between OC and psychopathology, as a geneenvironment interaction model, may also be studied in the general population(van Os et al., 2010).

In the present study, we aimed to investigate whether prospectively collected measures of OC are indeed associated with expression of mental ill health and whether these associations are moderated by a set of genes a priori selected on the basis of previous reports linking these genes with both hypoxia-response and schizophrenia (Schmidt-Kastner et al., 2012) in a well characterized cohort of young adult female twin pairs with increased risk for OC.

\section{Materials and Methods}

\section{Study population}

Data of the population based survey, the East Flanders Prospective Twin Survey (EFPTS), which has prospectively recorded all multiple births in East Flanders province since 1964, were used (Derom et al., 2013). One of the aims of the EFPTS is to investigate the role of gene-environment interactions in the vulnerability for psychiatric disorders, as described previously (Wigman et al., 2011). The original goal of the sample used for the present analyses was to study the role of stress-sensitivity in depression (Jacobs et al., 2006a). Only female twins were enrolled in the original study based on early studies showing sex-specific differences in environmental stressors associated with depression, and evidence for sex-specific genetic factors for depression and stress-sensitivity as measured by the personality trait neuroticism (Fanous et al., 2002). 
Of the original EFPTS sample, prospective data of OC and genotyping were available for 334 females in 180 twin pairs that comprised the current study population. Zygosity was determined through sequential analysis based on sex, fetal membranes, blood groups, and DNA fingerprints. All participants were Caucasian and Belgian. Participants were evaluated with questionnaires for 5 times at approximately 3 - to 4-monthly intervals over a period of 2.5 years. The study was approved by the local Medical Ethics Committee, and carried out in accordance with the Declaration of Helsinki. Written informed consent was obtained from each patient prior to participation. The mean age of the population was $24.4(\mathrm{SD}=5.2, \min -\mathrm{max}=18-36)$ years. Of the sample, $63.5 \%(\mathrm{n}=212)$ had a college or university degree, $36.5 \%(\mathrm{n}$ $=122)$ completed $>3$ years secondary education. Only $2 \%(n=7)$ of the participants were unemployed; $52 \%(\mathrm{n}=173)$ were employed and $46 \%(\mathrm{n}=153)$ were either student or else.

\section{Clinical Assessment}

The total score on the Symptom Checklist-90-Revised (SCL-90) was used for symptomatic phenotyping (LR, 1977, Arrindel W, 1986), which contains 90 items, scored on a 5-point severity scale, measuring 9 symptom dimensions named "somatization," "obsessive-compulsive," "interpersonal sensitivity," "depression," "anxiety," "hostility", "phobic anxiety," "paranoid ideation," and "psychoticism." Reliability and validity of the SCL-90-R were established previously (derogatis). The time frame is the past 2 weeks. We also investigated the scores on the SCL-90 subscales on items related to psychoticism, paranoid ideation and depression in more detailed analyses.

Neuropsychological assessment was directed to evaluate episodic memory (EM) and information processing speed (IPS) for phenotyping of cognition. As described previously (Simons et al., 2007), the EM factor was derived from the variables of the Auditory Verbal Learning Task (AVLT) (Brand and Jolles, 1985, Lezak, 1995) and the IPS factor was derived by using variables of the Stroop Color-Word Test (SCWT) (Lezak, 1995), the Concept Shifting Test (CST)(Houx PJ et al., 1991), and the Letter Digit Substitution Test (LDST)(Lezak, 1995).

The SCL-90 was assessed at each of the 5 evaluations, while the neuropsychological assessment was only performed at baseline.

\section{Obstetric Complication}

Using a subset of prospectively collected variables that were also used to generate the McNeil Sjöström Scale (MSS) (McNeil et al., 1994), a dichotomous obstetric complications (OC) variable was generated according to MSS severity scores. The 
MSS rates the severity of the several possible OCs from $1=$ not harmful or relevant to $6=$ very great harm or deviation in offspring, and is considered as the most sensitive scale to assess OC in schizophrenia (McNeil et al., 1994). We used MSS score $\geq 5$ to define severe OC in compliance with the previous study investigating the interaction between OC and hypoxia-response genes. (Nicodemus et al., 2008) Therefore, severe OC were defined as (1) birth-weight lower than 2 kilograms, (2) birth-weight $>20 \%$ lower than birth-weight of the sibling, (3) delivery mode was version extraction, (4) face/forehead presentation of fetus during delivery, or (5) umbilical cord complication. Twenty-three percent of the participants $(n=77)$ suffered from severe $\mathrm{OC}$ at birth.

\section{Gene Selection}

Genes were a priori selected on the basis of our analyses linking these genes with both hypoxia-response and schizophrenia(Schmidt-Kastner et al., 2012). A total of 23 SNPs in AKT1, BDNF, CHRNA7, DTNBP1, GABRB2, GRM3, NRG1, PLXNA2, RELN, RGS4, SNAP25, and YWHAE were analyzed (Table 1). The term "hypoxia-response genes" was defined by including all previously used criteria for annotation, including hypoxia-response, regulation by transcription factor hypoxiainducible factor 1 (HIF-1) and vascular expression or function(Schmidt-Kastner et al., 2012).

\section{DNA extraction and genotyping}

A total of 23 SNPs located at 12 genes were determined. Table 1 presents the list of genes, SNPs, and genotype frequencies. Genomic DNA was extracted from placental tissue, whole blood or buccal cell samples as described previously (Jacobs et al., 2006b) using QIAamp DNA Mini Kits (Qiagen, Venlo, the Netherlands) according to the appropriate protocol for each sample type. SNPs were determined

with the Sequenom MassARRAY iPLEX platform at the facilities of the manufacturer (Hamburg, Germany). None of the SNPs violated Hardy-Weinberg equilibrium. Two SNPs in the BDNF gene (rs12273539 and rs57083135) were excluded from the analyses due to very low minor allele frequencies. These SNPs had no variation even after recoding them into one dummy $(0,1)$ with combining the homogeneous minor allele and heterogeneous subjects (Table 1) Thus, in total 21 SNPs were analyzed.

\section{Statistical analyses}

Data were analyzed using the Stata 12.0.(StataCorp, 2011) Since data have a hierarchical structure, multiple assessments (level 1) were clustered within subjects (level 2), who were part of twin pairs (level 3), multilevel regression analyses were 


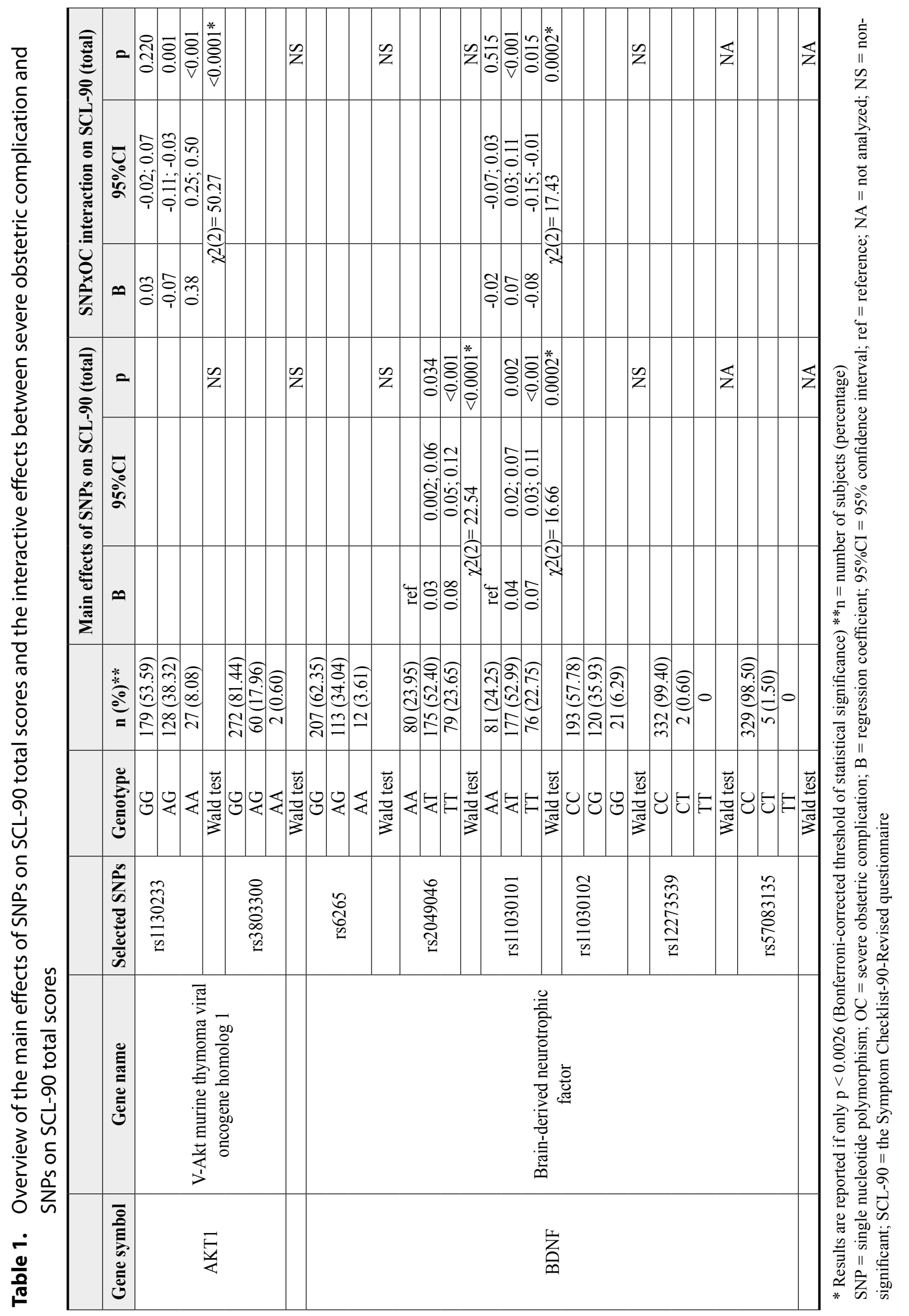

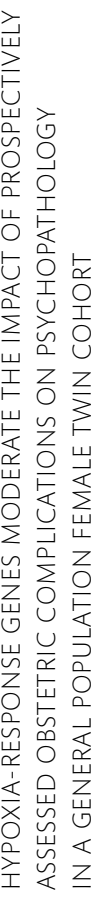




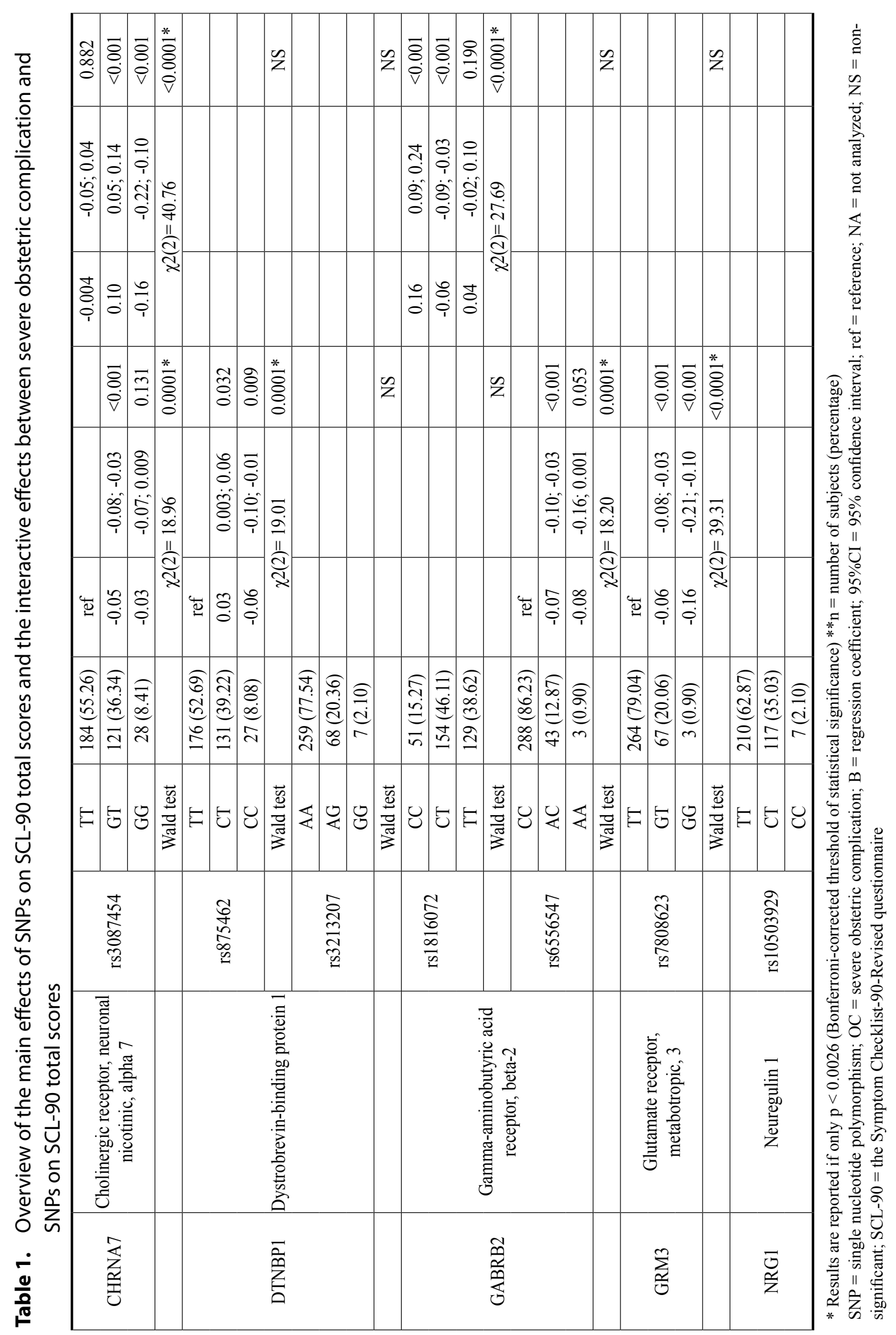




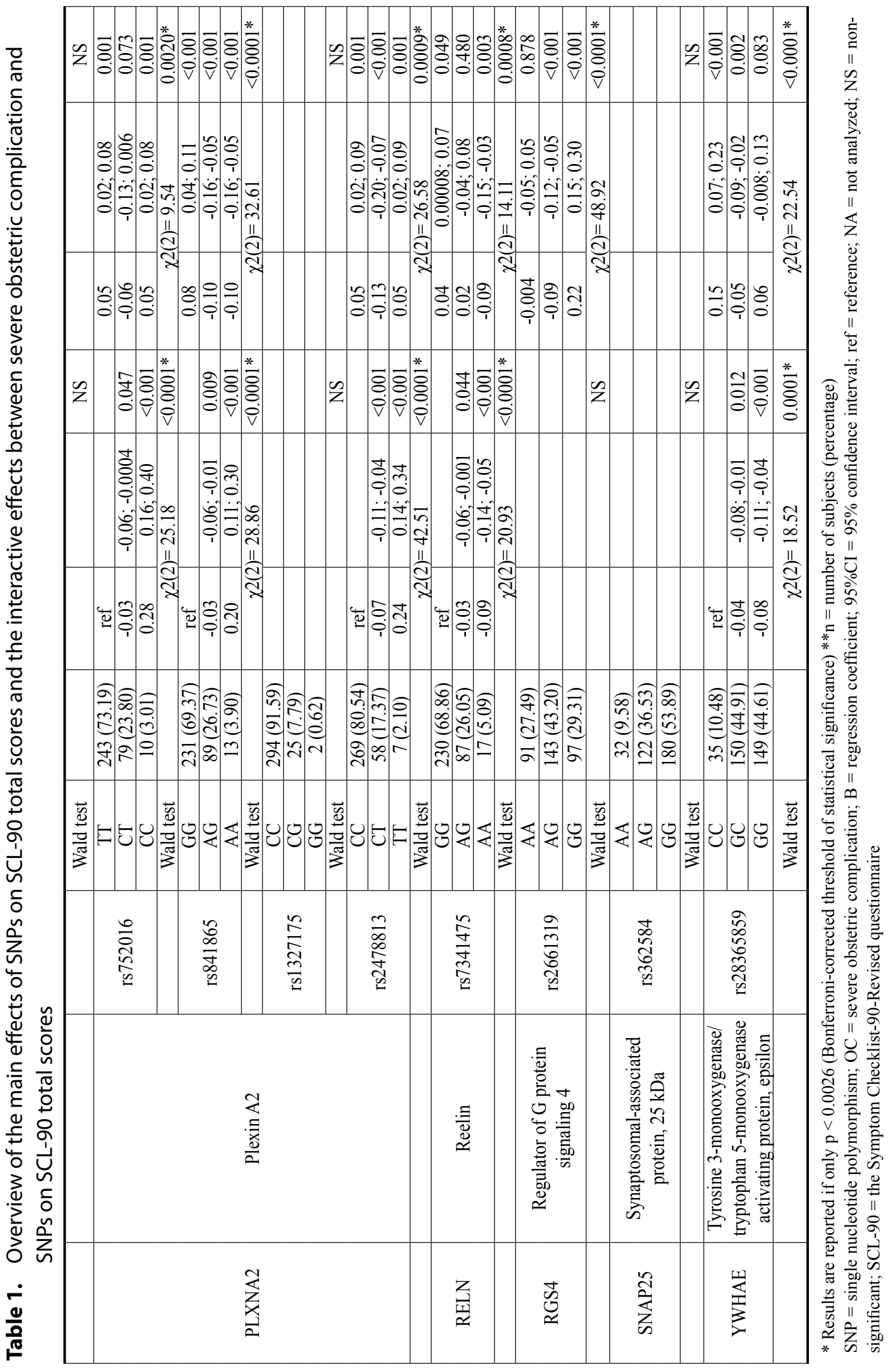

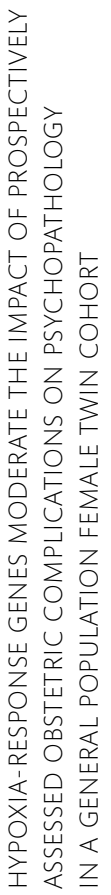


conducted. Multilevel linear regression (using the Stata XTMIXED command) is ideally suited for the analysis of such structured data, yielding twins clustered in twin pairs. Effect sizes of explanatory variables were expressed as regression coefficients (B) or odds ratios (OR), and can be interpreted identically to unilevel regression results.

First, main effects of SNPs (tested in separate models) and OC on SCL-90 measures, EM and IPS were analyzed. To check for gene-environment correlation, association between OC and SNPs was examined. Subsequently, for each SNP the interaction term $\mathrm{OC}^{*} \mathrm{SNP}$ was added to the model, where all SNPs were tested in separate models. The SNP variables were recoded into dummies $(0,1,2)$ when testing for main effects and interaction. When any of the interaction terms was statistically significant, the Stata LINCOM procedure was used to calculate regression coefficients for all categories of the SNP.

Given the number of statistical tests involved, we applied Bonferroni corrections for multiple testing to determine statistical significance. As most SNPs within one gene were significantly correlated (e.g., indicating that the SNPs are not independently inherited), and can therefore not be regarded as independent predictors in statistical analyses, we estimated the number of effective tests by the methods of Li and Ji(Benros et al., 2014) and Galway (Meyer, 2014), as being 19, thereby resulting into a critical alpha level of 0.0026 .

In addition, whole gene analysis was performed in order to capture the combined effect of SNPs located in one gene. Whole gene analysis is a procedure in which only the most extreme p-value of the SNPs per gene is extracted using permutation testing. An additional advantage is that permutation methods are in principal distribution free. In brief, when any of the SCL-90 measures was the dependent variable, each two blocks (twin 1 and twin 2) of five assessments were permutated to a different twin pair, while within the twin pair twin 1 and twin 2 were reshuffled. For each SNP of the respective gene, the interaction between $\mathrm{OC}$, as main independent variable, and SNP was analyzed and the p-value of the most significant SNP was copied to an empty database. This process of random permutation and analysis was performed 10000 times, resulting in a database with $10000 \mathrm{p}$-values representing the distribution of p-values under the null-hypothesis(Laird and Lange, 2011). On the other hand, the smallest p-value of all included SNPs of that particular gene was selected. As a final step, the $p$-value of the analysis in the original data was compared to distribution of p-values under the null-hypothesis (Laird and Lange, 2011). This was repeated for all 12 genes. A similar procedure was followed when cognition was the outcome, but twin pairs rather than two blocks of five assessments were permutated because cognition was only available from one time point. 
Table 2. Main effects of severe obstetric complication on SCL-90 and cognitive phenotypes

\begin{tabular}{lccc}
\hline & B & $\mathbf{9 5 \% C I}$ & $\mathbf{p}$ \\
\hline SCL-90 (total) & 0.02 & $-0.06 ; 0.09$ & 0.67 \\
SCL-90 (depression) & 0.03 & $-0.07 ; 0.14$ & 0.55 \\
SCL-90 (psychoticism) & -0.01 & $-0.05 ; 0.04$ & 0.79 \\
SCL-90 (paranoid ideation) & -0.04 & $-0.14 ; 0.07$ & 0.49 \\
Episodic memory & 0.05 & $-0.17 ; 0.28$ & 0.64 \\
Information processing speed & -0.02 & $-0.27 ; 0.24$ & 0.87 \\
\hline B = regression coefficient; 95\%CI $=95 \%$ confidence interval; SCL-90 $=$ the Symptom Checklist-90-Revised \\
questionnaire
\end{tabular}

\section{Results}

\section{Main Effects}

We found no statistically significant main effect of OC on psychopathology phenotypes (Table 2). There was no association between any of the SNPs and OC, thereby ruling out gene-environment correlation (results not shown). After controlling for multiple testing (with a conservative threshold of alpha=0.0026), we found main genetic effects of $B D N F$ (rs2049046, and rs11030101), CHRNA7 (rs3087454), DTNBP1 (rs875462), GABRB2 (rs6556547), GRM3 (rs7808623), PLXNA2 (rs752016, rs841865, and rs2478813), RELN (rs7341475), and YWHAE (rs28365859) genotypes on SCL-90 total scores (Table 1), but did not identify statistically significant main effects of SNPs on cognitive phenotypes (results not shown).

\section{Interaction effects}

Interaction analyses revealed that, after correction for multiple testing, SNPs in $A K T 1$ (rs1130233), BDNF (rs11030101), CHRNA7 (rs3087454), GABRB2 (rs1816072), PLXNA2 (rs752016, rs841865, rs2478813), RELN (rs7341475), RGS4 (rs2661319), and YWHAE (rs28365859) moderated the associations between severe OC and SCL-90 total scores (Fig 1). We found, after correction for multiple testing, no significant gene-environment interactions on the cognitive phenotypes (results not shown). Results for main genetic, and interactive effects on subscales of the SCL90 (psychoticism, paranoid ideation, and depression) are provided in Supplementary Tables S1 and S2.

\section{Whole gene interaction analysis}

Whole gene permutation analyses revealed that, when SNPs per gene were analyzed together in one model per gene, the variants in AKT1 but not in PLXNA2, 


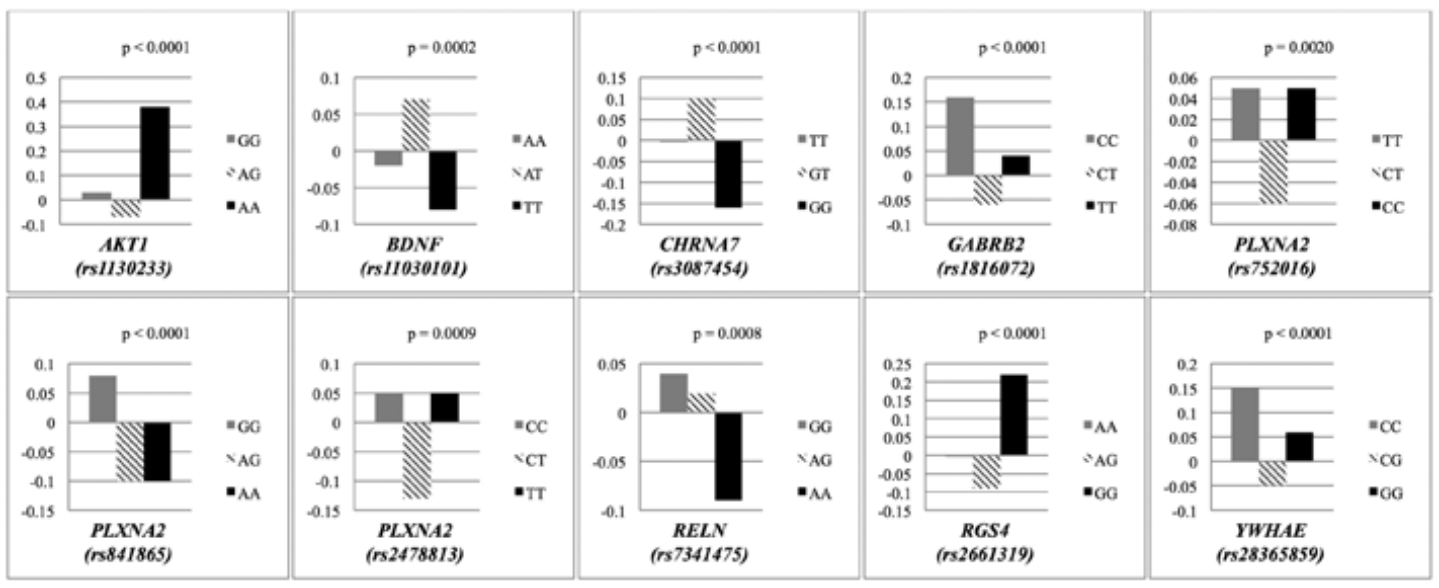

Figure 1. Interactive effects between severe obstetric complication and SNPs on SCL-90 total scores.

Results are reported if only $p<0.0026$ for (Bonferroni-corrected threshold of statistical significance) interactive effect. $Y$-axis represents the $B$ (unstandardized regression coefficient) for obstetric complication at each genotype of the SNP.

$B D N F, D T N B P 1$, or $G A B R B 2$ showed a statistically significant interaction with severe OC on SCL-90-total, SCL-90-depression, and SCL-90-psychoticism (Table 3).

Table 3. Whole gene permutation analyses: effects of the interaction between severe obstetric complication and whole genes on SCL-90

\begin{tabular}{|l|c|c|c|c|c|c|}
\hline & $\begin{array}{c}\text { SCL-90 } \\
\text { (total) }\end{array}$ & $\begin{array}{c}\text { SCL-90 } \\
\text { (depression) }\end{array}$ & $\begin{array}{c}\text { SCL-90 } \\
\text { (psychoticism) }\end{array}$ & $\begin{array}{c}\text { SCL-90 } \\
\text { (paranoid ideation) }\end{array}$ & $\begin{array}{c}\text { Episodic } \\
\text { memory }\end{array}$ & $\begin{array}{c}\text { Information } \\
\text { processing speed }\end{array}$ \\
\hline$A K T 1^{1}$ & $\mathrm{p}=0.0151$ & $\mathrm{p}=0.0156$ & $\mathrm{p}=0.0176$ & $\mathrm{p}=0.2167$ & $\mathrm{p}=0.3885$ & $\mathrm{p}=0.5635$ \\
\hline$B D N F^{2}$ & $\mathrm{p}=0.7935^{3}$ & $\mathrm{p}=0.8181$ & $\mathrm{p}=0.6716$ & $\mathrm{p}=0.9035$ & $\mathrm{p}=0.2597$ & $\mathrm{p}=0.2343$ \\
\hline $\mathrm{DTNBP} 1$ & $\mathrm{p}=0.9211$ & $\mathrm{p}=0.6861$ & $\mathrm{p}=0.8193$ & $\mathrm{p}=0.6893$ & $\mathrm{p}=0.1897$ & $\mathrm{p}=0.2187$ \\
\hline GABRB2 & $\mathrm{p}=0.1473$ & $\mathrm{p}=0.3338$ & $\mathrm{p}=0.3338$ & $\mathrm{p}=0.1934$ & $\mathrm{p}=0.1856$ & $\mathrm{p}=0.8473$ \\
\hline PLXNA2 $^{1}$ & $\mathrm{p}=0.0831$ & $\mathrm{p}=0.1023$ & $\mathrm{p}=0.1424$ & $\mathrm{p}=0.2989$ & $\mathrm{p}=0.6874$ & $\mathrm{p}=0.5119$ \\
\hline
\end{tabular}

${ }^{1}$ rs3803300 (AKT1), rs6556547 (GABRB2), rs841865 (PLXNA2) rs2478813 (PLXNA2) rs1327175 (PLXNA2) rs752016 (PLXNA2) SNPs were recoded $2=1$ ${ }^{2}$ rs $12273539(B D N F)$ was excluded

${ }^{3}$ In one of 10000 analyses: convergence not achieved.

$A K T 1$ includes rs 1130233 and $\mathrm{rs} 3803300$

$B D N F$ includes rs6265, rs2049046, rs11030101, rs11030102, rs57083135

$D T N B P 1$ includes rs875462, rs3213207

GABRB2 includes rs 1816072 , rs6556547

PLXNA2 includes rs752016, rs841865, rs1327175, rs2478813

SCL-90 $=$ the Symptom Checklist-90-Revised questionnaire 


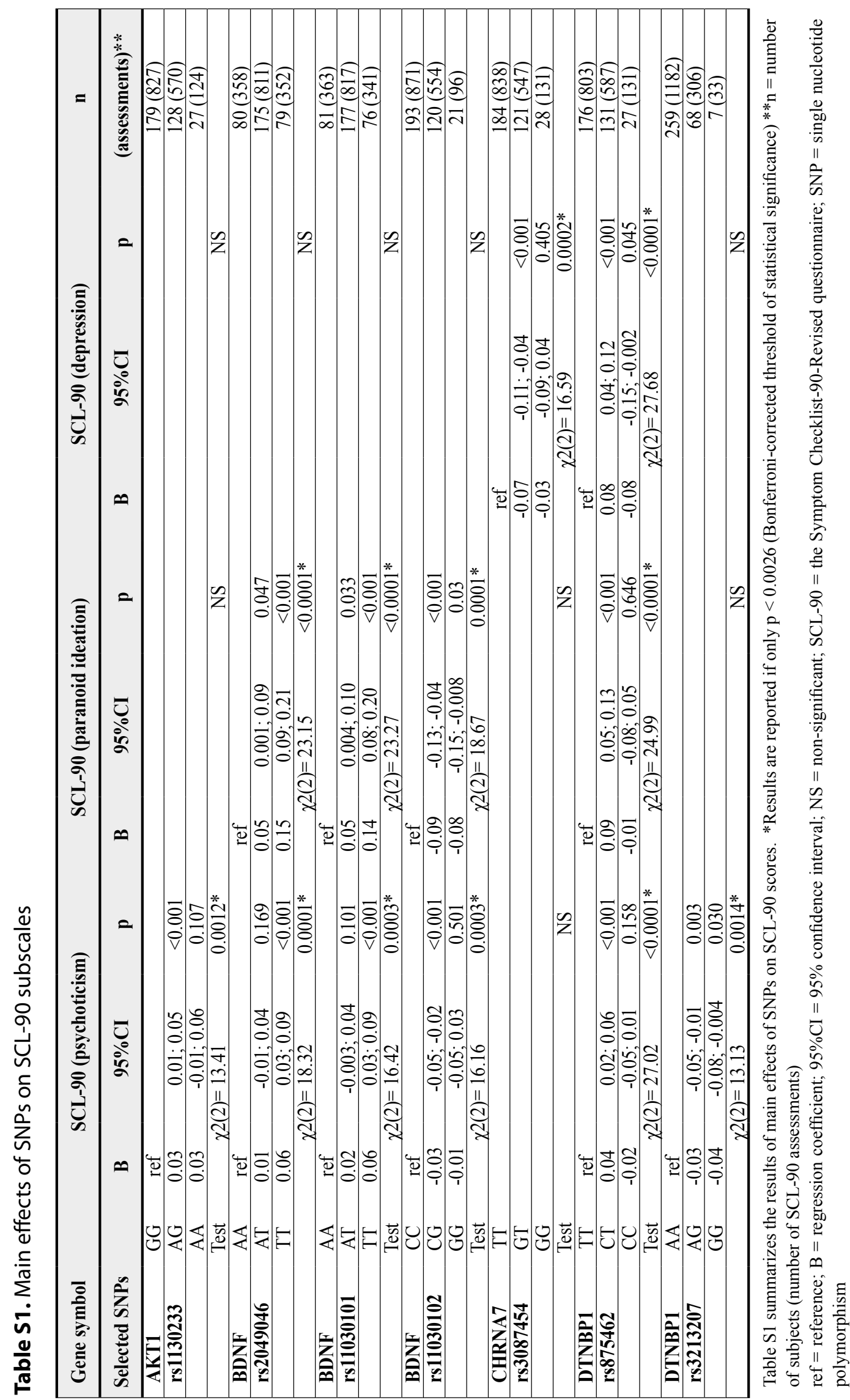

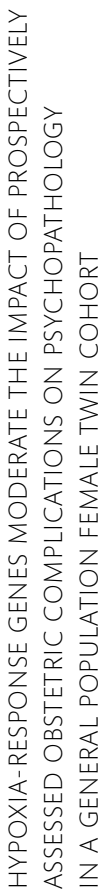




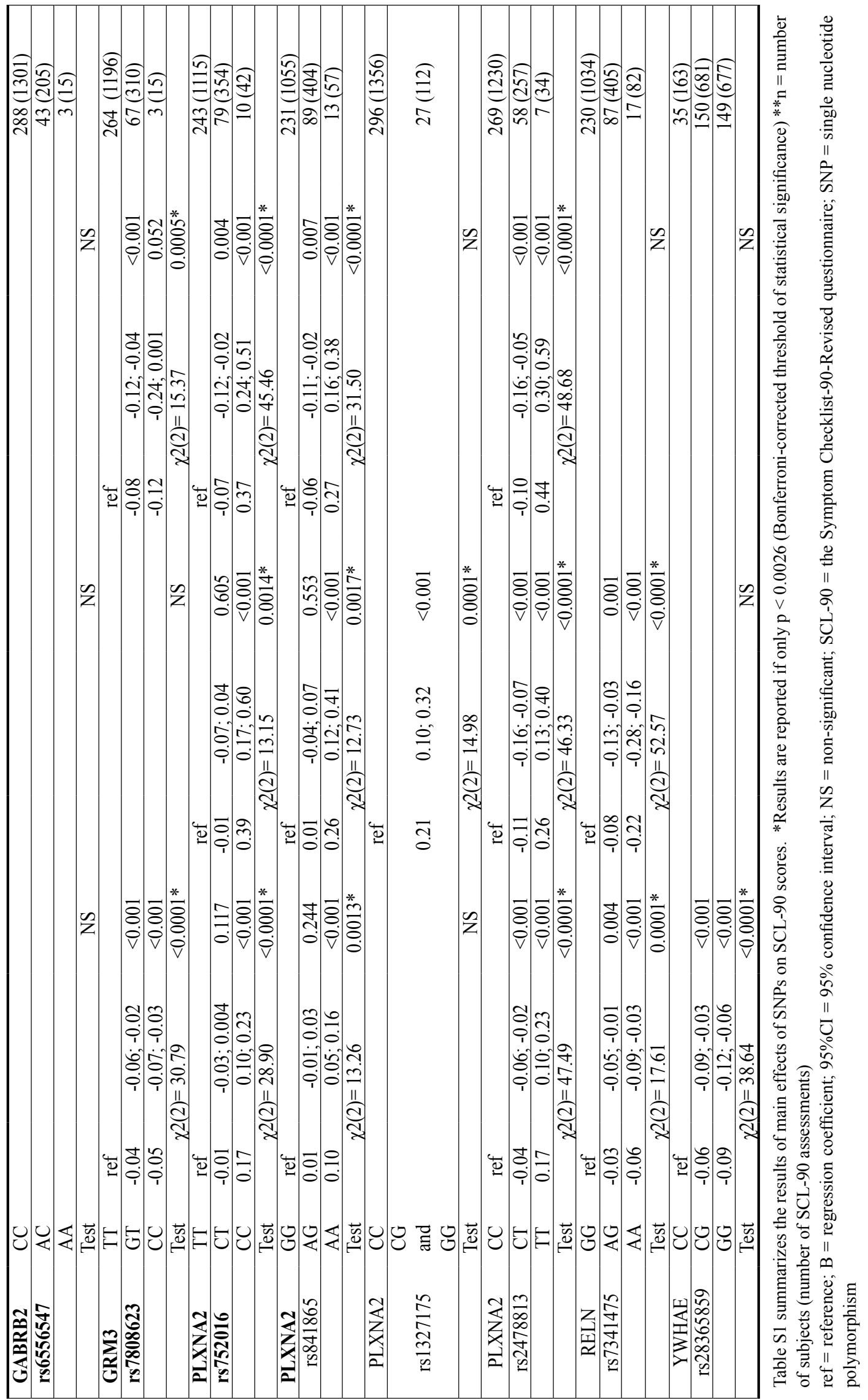




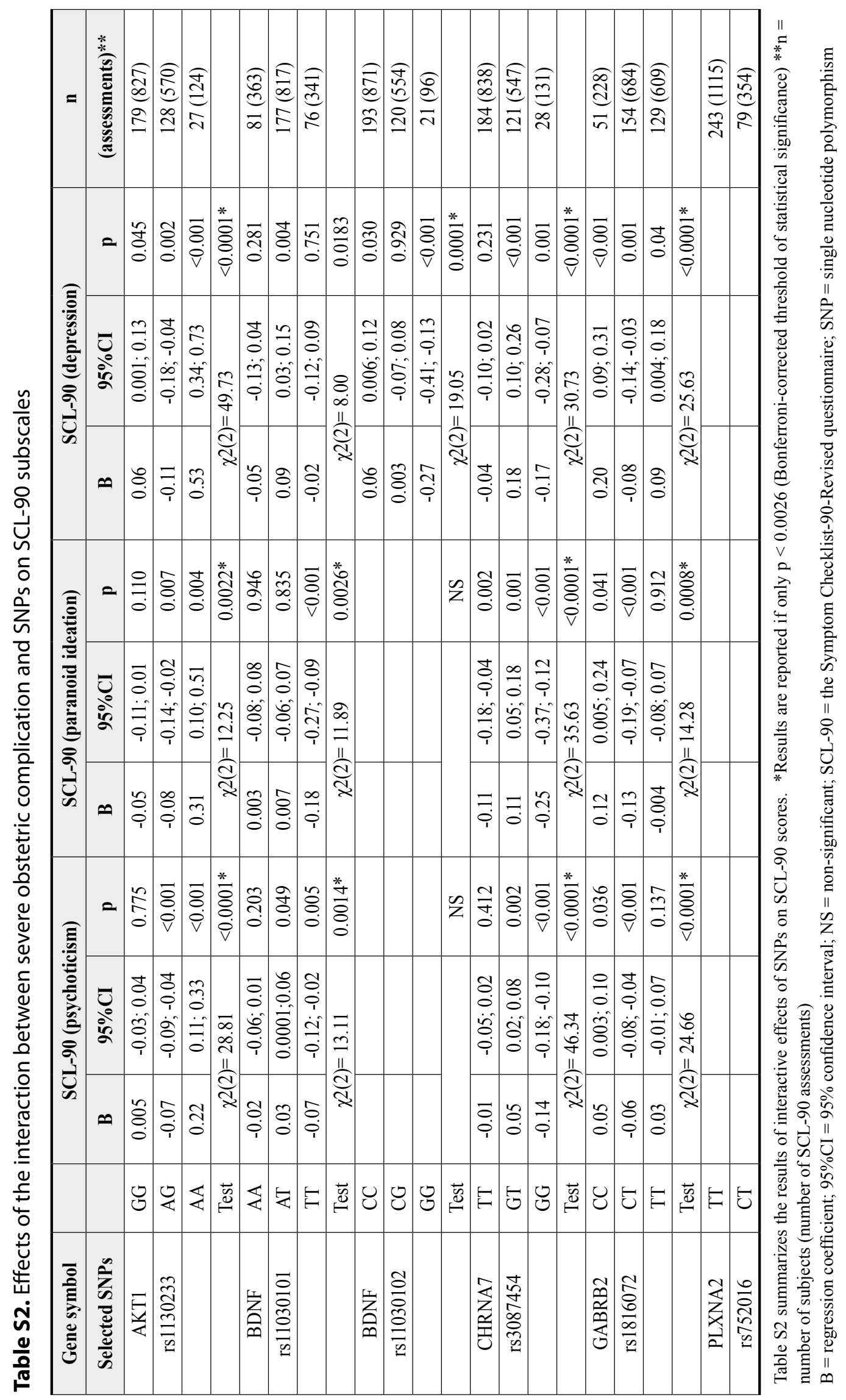

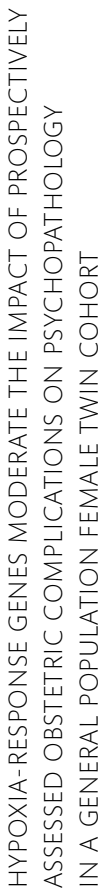




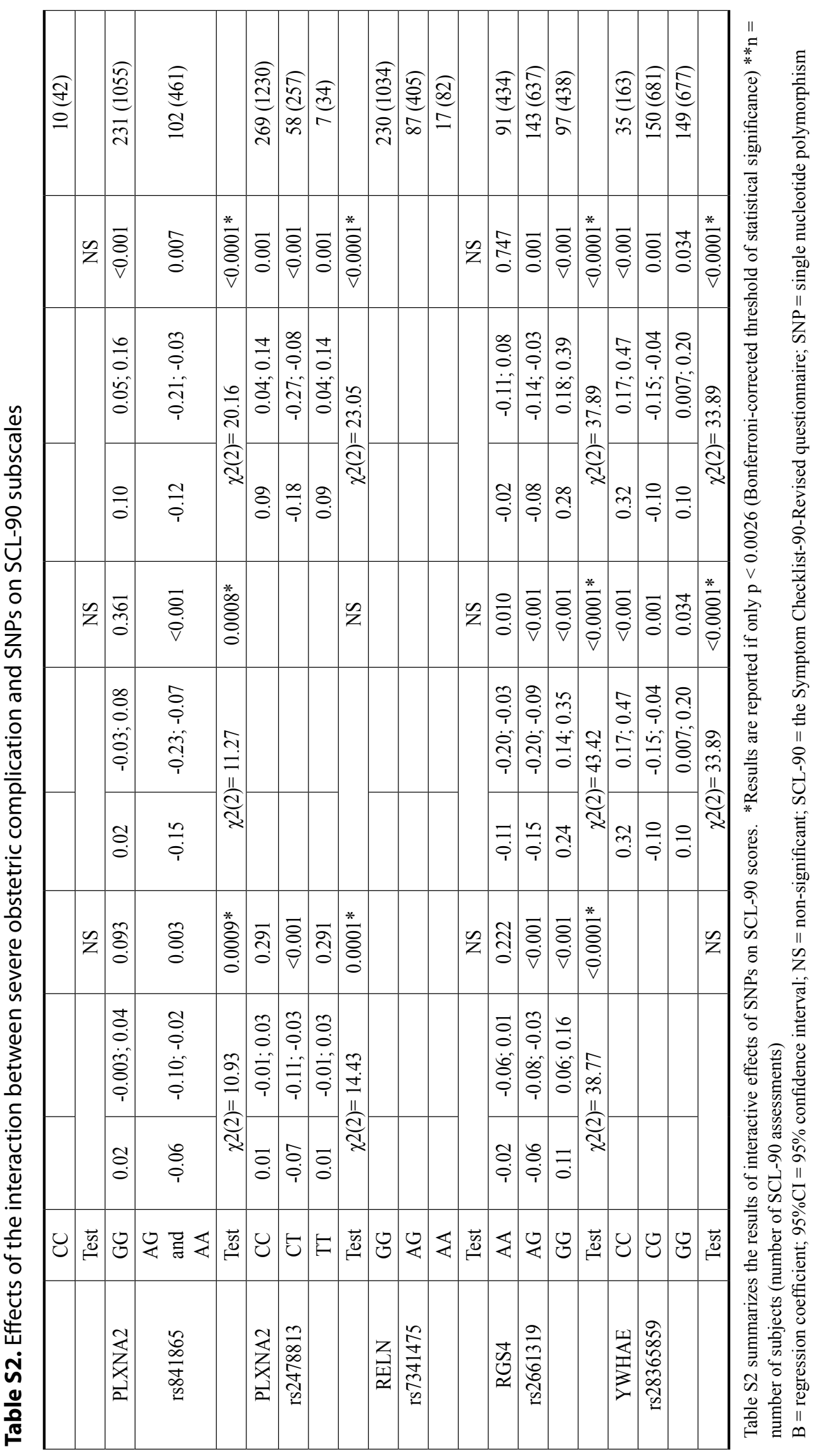




\section{Discussion}

To our knowledge, this is the first study investigating the interacting influence of $\mathrm{OC}$ and hypoxia-response genes on mental symptoms in the general population. We found that SNPs in $A K T 1$ (rs1130233), BDNF (rs11030101), CHRNA7 (rs3087454), GABRB2 (rs1816072), PLXNA2 (rs752016, rs841865, rs2478813), RELN(rs7341475), $R G S 4$ (rs2661319), and YWHAE (rs28365859) interacted with OC for self-reported subclinical symptoms of psychopathology. Furthermore, whole gene analysis revealed that $A K T 1$ moderated the effect of OC on the SCL-90.

AKT1 is highly expressed in the central nervous system (CNS), and plays a pivotal role in apoptosis, cell growth and differentiation (Dudek et al., 1997). AKT1, located on chromosome 14q32.32, has been associated with schizophrenia(Emamian et al., 2004, Ikeda et al., 2004, Schwab et al., 2005, Bajestan et al., 2006, Norton et al., 2007, Xu et al., 2007, Karege et al., 2010, Mathur et al., 2010, Thiselton et al., 2008, Shi et al., 2008), bipolar disorder (Karege et al., 2012), depressive and manic symptoms in patients with schizophrenia (Thiselton et al., 2008), suicidal behavior (Magno et al., 2010), antipsychotic treatment response(Ikeda et al., 2008), and cognitive functioning (Tan et al., 2008, van Winkel et al., 2011b, Ohi et al., 2013, Pietilainen et al., 2009). We demonstrated that the AA genotype of SNP rs1130233 in $A K T 1$ increased the association between severe OC and psychopathology load across all symptom dimensions assessed with the SCL-90. These findings are in line with a previous gene-environment interaction study reporting a 4-fold increased risk for schizophrenia in individuals with severe OC history, and having transmitted the minor allele of rs 1130233 (A) $(\mathrm{OR}=3.9795 \% \mathrm{CI}=1.13,13.92)$ (Nicodemus et al., 2008). However, the other SNP in $A K T 1$ (rs3803300), which was previously shown to be moderating the impact of severe OC on schizophrenia phenotype(Nicodemus et al., 2008), failed to produce statistically significant gene-environment interaction moderating psychopathology in the present study. A Korean study investigating six SNPs in the $A K T 1$ gene in patients with schizophrenia, demonstrated that rs1130233 was associated with the severity of the OC (assessed using the Lewis scale) in the subgroup of female patients, but not in the entire sample(Joo et al., 2009). A recent research using functional and structural magnetic resonance imaging showed that the minor allele of rs1130233 (A) impaired hippocampus-mediated plasticity related to memory encoding, and reduced medial temporal lobe development through epistatic interaction with $B D N F$ and $C O M T$ variants in healthy controls. Furthermore, this deleterious impact of $A K T 1$ (rs1130233) on cognition and neuroplasticity in schizophrenia patients appeared to be relatively reduced by $A K T 1$ activators such as lithium and valproate (Tan et al., 2012a). The A allele of rs1130233 was associated with reduced $A K T 1$ expression, reduced prefrontal-subcortical inhibitory effective 
connectivity, and less IQ change but only in association with higher anti-psychotic doses in schizophrenia, as well as disturbed inhibitory prefrontal-to-striatal effective connectivity in healthy controls (Tan et al., 2012b). Recent studies indicating that the influence of cannabis use on the expression of psychosis (van Winkel et al., 2011a) as well as cognitive functioning in psychotic disorders (van Winkel et al., 2011b) was moderated by genetic variation in $A K T 1$-including rs1130233- lend further support to the premise of $A K T 1$ variants as moderators of the impact of environmental exposures on mental health and psychopathology. Although, our findings warrant further confirmations from other prospective cohorts, we can at least speculate that AKT1 might influence the deleterious impact of severe OC on the developing CNS under ischemia-hypoxia conditions, which in turn leads to emergence of mental symptoms in the adulthood.

In our study, RGS4 variant rs2661319 also emerged as a promising SNP showing potentially relevant interactions with $\mathrm{OC}$ to moderate psychopathology consistently across symptom dimensions. The GG genotype of rs2661319 increased the association between severe OC and psychopathology load across all symptom dimensions assessed with the SCL-90, whereas the AG genotype appeared to be reducing this association. The RGS4 gene has been associated with schizophrenia, albeit inconsistently (Talkowski et al., 2006, Levitt et al., 2006, Nicodemus et al., 2007). Studies using endophenotypes such as schizotypy(Stefanis et al., 2008), prefrontal cortex abnormalities (Prasad et al., 2005), oculomotor parameters (Kattoulas et al., 2012), cognitive impairment (Stefanis et al., 2008, Prasad et al., 2010) as outcomes in both patient and general populations have shown that variants of $R G S 4$ are linked to the extended psychosis phenotype. Both statistical (Nicodemus et al., 2007) and functional epistasis(Buckholtz et al., 2007) between RGS4 and COMT influencing prefrontal cortex functioning were demonstrated. Overall, findings suggest, in a similar vein to those of $A K T 1$, that altered $R G S 4$ expression impacts global functioning of the CNS through regulation of signal transduction of several neurotransmitters (i.e. dopamine, glutamate, serotonin, and gamma aminobutyric acid), thereby linking to a broad spectrum of overlapping phenotypes that are across diagnostic categories.

The outcomes of the study should be interpreted in the light of its strengths and limitations. The cohort is relatively small in size (at least for genetic studies) and the current findings require replication. However, the study was sufficiently powered to discover statistically significant associations, owing to (a) the prospectively collected obstetric data (thereby eliminating recall bias) (b) in a population with an increased frequency of obstetric complications, (c) the multiple phenotypical assessments per individual, and (d) controlling each hypothesis for multiple testing that yielded a stringent threshold for alpha (thereby avoiding possible Type-I errors). 
Future studies may use cumulative risk scores of certain biologically informative (for example genes involved in the hypoxia-response) gene sets and test for main and interactive effects with environmental exposures, among which records of obstetric complications (European Network of National Networks studying Gene-Environment Interactions in et al., 2014).

Overall, this study shows that there is an interaction between genes meeting the criteria for a link to hypoxia-response, including vascular factors, and severe OC to moderate several dimensions related to psychopathology in a female twin cohort from the general population. The findings of this study, along with the previous evidence, suggest that an interaction between hypoxia-response genes and OC influences the expression of mental ill health in general, and not solely specific to schizophrenia. 


\section{Funding and disclosure}

The research leading to these results has received funding from the European Community's Seventh Framework Program under grant agreement No. HEALTH-F2-2009-241909 (Project EU-GEI). Since its origin the East Flanders Prospective Survey has been partly supported by grants from the Fund of Scientific Research, Flanders and Twins, a non-profit Association for Scientific Research in Multiple Births (Belgium). All authors declare that they have no conflict of interest.

\section{Acknowledgement}

We thank all twins for their cooperation. 


\section{References}

ARRINDEL W, E. J. 1986. The SCL90. A Multidimensional Instrument for the Assessment of Psychopathology [in Dutch]. Lisse, Swets \& Zeitlinger

BAJESTAN, S. N., SABOURI, A. H., NAKAMURA, M., TAKASHIMA, H., KEIKHAEE, M. R., BEHDANI, F., FAYYAZI, M. R., SARGOLZAEE, M. R., BAJESTAN, M. N., SABOURI, Z., KHAYAMI, E., HAGHIGHI, S., HASHEMI, S. B., EIRAKU, N., TUFANI, H., NAJMABADI, H., ARIMURA, K., SANO, A. \& OSAME, M. 2006. Association of AKT1 haplotype with the risk of schizophrenia in Iranian population. $A m$ $J$ Med Genet B Neuropsychiatr Genet, 141B, 383-6.

BENROS, M. E., EATON, W. W. \& MORTENSEN, P. B. 2014. The epidemiologic evidence linking autoimmune diseases and psychosis. Biol Psychiatry, 75, 300-6.

BRAND, N. \& JOLLES, J. 1985. Learning and retrieval rate of words presented auditorily and visually. The Journal of general psychology, 112, 201-10.

BUCKHOLTZ, J. W., SUST, S., TAN, H. Y., MATTAY, V. S., STRAUB, R. E., MEYERLINDENBERG, A., WEINBERGER, D. R. \& CALLICOTT, J. H. 2007. fMRI evidence for functional epistasis between COMT and RGS4. Mol Psychiatry, 12, 893-5, 885.

DEROM, C., THIERY, E., PEETERS, H., VLIETINCK, R., DEFOORT, P. \& FRIJNS, J. P. 2013. The East Flanders Prospective Twin Survey (EFPTS): an actual perception. Twin Res Hum Genet, 16, 58-63.

DUDEK, H., DATTA, S. R., FRANKE, T. F., BIRNBAUM, M. J., YAO, R., COOPER, G. M., SEGAL, R. A., KAPLAN, D. R. \& GREENBERG, M. E. 1997. Regulation of neuronal survival by the serine-threonine protein kinase Akt. Science, 275, 661-5.

EMAMIAN, E. S., HALL, D., BIRNBAUM, M. J., KARAYIORGOU, M. \& GOGOS, J. A. 2004. Convergent evidence for impaired AKT1GSK3beta signaling in schizophrenia. Nat Genet, 36, 131-7.
EUROPEAN NETWORK OF NATIONAL NETWORKS STUDYING GENEENVIRONMENT INTERACTIONS IN, S., VAN OS, J., RUTTEN, B. P., MYIN-GERMEYS, I., DELESPAUL, P., VIECHTBAUER, W., VAN ZELST, C., BRUGGEMAN, R., REININGHAUS, U., MORGAN, C., MURRAY, R. M., DI FORTI, M., MCGUIRE, P., VALMAGGIA, L. R., KEMPTON, M. J., GAYER-ANDERSON, C., HUBBARD, K., BEARDS, S., STILO, S. A., ONYEJIAKA, A., BOURQUE, F., MODINOS, G., TOGNIN, S., CALEM, M., O'DONOVAN, M. C., OWEN, M. J., HOLMANS, P., WILLIAMS, N., CRADDOCK, N., RICHARDS, A., HUMPHREYS, I., MEYERLINDENBERG, A., LEWEKE, F. M., TOST, H., AKDENIZ, C., ROHLEDER, C., BUMB, J. M., SCHWARZ, E., ALPTEKIN, K., UCOK, A., SAKA, M. C., ATBASOGLU, E. C., GULOKSUZ, S., GUMUS-AKAY, G., CIHAN, B., KARADAG, H., SOYGUR, H., CANKURTARAN, E. S., ULUSOY, S., AKDEDE, B., BINBAY, T., AYER, A., NOYAN, H., KARADAYI, G., AKTURAN, E., ULAS, H., ARANGO, C., PARELLADA, M., BERNARDO, M., SANJUAN, J., BOBES, J., ARROJO, M., SANTOS, J. L., CUADRADO, P., RODRIGUEZ SOLANO, J. J., CARRACEDO, A., GARCIA BERNARDO, E., ROLDAN, L., LOPEZ, G., CABRERA, B., CRUZ, S., DIAZ MESA, E. M., POUSO, M., JIMENEZ, E., SANCHEZ, T., RAPADO, M., GONZALEZ, E., MARTINEZ, C., SANCHEZ, E., OLMEDA, M. S., DE HAAN, L., VELTHORST, E., VAN DER GAAG, M., SELTEN, J. P., VAN DAM, D., VAN DER VEN, E., VAN DER MEER, F., MESSCHAERT, E., KRAAN, T., BURGER, N., LEBOYER, M., SZOKE, A., SCHURHOFF, F., LLORCA, P. M., JAMAIN, S., TORTELLI, A., FRIJDA, F., VILAIN, J., GALLIOT, A. M., BAUDIN, G., et al. 2014. Identifying gene-environment interactions in schizophrenia: contemporary challenges for integrated, large-scale investigations. Schizophr Bull, 40, 729-36. 
FANOUS, A., GARDNER, C. O., PRESCOTT, C. A., CANCRO, R. \& KENDLER, K. S. 2002. Neuroticism, major depression and gender: a population-based twin study. Psychol Med, 32, 719-28.

HOUX PJ, VREELING FW \& JOLLES J 1991. Age-associated cognitive decline is related to biological life-events. In: IQBAL K, MCLACHLAN DRC, WINBLAD B \& HM, W. (eds.) Alzheimer's Disease: Basic Mechanisms, Diagnosis and Therapeutic Strategies. Chichester: John Wiley \& Sons Ltd.

IKEDA, M., IWATA, N., SUZUKI, T., KITAJIMA, T., YAMANOUCHI, Y., KINOSHITA, Y., INADA, T. \& OZAKI, N. 2004. Association of AKT1 with schizophrenia confirmed in a Japanese population. Biol Psychiatry, 56, 698-700.

IKEDA, M., YAMANOUCHI, Y., KINOSHITA, Y., KITAJIMA, T., YOSHIMURA, R., HASHIMOTO, S., O’DONOVAN, M. C., NAKAMURA, J., OZAKI, N. \& IWATA, N. 2008. Variants of dopamine and serotonin candidate genes as predictors of response to risperidone treatment in first-episode schizophrenia. Pharmacogenomics, 9, 1437-43.

JACOBS, N., KENIS, G., PEETERS, F., DEROM, C., VLIETINCK, R. \& VAN OS, J. 2006a. Stress-related negative affectivity and genetically altered serotonin transporter function: evidence of synergism in shaping risk of depression. Archives of general psychiatry, 63, 989-96.

JACOBS, N., KENIS, G., PEETERS, F., DEROM, C., VLIETINCK, R. \& VAN OS, J. 2006b. Stress-related negative affectivity and genetically altered serotonin transporter function: evidence of synergism in shaping risk of depression. Arch Gen Psychiatry, 63, 989-96.

JOO, E. J., LEE, K. Y., JEONG, S. H., ROH, M. S., KIM, S. H., AHN, Y. M. \& KIM, Y. S. 2009. AKT1 Gene Polymorphisms and Obstetric Complications in the Patients with Schizophrenia. Psychiatry investigation, 6, 102-7.

KAREGE, F., MEARY, A., PERROUD, N., JAMAIN, S., LEBOYER, M., BALLMANN, E., FERNANDEZ, R., MALAFOSSE, A. \& SCHURHOFF, F. 2012. Genetic overlap between schizophrenia and bipolar disorder: a study with AKT1 gene variants and clinical phenotypes. Schizophr Res, 135, 8-14.

KAREGE, F., PERROUD, N., SCHURHOFF, F., MEARY, A., MARILLIER, G., BURKHARDT, S., BALLMANN, E., FERNANDEZ, R., JAMAIN, S., LEBOYER, M., LA HARPE, R. \& MALAFOSSE, A. 2010. Association of AKT1 gene variants and protein expression in both schizophrenia and bipolar disorder. Genes Brain Behav, 9, 503-11.

KATTOULAS, E., STEFANIS, N. C., AVRAMOPOULOS, D., STEFANIS, C. N., EVDOKIMIDIS, I. \& SMYRNIS, N. 2012. Schizophrenia-related RGS4 gene variations specifically disrupt prefrontal control of saccadic eye movements. Psychol Med, 42, 757-67.

LAIRD, N. M. \& LANGE, C. 2011. The Fundamentals of Modern Statistical Genetics, New York Dordrecht Heidelberg London, Springer.

LEVITT, P., EBERT, P., MIRNICS, K., NIMGAONKAR, V. L. \& LEWIS, D. A. 2006. Making the case for a candidate vulnerability gene in schizophrenia: Convergent evidence for regulator of G-protein signaling 4 (RGS4). Biol Psychiatry, 60, 534-7.

LEZAK, M. D. 1995. Neuropsychological Assessment Oxford., Oxford University Press.

LR, D. 1977. SCL90: Administration, Scoring and Procedures Manual I., Baltimore, MD., John Hopkins School of Medicine.

MAGNO, L. A., MIRANDA, D. M., NEVES, F. S., PIMENTA, G. J., MELLO, M. P., DE MARCO, L. A., CORREA, H. \& ROMANOSILVA, M. A. 2010. Association between AKT1 but not AKTIP genetic variants and increased risk for suicidal behavior in bipolar patients. Genes Brain Behav, 9, 411-8.

MATHUR, A., LAW, M. H., MEGSON, I. L., SHAW, D. J. \& WEI, J. 2010. Genetic association of the AKT1 gene with schizophrenia in a British population. Psychiatr Genet, 20, 118-22.

MCNEIL, T. F., CANTOR-GRAAE, E. \& SJOSTROM, K. 1994. Obstetric complications as antecedents of schizophrenia: empirical effects of using different obstetric complication 
scales. Journal of psychiatric research, 28, 519-30.

MEYER, U. 2014. Prenatal poly(i:C) exposure and other developmental immune activation models in rodent systems. Biol Psychiatry, 75, 307-15.

MITTAL, V. A., ELLMAN, L. M. \& CANNON, T. D. 2008. Gene-environment interaction and covariation in schizophrenia: the role of obstetric complications. Schizophrenia bulletin, 34, 1083-94.

NICODEMUS, K. K., KOLACHANA, B. S., VAKKALANKA, R., STRAUB, R. E., GIEGLING, I., EGAN, M. F., RUJESCU, D. \& WEINBERGER, D. R. 2007. Evidence for statistical epistasis between catechol-Omethyltransferase (COMT) and polymorphisms in RGS4, G72 (DAOA), GRM3, and DISC1: influence on risk of schizophrenia. Hum Genet, 120, 889-906.

NICODEMUS, K. K., MARENCO, S., BATTEN, A. J., VAKKALANKA, R., EGAN, M. F., STRAUB, R. E. \& WEINBERGER, D. R. 2008. Serious obstetric complications interact with hypoxia-regulated/vascular-expression genes to influence schizophrenia risk. Molecular psychiatry, 13, 873-7.

NORTON, N., WILLIAMS, H. J., DWYER, S., CARROLL, L., PEIRCE, T., MOSKVINA, V., SEGURADO, R., NIKOLOV, I., WILLIAMS, N. M., IKEDA, M., IWATA, N., OWEN, M. J. \& O'DONOVAN, M. C. 2007. Association analysis of AKT1 and schizophrenia in a UK case control sample. Schizophr Res, 93, 58-65.

OHI, K., HASHIMOTO, R., YASUDA, Y., FUKUMOTO, M., NEMOTO, K., OHNISHI, T., YAMAMORI, H., TAKAHASHI, H., IIKE, N., KAMINO, K., YOSHIDA, T., AZECHI, M., IKEZAWA, K., TANIMUKAI, H., TAGAMI, S., MORIHARA, T., OKOCHI, M., TANAKA, T., KUDO, T., IWASE, M., KAZUI, H. \& TAKEDA, M. 2013. The AKT1 gene is associated with attention and brain morphology in schizophrenia. World J Biol Psychiatry, 14, 100-13.

PIETILAINEN, O. P., PAUNIO, T., LOUKOLA, A., TUULIO-HENRIKSSON, A., KIESEPPA, T., THOMPSON, P., TOGA, A. W., VAN ERP, T. G., SILVENTOINEN, K., SORONEN, P., HENNAH, W., TURUNEN, J. A., WEDENOJA, J., PALO, O. M., SILANDER,
K., LONNQVIST, J., KAPRIO, J., CANNON, T. D. \& PELTONEN, L. 2009. Association of AKT1 with verbal learning, verbal memory, and regional cortical gray matter density in twins. Am J Med Genet B Neuropsychiatr Genet, 150B, 683-92.

PRASAD, K. M., ALMASY, L., GUR, R. C., GUR, R. E., POGUE-GEILE, M., CHOWDARI, K. V., TALKOWSKI, M. E. \& NIMGAONKAR, V. L. 2010. RGS4 polymorphisms associated with variability of cognitive performance in a family-based schizophrenia sample. Schizophr Bull, 36, 983-90.

PRASAD, K. M., CHOWDARI, K. V., NIMGAONKAR, V. L., TALKOWSKI, M. E., LEWIS, D. A. \& KESHAVAN, M. S. 2005. Genetic polymorphisms of the RGS4 and dorsolateral prefrontal cortex morphometry among first episode schizophrenia patients. $\mathrm{Mol}$ Psychiatry, 10, 213-9.

SCHMIDT-KASTNER, R., VAN OS, J., ESQUIVEL, G., STEINBUSCH, H. W. \& RUTTEN, B. P. 2012. An environmental analysis of genes associated with schizophrenia: hypoxia and vascular factors as interacting elements in the neurodevelopmental model. Molecular psychiatry.

SCHMIDT-KASTNER, R., VAN OS, J., H, W. M. S. \& SCHMITZ, C. 2006. Gene regulation by hypoxia and the neurodevelopmental origin of schizophrenia. Schizophrenia research, 84, 253-71.

SCHWAB, S. G., HOEFGEN, B., HANSES, C., HASSENBACH, M. B., ALBUS, M., LERER, B., TRIXLER, M., MAIER, W. \& WILDENAUER, D. B. 2005. Further evidence for association of variants in the AKT1 gene with schizophrenia in a sample of European sib-pair families. Biol Psychiatry, 58, 446-50.

SHI, J., GERSHON, E. S. \& LIU, C. 2008. Genetic associations with schizophrenia: meta-analyses of 12 candidate genes. Schizophr Res, 104, 96-107.

SIMONS, C. J., JACOBS, N., JOLLES, J., VAN OS, J. \& KRABBENDAM, L. 2007. Subclinical psychotic experiences and cognitive functioning as a bivariate phenotype for genetic studies in the general population. Schizophrenia research, 92, 24-31. 
STATACORP 2011. Stata/SE Statistical Software, Release 12. College Station, TX: StataCorp LP.

STEFANIS, N. C., TRIKALINOS, T. A., AVRAMOPOULOS, D., SMYRNIS, N., EVDOKIMIDIS, I., NTZANI, E. E., HATZIMANOLIS, A., IOANNIDIS, J. P. \& STEFANIS, C. N. 2008. Association of RGS4 variants with schizotypy and cognitive endophenotypes at the population level. Behav Brain Funct, 4, 46.

TALKOWSKI, M. E., SELTMAN, H., BASSETT, A. S., BRZUSTOWICZ, L. M., CHEN, X., CHOWDARI, K. V., COLLIER, D. A., CORDEIRO, Q., CORVIN, A. P., DESHPANDE, S. N., EGAN, M. F., GILL, M., KENDLER, K. S., KIROV, G., HESTON, L. L., LEVITT, P., LEWIS, D. A., LI, T., MIRNICS, K., MORRIS, D. W., NORTON, N., O'DONOVAN, M. C., OWEN, M. J., RICHARD, C., SEMWAL, P., SOBELL, J. L., ST CLAIR, D., STRAUB, R. E., THELMA, B. K., VALLADA, H., WEINBERGER, D. R., WILLIAMS, N. M., WOOD, J., ZHANG, F., DEVLIN, B. \& NIMGAONKAR, V. L. 2006. Evaluation of a susceptibility gene for schizophrenia: genotype based meta-analysis of RGS4 polymorphisms from thirteen independent samples. Biological psychiatry, $60,152-62$.

TAN, H. Y., CHEN, A. G., CHEN, Q., BROWNE, L. B., VERCHINSKI, B., KOLACHANA, B., ZHANG, F., APUD, J., CALLICOTT, J. H., MATTAY, V. S. \& WEINBERGER, D. R. 2012a. Epistatic interactions of AKT1 on human medial temporal lobe biology and pharmacogenetic implications. Molecular psychiatry, 17, 1007-16.

TAN, H. Y., CHEN, A. G., KOLACHANA, B., APUD, J. A., MATTAY, V. S., CALLICOTT, J. H., CHEN, Q. \& WEINBERGER, D. R. 2012 b. Effective connectivity of AKT1-mediated dopaminergic working memory networks and pharmacogenetics of anti-dopaminergic treatment. Brain, 135, 1436-45.

TAN, H. Y., NICODEMUS, K. K., CHEN, Q., LI, Z., BROOKE, J. K., HONEA, R., KOLACHANA, B. S., STRAUB, R. E., MEYER-LINDENBERG, A., SEI, Y., MATTAY, V. S., CALLICOTT, J. H. \& WEINBERGER, D. R. 2008. Genetic variation in AKT1 is linked to dopamine-associated prefrontal cortical structure and function in humans. J Clin Invest, 118, 2200-8.

THISELTON, D. L., VLADIMIROV, V. I., KUO, P. H., MCCLAY, J., WORMLEY, B., FANOUS, A., O'NEILL, F. A., WALSH, D., VAN DEN OORD, E. J., KENDLER, K. S. \& RILEY, B. P. 2008. AKT1 is associated with schizophrenia across multiple symptom dimensions in the Irish study of high density schizophrenia families. Biol Psychiatry, 63, 449-57.

VAN OS, J. 2013. The dynamics of subthreshold psychopathology: implications for diagnosis and treatment. Am J Psychiatry, 170, 695-8.

VAN OS, J., KENIS, G. \& RUTTEN, B. P. 2010. The environment and schizophrenia. Nature, 468, 203-12.

VAN WINKEL, R., GENETIC, R. \& OUTCOME OF PSYCHOSIS, I. 2011a. Family-based analysis of genetic variation underlying psychosis-inducing effects of cannabis: sibling analysis and proband follow-up. Arch Gen Psychiatry, 68, 148-57.

VAN WINKEL, R., VAN BEVEREN, N. J., SIMONS, C., GENETIC, R. \& OUTCOME OF PSYCHOSIS, I. 2011b. AKT1 moderation of cannabis-induced cognitive alterations in psychotic disorder. Neuropsychopharmacology, 36, 2529-37.

WIGMAN, J. T., VAN WINKEL, R., JACOBS, N., WICHERS, M., DEROM, C., THIERY, E., VOLLEBERGH, W. A. \& VAN OS, J. 2011. A twin study of genetic and environmental determinants of abnormal persistence of psychotic experiences in young adulthood. American journal of medical genetics. Part $B$, Neuropsychiatric genetics : the official publication of the International Society of Psychiatric Genetics, 156B, 546-52.

XU, M. Q., XING, Q. H., ZHENG, Y. L., LI, S., GAO, J. J., HE, G., GUO, T. W., FENG, G. Y., XU, F. \& HE, L. 2007. Association of AKT1 gene polymorphisms with risk of schizophrenia and with response to antipsychotics in the Chinese population. J Clin Psychiatry, 68, 1358-67. 


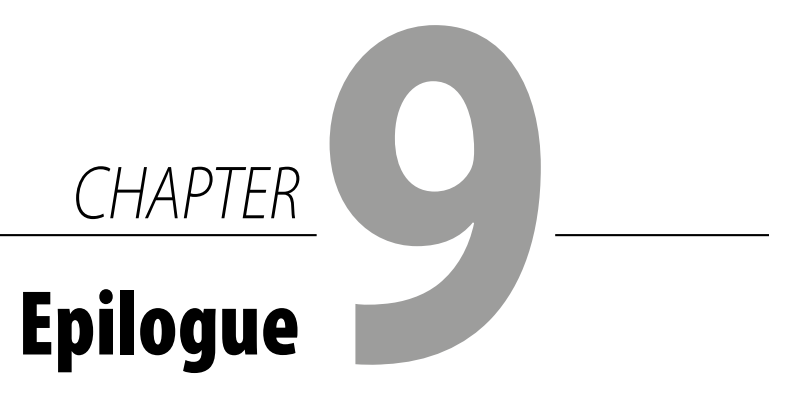



The overall aim of this thesis was to investigate the role of immune-related pathways in the pathogenesis of mood disorders. My research has addressed several research questions related to this overall aim and used several approaches. I have furthermore extended this work with a study on links between hypoxia-related genes and the impact of obstetric complications on expression of psychopathology. The background of these research questions and the outcomes of these studies are summarized below, and are followed by a discussion of methodological issues as well as future directions and conclusion.

\section{Immune deregulation in bipolar disorder: Is it trait or state?}

To date, aberrant immune functioning in bipolar disorder (BD) has been widely acknowledged (Berk et al., 2011, Stertz et al., 2013). Numerous studies demonstrate that pro-inflammation emerges during manic episodes evidenced by an increase in circulating pro-inflammatory immune markers, such as tumor necrosis factor alpha (TNF- $\alpha$ ) (O'Brien et al., 2006, Brietzke et al., 2009, Kim et al., 2004), interleukin (IL-6) (Kim et al., 2004, Brietzke et al., 2009), interferon gamma (IFN- $\gamma$ ) (Kim et al., 2004), chemokines (Barbosa et al., 2013), C-reactive protein (CRP) (Cunha et al., 2008), and oxidative stress (Berk et al., 2011). Similarly, bipolar depression is likely associated with escalated inflammation, but more research is required to reach a firm conclusion as relatively few studies have thus far focused on depressive episodes (Brietzke et al., 2009, Ortiz-Dominguez et al., 2007, O’Brien et al., 2006, Breunis et al., 2003). Certainly, one of the most intriguing questions remaining unresolved is whether these immune changes persist into the euthymic period, and could therefore be used as trait markers underpinning the immune-related pathogenesis of BD. However, the multi-faceted nature of BD hinders further progress in understanding of the underlying immune-related pathophysiological mechanisms.

As TNF- $\alpha$ concentrations were persistently increased up to 6 weeks even after treatment for manic symptoms, it has been argued that TNF- $\alpha$ might be a trait marker (Kim et al., 2007). Furthermore, there are some studies showing higher TNF- $\alpha$ and soluble tumor necrosis factor receptor-1 (TNFR-I) concentrations in euthymic patients compared to those in healthy controls (Brietzke et al., 2009, Barbosa et al., 2011).

Nevertheless, it should be taken into account that several confounding factors may have an impact on these immune markers. For instance, weight gain has been linked to pro-inflammation via disturbed TNF- $\alpha$ mediated pathways (Hotamisligil et al., 1994, Hotamisligil et al., 1993). Likewise, increased pro-inflammation, with respect to increased TNF- $\alpha$ after antipsychotic treatment, has been attributed to antipsychotic induced weight gain (Pollmacher et al., 1996, Hinze-Selch et al., 2000, 
Kluge et al., 2009). However, this theory has been challenged because of the lack of strong evidence implying causality, with the exception of temporal direction. It is therefore possible that increased TNF- $\alpha$ might be merely a consequence of weight gain (Baptista and Beaulieu, 2002). In both scenarios, body mass index (BMI) stands as an important factor while investigating the circulating immune markers in psychiatric disorders (Haack et al., 1999). Nearly all of the current psychiatric medications are indeed shown to be influencing circulating cytokine concentrations (Pollmacher et al., 2000, Haack et al., 1999). Immune-modulatory effects of lithium have been widely recognized for a long period of time and tested for the treatment of several medical conditions associated with immune deregulation (Rybakowski, 2000). Evidence suggests, albeit inconclusively, that mood stabilizers such as valproate (Ichiyama et al., 2000) and carbamazepine (Himmerich et al., 2005) may also have immunemodulating effects. Similarly, numerous studies revealed that antipsychotics, with the exception of haloperidol (Pollmacher et al., 1997), influence circulating cytokine concentrations either through weight gain or other possible mechanisms that require further investigation (Miller et al., 2011). Age and sex also alter peripheral cytokine concentrations (Himmerich et al., 2006, Haack et al., 1999). These confounders should therefore be taken into account when investigating whether immune activation is an authentic disease-related trait/state marker of BD or merely an artifact of confounders.

Chapter 2 aims to explore this topic through measuring serum cytokine concentrations (IFN- $\gamma$, TNF- $\alpha$, IL- 2, IL-4, IL-5, and IL-10) in a carefully selected homogeneous sample of patients with $\mathrm{BD}$ to address the confounding factors (age, sex, BMI and medication). For the first time in the field, the study recruited a subsample consisting of medication-free euthymic bipolar patients using the advantage of utilizing the largest number of patients registered at a tertiary referral mood disorders outpatient unit in Turkey with high quality medical record keeping procedures as prescribed by the SKIP-TURK nationwide mood disorder follow-up program (Tirpan et al., 2004). Subsequently, age and sex matched bipolar patients who had been on lithium monotherapy for more than 8 weeks, and healthy controls without psychiatric illness were recruited for comparison. There were no differences in cytokine concentrations between medication-free euthymic bipolar patients and healthy controls, but both TNF- $\alpha$ and IL-4 were higher in lithium treated patients than in both medication-free euthymic bipolar patients and healthy controls. These findings suggest that the aberrant immune functioning in $\mathrm{BD}$ resolves during euthymia, and that pro-inflammation might be a state rather than a trait.

However, it should be noted that these medication-free euthymic bipolar patients might be at the less severe end of the spectrum, and it is likely that more severe clinical prognoses might be more closely linked to immune deregulation (Kapczinski 
et al., 2009). Inflammation may even remain present throughout the euthymic period in treatment resistant cases with ongoing residual symptoms or in cases with a shorter euthymic period as a result of frequent relapses.

This is in line with the results presented in chapter 3 suggesting that plasma TNF- $\alpha$ concentrations were higher in patients with poor lithium response compared to those with good response -after controlling for confounders. Furthermore, TNF- $\alpha$ concentrations were negatively associated with ALDA lithium response scores. These findings further support the idea of ongoing subthreshold inflammation in more severe cases. However, the study failed to demonstrate any difference in sTNF-R1, sIL$6 \mathrm{R}$ and sIL-2R concentrations between euthymic bipolar patients with and without subsyndromal symptoms (see Chapter 4). Unfortunately, the cross-sectional design of these studies precluded conclusive interpretations.

After chapter 2, 3 and 4 were published, three meta-analytical reviews focusing on circulating cytokine alterations in BD were performed. The first meta-analysis including both in vivo and in vitro studies (30 studies with a total of 2599 participants) demonstrated that IL-4, IL-10, sIL-2R, TNF- $\alpha$, sTNF-R1, IL-1 receptor antagonists were higher in BD (euthymia, mania and depression combined) than in healthy controls (Modabbernia et al., 2013). Second, Munkholm et al. found that sIL-2R, TNF- $\alpha$, sTNF-R1, sIL-6R, IL-4 were higher in BD than in healthy controls in their meta-analysis including only in vivo studies (18 studies including a total of 761 bipolar patients and 919 healthy controls (Munkholm et al., 2013). These two meta-analytical reviews provide some evidence that circulating cytokine concentrations are increased in $\mathrm{BD}$ regardless of the mood state. However, both of them also point out that the majority of studies have not addressed the influence of confounding factors (e.g., BMI, age, and medication). Therefore this limitation, along with the heterogeneity of samples, severely impeded their capacity to infer more conclusive evidence from the current data.

Overall, substantial evidence confirms the existence of pro-inflammation in BD, but the question whether this inflammatory state persists through the euthymic period still remains unanswered.

\section{Impact of lithium on immune system: Does it have a role in the therapeutic efficacy of lithium in bipolar disorder?}

Due to its immune-modulatory effects, lithium could be successfully used to treat Herpes Simplex Virus infections (Amsterdam et al., 1990) and medication induced leukopenia (Mattai et al., 2009). Numerous studies investigating the in vivo and in vitro effects of lithium on immune system in patients with $\mathrm{BD}$ have established that 
lithium moderates several pathways in a bidirectional manner to regulate immune response (Rapaport et al., 1999, Rapaport and Manji, 2001, Boufidou et al., 2004, Maes et al., 1999). However, these studies do not particularly focus on the possible role of these alterations as a therapeutic mechanism of action of lithium.

To extend the current knowledge, Chapter 3 focuses on the role of TNF- $\alpha$ as a biological indicator for the long-term lithium response. An inverse correlation between TNF- $\alpha$ and total ALDA lithium response scale scores, and higher TNF- $\alpha$ concentrations in poor lithium responders than in good responders were demonstrated. Given that, it is plausible to speculate that downregulation of the activated immune response, which in this case was estimated by circulating TNF- $\alpha$ concentrations, likely plays a role in lithium's long-term mood stabilizing effects along with several other postulated mechanisms.

Additionally, our findings showing no difference in unstimulated serum concentrations of IFN- $\gamma$, TNF- $\alpha$, IL- 2 , IL-4, IL-5, and IL-10 between well-controls and medication-free bipolar patients, who were euthymic for a mean period of 133.7 weeks $(\mathrm{SD}=137.5)$ without medication, show that the restoration of immune balance might be essential for the mood stabilization (see Chapter 2). Interestingly, in comparison to well-controls and medication-free bipolar patients, lithium monotherapy bipolar patients, who were also euthymic for a similar time period $(M=190.4, \mathrm{SD}=181.4$ weeks), with a mean duration of lithium use for $155.1(\mathrm{SD}=183.1)$ weeks, had higher levels of TNF- $\alpha$ (a major pro-inflammatory cytokine) and IL-4 (an anti-inflammatory cytokine counterbalancing the effect of pro-inflammatory mediators).

The findings from our studies combined with the current literature suggest that immune regulatory effects of lithium might have a role in its mechanism of action. However, the lack of prospective data once more prevents us from proposing a more solid statement.

\section{Effects of anti-inflammatory medications on mood symptoms in inflammatory diseases: new hope for the treatment of mood disorders?}

Abundant evidence shows the link between immune activation and depressive symptoms in chronic inflammatory diseases with a relapsing-remitting course, i.e. Crohn's Disease (CD) (Fuller-Thomson and Sulman, 2006, Loftus et al., 2011) and Rheumatoid Arthritis (RA) (Dickens et al., 2002). Furthermore, clinical drug trials show that anti-inflammatory medications used to treat these conditions, such as TNF- $\alpha$ antagonists, display distinctive antidepressant effects (Persoons et al., 2005, Kurz et al., 2011). Overall, these studies highlight the critical role of underlying immune- 
mediated mechanisms involved in depressive symptoms which are commonly observed in chronic inflammatory disorders, and thereby paving the way for novel anti-inflammatory treatment of mood disorders.

Chapter 5 investigated the impact of anti-TNF- $\alpha$ (infliximab) infusion on depressive symptoms, in association with immune markers (acute phase proteins [APP] and zinc) and tryptophan availability in $\mathrm{CD}$ as an inflammatory disease model, in order to elucidate the underlying mechanisms linking depressive symptoms and the immune activation in chronic inflammatory diseases. This study showed that infliximab reduced depressive symptoms, and that both the level and the percentage of gamma fraction were associated with the Symptom Checklist (SCL-90) depression scores over time, even after correction for the disease activity assessed by the HarveyBradshaw Index (HBI). Additionally, patients with a current/past depressive disorder displayed increased positive APP (levels of $\gamma, \alpha 2, \beta$ fractions; and percentages of $\gamma, \alpha 2$ fractions) and lower negative APP (the level of albumin fraction, and the percentage of albumin fraction) and zinc, again even after correction for the disease activity. These findings support the notion that the immune activation may play a role in the pathogenesis of comorbid depression in $\mathrm{CD}$, and that anti-TNF- $\alpha$ (infliximab) is beneficial in reducing depressive symptoms, in part independent of its effect on the disease activity. Given that, it is plausible to speculate that anti-inflammatory medications such as anti-TNF- $\alpha$ might be useful in the treatment of depressive disorders, particularly in treatment-resistant cases.

The majority of psychotropics have immune-modulatory effects, and a metaanalysis demonstrated that antidepressants reduce circulating pro-inflammatory cytokine (IL-1 $\beta$ and IL-6) concentrations, with serotonin reuptake inhibitors decreasing TNF- $\alpha$ as well (Hannestad et al., 2011). However, it remains elusive whether these immune-modulatory effects also contribute to the therapeutic efficacy of antidepressants in depression.

Furthermore, Raison et al. demonstrated that infliximab was effective for treatmentrefractory depression in a subgroup of patients with increased baseline concentrations of immune markers. However, infliximab failed to produce a significant effect over placebo in the rest of the sample (Raison et al., 2012). Although recent evidence is promising for anti-inflammatory treatment in mood disorders, an extensive series of double-blind randomized controlled drug trials should be conducted before introducing these medications as safe and efficacious treatment options in routine clinical practice. In this regard, several studies have studied the efficacy of medications with TNF- $\alpha$ antagonism (infliximab and minocycline) for treatment-refractory depression and bipolar depression, in association with inflammatory markers, with some encouraging findings (Savitz et al., 2012, Miyaoka et al., 2012, Dean et al., 2014). 


\section{ECT \& immune functioning: can we observe links between markers of the immune system and the therapeutic efficacy of ECT?}

Electroconvulsive therapy (ECT) has remained the most effective and the fastest acting treatment for mood disorders over almost a century. However, the mechanism of action of ECT remains elusive. Interestingly, despite growing evidence that suggests the importance of aberrant immune functioning in the pathophysiology of mood disorders, the role of immune-related pathways in the mechanism of action of ECT has received little attention. Few studies investigating the impact of ECT on circulating immune markers indicate that ECT induces a transient immune activation immediately after a single ECT session, whereas repeated ECT might downregulate immune activation (see Chapter 6).

Immune mediated tryptophan catabolism has been suggested to play a pivotal role in bridging the aberrant immune functioning and neurotransmitter deregulation involved in the pathophysiology of depression. Research shows circulating kynurenine (KYN)/tryptophan (TRP) (tryptophan turnover ratio) concentrations were higher, whereas kynurenic acid (KYNA) (a putative neuroprotective molecule with $\mathrm{N}$-methyl-D-aspartate (NMDA) receptor antagonism), kynurenic acid/ kynurenine (kynurenine to kynurenic acid conversion ratio), and tryptophan/large neutral amino acids (tryptophan availability) were lower in medication-free patients with major depression than in normal controls.

Given that, Chapter 7 aims to investigate the impact of ECT treatment on the tryptophan-kynurenine metabolic pathway - as a means of exploring the connection between brain and immunity- in patients with unipolar or bipolar depression. The study examined whether circulating metabolites on the tryptophan-kynurenine pathway change over the treatment period and the following 6 weeks, in association with depression scores, and whether these metabolite concentrations at baseline predict the response to ECT. This study provides first line evidence for the longterm impact of ECT on the tryptophan-kynurenine metabolic pathway, with results showing that KYNA, KYNA/3-HK, KYNA/KYN, and KYN/TRP levels increased after ECT, and that levels of KYN and KYN/TRP were negatively associated with total depression scores. These findings demonstrate that ECT influences the TRPKYN pathway with a shift toward the 'neuroprotective' side. Although these results provide a perspective about the long-term effects of ECT on the TRP-KYN metabolic pathway, and therefore yield further support for the hypothesis that the impact of ECT on immune-regulated processes might play a role in its working mechanism, more research that measures both direct and remote indicators of inflammation in large 
samples needs to be undertaken before the link between ECT and the immune system is more clearly understood.

\section{Understanding the role of obstetric complications in psychopathology using a gene-environment interaction model.}

Findings from large epidemiological studies have now established that obstetric complications (OC) increase the risk for psychiatric syndromes, particularly psychosis. However, efforts to take this statistical association one step further and eventually identify underlying mechanisms have thus far been unsuccessful. While it has been long recognized that most psychiatric disorders are highly heritable, indicating a strong contribution of genetic variation to etiopathogenesis, many studies have consistently shown that exposure to environmental risk factors, for instance obstetric complications, also plays a significant role in the process. Considering that, it is plausible to apply a gene-environment interaction model to investigate the biological mechanisms underlying the link between obstetric complications and psychopathology. Nicodemus et al., analyzing a set of genes involved in hypoxiaresponse in a case-control sample, successfully identified that several variants in the schizophrenia candidate genes (AKT1, BDNF, DTNBP1, GRM3) interact with severe obstetric complications to increase the risk of schizophrenia (Nicodemus et al., 2008). A systematic review and analysis of current genetic literature -exploring the link between hypoxia-response and schizophrenia on a theoretical level-identified that $55 \%$ of the schizophrenia candidate genes also matched criteria for hypoxia-response (Schmidt-Kastner et al., 2012).

In the light of this evidence, Chapter 8 intends to elucidate the role of geneenvironment interactions underlying the association between obstetric complications and psychopathology in a deeply phenotyped cohort of young adult female twin pairs with increased risk for OC. Of 23 SNPs in 12 genes a priori selected on the basis of previous evidence linking them with both hypoxia-response and schizophrenia, SNPs in $A K T 1$ (rs1130233), BDNF (rs11030101), CHRNA7 (rs3087454), GABRB2 (rs1816072), PLXNA2 (rs752016, rs841865, rs2478813), RELN (rs7341475), RGS4 (rs2661319), and YWHAE (rs28365859) interacted with prospectively collected measures of OC to influence self-reported subclinical symptoms of psychopathology (SCL-90 total). Among significant SNPs, AKT1 variant rs1130233 and RGS4 variant rs2661319 emerged as the most promising SNPs that show potentially relevant interactions with OC to moderate psychopathology consistently across symptom dimensions. In accordance, whole gene analysis revealed that AKT1 moderated the effect of OC on the SCL-90. Although these results (AKT1) are in agreement with 
those of Nicodemus et al. (2001), the present study failed to replicate the finding of gene-environment interaction for other SNPs ( $A K T 1$ [rs3803300] BDNF [rs2049046] DTNBP1 [rs875462] GRM3 [rs7808623]).

Overall, our findings further support the idea of GxE interaction, where hypoxiaresponse genes operate in synergy with obstetric complications to influence the expression of mental ill health in general in adulthood.

\section{Methodological issues}

Despite numerous studies implicating the role of the aberrant immune functioning in mood disorders, we are still far from translating these findings to be applied in clinical practice -identifying biomarkers and novel molecules that target immunemediated mechanisms for the treatment of mood disorders. The complex nature of the immune system composed of intertwined pathways and the difficulty of identifying disease phenotypes hinder further progress.

Furthermore, the vast majority of previous studies have several limitations that need to be addressed in future research. While several confounders (e.g. BMI, age, sex) can be controlled rather easily either by matching patients with healthy controls or applying statistical adjustments, absolute elimination of the confounding effect of psychotropic medications is almost unattainable as finding a large group of medication-naïve patients would be extremely difficult.

To date, sample sizes of the studies carried out in the field of psychoneuroimmunology have been relatively small. Additionally, the scarcity of prospective studies severely hampers the ability to reach a firm conclusion on whether immune system disturbances are causally linked to the pathophysiology of mood disorders.

The majority of the studies pragmatically measured circulating immune marker concentrations given peripheral concentrations of immune markers have a value in estimating the inflammation in the CNS, and obtaining cerebrospinal fluid (CSF) through lumbar puncture is an invasive technique with well-defined risks that might exceed the benefit of using a more direct approach.

\section{Conclusion and Future Perspectives}

Despite efforts, psychiatry -in contrast to the rest of medicine- has not taken further steps towards elucidating the etiopathogenesis of psychiatric disorders which are currently classified based on a grouping of several behavioral symptoms and signs. One of the main reasons is that not just a single biomarker has been identified in 
psychiatry. To understand psychopathology, clinicians solely rely on their psychiatric interview skills to gather subjective self-report information, which is generally adequate to make the initial diagnosis based on psychiatric classification systems. There is a certain need to identify biomarkers for reliable diagnosis of psychiatric disorders that would eventually lead to a better biological understanding. In addition to diagnostic markers, surrogate markers -similar to those widely used in medicine, such as $\mathrm{HbAlC}$ predicting microvascular complications in diabetes or viral load predicting survival in chronic HIV-could be extremely useful to measure the effects of a specific treatment.

Numerous studies have shown, albeit inconsistently, that anti-inflammatory drugs such as aspirin, celecoxib, omega-3 fatty acids, and minocycline may be beneficial as an augmentation treatment (Rosenblat et al., 2014). Taking into account that the data showing that higher TNF- $\alpha$ was associated with poor response to lithium prophylaxis in bipolar disorder (see Chapter 3), and that infliximab (a TNF- $\alpha$ antagonist) was efficacious in treating depressive symptoms of only patients with high baseline inflammatory biomarkers (Raison et al., 2012), it is plausible to argue that this inconsistency might arise from the collective analysis of heterogeneous samples in terms of immune profiles. The next step should therefore be to test whether broad immune profiling of patients with mood disorders at baseline predicts treatment response and remission, which might be helpful to define patients who can benefit from add-on anti-inflammatory treatment in the long run. Identifying these different subtypes, such as "inflamed" depression, might give us the advantage of tailoring individualized treatments.

Current studies investigating the relationship between inflammation and mood disorders have only used single platform measures, particularly blood bioassays measuring circulating inflammatory markers. Research in this area clearly needs to move beyond this and adapt a multimodal approach that combines different techniques (e.g., genetics and neuroimaging) to connect the dots between peripheral immune alterations and the neuroinflammation. Using the peripheral benzodiazepine receptor radioligand [11C]-(R)-PK11195, microglial/astrocytic activation can now be successfully and reliably imaged by positron emission tomography. For instance, while underpowered, the single study investigating neuroinflammation in vivo in $\mathrm{BD}$ demonstrated the statistically significant increased binding potential of [11C]-(R)PK11195 in the right hippocampus of euthymic bipolar patients compared to healthy controls (Haarman et al., 2014).

Accumulating evidence indicates that there are no clear boundaries between categorical diagnoses in psychiatry. In accordance, a recent meta-analytical comparison of blood cytokine concentrations across major psychiatric disorders in 
reference to the general population showed a similar pattern for cytokine alterations in bipolar disorder, major depression, and schizophrenia(Goldsmith et al., 2015). The introduction of transdiagnostic approaches, independent from the current classification systems, such as the National Institute of Mental Health initiative - the Research Domain Criteria Project (RDoC)(Insel et al., 2010), would allow us to better understand shared pathways of aberrant immune functioning in psychopathology.

In conclusion, major strides have been made during the last decade in our understanding of the underlying immune mechanisms of mood disorders. However, this is only a successful start to an arduous journey. 


\section{References}

AMSTERDAM, J. D., MAISLIN, G. \&

RYBAKOWSKI, J. 1990. A possible antiviral action of lithium carbonate in herpes simplex virus infections. Biol Psychiatry, 27, 447-53.

BAPTISTA, T. \& BEAULIEU, S. 2002. Are leptin and cytokines involved in body weight gain during treatment with antipsychotic drugs? Can J Psychiatry, 47, 742-9.

BARBOSA, I. G., HUGUET, R. B., MENDONCA, V. A., SOUSA, L. P., NEVES, F. S., BAUER, M. E. \& TEIXEIRA, A. L. 2011. Increased plasma levels of soluble TNF receptor I in patients with bipolar disorder. European archives of psychiatry and clinical neuroscience, 261, 139-43.

BARBOSA, I. G., ROCHA, N. P., BAUER, M. E., DE MIRANDA, A. S., HUGUET, R. B., REIS, H. J., ZUNSZAIN, P. A., HOROWITZ, M. A., PARIANTE, C. M. \& TEIXEIRA, A. L. 2013. Chemokines in bipolar disorder: trait or state? Eur Arch Psychiatry Clin Neurosci, 263, 159-65.

BERK, M., KAPCZINSKI, F., ANDREAZZA, A. C., DEAN, O. M., GIORLANDO, F., MAES, M., YUCEL, M., GAMA, C. S., DODD, S., DEAN, B., MAGALHAES, P. V., AMMINGER, P., MCGORRY, P. \& MALHI, G. S. 2011. Pathways underlying neuroprogression in bipolar disorder: focus on inflammation, oxidative stress and neurotrophic factors. Neurosci Biobehav Rev, 35, 804-17.

BOUFIDOU, F., NIKOLAOU, C., ALEVIZOS, B., LIAPPAS, I. A. \& CHRISTODOULOU, G. N. 2004. Cytokine production in bipolar affective disorder patients under lithium treatment. $J$ Affect Disord, 82, 309-13.

BREUNIS, M. N., KUPKA, R. W., NOLEN, W. A., SUPPES, T., DENICOFF, K. D., LEVERICH, G. S., POST, R. M. \& DREXHAGE, H. A. 2003. High numbers of circulating activated $T$ cells and raised levels of serum IL-2 receptor in bipolar disorder. Biol Psychiatry, 53, 157-65.

BRIETZKE, E., STERTZ, L., FERNANDES, B. S., KAUER-SANT'ANNA, M., MASCARENHAS, M., ESCOSTEGUY VARGAS, A., CHIES, J. A. \& KAPCZINSKI, F. 2009. Comparison of cytokine levels in depressed, manic and euthymic patients with bipolar disorder. J Affect Disord, 116, 214-7.

CUNHA, A. B., ANDREAZZA, A. C., GOMES, F. A., FREY, B. N., DA SILVEIRA, L. E., GONCALVES, C. A. \& KAPCZINSKI, F. 2008. Investigation of serum high-sensitive C-reactive protein levels across all mood states in bipolar disorder. Eur Arch Psychiatry Clin Neurosci, 258, 300-4.

DEAN, O. M., MAES, M., ASHTON, M., BERK, L., KANCHANATAWAN, B., SUGHONDHABIROM, A., TANGWONGCHAI, S., NG, C., DOWLING, N. \& MALHI, G. S. 2014. Protocol and Rationale-The Efficacy of Minocycline as an Adjunctive Treatment for Major Depressive Disorder: A Double Blind, Randomised, Placebo Controlled Trial. Clinical Psychopharmacology and Neuroscience, 12, 180-188.

DICKENS, C., MCGOWAN, L., CLARKCARTER, D. \& CREED, F. 2002. Depression in rheumatoid arthritis: a systematic review of the literature with meta-analysis. Psychosom Med, 64, 52-60.

FULLER-THOMSON, E. \& SULMAN, J. 2006. Depression and inflammatory bowel disease: findings from two nationally representative Canadian surveys. Inflammatory bowel diseases, 12, 697-707.

GOLDSMITH, D., MILLER, M. \& RAPAPORT, M. H. 2015. Meta-analysis of cytokine alterations in acutely ill psychiatric patients: comparisons between schizophrenia, bipolar disorder, and depression. Schizophr Bull, 39, S140.

HAACK, M., HINZE-SELCH, D., FENZEL, T., KRAUS, T., KUHN, M., SCHULD, A. \& POLLMACHER, T. 1999. Plasma levels of cytokines and soluble cytokine receptors in psychiatric patients upon hospital admission: effects of confounding factors and diagnosis. Journal of psychiatric research, 33, 407-18.

HAARMAN, B. C., RIEMERSMA-VAN DER LEK, R. F., DE GROOT, J. C., RUHE, H. G., KLEIN, H. C., ZANDSTRA, T. E., BURGER, H., SCHOEVERS, R. A., DE VRIES, E. 
F., DREXHAGE, H. A., NOLEN, W. A. \& DOORDUIN, J. 2014. Neuroinflammation in bipolar disorder - A [(11)C]-(R)-PK11195 positron emission tomography study. Brain Behav Immun, 40, 219-25.

HANNESTAD, J., DELLAGIOIA, N. \& BLOCH, M. 2011. The effect of antidepressant medication treatment on serum levels of inflammatory cytokines: a meta-analysis. Neuropsychopharmacology, 36, 2452-9.

HIMMERICH, H., FULDA, S., LINSEISEN, J., SEILER, H., WOLFRAM, G., HIMMERICH, S., GEDRICH, K. \& POLLMACHER, T. 2006. TNF-alpha, soluble TNF receptor and interleukin-6 plasma levels in the general population. Eur Cytokine Netw, 17, 196-201.

HIMMERICH, H., KOETHE, D., SCHULD, A., YASSOURIDIS, A. \& POLLMACHER, T. 2005. Plasma levels of leptin and endogenous immune modulators during treatment with carbamazepine or lithium. Psychopharmacology (Berl), 179, 447-51.

HINZE-SELCH, D., SCHULD, A., KRAUS, T., KUHN, M., UHR, M., HAACK, M. \& POLLMACHER, T. 2000. Effects of antidepressants on weight and on the plasma levels of leptin, TNF-alpha and soluble TNF receptors: A longitudinal study in patients treated with amitriptyline or paroxetine. Neuropsychopharmacology, 23, 13-9.

HOTAMISLIGIL, G. S., MURRAY, D. L., CHOY, L. N. \& SPIEGELMAN, B. M. 1994. Tumor necrosis factor alpha inhibits signaling from the insulin receptor. Proc Natl Acad Sci US A, 91, 4854-8.

HOTAMISLIGIL, G. S., SHARGILL, N. S. \& SPIEGELMAN, B. M. 1993. Adipose expression of tumor necrosis factor-alpha: direct role in obesity-linked insulin resistance. Science, 259, 87-91.

ICHIYAMA, T., OKADA, K., LIPTON, J. M., MATSUBARA, T., HAYASHI, T. \& FURUKAWA, S. 2000. Sodium valproate inhibits production of TNF-alpha and IL-6 and activation of NF-kappaB. Brain Res, 857, 246-51.

INSEL, T., CUTHBERT, B., GARVEY, M., HEINSSEN, R., PINE, D. S., QUINN, K., SANISLOW, C. \& WANG, P. 2010. Research domain criteria (RDoC): toward a new classification framework for research on mental disorders. Am J Psychiatry, 167, 748-51.

KAPCZINSKI, F., DIAS, V. V., KAUERSANT'ANNA, M., BRIETZKE, E., VAZQUEZ, G. H., VIETA, E. \& BERK, M. 2009. The potential use of biomarkers as an adjunctive tool for staging bipolar disorder. Prog Neuropsychopharmacol Biol Psychiatry, 33, 1366-71.

KIM, Y. K., JUNG, H. G., MYINT, A. M., KIM, H. \& PARK, S. H. 2007. Imbalance between proinflammatory and anti-inflammatory cytokines in bipolar disorder. J Affect Disord, 104, 91-5.

KIM, Y. K., MYINT, A. M., LEE, B. H., HAN, C. S., LEE, S. W., LEONARD, B. E. \& STEINBUSCH, H. W. 2004. T-helper types 1, 2 , and 3 cytokine interactions in symptomatic manic patients. Psychiatry Res, 129, 267-72.

KLUGE, M., SCHULD, A., SCHACHT, A., HIMMERICH, H., DALAL, M. A., WEHMEIER, P. M., HINZE-SELCH, D., KRAUS, T., DITTMANN, R. W. \& POLLMACHER, T. 2009. Effects of clozapine and olanzapine on cytokine systems are closely linked to weight gain and drug-induced fever. Psychoneuroendocrinology, 34, 118-28.

KURZ, K., HEROLD, M., WINKLER, C., KLOTZ, W., RUSSE, E. \& FUCHS, D. 2011. Effects of adalimumab therapy on disease activity and interferon-gamma-mediated biochemical pathways in patients with rheumatoid arthritis. Autoimmunity, 44, 235-42.

LOFTUS, E. V., JR., GUERIN, A., YU, A. P., WU, E. Q., YANG, M., CHAO, J. \& MULANI, P. M. 2011. Increased risks of developing anxiety and depression in young patients with Crohn's disease. Am J Gastroenterol, 106, 1670-7.

MAES, M., SONG, C., LIN, A. H., PIOLI, R., KENIS, G., KUBERA, M. \& BOSMANS, E. 1999. In vitro immunoregulatory effects of lithium in healthy volunteers. Psychopharmacology (Berl), 143, 401-7.

MATTAI, A., FUNG, L., BAKALAR, J., OVERMAN, G., TOSSELL, J., MILLER, R., RAPOPORT, J. \& GOGTAY, N. 2009. Adjunctive use of lithium carbonate for the management of neutropenia in clozapinetreated children. Hum Psychopharmacol, 24, 584-9. 
MILLER, B. J., BUCKLEY, P., SEABOLT, W., MELLOR, A. \& KIRKPATRICK, B. 2011. Meta-analysis of cytokine alterations in schizophrenia: clinical status and antipsychotic effects. Biol Psychiatry, 70, 663-71.

MIYAOKA, T., WAKE, R., FURUYA, M., LIAURY, K., IEDA, M., KAWAKAMI, K., TSUCHIE, K., TAKI, M., ISHIHARA, K., ARAKI, T. \& HORIGUCHI, J. 2012. Minocycline as adjunctive therapy for patients with unipolar psychotic depression: an openlabel study. Prog Neuropsychopharmacol Biol Psychiatry, 37, 222-6.

MODABBERNIA, A., TASLIMI, S., BRIETZKE, E. \& ASHRAFI, M. 2013. Cytokine alterations in bipolar disorder: a meta-analysis of 30 studies. Biol Psychiatry, 74, 15-25.

MUNKHOLM, K., BRAUNER, J. V., KESSING, L. V. \& VINBERG, M. 2013. Cytokines in bipolar disorder vs. healthy control subjects: a systematic review and meta-analysis. $J$ Psychiatr Res, 47, 1119-33.

NICODEMUS, K. K., MARENCO, S., BATTEN, A. J., VAKKALANKA, R., EGAN, M. F., STRAUB, R. E. \& WEINBERGER, D. R. 2008. Serious obstetric complications interact with hypoxia-regulated/vascular-expression genes to influence schizophrenia risk. Molecular psychiatry, 13, 873-7.

O'BRIEN, S. M., SCULLY, P., SCOTT, L. V. \& DINAN, T. G. 2006. Cytokine profiles in bipolar affective disorder: focus on acutely ill patients. J Affect Disord, 90, 263-7.

ORTIZ-DOMINGUEZ, A., HERNANDEZ, M. E., BERLANGA, C., GUTIERREZ-MORA, D., MORENO, J., HEINZE, G. \& PAVON, L. 2007. Immune variations in bipolar disorder: phasic differences. Bipolar Disord, 9, 596-602.

PERSOONS, P., VERMEIRE, S., DEMYTTENAERE, K., FISCHLER, B., VANDENBERGHE, J., VAN OUDENHOVE, L., PIERIK, M., HLAVATY, T., VAN ASSCHE, G., NOMAN, M. \& RUTGEERTS, P. 2005. The impact of major depressive disorder on the short- and long-term outcome of Crohn's disease treatment with infliximab. Alimentary pharmacology \& therapeutics, 22, 101-10.

POLLMACHER, T., HAACK, M., SCHULD, A., KRAUS, T. \& HINZE-SELCH, D. 2000.
Effects of antipsychotic drugs on cytokine networks. J Psychiatr Res, 34, 369-82.

POLLMACHER, T., HINZE-SELCH, D., FENZEL, T., KRAUS, T., SCHULD, A. \& MULLINGTON, J. 1997. Plasma levels of cytokines and soluble cytokine receptors during treatment with haloperidol. Am J Psychiatry, 154, 1763-5.

POLLMACHER, T., HINZE-SELCH, D. \& MULLINGTON, J. 1996. Effects of clozapine on plasma cytokine and soluble cytokine receptor levels. J Clin Psychopharmacol, 16, 403-9.

RAISON, C. L., RUTHERFORD, R. E., WOOLWINE, B. J., SHUO, C., SCHETTLER, P., DRAKE, D. F., HAROON, E. \& MILLER, A. H. 2012. A Randomized Controlled Trial of the Tumor Necrosis Factor Antagonist Infliximab for Treatment-Resistant Depression: The Role of Baseline Inflammatory Biomarkers. Archives of general psychiatry, $1-11$.

RAPAPORT, M. H., GUYLAI, L. \& WHYBROW, P. 1999. Immune parameters in rapid cycling bipolar patients before and after lithium treatment. J Psychiatr Res, 33, 335-40.

RAPAPORT, M. H. \& MANJI, H. K. 2001. The effects of lithium on ex vivo cytokine production. Biol Psychiatry, 50, 217-24.

ROSENBLAT, J. D., CHA, D. S., MANSUR, R. B. \& MCINTYRE, R. S. 2014. Inflamed moods: a review of the interactions between inflammation and mood disorders. Prog Neuropsychopharmacol Biol Psychiatry, 53, 23-34.

RYBAKOWSKI, J. K. 2000. Antiviral and immunomodulatory effect of lithium. Pharmacopsychiatry, 33, 159-64.

SAVITZ, J., PRESKORN, S., TEAGUE, T. K., DREVETS, D., YATES, W. \& DREVETS, W. 2012. Minocycline and aspirin in the treatment of bipolar depression: a protocol for a proof-ofconcept, randomised, double-blind, placebocontrolled, 2x2 clinical trial. BMJ open, 2, $\mathrm{e} 000643$.

SCHMIDT-KASTNER, R., VAN OS, J., ESQUIVEL, G., STEINBUSCH, H. W. \& RUTTEN, B. P. 2012. An environmental analysis of genes associated with 
schizophrenia: hypoxia and vascular factors as interacting elements in the neurodevelopmental model. Molecular psychiatry.

STERTZ, L., MAGALHAES, P. V. \&

KAPCZINSKI, F. 2013. Is bipolar disorder an inflammatory condition? The relevance of microglial activation. Curr Opin Psychiatry, 26, 19-26.

TIRPAN, K., OZERDEM, A., TUNCA, Z., YAZICI, O., ORAL, E. T., KURT, E. \& VAHIP, S. 2004. A computerized registry program for bipolar illness in Turkey. Journal of affective disorders, 78(suppl), 126-127. 


\section{Summary}



In chapter 1, a brief summary about phenomenology, classification and epidemiology of mood disorders was provided. Furthermore, the pathoetiology of mood disorders, with a focus on immune-related mechanisms, was discussed. First, the close relationship between immune-related diseases and mood disorders was discussed. Second, evidence implicating the role of disturbed cytokine network in mood disorders was provided. Third, tryptophan metabolic pathway, linking immune system to central nervous system, was promoted. Fourth, the potential of antiinflammatory medications for the treatment of mood disorders is discussed. Fifth, the importance of hypoxia-ischaemia as a mechanism underlying psychiatric syndromes, in association with the maternal immune activation and microglial activity, and its link to the immune system disturbance was discussed. Finally, the aims and outline of the thesis were presented.

Chapter 2 presents a cross-sectional study, in which peripheral pro- and antiinflammatory cytokine balance (IFN- $\gamma$, TNF- $\alpha$, IL-2, IL-4, IL-5, and IL-10) was examined using flow cytometry in euthymic bipolar patients (medication-free $(n=16)$ and lithium-monotherapy $(\mathrm{n}=15))$, in comparison to age and gender matched healthy controls $(n=16)$. While there was no difference between medication-free and healthy controls in circulating cytokine profile, TNF- $\alpha$ and IL-4 concentrations in euthymic bipolar patients on lithium-monotherapy were higher than in both the medication-free euthymic bipolar patients and healthy controls. Given that, it is plausible to speculate that the pro-inflammatory state reported in manic and depressive episodes resolves in euthymia, and lithium exerts a complex immune-modulatory action by increasing both pro- and anti-inflammatory cytokines, thereby also emerging as a confounding factor while investigating the disease-related pathogenesis of bipolar disorder.

Chapter 3 presents a study investigating the possible association between circulating TNF- $\alpha$ concentration assessed using enzyme-linked immunosorbent assay and longterm lithium response assessed using ALDA lithium response scale in 60 euthymic bipolar patients (17 with good lithium response, 23 with partial lithium response, 20 with poor lithium response). TNF- $\alpha$ concentrations in patients with a poor response to lithium were higher than in patients with a good response; both Criterion A (the degree of improvement over the course of lithium treatment) and total ALDA lithium response scale scores (Criterion A subtracted by Criterion B assessing the causality between improvement and lithium treatment) were negatively associated with TNF- $\alpha$ concentrations after controlling for the a priori selected confounders. These findings indicate that circulating TNF- $\alpha$ concentration may impact on the clinical response to lithium and a continuous immune imbalance in poor lithium responders may be related to treatment resistance. 
Chapter 4 presents a study investigating the possible association between peripheral markers of an ongoing chronic pro-inflammatory process (soluble tumor necrosis factor receptor-1 (sTNF-R1), soluble interleukin-6 receptor (sIL-6R) and soluble interleukin-2 receptor (sIL-2R)) and persistent subsyndromal symptoms in bipolar disorder in a sample consisted 22 euthymic bipolar patients with subsyndromal symptoms and 23 euthymic bipolar patients without subsyndromal symptoms and 23 well controls. sTNF-R1 and sIL-6R concentrations were increased in both patients with and without and without subsyndromal symptoms in comparison to that in well controls, also after controlling age and sex, however there was no difference in sTNF-R1 and sIL-6R concentrations between patients with and without subsyndromal symptoms. These findings indicate that the pro-inflammatory shift might be evident in bipolar patients compared to well controls, but subsyndromal symptoms are not associated with additive increasing effects.

Chapter 5 presents an 8-week, prospective study investigating the impact of antiTNF- $\alpha$ (infliximab) infusion on disease activity, quality of life, fatigue and depressive symptoms along with its possible relation to immune parameters, and the tryptophan availability (tryptophan/competing amino acids) in 15 patients with Crohn's Disease. The findings were: (i) scores of depression scales were decreased after anti-TNF- $\alpha$ infusion and this effect was to a degree, but not entirely, reducible to disease activity; (ii) there was no change in the tryptophan availability after anti-TNF- $\alpha$ infusion and neither scores of depression scales, nor immune parameters were associated with tryptophan availability; (iii) immune activation was higher in patients with current/ past depressive disorder. These findings indicate that anti-TNF- $\alpha$ infusion in patients with Crohn's Disease reduces depressive symptoms, in part independently of disease activity, and that the effect on depressive symptoms is not associated with immuneinduced changes in tryptophan availability to the brain, as estimated indirectly by serum tryptophan/competing amino acids ratio.

Chapter 6 presents a literature overview on the effect of electroconvulsive therapy (ECT) on the immune system. The literature search identified limited number of studies. Although inconsistency in findings and methodological issues -statistical power and consideration of confounding factors impacting cytokine concentrationspreclude definitive conclusion; the findings suggest that a single session of ECT induces an acute, transient immune activation, whereas repetitive ECT treatment results in long-term down-regulation of immune activation.

Chapter 7 presents a prospective study investigating the impact of ECT on the metabolites in tryptophan-kynunerine pathway (tryptophan (TRP), kynunerine (KYN), kynurenic acid (KYNA), 3-hydroxykynurenine (3-HK), 3-Hydroxyanthranilic acid (3HAA), 5-Hydroxyindoleacetic acid (5-HIAA), KYN/TRP, KYNA/KYN, KYNA/3- 
HK, 5-HIAA/ KYN), in association with ECT-related alterations in depressive symptoms in 23 patients with unipolar or bipolar depression. The findings were: (i) KYNA, KYNA/3-HK, KYNA/KYN and KYN/TRP concentrations increased over time; (ii) $\mathrm{KYN}$ and KYN/TRP were negatively associated with total HDRS scores; (iii) Baseline TRP metabolite concentrations did not predict time to ECT response. Notwithstanding its limitations, this study highlights the impact of ECT on TRPKYN pathway with a shift toward neuroprotective side, which may play a role in its mechanism of action.

Chapter 8 presents a gene-environment interaction study investigating in a general population sample of 334 females in 180 twin pairs whether associations between obstetric complications (OC) and expression of psychopathology were moderated by selected single nucleotide polymorphisms (SNPs) in genes that were previously shown to be associated with hypoxia-response regulation and schizophrenia. SNPs in AKT1 (rs1130233), BDNF (rs11030101), CHRNA7 (rs3087454), GABRB2 (rs1816072), PLXNA2 (rs752016, rs841865, rs2478813), RELN (rs7341475), RGS4 (rs2661319), and YWHAE (rs28365859) moderated the associations between OC and the Symptom Checklist-90-Revised (SCL-90) total scores. In addition, there were significant main genetic, and interactive effects on subscales of the SCL-90, but not on neurocognitive tests. When SNPs per gene were analyzed together in one model per gene, only the variants in $A K T 1$ showed a statistically significant interaction with OC on SCL-90 total, depression, and psychoticism scores. The findings suggest that the interaction between hypoxia-response genes and $\mathrm{OC}$ influences the expression of mental ill health in general, and not just the expression of schizophrenia-specific psychopathological dimensions.

Chapter 9 provides an overview of the findings and discusses them in the light of the current evidence. The findings derived from the studies in this thesis investigating the role of aberrant immune functioning in mood disorders from different perspectives are integrated to elucidate possible underlying immune-related mechanisms in the pathogenesis of mood disorders; and to provide directions for future research. 



\section{Valorization}



Mood disorders (bipolar disorder and major depressive disorder) are highly prevalent, and are associated with increased morbidity and mortality. Although treatment of depression has advanced, current medications do not meet expectations - only onethird of patients diagnosed with major depression respond to first level treatment. Likewise, polypharmacy is a rule rather than an exception for treatment of bipolar disorder - even lithium, closest to the definition of an ideal mood stabilizer aside from its side-effects, has limited success as a monotherapy. It appears that the monoamine theory, solely, cannot explain all features of mood disorders, and accordingly, current antidepressants targeting monoamine systems are efficient in only a subgroup of patients. Novel treatment options are urgently needed. To improve treatment, pathoetiology of mood disorders should be elucidated. Understanding pathoetiology -in contrast to serendipitous drug discoveries- would enable us to design disorderspecific drugs and optimize treatment by measuring target engagement.

\section{Relevance}

Converging evidence has moved the scientific community to view inflammation as a key process that might improve understanding of the pathoetiology of mood disorders. Insight into the aberrant immune functioning as a complementary mechanism underlying mood disorders can deliver important prognostic information to personalize and optimize treatment. From a general perspective, this thesis seeks to deliver the next step in this translational aim.

The findings add important and potentially transformative data to explain the relationship between inflammation and mood disorders. To date, inflammation in the acute phase of mood disorders (e.g. mania, depression) has been widely acknowledged. However, few studies, usually not taking into account the effect of medication on immune markers, have examined whether the aberrant immune functioning in bipolar disorder resolves during euthymia. This thesis, examining the circulatory immune profile of medication-free euthymic bipolar patients and the role of immune modulation as a mechanism of action of lithium, has therefore filled an important gap in the scientific field. In combination with recent evidence, this suggest that inflammatory state likely resolves in euthymic period of bipolar disorder, and that the immune-balancing effects of lithium, along with several other postulated mechanisms, may be essential for its long-term mood stabilizing effects.

This thesis also provides important evidence towards the role of immunerelated pathways (immune mediated tryptophan catabolism) in the mechanism of action of ECT, which has thus far received little attention. Current knowledge about antidepressant effects of infliximab (an anti-inflammatory drug) in Crohn's Disease 
is extended, thereby facilitating the concept of anti-inflammatory treatment of mood disorders. Recent data suggest that prenatal and perinatal complications impact on the maternal immune activation and microglial activity, and this work was further extended with a study investigating whether hypoxia-related genes moderate the impact of obstetric complications on expression of psychopathology. The findings further support the idea of gene $\mathrm{X}$ environment interaction, whereby hypoxia-response genes operate in synergy with obstetric complications to influence the expression of mental ill health in general in adulthood.

The exploration of inflammation and the pathoetiology of mood disorders is an active area of investigation in the scientific community. This thesis offers some insight into indices of inflammation underlying mood disorders, and delivers translational information about the role of inflammation in treatment of mood disorders. Although further longitudinal studies are required, these findings, from a broad perspective, suggest that immune stratification of patients with mood disorders - such as, from the most basic perspective, categorizing patients into low and high inflammation groups- might be helpful in predicting treatment response and remission. In addition, identifying subtypes, such as "inflamed" depression, may open up new avenues leading to individually tailored treatment with better outcomes.

Social and economic burden of mood disorders include disability, decreased work productivity, and increased health services utilization. A more effective treatment would not only decrease mood symptoms, but also improve quality of life and restore functioning. Although treatment of mood disorders has improved substantially, the rate of complete remission is low -indicating a need for treatment with novel mechanisms of action. There is some evidence to suggest that anti-inflammatory drugs (i.e. aspirin, celecoxib, omega-3 fatty acids, and minocycline) are beneficial as an augmentation treatment for mood disorders. However, study results are inconsistent. This is likely due to collective analysis of immunologically heterogeneous samples. Therefore, immune profiling may be essential to define patients who may benefit more from adjuvant anti-inflammatory treatment.

Although reported findings can be considered as another brick in the wall, even the Great Wall of China was built laying one brick at a time. Studies investigating immune hypotheses have thus far provided substantial evidence suggesting that measurement of immune alterations may serve as biomarkers in mood disorders. However, we are still far from translating these findings to be applied in clinical practice because further prospective, controlled investigations are needed. Studies should aim to investigate large samples and carefully take into account various 
confounders that can easily distort results, such as medication effect demonstrated in this thesis.

\section{Target groups}

Considering that the impact of mood disorders spread across the society, with various effects, from patients to family members and from organizations to taxpayers, a wide range of people can benefit from optimization of diagnosis and treatment of mood disorders, either directly or indirectly. Therefore, the findings of this thesis extending the knowledge to pave the way to advanced diagnostic panels and better treatment options may be of use to a broader population. In psychiatric practice, healthcare professionals usually struggle to identify future treatment-resistant cases, and this results in inadequate treatment initially, followed by several drug trials until optimal treatment is achieved. Not to mention that extended duration of inadequate treatment is associated with disability, but it also poses a great risk to patients by increasing the likelihood of suicide. Unfortunately, there exists no biomarker that can help healthcare professionals to predict response or remission in patients with mood disorders. Given that, healthcare professionals can certainly benefit from tracking immune markers to develop personalized treatment strategies, which eventually reduce duration of inadequate treatment. This decrease of time lost by inadequate treatment, will subsequently decrease service utilization and costs. These are also important objectives that policy makers seek to achieve for improving costeffectiveness. However, it would be an overstatement to claim that immune markers are ready for use in everyday clinical practice. Circulatory immune markers are prone to the impact of confounding factors, unreliable at times, and still expensive to measure with available methods. Rapidly advancing measurement technologies delivered assays that allow measurement of multiple immune markers using a single kit and, therefore, led to a dramatic reduction in costs. This downward trend in costs will accelerate even more in the forthcoming years.

Obviously, the present findings support the development of anti-inflammatory therapy for mood disorders. There is already some evidence that augmentation treatment with potent anti-inflammatory therapies might increase response rates and reduce time to response, particularly in treatment-refractory cases. However, side effects that include increased risk of serious infections limit their use. Hopefully, the next generation of anti-inflammatory drugs, targeting specific molecular pathways, with fewer side effects may add to clinicians' arsenal for treatment-resistant cases. 


\section{Innovation}

This thesis delivers actionable and reliable information for future studies, and it is innovative in several specific ways. First, it used several approaches in a variety of samples to delineate putative role of inflammation in pathoetiology of mood disorders. Second, it shed light on neglected areas in the literature on psychoneuroimmunology, such as the role of immune-related pathways in the mechanism of action of ECT. Third, it analyzed data derived from unique patient populations, such as unmedicated euthymic bipolar patients and euthymic bipolar patients with subthreshold symptoms. 


\section{Acknowledgement}



Now the Thesis was formless and empty, darkness was over the surface of the deep, and the Spirit of Jim was hovering over the pages. And Jim said "Let there be light," and there was light.

There are several people I would like to thank for their support. First and foremost, I would like to thank my supervisor, Prof. Jim van Os. I usually don't consider myself as a lucky person in general, but having known him was one of the brilliant moments in my life. Jim, you have certainly expanded my horizons, but more importantly your optimism and passion to science and life in general helped me keep going, even in the most difficult and disheartening times. Your dedication has always inspired me. I still wonder how you manage to give such a thoughtful feedback in the nick of a time, even when you have to deal with many other tasks at the same time. And, thanks to your humble and patient character, I was able to ask you infinite questions.

If Jim were the father figure for me in the academic world, my co-supervisor, Dr. Bart "Boss" Rutten would be the elder brother. You have always motivated me to get better, and your creative feedbacks helped me to think outside the box. Above all, I would like to thank you for the unconditional support. Of course, thanks for the fun time, all the laughter, and those memorable moments! I would like to thank my co-supervisor, Dr. Marjan Drukker. She is instrumental in helping me to understand the language of STATA. I certainly believe her organized and principled character developed me into a more meticulous researcher.

I would like to express my gratitude to Dr. Gunter Kenis (for sharing his experience about neuroimmunology and molecular genetics), Dr. Wolfgang Viechtbauer (for sharing his invaluable knowledge in statistics), Dr. Marieke Wichers (for her contributions), Dr. Ehsan Pishva (for his company in Maastricht), Sharon Walters (for her companion during those times when we were relentlessly working on the ECT data), Truda (for her patience while we kept bugging her), Leni and Tineke (for their support and friendship-indeed, my Maastricht journey has begun with them), Karin and Wendy (for their help in the EU-GEI)

I would like to express my heartfelt thanks to Prof. Cem Atbasoglu (for offering me the position in the EU-GEI Turkey and sharing his wisdom), Prof. Meram Can Saka (for his support and patience in the EU-GEI Turkey), Dr. Cenk Tek (for providing me a chance to work at his lab and supporting me through the $\mathrm{PhD}$ process), Dr. Vinod Srihari (for providing me an opportunity to join his team and sharing his intellect), and Esra $\mathrm{Oz}$ (for helping me to disseminate the findings of our research).

Christie, thanks for helping me to get familiar with American culture and language. Kursat, you have always been my strongest support. With a friend and colleague like you, I feel blessed. A "Royal" thanks to Muzaffer for his thoughtful advises, and Sameer, you've always encouraged me. How can I forget my old-time friend, Bahri? 
And thanks Tolga for guiding me through the process and introducing Turgay Arik, who has done a wonderful job with the design. Thank you very much Semra for "adopting" me during my stay in Ankara while working for the EU-GEI, and Cansu "my step sister" for accepting me as a member of the family. Thank you Uncle Fikret, Inci Abla, and Pasha Baris for all the good times and support.

Mother, it is never enough even if I thank you a million times for all the sacrifices you made. Selin, my dear wife, you patiently endured this long process with me, always offering support and love. You make me a better person.

Last but not least, I will be forever grateful to Prof. Timucin Oral for being such an important role model in my life; he always inspired me to yearn more, and excel in my career. Without his guidance, I would be lost. I still remember my first poster presentation as if it were yesterday. Thereafter, I have always felt his infinite and unconditional support. I also would like to thank him for helping me with the cover design by sharing his collection of photos.

I would like to dedicate this thesis to my father, a brilliant economist, who had desired to become an academic, but never given the chance -instead blacklisted after the 1980 Military Coup, because of his political ideology. 


\section{Curriculum Vitae}



Sinan Guloksuz was born on February $27^{\text {th }} 1981$ in Ankara, Turkey. He graduated from Izmir Karsiyaka Anatolian High School in 1999. In 1999, he started studying Medicine at Ankara Gazi University where he received his medical doctor degree in medicine in 2005. He started his residency in Psychiatry at Istanbul Bakirkoy Research and Training Hospital for Psychiatry, Neurology and Neurosurgery. During his residency in Psychiatry, he won a visiting research fellowship award from the Psychiatric Association of Turkey and spent a term with Prof. Craddock's psychiatric genetics lab at Cardiff University to increase his knowledge about genetic bio-banking. Following his return, he was instrumental in the establishment of a Psychiatric Genetics Research Center in his training hospital. He was granted European Union's Spinoza award through the European Accreditation Committee in CNS (EACIC), which enabled him to successfully complete a Master's Degree Program of Affective Neuroscience in Maastricht University with the thesis titled "Cytokine levels in euthymic bipolar patients" in 2010. After completing his residency in 2011, he took part as a researcher and country coordinator (Turkey) in the European Network of National Schizophrenia networks studying Gene-Environment Interactions (EU-GEI), a multi-national, multi-centered project aiming to identify interactive genetic, clinical and environmental determinants, involved in the development, severity and outcome of schizophrenia, led by Prof. van Os at Maastricht University. In 2011, he started his Ph.D. at the School for Mental Health and Neuroscience in the Department of Psychiatry and Neuropsychology at Maastricht University. He has served as a member in the committees, and the task forces of several different professional organizations at both national and international level. His research won awards from Psychiatric Association of Turkey, and he was granted scholarships from Psychiatric Association of Turkey, European Psychiatric Association, and World Psychiatric Association. In 2013, he started to work as a Post-Doctoral Associate at Yale University Department of Psychiatry. 

List of Publications 



\section{International Journals}

Gülöksüz S, Oral ET, Ulas, H. Attitudes and behaviors of psychiatry residents and psychiatrists working in training institutes towards the relationship between the pharmaceutical industry and physicians. (2009) Turk Psikiyatri Derg. 20:236-42.

Jahuar S, Research Group of the European Federation of Psychiatric Trainees. Are new drugs for schizophrenia better than old ones? Lancet. 2009 373:1249.

Jahuar S, EFPT Research Group. Trends in drug prescription of young psychiatrists and trainees: A survey of the European Federation of Trainees' Research Group. Die Psychiatrie 2009; 6: 80-83

Gülöksüz S, Akdeniz F, Ince B, Oral ET. (2010) The treatment of bipolar disorder during pregnancy and the postpartum period. Turk Psikiyatri Derg. 21:155-66.

Guloksuz S, Eren K, Gurol DT. (2010). A case of oxybutynin dependency. Gen Hosp Psychiatry. 32:e5-6.

Guloksuz S, Cetin EA, Cetin T, Deniz G, Oral ET, Nutt DJ. (2010) Cytokine levels in euthymic bipolar patients. J Affect Disord. 126:458-62.

Fiorillo A, Luciano M, Giacco D, Del Vecchio V, Baldass N, De Vriendt N, Theodorides N, Piir P, Courtois AC, Gerber S, Lahera G, Riese F, Bendix M, Guloksuz S, Banu Aslantas E, Oakley C. (2011) Training and practice of psychotherapy in Europe: results of a survey. World Psychiatry. 10:238.

Cetin EA, Ciftci F, Guloksuz S, Koksalan K, Sezer O, Oral ET, Cetin T, Kurt E, Kaya H, Deniz G. (2012) QuantiFERON-TB Gold test may be more advantageous than tuberculin skin test for screening latent tuberculosis infection in psychiatry clinics. Balkan Med J. 29:115-6.

Jauhar S, Guloksuz S, Andlauer O, Lydall G, Marques JG, Mendonca L, Dumitrescu I, Roventa C, De Vriendt N, Van Zanten J, Riese F, Nwachukwu I, Nawka A, Psaras R, Masson N, Krishnadas R, Volpe U; European Federation of Psychiatric Trainees' Research Group. (2012) Choice of antipsychotic treatment by European psychiatry trainees: are decisions based on evidence? BMC Psychiatry. 12:27.

Guloksuz S, Altinbas K, Aktas Cetin E, Kenis G, Bilgic Gazioglu S, Deniz G, Oral ET, van Os J. (2012) Evidence for an association between tumor necrosis factoralpha levels and lithium response. J Affect Disord. 143:148-52.

Cetin T*, Guloksuz S*, Cetin EA, Gazioglu SB, Deniz G, Oral ET, van Os J. (2012) Plasma concentrations of soluble cytokine receptors in euthymic bipolar patients with and without subsyndromal symptoms. BMC Psychiatry. 12:158.

Ozkose MM, Guloksuz S, Ince B, Altinbas K. (2012) Reversible ptosis probably related to duloxetine use. Gen Hosp Psychiatry. 34:e9-e10. 
Guloksuz S, Wichers M, Kenis G, Russel MG, Wauters A, Verkerk R, Arts B, van Os J. (2013) Depressive symptoms in Crohn's disease: relationship with immune activation and tryptophan availability. PLoS One. 8(3):e60435.

Altinbas K, Guloksuz S, Oral ET. (2013) Metabolic syndrome prevalence in different affective temperament profiles in bipolar-I disorder. Rev Bras Psiquiatr. $35: 131-5$.

Altınbas, K, Guloksuz S, Oral ET. (2013) Clinical potential of cariprazine in the treatment of acute mania. Psychiatr Danub. 25:207-13.

Atbaşoğlu EC, Gülöksüz S. Science, Psychiatry, and the DSM. (2013) Turk Psikiyatri Derg. 24:202-12.

İnce B, Guloksuz S, Altınbas, K, Oral ET, Alpkan LR, Altinoz MA. (2013) Minor hemoglobins $\mathrm{HbA} 2$ and $\mathrm{HbF}$ associate with disease severity in bipolar disorder with a likely protective role of $\mathrm{HbA} 2$ against post-partum episodes. J Affect Disord. 151:405-8.

Tek C, Guloksuz S, Srihari VH, Reutenauer EL. (2013) Investigating the safety and efficacy of naltrexone for anti-psychotic induced weight gain in severe mental illness: study protocol of a double- blind, randomized, placebo-controlled trial. BMC Psychiatry.13:176.

Kucukgoncu S, Tek C, Bestepe E, Musket C, Guloksuz S. (2014) Clinical Features of Night Eating Syndrome among Depressed Patients. Eur Eat Disord Rev. 2014 Mar;22(2):102-8.

Maçkalı Z, Gülöksüz S, Oral T. (2014) Creativity and bipolar disorder. Turk Psikiyatri Derg. 25:50-9.

Guloksuz S, Rutten BPF, Arts B, van Os J, Kenis G. (2014) The immune system and electroconvulsive therapy for depression. J ECT. 30:132-7.

European Network of National Networks studying Gene-Environment Interactions in Schizophrenia (EU-GEI) (2014) Identifying gene-environment interactions in schizophrenia: contemporary challenges for integrated, large-scale investigations. Schizophr Bull. 40:729-36.

Altinbas K, Guloksuz S, Caglar IM, Caglar FN, Kurt E, Oral ET. (2014) Electrocardiography changes in bipolar patients during long-term lithium monotherapy. Gen Hosp Psychiatry. 36:694-7.

Tek C, Palmese LB, Krystal AD, Srihari VH, DeGeorge PC, Reutenauer EL, Guloksuz S. (2014) The impact of eszopiclone on sleep and cognition in patients with schizophrenia and insomnia: A double-blind, randomized, placebo-controlled trial. Schizophr Res. 160:180-5.

Riese F, Guloksuz S, Roventa C, Fair JD, Haravuori H, Rolko T, Flynn D, Giacco D, Banjac V, Jovanovic N, Bayat N, Palumbo C, Rusaka M, Kilic O, Augènaite J, 
Nawka A, Zenger M, Kekin I, Wuyts P, Barrett E, Bausch-Becker N, Mikaliūnas J, Del Valle E, Feffer K, Lomax GA, Marques JG, Jauhar S. (2014) Pharmaceutical industry interactions of psychiatric trainees from 20 European countries. Eur Psychiatry. In press. doi: 10.1016/j.eurpsy.2014.09.417.

Stuart H, Sartorius N, Liinamaa T; Images Study Group. (2015) Images of psychiatry and psychiatrists. Acta Psychiatr Scand. 131:21-8.

Stuart H, Sartorius N, Liinamaa T; Images Study Group. (2014) The images of psychiatry scale: development, factor structure, and reliability. BMC Psychiatry. $14: 337$

Guloksuz S, Arts B, Walter S, Drukker M, Rodriguez L, Myint AM, Schwarz MJ, Ponds R, van Os J, Kenis G, Rutten BP. (2015). The impact of electroconvulsive therapy on the tryptophan-kynurenine metabolic pathway. Brain Behav Immun. Mar 9. pii: S0889-1591(15)00072-0. doi: 10.1016/j.bbi.2015.02.029.

Guloksuz S, van Nierop M, Lieb R, van Winkel R, Wittchen HU, van Os J. (2015) Evidence that the presence of psychosis in non-psychotic disorder is environmentdependent and mediated by severity of non-psychotic psychopathology. Psychol Med. Mar 25:1-13. In press.

Altınbaş G, Altınbaş K, Gülöksüz SA, Gülöksüz S, Aydemir Ö, Özgen G. (2015) Temperament characteristics in patients with panic disorder and their first-degree relatives. Compr Psychiatry. Apr 2. doi: 10.1016/j.comppsych.2015.03.008

Guloksuz SA, Abali O, Aktas Cetin E, Bilgic Gazioglu S, Deniz G, Yildirim A, Kawikowa I, Guloksuz S, Leckman JF. Elevated S100B and tumor necrosis factor alpha in autism spectrum disorders. Submitted.

Guloksuz S, Jauhar S, Tomori S, EFPT-PRIRS Study Group, Riese F. Impact of guidelines and education on interactions between psychiatric trainees and the pharmaceutical industry in 20 European countries. Submitted.

Guloksuz S, Drukker M, Schmidt-Kastner R, Kenis G, Viechtbauer W, Pishva E, Wichers M, Jacobs N, Thiery E, Derom C, Myin-Germeys I, van Winkel R, van Os J, Rutten BP. Hypoxia-response genes moderate the impact of prospectively assessed obstetric complications on psychopathology in a general population female twin cohort. Submitted.

Guloksuz S, van Nierop M, Bak M, de Graaf R, ten Have M, van Dorsselaer S, Gunther N, Lieb R, van Winkel R, Wittchen HU, van Os J. Replication in two general population cohort studies that exposure to environmental factors increases connectivity between symptom domains in the psychopathology network. Submitted.

Rutten BP, Arts B, Guloksuz S, Walter S, Drukker M, Peerbooms O, Rodriguez L, Ponds R, van Os J, Kenis G. Longitudinal alterations in mRNA expression 
of the BDNF-neurotrophin signaling cascade in lymphocytes correlate with the antidepressant response to electroconvulsive therapy. Submitted.

*Equally contributed

\section{National Journals}

Guloksuz S, Oral E.T, Alpkan L.R. (2008) Is it a shame to misdiagnosis conversion disorder. Archives of Neuropsychiatry. 45:97-99 (article in Turkish)

Basterzi AD, Guloksuz S. (2009) Ethics training in psychiatry. Current Approaches in Psychiatry. 1:229-239 (article in Turkish)

Altinbas K, Guloksuz S, Ozcetinkaya S, Oral ET (2010). Biological Correlates of Empathy. Current Approaches in Psychiatry; 2(1):15-25 (article in Turkish)

Altinbas K, Guloksuz S, Yigiter S, Kurt E, Oral ET (2010). Does follow-up in a specialized center influence symptom profile and severity of bipolar depression? Dusunen Adam The Journal of Psychiatry and Neurological Science; 23: 13-17 (article in Turkish)

Altinbas K, Tunc S, Yazar MS, Ozcetinkaya S, Guloksuz S, Oral ET. If Kraepelin was still alive would dichotomy still survive? (2011) Dusunen Adam The Journal of Psychiatry and Neurological Science. 24: 321-330 (article in Turkish)

Atagun I, Altinbas K, Yesilyurt S, Yesilbas D, Guloksuz S, Oral T (2012). Evaluation of antidepressant choices for the treatment of depressive symptoms in patients with bipolar disorder. Dusunen Adam The Journal of Psychiatry and Neurological Science. 25:151-56 (article in Turkish)

Altinbas K, Enez Darcin A, Guloksuz S, Oral ET (2012). Seasonal variation of metabolic syndrome prevalence in bipolar disorder. JMOOD. 2: 51-57. (article in Turkish)

Guloksuz S, Mance Calisir O. (2012). A difficult puzzle to solve: schizophrenia. Bilim ve Teknik (Science and Technology). 530: 34-39. (article in Turkish)

Ince B, Guloksuz S (2013). Effects of antidepressants on fetus pregnancy (article in Turkish) Journal of Psychiatric Association of Turkey for Continuing Education. 3:312-22. (article in Turkish)

\section{Book Chapter}

Alkin T, Aydemir O, Basterzi AD, Guloksuz S, Konuk N, Ozguven HD, Unal S, Vahip S, Yazici A The aims and objectives in psychiatric training. In: Tukel R, Alkin T, 
Ulusahin A, eds. ${ }^{\text {st }}$ ed., Ankara, Tuna Press. 2009; 49-107. Competency in Psychiatric Training and Accreditation of Psychiatric Training (article in Turkish)

Andlauer O, Nawka A, Lydall G, Guloksuz S, Galderisi S. Social media and e-learning for professional development in psychiatry. In: Psychiatry in Practice: A Guide for Early Career Psychiatrists. Fiorillo A, Volpe U, Bhugra D, eds. $1^{\text {st }}$ ed., Oxford, Oxford University Press.

\section{Research Support}

Ministry of Health of Turkey Resources Grant: Cytokine levels in bipolar depression: a prospective study. Guloksuz (PI) 01/01/2010 - 03/01/2011. The goal of this study was to identify the role of immune mediators, particularly cytokines in depressive episode of bipolar disorder.

1001 112S475, TUBITAK: Investigation of the association between liability to diabetes mellitus and liability to psychosis. Atbasoglu (PI) 03/01/2013 $03 / 01 / 2015$. The goal of this study is to examine the possible association between psychosis and diabetes mellitus, in association with shared genetic pathways.

R01MH103831-03S1, NIH: Predictive value of immune markers for psychosis onset, progression, remission, and treatment response. Srihari (PI) 9/01/2015 $9 / 01 / 2016$. The aim of this project is to investigate whether circulating immune markers (cytokines) predict response, remission, and recovery in first episode psychosis.

\section{Honors}

Award for $3^{\text {rd }}$ Best Poster in 15th Annual Forum, European Federation of Psychiatric Trainees (2007)

Award for $2^{\text {nd }}$ Best Poster in 17th Annual Forum, European Federation of Psychiatric Trainees (2009)

Early Career Psychiatrists Scholarship, World Psychiatric Association, Turkey (2010)

Award for $2^{\text {nd }}$ Best Research in 14th Spring Symposium, Psychiatric Association of Turkey (2010)

European Accreditation Committee in CNS (EACIC) Spinoza Grant (2010)

Visiting Scholarship Program, Psychiatric Association of Turkey (2010)

Award for $3^{\text {rd }}$ Best Research in 15th Spring Symposium, Psychiatric Association of Turkey (2011) 
Early Career Psychiatrists Scholarship, World Psychiatric Association, Argentina (2011)

Early Career Psychiatrists Scholarship, European Psychiatric Association, France (2013)

\section{Professional Activities}

2007-2009 Executive Committee of Istanbul Branch, Psychiatric Association of Turkey

2007-2010 Chair, Trainee Section, Psychiatric Association of Turkey

2007-2010 Subcommittee of Development of Training in Psychiatry of Psychiatry Board, Psychiatric Association of Turkey

2007-2011 Controlling Committee, Society of Bipolar Disorders (Turkey)

2008-2009 Member, International Society of Bipolar Disorders

2008-2010 Psychiatric Hospital Conditions Task Force, Psychiatric Association of Turkey

2008-2009 Controlling Committee, European Federation of Psychiatric Trainees 2009-2010 Controlling Committee, European Federation of Psychiatric Trainees 2008-cont. Research group, European Federation of Psychiatric Trainees 2009-2014. Early Career Psychiatrists Council, World Psychiatric Association 2009-cont. Foreign Affairs Task Force, Psychiatric Association of Turkey 2012-cont. Task Force on Publications of Early Career Psychiatrists, European Psychiatric Association 